BÁRBARA MARCELA BERINGUEL

PADRÕES ESPAÇO-TEMPORAIS DO SUICÍDIO NO ESTADO DE PERNAMBUCO, BRASIL 


\title{
PADRÕES ESPAÇO-TEMPORAIS DO SUICÍDIO NO ESTADO DE PERNAMBUCO, BRASIL
}

\begin{abstract}
Dissertação apresentada ao Programa de Pósgraduação em Saúde Coletiva do Centro de Ciência da Saúde da Universidade Federal de Pernambuco, como parte dos requisitos parciais para obtenção do título de mestre em Saúde Coletiva.
\end{abstract}

Área de contração: Saúde Coletiva

Orientadora: Prof ${ }^{a}$. Dr ${ }^{\text {a. }}$ Cristine Vieira do Bonfim

Coorientadora: Prof ${ }^{\mathrm{a}}$. Dr ${ }^{\mathrm{a}}$. Amanda Priscila de Santana Cabral Silva 
Catalogação na Fonte

Bibliotecária: Mônica Uchôa, CRB4-1010

B511p Beringuel, Bárbara Marcela.

Padrões espaço-temporais do suicídio no estado de Pernambuco, Brasil / Bárbara Marcela Beringuel. - 2018.

175 f.: il.; $30 \mathrm{~cm}$.

Orientadora: Cristine Vieira do Bonfim.

Dissertação (Mestrado) - Universidade Federal de Pernambuco, CCS, Programa de Pós-Graduação em Saúde Coletiva. Recife, 2018.

Inclui referências e anexos.

1. Suicídio. 2. Análise espacial. 3. Tendências. 4. Sistemas de informação em saúde. 5. Estatísticas vitais. I. Bonfim, Cristine Vieira do (Orientadora). II. Título. 


\section{PADRÕES ESPAÇO-TEMPORAIS DO SUICÍDIO NO ESTADO DE PERNAMBUCO, BRASIL}

Dissertação apresentada ao Programa de Pósgraduação em Saúde Coletiva do Centro de Ciência da Saúde da Universidade Federal de Pernambuco, como parte dos requisitos parciais para obtenção do título de mestre em Saúde Coletiva.

Aprovada em: 04/05/2018

BANCA EXAMINADORA

Prof $^{\mathrm{a}}$. Dr ${ }^{\mathrm{a} .}$ Cristine Vieira do Bonfim (Orientadora)

Fundação Joaquim Nabuco

Dr ${ }^{\mathrm{a}}$ Marcella de Brito Abath (Examinadora Externa)

Secretaria de Saúde do Estado de Pernambuco

Prof ${ }^{\mathrm{a}}$. Dr ${ }^{\mathrm{a} .}$ Mirella Bezerra Rodrigues Vilela (Examinadora Externa)

Universidade Federal de Pernambuco 
À voinha (Clotilde Beringuel), por dedicar quase nove décadas a quem ama. Sou grata por estar entre esses, (in memorian)

Dedico. 


\section{AGRADECIMENTOS}

Às orientadoras Cristine Vieira do Bonfim e Amanda Priscila de Santana Cabral Silva, pela disponibilidade, atenção e competência ao ensinar durante todo o transcorrer do mestrado.

Aos professores Rafael Moreira, Mirella Rodrigues e Marcella Abath pelas contribuições valiosas dadas no momento da qualificação e defesa dessa pesquisa.

Agradeço a Heitor Costa e Dinilson Pedroza Júnior pelo apoio nas análises estatísticas, igualmente à Secretaria Estadual de Saúde de Pernambuco pela agilidade na obtenção dos dados utilizados no presente estudo.

Às amigas que ganhei do mestrado para a vida: Jaqueline Francisca, Thayná Rhayssa e Vanessa Coêlho. Obrigada por todos os momentos divididos.

À Victor Beringuel, pelo auxílio dado na submissão dos artigos. Às amigas Ana Paula e Sandra Salgueiro por todo apoio prestado.

Ao meu pai Alfredo Teixeira por ter "escolhido" ser parte da minha vida, pelos ensinamentos que me conduziram até aqui. Minha mãe Maria Beringuel e avó Clotilde Beringuel pelo cuidado eterno.

À Ricardo Silveira Filho, por todo companheirismo, afeto e segurança. Obrigada por ser meu porto seguro nas horas difíceis e compartilhar os risos em momentos suaves, por segurar a minha mão nessa longa caminhada da vida. 
Só existe um problema filosófico realmente sério: é o suicídio. Julgar se a vida vale ou não vale a pena ser vivida é responder à questão fundamental da filosofia. $\mathrm{O}$ resto, se o mundo tem três dimensões, se o espírito tem nove ou doze categorias, aparece em seguida (CAMUS, 1942, p. 6). 


\section{RESUMO}

O suicídio é considerado um problema de saúde pública mundial. Conhecer a distribuição espacial e temporal da morte autoprovocada poderá subsidiar o planejamento, implantação e avaliação de ações de prevenção. Objetivou-se descrever a ocorrência e a distribuição espaçotemporal da mortalidade por suicídio. Trata-se de um estudo ecológico com dados do Sistema de Informações sobre Mortalidade ocorridos no estado de Pernambuco, entre 1996 e 2015. O padrão espacial foi elaborado, segundo décadas, por meio de mapas temáticos dos coeficientes médios brutos e método bayesiano empírico local. Para verificação da autocorrelação espacial e conglomerados críticos empregou-se o Índice de Moran Global e Indicador Local de Associação Espacial. Para a análise da série temporal utilizou-se o Modelo Auto Regressivo Integrado de Médias Móveis com componente sazonal (p,d,q). Registrou-se 6.229 suicídios. O coeficiente de mortalidade foi de 4,5 e 4,6/100.000 hab., na primeira e segunda década, respectivamente. Constatou-se forte autocorrelação espacial do suicídio, I = 0,6876 (1996-2005) e I = 0,68704 (2006-2015). Três agrupamentos Q1, considerados críticos, foram identificados em cada período, somando-se 25 municípios no primeiro decênio e 21 no segundo. $\mathrm{Na}$ análise da série temporal verificou-se a presença do componente sazonal, embora não muito acentuado. A previsão dos coeficientes de suicídio, para o período de janeiro de 2016 a dezembro de 2020 foi estável com pouca variação. A análise espacial identificou áreas críticas distanciadas da Região Metropolitana do Recife. Descrever o comportamento espacial e temporal do suicídio são aspectos importantes para adotar intervenções que busquem a redução dessa violência.

Palavras-chave: Suicídio. Análise espacial. Tendências. Sistemas de informação em saúde. Estatísticas vitais. 


\begin{abstract}
Suicide is considered a global public health problem. Knowing the spatial and temporal distribution of self-inflicted death may subsidize the planning, implementation and evaluation of prevention actions. The objective of this study was to describe the occurrence and the spatio-temporal distribution of mortality due to suicide. Ecological study with data from the Mortality Information System occurred in the state of Pernambuco between 1996 and 2015. The spatial pattern was elaborated, according to decades, through thematic maps of the gross average coefficients and local empirical Bayesian method. To verify the spatial autocorrelation and critical conglomerates, the Global Moran's Index and Local Indicators of Spatial Association were used. To analyze the time series, the Auto-Regressive Integrated Moving Average model with seasonal component (p, d, q) was used. There were 6,229 suicides. The mortality coefficient was 4.5 and 4.6/100,000 inhabitants, in the first and second decade, respectively. A strong spatial autocorrelation of suicide was found, $\mathrm{I}=0.6876$ (19962005) and $\mathrm{I}=0.68704$ (2006-2015). Three Q1 groups, considered critical, were identified in each period, adding 25 municipalities in the first decade and 21 in the second. In the analysis of the time series, the presence of the seasonal component was verified, although not very accentuated. The prediction of suicide coefficients for the period from January 2016 to December 2020 was stable with little variation. The spatial analysis identified critical areas distanced from the Metropolitan Region of Recife. Describing the spatial and temporal behavior of suicide are important aspects for adopting interventions that seek to reduce this violence.
\end{abstract}

Keywords: Suicide. Spatial analysis. Trends. Health information systems. Vital statistics. 


\section{LISTA DE ILUSTRAÇÕES}

\section{Introdução}

Figura 1 - Distribuição mundial dos coeficientes de mortalidade por suicídio padronizado por idade, por 100.000 hab., em ambos os sexos, 2015

Figura 2 - Distribuição do coeficiente de mortalidade por suicídio100.000 hab., segundo sexo e Unidade de Federação, Brasil, 2011 a 2015.

\section{Procedimentos Metodológicos}

Figura 3 - Distribuição das Regionais de Saúde em Pernambuco. 33

Figura 4 - Diagrama de espalhamento de Moran.................................................................40

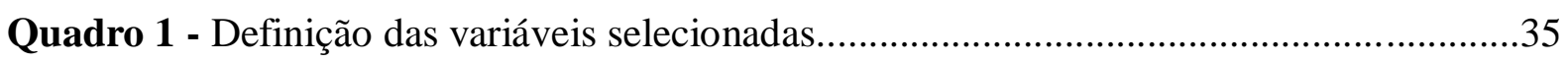

Quadro 2 - Adaptação dos escores de completude propostos por Romero e Cunha. 36

\section{Artigo 3}

Mortalidade por suicídio no estado de Pernambuco, Brasil (1996 a 2015)

Figura 1 - Coeficiente de mortalidade por suicídio da população total do estado de Pernambuco e por sexo (1996-2015)

\section{Artigo 4}

Mortalidade por suicídio em um estado do Nordeste brasileiro: uma análise dos padrões espaciais, 1996 a 2015

Figura 1 - Coeficiente médio de mortalidade por suicídio. Pernambuco, 1996 a 2015. 100

Figura 2 - Coeficiente médio de mortalidade por suicídio estimado pelo método bayesiano empírico local. Pernambuco, 1996 a 2015

Figura 3 - Distribuição espacial do diagrama de espalhamento de Moran do coeficiente médio de mortalidade por suicídio (Box Map). Pernambuco, 1996 a 2015.

Figura 4 - Identificação das áreas críticas para a mortalidade por suicídio, segundo o espalhamento de Moran com significância estatística de 5\% (Moran Map). Pernambuco, 1996-2015. 103

\section{Artigo 5}

Previsão do suicídio no estado de Pernambuco: análise com modelo de série temporal

Figura 1 - Taxa de mortalidade (A), decomposição da série histórica (B) e sazonalidade (C), das taxas mensais de mortalidade por suicídio no estado de Pernambuco de janeiro de 1996 até dezembro de 2015. 
Figura 2 - Função de Autocorrelação (A), primeira diferenciação da série temporal (B) e série temporal bruta observada e modelo SARIMA ajustado (C) das taxas de mortalidade por suicídio no estado de Pernambuco (1996-2015) .......................116

Figura 3 - Análise dos resíduos do modelo SARIMA segundo teste Ljung-Box (A), Função de Autocorrelação (B) e teste de normalidade (C).........................................117

Figura 4 - Previsão das taxas de mortalidade por suicídio no estado de Pernambuco para o período de janeiro de 2016 a dezembro de 2020 118 


\section{LISTA DE TABELAS}

\section{Artigo 2}

Avaliação da completude das informações sobre suicídios, Pernambuco, Brasil, 1996 a 2015

Tabela 1 - Tendência da completude dos óbitos por suicídio em Pernambuco registrados no Sistema de Informações sobre Mortalidade, segundo variáveis sociodemográficas e de óbito 1996 a 2015

Tabela 2 - Percentual da completude dos óbitos por suicídio nas Regiões de Saúde e estado de Pernambuco registrado no Sistema de Informações sobre Mortalidade, segundo variáveis sociodemográficas e de óbito, 1996-2005 e 2006-2015

Tabela 3 - Variação percentual da completude dos óbitos por suicídio nas Regiões de Saúde e estado de Pernambuco registrado no Sistema de Informações sobre Mortalidade, segundo variáveis sociodemográficas e de óbito, 1996-2005 e 2006-2015. .65

\section{Artigo 3}

\section{Mortalidade por suicídio no estado de Pernambuco, Brasil (1996 a 2015)}

Tabela 1 - Análise de tendências e modelo ajustado do coeficiente padronizado de suicídio total, por sexo e faixa etária da população residente do estado de Pernambuco (1996-2015)

Tabela 2 - Caracterização epidemiológica dos óbitos por suicídio no estado de Pernambuco, segundo décadas (1996-2005/2006-2015) .78

Tabela 3 - Caracterização da causa básica de óbitos por suicídio no estado de Pernambuco por sexo, segundo décadas (1996-2005/2006-2015)

\section{Artigo 5}

\section{Previsão do suicídio no estado de Pernambuco: análise com modelo de série temporal}

Tabela 1 - Previsão da taxa de mortalidade por suicídio mensal (Intervalo de confiança - IC de 95\%) para o estado de Pernambuco entre janeiro de 1996 e dezembro de 2020. 


\section{LISTA DE SIGLAS}

ARIMA Modelo Auto Regressivo Integrado de Médias Móveis

CID Classificação Internacional de Doenças

DO Declaração de óbito

EUA Estados Unidos da América

Hab. Habitantes

IBGE Instituto Brasileiro de Geografia e Estatística

LISA Indicador Local de Associação Espacial

OMS Organização Mundial de Saúde

RS Regional de Saúde

SARIMA Modelo Auto Regressivo Integrado de Médias Móveis Sazonal

SES-PE Secretaria Estadual de Saúde de Pernambuco

SIG Sistema de Informação Geográfica

SIM Sistemas de Informações sobre Mortalidade

St Série temporal

TMS Taxa de mortalidade por suicídio

WHO World Health Organization 


\section{SUMÁRIO}

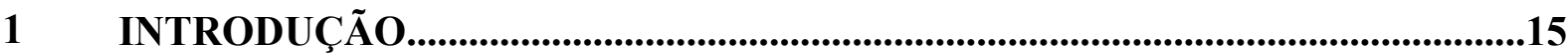

1.1 O SUICÍDIO: CONCEITO, COMPORTAMENTOS, FATORES DE RISCO E PREVENÇÃO.

1.2 ASPECTOS EPIDEMIOLÓGICOS E TEMPORAIS DO SUICÍDIO NO MUNDO, NO BRASIL E NO ESTADO DE PERNAMBUCO.

1.3 USO DA ANÁLISE ESPACIAL NA EPIDEMIOLOGIA E NOS ESTUDOS APLICADOS AO SUICÍDIO.

1.4 SÉRIES TEMPORAIS E APLICAÇÕES EM PESQUISAS SOBRE SUICÍDIO.

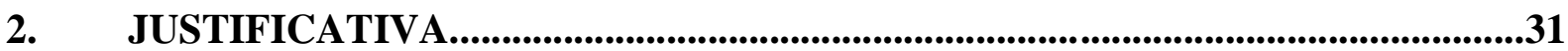

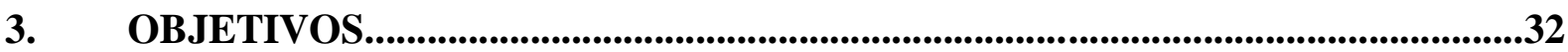

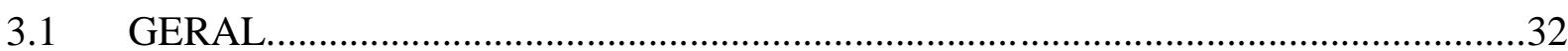

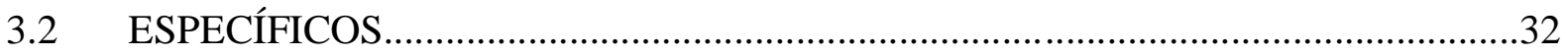

4. PROCEDIMENTOS METODOLÓGICOS.........................................................33

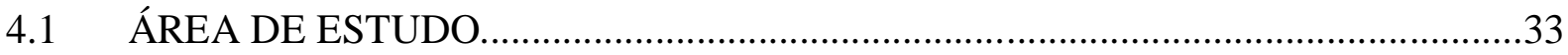

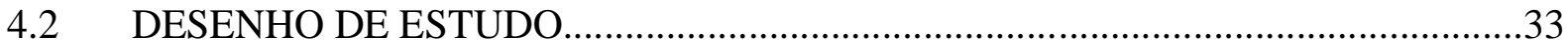

4.3 POPULAÇÃO DE ESTUDO E PERÍODO DE REFERÊNCIA.....................................34

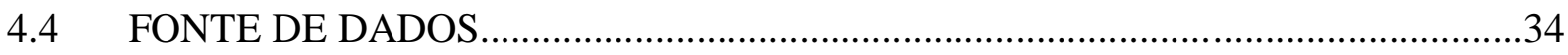

4.5 DEFINIÇÃO DE VARIÁVEIS E INDICADORES.....................................................34

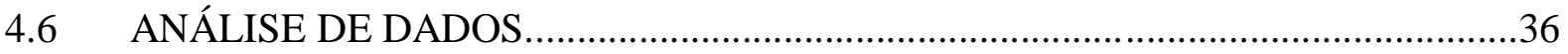

4.6.1 Análise da completude.....................................................................................................36

4.6.2 Análise estatística.........................................................................................................36

4.6.3 Análise espacial.........................................................................................................37

4.6.4 Análise da série temporal...........................................................................41

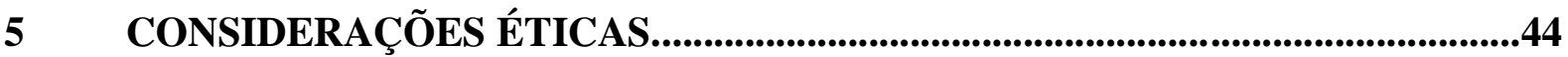

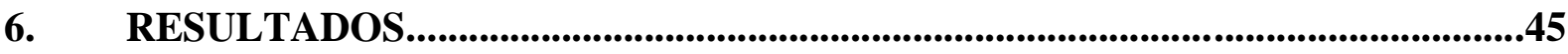

6.1 PADRÕES ESPAÇO-TEMPORAL DO SUICÍDIO NO ESTADO DE PERNAMBUCO, BRASIL: ESTUDO ECOLÓGICO_..................................................46

6.2 AVALIAÇÃO DA COMPLETUDE DAS INFORMAÇÕES SOBRE SUICÍDIOS, PERNAMBUCO, BRASIL, 1996 A 2015.

6.3 MORTALIDADE POR SUICÍDIO NO ESTADO DE PERNAMBUCO, BRASIL (1996 A 2015) 
6.4 MORTALIDADE POR SUICÍDIO EM UM ESTADO DO NORDESTE BRASILEIRO: UMA ANÁLISE DOS PADRÕES ESPACIAIS...............................90

6.5 PREVISÃO DO SUICÍDIO NO ESTADO DE PERNAMBUCO: ANÁLISE COM

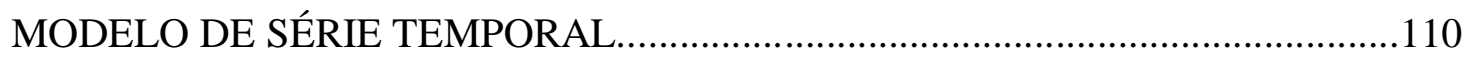

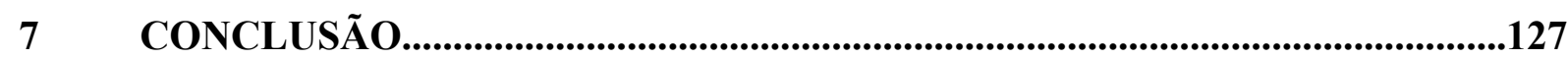

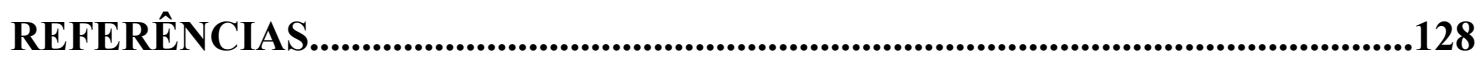

ANEXO A - DISTRIBUIÇÃO DOS MUNICÍPIOS DE PERNAMBUCO SEGUNDO REGIONAIS DE SAÚDE..................................................................154

ANEXO B - MODELO DA DECLARAÇÃO DE ÓBITO.......................................155

ANEXO C - CID 10: X60-X84. LESÕES AUTOPROVOCADAS VOLUNTARIAMENTE, SEGUNDO CATEGORIAS..........................................156

ANEXO D - PARECER CONSUBSTANCIADO DO COMITÊ DE ÉTICA EM

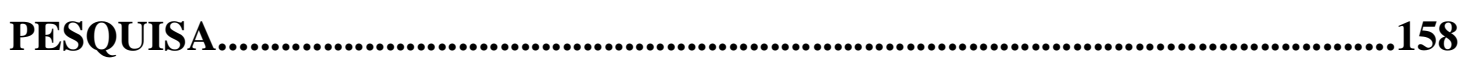

ANEXO E - DECLARAÇÃO DE ANUÊNCIA DA SECRETARIA ESTADUAL DE SAÚDE DE PERNAMBUCO..............................................................................163

ANEXO F - COMPROVANTE DE SUBMISSÃO DO ARTIGO 1 A ONLINE BRAZILIAN JOURNAL OF NURSING.............................................................164 ANEXO G - COMPROVANTE DE SUBMISSÃO DO ARTIGO 3 A REVISTA BRASILEIRA DE ENFERMAGEM. .165 ANEXO H - INSTRUÇÕES DE FORMATAÇÃO AOS AUTORES SEGUNDO AS NORMAS DA REVISTA BRASILEIRA DE ENFERMAGEM....................166 ANEXO I - COMPROVANTE DE SUBMISSÃO DO ARTIGO 4 A REVISTA CIÊNCIA E SAÚDE COLETIVA.............................................................................171 ANEXO J - INSTRUÇÕES DE FORMATAÇÃO AOS AUTORES SEGUNDO AS NORMAS DA REVISTA CIÊNCIA E SAÚDE COLETIVA. 


\section{INTRODUÇÃO}

\subsection{O SUICÍDIO: CONCEITO, COMPORTAMENTO, FATORES DE RISCO E PREVENÇÃO}

A origem da palavra suicídio é derivada do latim, sui (de si mesmo) e caederes (matar) (FERREIRA, 2015). Tal termo foi utilizado pela primeira vez no século XVII, e embora sua definição apresente divergências a ideia central baseia-se no ato humano intencional de cessar com a própria vida (BOTEGA, 2015). O suicídio acompanha a humanidade desde os seus tempos remotos, está presente em registros deixados por civilizações passadas, em quase todos os livros sagrados e nas mitologias dos povos antigos (BERTOLOTE, 2012).

Historicamente, os indivíduos que cometem suicídio são vistos negativamente, quando comparados com aqueles que morreram de outras causas (SILVA; SOUGEY; SILVA, 2015). No entanto, a morte autoinfligida é encarada de maneiras diferentes, sendo influenciada pelo modo de pensar e agir dos povos (VENCO; BARRETO, 2014). Na Grécia e Roma antiga, de forma geral, era bem tolerado. Na Europa, durante a Idade Média, era o pior dos pecados e fruto de ação demoníaca, onde a vítima tinha seu corpo exposto a castigos e era impedida de ser sepultada em cemitérios (BOTEGA, 2015).

A morte autoprovocada traz consigo um conjunto de emoções negativas, e representa um dos comportamentos mais enigmáticos e perturbadores que afetam o homem (SCOCCO et al., 2017). A comoção social do suicídio é incomensurável e provoca profundas marcas emocionais entre aqueles que, direta ou indiretamente, conviveram em sua presença (BUUS et al., 2014).

Considerado um fenômemo complexo o comportamento suicidaé definido como o conjunto de ideias, desejos e manifestações ligados à intenção de morte, que surgem de modo esporádico ou frequente (ORES et al., 2012). Manifesta-se através de fenômenos como ideias e planejamentos que possuem a possibilidade de resultar em um ato suicida, cujo desfecho pode ser fatal (suicídio) ou não (tentativa de suicídio) (CAVALCANTE; MINAYO, 2015).

Fatores demográficos, biológicos e sociais influenciam o suicídio (SAMAAN et al., 2015). A presença de doenças mentais, especialmente a depressão, traços de personalidade como agressividade e impulsividade, e violência sofrida pelo menos uma vez na vida, estão associados à ideação suicida (ARENAS; GÓMEZ-RESTREPO; RONDÓN, 2016). Idosos e pessoas residentes de áreas rurais em situação de depressão tem chances aumentadas de 
cometerem o suicídio, assim como, tentativas com elevada intencionalidade suicida (LIU; WANG; JIA, 2017; YEH; NG; WU, 2017).

O planejamento suicida representa um fator de risco relevante para o suicídio (KLONSKY; MAY, 2013). Adolescentes com planos suicidas apresentam maior risco de evolução para uma tentativa de suicídio (NOCK et al., 2013). Pesquisas apontam que jovens que fazem uso de drogas têm se revelado mais propensos a terem ideias suicidas (PELTZER; PENGPID, 2017; SERRANO et al., 2017). Estados depressivos e doenças graves, como o câncer, frequentemente estão associados à formulação de estratégias suicidas (ALMEIDA; QUINTÃO, 2012; DIAZ-FRUTOS et al., 2016; FINDLAY, 2017; ZHONG et al., 2017)

A tentativa de suicídio é o principal preditor para o suicídio (MARTINS JÚNIOR, 2016). Estima-se que um entre 25 pacientes atendidos por tentativas de suicídio em emergências hospitalares irá se matar nos próximos cinco anos, esse risco é mais elevado entre pacientes do sexo masculino, mais velhos e os que utilizam métodos mais letais (CARROLL; METCALFE; GUNNELL, 2014).

O risco do suicídio aumenta de acordo com o número de tentativas e está associado a menores intervalos de tempo entre essas tentativas (VIDAL; GONTIJO; LIMA, 2013). Ao contrário do que ocorre com o suicídio, a frequência das tentativas é maior entre as mulheres, e estas geralmente optam por métodos menos letais como ingestão de medicamentos e autoenvenenamento (ABREU et al., 2010).

Os fatores de risco para o suicídio podem ser descritos como distais ou proximais (MELEIRO, 2013). Os fatores distais são acontecimentos e condicionamentos remotos, os quais criam condições para os comportamentos suicidas, como tentativas prévias de suicídio, uso de drogas, abuso físico, emocional ou sexual na infância e isolamento social. Os fatores proximais são estressores recentes que geralmente estão relacionados às perdas ou mudanças negativas de status social ou econômico, entre eles a ruptura de relação amorosa, perturbações familiares, perda de emprego e modificação da situação financeira (BERTOLOTE; MELLOSANTOS; BOTEGA, 2010).

As razões pelas quais ocorre o suicídio não são totalmente esclarecidas (BAKHIYI et al., 2017). Algumas áreas do conhecimento como a psiquiatria, psicologia, psicanálise e filosofia tem se encarregado de estudar o fenômeno suicida em seu aspecto individual. Enquanto que ciências como a epidemiologia, antropologia, demografia e sociologia, por exemplo, encarregam-se de um olhar no âmbito coletivo (BEZERRA FILHO et al., 2012). 
Vários modelos explicativos têm sido propostos para compreender o suicídio (COSTA, 2013). O modelo nosológico trata a questão como uma doença ou o resultado de um processo de doenças; o modelo sociológico de Durkheim defende a causa do suicídio como um conjunto de fenômenos coletivos com causas sociais; e por fim, o modelo psicológico, analisa o evento suicida como resultado de conflitos individuais (BRZOZOWSKI et al., 2010).

No início do século XVIII o psiquiatra Philippe Pinel afirmou que a existência de uma lesão no cérebro causava uma sensação de dor diante da existência do indivíduo, levando-o ao suicídio (PINEL, 1801). Émile Durkheim, em sua obra clássica O suicídio: estudo de sociologia (1897) propôs que o suicídio se tratava de um fenômeno social e não individual ou patológico. Sua obra foi um dos primeiros estudos de abordagem populacional e espacial tratando a questão do suicídio (DURKHEIM, 1897).

Edwin Shneidman no campo psicológico, acreditou que o suicídio decorre de uma dor psíquica insuportável o qual o indivíduo está mergulhado por uma combinação de desespero e desesperança (SHNEIDMAN, 1993). Para este autor, a explicação universal do suicídio inexiste, uma vez que considera cada evento único e particular (SHNEIDMAN, 1993). Todos os modelos que buscam explicações para o comportamento suicida nas sociedades contribuem para a melhor compreensão desse fenômeno e são importantes para a implantação de medidas preventivas (ORES et al., 2012).

Embora o suicídio seja um evento passível de prevenção, evitar a morte autoinfligida não é uma tarefa simples, pois exige esforços de diversos setores públicos e da sociedade (SINYOR; TSE; PIRKIS, 2017). Alguns aspectos são fundamentais para impedir o ato suicida, como o fortalecimento de políticas que tratem do uso abusivo de álcool, o acesso facilitado aos serviços de saúde mental e a capacitação dos profissionais de saúde (VIJAYAKUMAR, 2016).

As ações para intervir sobre o suicídio podem ser direcionadas a diferentes grupos populacionais (ZALSMAN et al., 2016). Tais ações são consideradas universais quando aplicadas a população geral; seletivas, na ocasião em que envolvem grupos com algum risco; ou individuais, quando direcionadas a indivíduos com elevado risco suicidas, como aqueles que já tentaram o suicídio (AYUSO-MATEOS et al., 2012).

A Organização Mundial da Saúde (OMS) tem criado documentos com a finalidade de orientar os países a respeito de estratégias nacionais de prevenção (WORLD HEALTH ORGANIZATION, 2013). No Plano de Ação em Saúde Mental da OMS, diversos países, 
incluindo o Brasil, comprometeram-se com a meta de redução de $10 \%$ da taxa global de suicídio (WORLD HEALTH ORGANIZATION, 2013). Para a implantação de estratégias preventivas é necessário que haja a promoção de ações intersetoriais, compreensão dos aspectos que envolem o suicídio, determinação dos fatores de risco específicos de cada país, identificação de subgrupos de risco e uma definição clara da sua distribuição geográfica (AKTAS; KANTAR, 2016). Alguns países como a Nova Zelândia, por exemplo, já comprovaram que estratégias nacionais de prevenção, quando bem conduzidas, podem auxiliar na diminuição dos coeficientes de suicídios (BEAUTRAIS et al., 2007).

No Brasil, algumas diretrizes foram propostas no tocante à prevenção do suicídio (CONTE et al., 2012). Entre essas, merecem destaque: o desenvolvimento de estratégias de promoção da qualidade de vida, de comunicação da sociedade; promoção e organização de cuidados integrais; identificação da prevalência dos determinantes e condicionantes do suicídio e tentativas; desenvolvimento de métodos de coleta e análise de dados e educação permanente dos profissionais de saúde (BRASIL, 2006). No entanto, tais diretrizes não foram capazes de refletir a diminuição dessa violência no país, uma vez, que ainda não se encontram suficientemente implantadas e articuladas (BERTOLOTE, 2012).

Percebe-se o crescente esforço nacional, no engajamento de ações públicas de saúde que almejam a redução dos coeficientes de mortalidade por suicídio (MÜLLER; ZANON, 2017). Recentemente, o Ministério da Saúde publicou a agenda de ações estratégicas para a vigilância e prevenção do suicídio, baseada em três eixos, vigilância e qualificação da informação, prevenção do suicídio e promoção da saúde (BRASIL, 2017a).

O objetivo desse documento é ampliar as atuações de promoção, vigilância, prevenção e atenção integral, especialmente em grupos mais vulneráveis e municípios com altos coeficientes, no período de 2017 a 2020 (BRASIL, 2017a). Para alcançar esse objetivo algumas ações foram definidas: qualificação das informações registradas nas declarações de óbitos (DO); incentivo a publicação de pesquisas; ampliação da articulação inter e intrassetorial, e; mobilização e sensibilização dos profissionais de comunicação vislumbrando a desconstrução do estigma relacionado ao suicídio, assim como, a disseminação de estratégias de prevenção (BRASIL, 2017a).

\subsection{ASPECTOS EPIDEMIOLÓGICOS E TEMPORAIS DO SUICÍDIO NO MUNDO, NO BRASIL E NO ESTADO DE PERNAMBUCO}


O suicídio representa um importante problema de saúde pública no mundo (VÄRNIK et al., 2012). No ano de 2012, constituiu a segunda causa de morte entre pessoas de 15 a 29 anos de idade (WORLD HEALTH ORGANIZATION, 2014). Estimativas apontam que tal evento contribuirá com mais de $2 \%$ para a carga total de mortalidade até 2020 (WORLD HEALTH ORGANIZATION, 2012). Embora a morte autoprovocada configure uma violência de grande magnitude em países de renda elevada, aqueles com baixa e média renda concentram a maior parte dos casos (75\%) (WORLD HEALTH ORGANIZATION, 2014).

Anualmente, cerca de um milhão de pessoas cometem suicídio em todo o mundo, sendo a sua tentativa 20 vezes mais frequente (WORLD HEALTH ORGANIZATION, 2012). O coeficiente global de mortalidade por suicídio, em 2013, foi de 10,5 por 100.000 habitantes (hab.), sendo superior no sexo masculino (16,5 por 100.000 hab.) (KHAZAEI, 2017). De modo geral, o Leste da Europa e o Norte da Ásia são as regiões que possuem os maiores coeficientes, enquanto a África, América Central e do Sul os menores (Figura 1) (WORLD HEALTH ORGANIZATION, 2015).

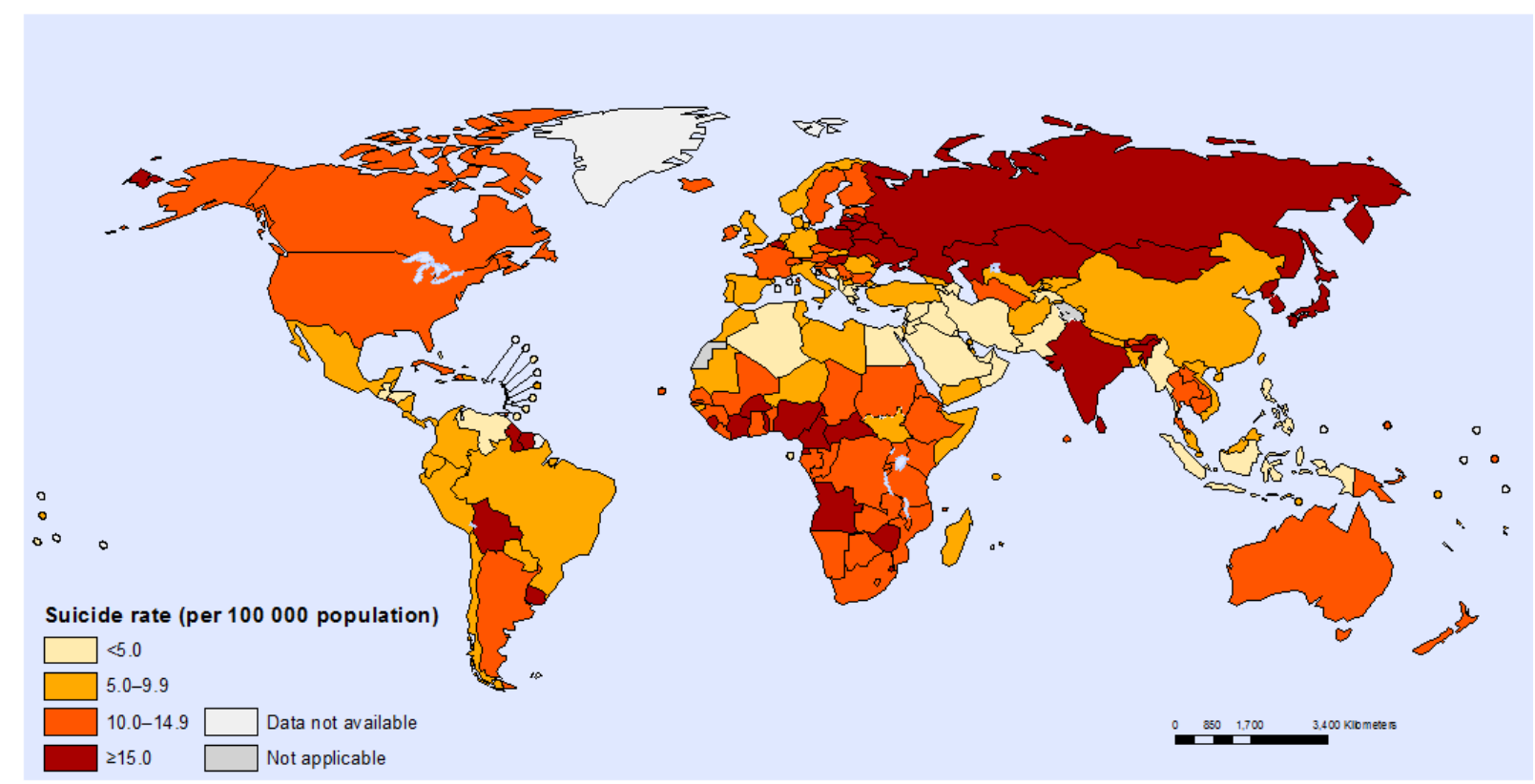

Figura 1- Distribuição mundial dos coeficientes de mortalidade por suicídio padronizados por idade, por 100.000 hab., em ambos os sexos, 2015.

Fonte: WORLD HEALTH ORGANIZATION, 2015.

Em termos globais, a tendência temporal do suicídio apresentou mudanças ao longo dos anos (VÄRNIK et al., 2012). A OMS identificou uma redução de $26 \%$ no coeficiente de mortalidade por suicídio durante o período de 2000 a 2012 (WORLD HEALTH ORGANIZATION, 2014). Na América do Sul, este coeficiente registrou aumento de 4,3 por 
100.000 hab. para 5,1 por 100.000 hab., entre 1990 e 2009 (PAN AMERICAN HEALTH ORGANIZATION, 2014).

Pesquisa recente demonstrou que os coeficientes da mortalidade por suicídio sofreram modificações no decorrer do tempo, entre os diferentes sexos e faixas etárias (BRAZINOVA et al., 2017). Um estudo realizado entre pessoas de 10 a 24 anos (1994-2012), nos Estados Unidos da América (EUA), identificou o incremento do coeficiente de suicídio nas mulheres (2,7 por 100.000 hab. para 3,2 por 100.000 hab.) e declínio nos homens (15,7 por 100.000 hab. para 11,9 por 100.000 hab.) (SULLIVAN et al., 2015). Outra análise ocorrida de 1975 a 2012, em uma cidade da Espanha, detectou um aumento nos coeficientes de suicídio em homens e mulheres entre 15 a 44 anos, e uma tendência decrescente em ambos os sexos entre os maiores ou iguais a 65 anos (ALAMEDA-PALACIOS; RUIZ-RAMOS; GARCÍAROBREDO, 2014).

Os determinantes sociais e econômicos também podem estar relacionados às mortes ocorridas pelo suicídio (YIN et al., 2016). Ao comparar o coeficiente médio de suicídio (2001-2011) em adolescentes, entre 15 e 19 anos, moradores de dois países Europeus, foi observado um valor maior entre os socioeconomicamente desfavorecidos (10,9 por 100.000 hab.) quando comparados àqueles com melhores condições sociais (6,1 por 100.000 hab.) (REDMORE et al., 2016). Outra investigação realizada no Iran, no período de 2006 a 2010, mostrou que homens residentes em províncias com baixo nível socioeconômico encontravamse em maior risco de morrer por esta violência (KIADALIRI et al., 2014).

Nos adolescentes e adultos jovens o suicídio é um problema de saúde pública em muitos países, mundialmente, é responsável por $8,5 \%$ de todas as mortes entre aqueles com 15 a 29 anos (WHO, 2014). No período entre 1972 a 2011, percebeu-se uma elevação nos coeficientes de suicídio em adolescentes do sexo masculino residentes da Inglaterra e País de Gales, de 3,1 por 100.000 hab. em 1972, para 4,8 por 100.000 hab. em 2011 (REDMORE et al., 2016). No entanto, diferentes tendências da morte por suicídio em adolescentes têm sido observadas (SÁNCHEZ-CERVANTES; SERRANO-GONZÁLES; MÁRQUEZ-CARAVEO, 2015). Estudo realizado em adolescentes de 15 a 19 anos de todo o mundo, notou que os coeficientes de mortalidade por suicídio obtiveram declínio entre 1990 a 2009, passando de 8,2 por 100.000 hab. para 6,8 por 100.000 hab. (MCLOUGHLIN; GOULD; MALONE, 2015).

Entre os fatores relacionados ao suicídio em adolescentes está a vulnerabilidade psicossocial que inclui depressão, abuso de substâncias, ansiedade, traços de agressividade ou 
impulsividade e problemas familiares ou escolares (CORTÉS-ALFARO, 2014). Algumas medidas estão associadas à redução da morte por suicídio em jovens, entre elas, a restrição a meios suicidas, como a limitação do comércio de armas de fogo e o controle da venda e uso de pesticidas, além, do tratamento de transtornos mentais (KINIP et al., 2014).

Os coeficientes de suicídio, tanto em homens como em mulheres aumentam com a idade, agravando-se entre o grupo com 65 anos ou mais (SKINNER et al., 2016). Uma investigação do suicídio em idosos (2003-2013) verificou a redução da mortalidade em homens (14,2 para 8,4 por 100.000 hab.) e mulheres (16,8 para 6,7 por 100.000 hab.) (SHAO et al., 2016). Alguns fatores como a solidão, ausência de apoio social, presença de transtornos mentais, limitação da capacidade funcional e doenças crônicas estão associados aos comportamentos suicidas na pessoa idosa (KIM, 2016; ERLANGSEN; STENAGER; CONWELL, 2015).

O evento suicida não ocorre da mesma forma entre as diferentes raças e, no transcorrer do tempo, mudanças nos coeficientes de suicídio podem ocorrer (LAVOME et al., 2016). Nos EUA, observou-se uma queda nos coeficientes de suicídio em brancos e negros nos anos de 1990, após o ano 2000, esse coeficiente em ambos os sexos apresentou aumento para os brancos, nesse último período, mulheres e homens negros obtiveram redução (WANG et al., 2016). Em brancos norte-americanos foram identificados o acréscimo na mortalidade por suicídio (1999-2015), de 14,9 para 18,1 por 100.000 hab., já os negros apresentaram uma discreta elevação, de 6,3 para 6,5 por 100.000 hab. (KEGLER; STONE; HOLLAND, 2017).

Variações nos coeficientes do suicídio são observadas em regiões urbanas e rurais (QI et al., 2014). Entre 1992 e 2012, verificou-se em um país Asiático um padrão caracterizado pelo incremento do coeficiente da morte autoprovocada em jovens e adultos moradores de grandes cidades, e em idosos residentes em áreas rurais (CHAN et al., 2015). Outro estudo mostrou resultados similares (2002-2011), ao identificar crescimento do suicídio em idosos com mais de 65 anos em regiões rurais (WANG; CHAN; YIP, 2014).

Os métodos escolhidos para cometer o suicídio podem modificar ao longo do tempo e são influenciados pelo sexo, aspectos culturais e disponibilidade do acesso (MATTHAY; GALIN; AHERN, 2017). Suicídios ocasionados por monóxido de carbono aumentaram em cinco países do Leste e Sudeste asiático, tal elevação foi mais expressiva em Cingapura, onde os coeficientes passaram de 0,1 por 100.000 hab., em 1995, para 4,8 por 100.000 hab., em 2011 (CHANG et al., 2014). 
Para documentar de forma segura os casos suicídio é imprescindível a disponibilidade de dados precisos e confiáveis (FOND et al., 2016, HAGAMAN et al., 2016). Diferentes sistemas de registro de estatísticas vitais vigoram em todo o mundo (FOWLER et al., 2018; ÖZDEMIR et al., 2015; QADDUMI et al, 2017; SUTHERLAND et al., 2017). Esses sistemas têm apresentado avanços no seu funcionamento (FOWLER et al., 2018; JOUBERT et al., 2013; ÖZDEMIR et al., 2015). No entanto, erros de notificação nos registros das mortes são descritos em muitos países, entre as falhas mais comuns estão incompletude dos dados e registro incorreto da causa básica de morte (QADDUMI et al., 2017).

A transição epidemiológica trouxe consigo algumas características marcantes no Brasil, entre elas, o aumento dos óbitos por causas externas (PEREIRA; ALVES-SOUZA; VALE, 2015). O suicídio tem contribuído para este aumento (BRASIL, 2015a). O país encontra-se entre os dez países que registram os maiores números absolutos de morte por suicídio, onde (VÄRNIK, 2012). No período de 2011 a 2015, foram registrados 55.649 óbitos por suicídio no Brasil, com coeficiente geral de 5,5 por 100.000 hab., variando de 5,3 em 2011 a 5,7 em 2015; o enforcamento, armas de fogo e autointoxicação por pesticida foram os meios mais empregados (BRASIL, 2017b; MACHADO; SANTOS, 2015). As mortes autoprovocadas podem ter uma grandeza ainda maior, tendo em vista as subnotificações, resultantes do forte estigma, cercado por mitos e tabus e falhas na determinação precisa da causa da morte (SOUSA; SILVA; CAVALCANTE, 2016).

Variações regionais do coeficiente de suicídio são percebidas no país (BANDO; LESTER, 2014; BOTEGA et al., 2014). Observou-se em ambos os sexos (2011-2015), maiores coeficientes nos estados da região Sul e Centro-Oeste, Santa Catarina obteve o coeficiente mais elevado para homens e mulheres, 16,5 e 4,2 por 100.000 hab., respectivamente (Figura 2) (BRASIL, 2017b).

Na região Nordeste (2000-2014) o coeficiente de suicídio mais elevado foi percebido no estado do Piauí (7,7 por 100.000 hab.), seguido do Ceará (6,9 por 100.000 hab.) e Rio Grande do Norte (6,5 por 100.000 hab.) (SANTOS; BRABOSA, 2017). Entre 2002 e 2010 foi realizada uma série histórica em seis capitais brasileiras, Porto Alegre (RS) registrou o maior coeficiente de mortalidade por suicídio (6,5 por 100.000 hab.), seguido de São Paulo (SP) (4,3 por 100.000 hab.) e Recife (PE) (3,1 por 100.000 hab.) (CECCON et al., 2014). 


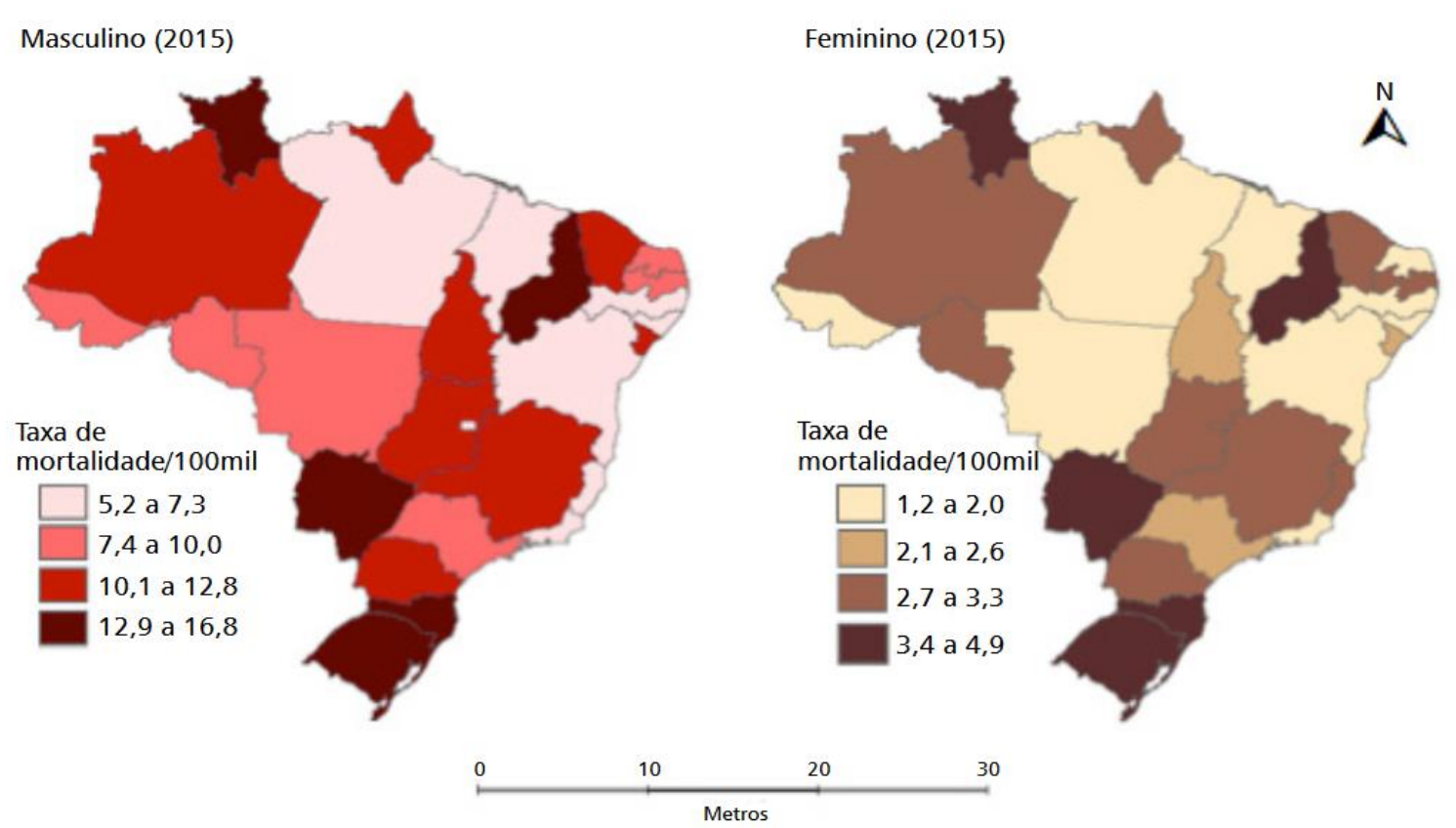

Figura 2- Distribuição do coeficiente de mortalidade por suicídio100.000 hab., segundo sexo e Unidade de Federação, Brasil, 2011 a 2015

Fonte: BRASIL, 2017b.

Alguns grupos populacionais apresentam coeficientes de suicídio mais elevados, como os indígenas da região Norte (18,4 por 100.000 por hab.) e Centro-Oeste (18,0 por 100.000 hab.), bem como, os agricultores do interior da região Sul (29,9 por 100.000 hab.) (MACENTE; ZANDONADE, 2012; ORELLANA et al., 2016; SOUZA; ORELLANA, 2013). Fatores socioculturais, econômicos, sofrimento mental e o uso abusivo de bebidas alcoólicas podem estar associados a tais coeficientes (MARIN-LEÓN; OLIVEIRA; BOTEGA, 2012).

Em 2012, os homens brasileiros cometeram suicídio numa razão três vezes maior em relação às mulheres (MACHADO; SANTOS, 2015). Entre as explicações, está o uso frequente de meios letais (SENA-FERREIRA et al., 2014). A menor ocorrência do suicídio entre as mulheres também tem sido atribuída a outros aspectos como baixa prevalência de alcoolismo, maior envolvimento religioso e ao desempenho de papéis durante a vida, especialmente o materno (BRAGA; DELL'AGLIO, 2013). Além disso, elas reconhecem precocemente sinais de risco para depressão, buscando ajuda em momentos de crise (O'NEILL, et al., 2017).

O coeficiente de suicídio tende a ser mais elevado nos idosos brasileiros (MINAYO et al., 2012). Entre os anos de 1980 e 2009, permaneceu por volta de 7,0 por 100.000 hab. em ambos os sexos, chegando ao patamar de 12,0 por 100.000 hab. nos idosos do sexo masculino (PINTO et al., 2012). No período de 2004 a 2011, a população de idosos residente nas regiões 
Sul e Centro Oeste obtiveram declínio em seus coeficientes, enquanto as demais regiões mantiveram valores estáveis (ZANNIN, 2013). Crescimento significativo de suicídios em homens brasileiros com 60 anos ou mais, foi observado entre 1980 e 2006, onde os coeficientes elevaram-se de 12,1, em 1980, para 14,0 por 100.000 hab. em 2006 (15,4 por 100.000 hab.) (MINAYO et al., 2012).

Foram registrados no estado de Pernambuco 6.065 óbitos por suicídio, entre os anos de 1996 e 2015 (BRASIL, 2015b). Neste estado, o coeficiente médio de suicídio entre 2000 e 2014 foi de 4,9 por 100.000 hab. (SANTOS; BARBOSA, 2017). Do total das causas externas ocorridas no estado, analisadas em dois períodos, 2011 a 2003 e 2011 a 2013, as mortes autoprovocadas representaram 3,7\% e 4,2\%, sucessivamente, o que representou aumento de 15,9\% (MELO; ALVES; LIMA, 2015).

Características geográficas como o espaço urbano/rural ou áreas geográficas de diferentes portes populacionais podem influenciar a mortalidade por suicídio (BEZERRA FILHO et al., 2012; CHEUNG; SPITTAL; YIP, 2012, SAMAN et al., 2012). O uso de técnicas de análise espacial constitui uma ferramenta válida para identificar, localizar e acompanhar aspectos relacionados ao fenômeno suicida em diferentes populações (NARDI et al., 2013).

\subsection{USO DA ANÁLISE ESPACIAL NA EPIDEMIOLOGIA E NOS ESTUDOS APLICADOS AO SUICÍDIO}

O espaço pode ser compreendido como algo além de um conjunto de estruturas da natureza, ele é considerando a soma dessas estruturas com a sociedade, inseridas suas relações sociais do passado e do presente, sempre em constantes mudanças (SANTOS, 2004). Território, por sua vez, é uma configuração de área definida e delimitada, constituída por sistemas naturais, elementos resultantes da ação do homem, compreendendo as relações de como vivem (SANTOS, 1999).

As populações e seus convívios sociais estão contidos no espaço geográfico, à medida que criam novas interações entre si e com o meio geram fatores relacionados com o desenvolvimento das doenças, com potencialidade de propagação (MENDONÇA; ARAÚJO; FOGAÇA, 2014). Embora fatores biológicos e hábitos de vida estejam associados à saúde, aspectos como as características de um povo e seu contexto de vizinhança também interferem no processo saúde-doença (SANTANA; FREITAS, 2015). 
Durante a segunda metade do século XX, o desenvolvimento da tecnologia da informação apoiou a compreensão do comportamento de doenças e agravos à saúde, auxiliando os profissionais na análise de grandes quantidades de informação (GUIMARÃES, 2016). O uso do geoprocessamento para o reconhecimento das condições de risco no território tem sido utilizado com frequência pela saúde pública, em especial, pela epidemiologia (NARDI et al., 2013).

Em seu conceito o geoprocessamento é um conjunto de tecnologias as quais permitem operações como análise, coleta, armazenamento e criação de bancos de dados e mapas (WRUBLACK et al., 2014). Entre as técnicas aplicadas no geoprocessamento está o Sistema de Informação Geográfica (SIG) (CAVICCHIOLI NETO et at., 2014).

O SIG possui como característica principal a associação de dois dados: espaciais e de atributos (CÂMARA et al., 2004). O dado espacial consiste nas coordenadas geográficas que contêm informações sobre o local, as dimensões das características físicas da superfície terrestre e as relações entre as estruturas presentes no relevo. Já os dados de atributo representam variáveis de censo, condições de saúde, taxas de mortalidade, aspectos sem expressão espacial para o banco de dados (O’CARROL et al., 2003).

Esse sistema pode atuar na identificação de áreas e grupos de risco de doenças e agravos, reconhecendo aqueles que compartilham fatores de risco similares (KOLIFARHOOD et al., 2015). O SIG ainda é adotado para formular hipóteses sobre a etiologia de patologias e nortear ações de intervenção em saúde (CUNHA-SILVA et al., 2014; HERNÁNDEZ-ÁVILA et al., 2013). Contribui ainda para o monitoramento de doenças e eventos relacionados à saúde, além de fornecer informações atualizadas da real situação epidemiológica no espaço geográfico (DOGRU et al., 2017).

Estudos demonstram que o SIG pode operar na análise da acessibilidade e disponibilidade de centros médicos, o que permite visualizar como as populações usam suas redes de saúde (MURAD, 2014; RESHADAT et al., 2015; WALKER et al., 2016). Essas informações fornecem subsídios para o planejamento ao acesso de pacientes em regiões onde os recursos são escassos (FERGUSON; KEMP; KOST, 2016).

A análise espacial, por sua vez, é um conjunto de técnicas que buscam descrever padrões existentes em dados espaciais (BECKER; NERO, 2012). Pode ser considerada uma ferramenta que possibilita a manipulação desses dados de diferentes formas extraindo conhecimentos como resposta (BAILEY, 2001). Na epidemiologia é especialmente útil para mapear doenças e outros eventos de interesse, medir associações socioeconômicas, ambientais 
ou demográficas e identificar agrupamentos de risco (ALEMU et al., 2016; KIRBY; DELMELLE; EBERTH, 2017; LIMA; MOREIRA; NGWA et al., 2016; NÓBREGA, 2016).

Algumas técnicas de análise espacial têm sido empregadas para a observação de padrões de doenças e violências (BARBOZA, 2016; BRAZ et al., 2014; CHEN et al., 2013; CRIGHTON et al., 2015; SOUZA; PINTO; SOUZA, 2014; TSAI, 2012). Entre essas técnicas, a abordagem bayesiana e as técnicas de autocorrelação espacial, como o Índice de Moran Global e o Indicador Local de Associação Espacial (LISA), têm sido adotadas conjuntamente com objetivo de estabelecer padrões espaciais de diversos eventos relacionados à saúde (CHANG et al., 2012; HSU et al., 2015; KAWAGUCHI; KOIKE, 2016; MACENTE; ZANDONAD, 2012; PIUVEZAM et al., 2015; VENÂNCIO; TUAN; NASCIMENTO, 2015).

As técnicas de análise espacial no suicídio tem sido usadas com frequência em pesquisas realizadas em todo o mundo (BANDO et al., 2012; JONES et al., 2013; PÉREZCOSTILLAS et al., 2015; SAMAN et al., 2012). Essas técnicas quando postas em prática no estudo do suicídio possibilitam a observação de diferentes padrões de distribuição espacial, a identificação de aglomerados espaciais de risco e associações de grupos vulneráveis com fatores sociodemográficos (JOO, 2017; KNIP et al., 2017; PHILLIPS, 2013; XIN; SHILU; WENBIAO, 2012).

Técnicas de análise espacial têm proporcionado a observação de agrupamentos de risco para o suicídio em áreas rurais, de pequenos portes territoriais e pouco habitados (ÁLVARO-MECA et al., 2013; OKA et al., 2014). Outras pesquisas referem a presença desses agrupamentos próximos a grandes metrópoles (NGUI et al., 2014; TOMITA; KUBOTA; ISHIOKA, 2015). Através dessas técnicas alguns grupos populacionais como os idosos e a população masculina foram associados a conglomerados de risco para o suicídio (AKTAS; KANTAR, 2016; JOHNSON et al., 2017).

Mediante abordagem bayesiana e análise espacial, foram localizados grupos de risco para mortes autoprovocadas por pesticidas compostos especialmente por homens residentes de áreas rurais (CHANG et al., 2012). Resultados similares, alcançados por meio do método bayesiano, foram encontrados em casos de suicídio causados por inalação de monóxido de carbono através da queima de carvão vegetal (YOSHIOKA; SAIJO; KAWACHI, 2016). Achados que demonstram um risco de suicídio aumentado em áreas rurais em relação às urbanas foi alcançado através do emprego do referido método (QI et al., 2014). 
Uma análise da associação entre a mortalidade por suicídio e condições socioeconômicas, aplicando o modelo bayesiano, revelou a relação positiva entre tal violência e reduzidas condições sociais e econômicas (YOON et al., 2015). Através da técnica de análise espacial LISA foi encontrada relação entre a morte autoprovocada e áreas altamente desfavorecidas, especialmente entre o sexo masculino (HONG; KNAPP, 2013). Estatísticas de varredura espacial foram usadas para detectar grupos de risco para o suicídio (2004-2013), dois aglomerados foram localizados, sendo fortemente associados à privação socioeconômica (FONTANELLA et al., 2018).

Por meio do uso simultâneo da abordagem bayesiana e LISA foi observada a relação entre o suicídio e o número de médicos psiquiátricos distribuídos por município, onde foi identificada uma associação positiva (KAWAGUCHI; KOIKE, 2016). As técnicas acima citadas constataram maiores taxas de suicídio em moradores de áreas de campo, onde características como imigração, população rural e atividades econômicas ligadas à agricultura e pecuária são peculiares (MACENTE; ZANDONAD, 2012).

Em áreas urbanas, a análise espacial tem sido utilizada para identificar conglomerados de suicídio correlacionados às condições de privação social (desemprego, baixo nível de escolaridade e locais de baixa renda) e ausência de apoio social (HSU et al., 2015). Situação semelhante foi vista em áreas rurais, onde tais conglomerados foram associados a áreas economicamente desfavorecidas (CHEUNG et al., 2013).

No Brasil, os estados do Nordeste, obtiveram (2000-2014) fraca autocorrelação espacial do suicídio (SANTOS; BARBOSA, 2017). Pesquisa que analisou espacialmente os municípios do país (1998-2002), notou autocorrelação espacial da morte autoprovocada, sobretudo, nas regiões Sul e Centro-Oeste, além de mostrar associação positiva entre os coeficientes de suicídio e ruralização (GONÇALVES; GONÇALVES; OLIVEIRA JÚNIOR, 2011).

As técnicas de análise espacial utilizadas no estudo do suicídio são úteis para descrever os padrões desta violência em diferentes regiões, identificando áreas prioritárias que merecem maior atenção (HONG; KNAPP, 2013). Tais técnicas, podem ter ainda aplicações significativas no estudo do suicídio, sendo relevante no desenvolvimento de estratégias de controle e prevenção (QI, 2012).

\subsection{SÉRIES TEMPORAIS E APLICAÇÕES EM PESQUISAS SOBRE SUICÍDIO}


Os estudos de séries temporais buscam descrever o comportamento de eventos por meio dos seus componentes, avaliar os possíveis fatores envolvidos e realizar estimativas de previsão (ANTUNES; CARDOSO, 2015). Em seu conceito, série temporal ou histórica é uma sequência contínua de observações sobre uma população, tomadas repetidamente, normalmente em intervalos iguais, ao longo do tempo (BERNAL; CUMMINS; GASPARRINI, 2017).

Fazem parte dos componentes de uma série histórica a tendência, sazonalidade e variação aleatória, esta última, também denominada de ruído branco (ANTUNES; CARDOSO, 2015). A tendência é descrita como movimento prolongado em uma série ordenada, que pode ser crescente, decrescente ou estacionária (PORTA, 2014). Sazonalidade é a ocorrência regular de um determinado fenômeno em períodos fixos de tempo (PRETI; LENTINI, 2016). Variação aleatória é definida como flutuações irregulares e erráticas, causadas por fatores do acaso, impossíveis de serem antecipados, detectados, identificados ou eliminados (ANTUNES; CARDOSO, 2015).

No âmbito da saúde coletiva, o estudo de séries históricas é útil para planejar ações de saúde e avaliar sua eficácia (BERNAL; CUMMINS; GASPARRINI, 2017). Nas pesquisas epidemiológicas são empregadas para observar tendências de mortalidade e morbidade, além de investigar fatores de risco envolvidos em processos desencadeadores de doenças e agravos à saúde (KANE et al., 2014; LASLETT; JIANG; CHIKRITZHS, 2018; RAZVODOVSKY; ZOTOV, 2017). Existe vários procedimentos estatísticos utilizados para analisar a atuação de uma série temporal, entre esses, estão os modelos auto regressivos (PRETI; LENTINI, 2016). Entre os modelos auto regressivos estão o ARIMA (modelo auto regressivo integrado de médias móveis) e o SARIMA (modelo auto regressivo integrado de médias móveis sazonal) (KANE, 2014). O primeiro é utilizado em séries estacionárias, que não possuem tendência (LATORRE; CARDOSO, 2001). Quando o objetivo é incorporar o componente da sazonalidade, o modelo SARIMA é indicado (AJDACIC-GROSS et al., 2015).

O ARIMA foi inicialmente desenvolvido por Box-Jenkins (1976) e representa um dos métodos mais clássicos e utilizados na análise de séries temporais (LIN et al., 2015). O modelo baseia-se no ajuste dos valores observados, visando reduzir para próximo de zero a diferença dos valores produzidos no modelo e os valores observados (SATO, 2013).

Na epidemiologia o ARIMA é amplamente utilizado para prever a incidência de doenças infecciosas e crônicas, além de avaliar a tendência da mortalidade geral, específica e por causas violentas (AZAM et al., 2016; BABALOLA; RAZZAQUE; BISHAI, 2018; DE et 
al, 2016; KANE et al, 2014; LIN et al, 2015; LIU et al, 2011; QU et al., 2017). Esse modelo vem sendo empregado nos estudos internacionais de série histórica da mortalidade por suicídio, sobretudo, naqueles relacionados às questões climáticas, sazonais, econômicas e sociodemográficas (NORSTRÖM; GRÖNQVIST, 2015; PRETI; LENTINI, 2016; SHELYGIN, 2017; TSAI; CHO, 2011).

Em uma análise de série temporal, entre 1991 e 2010, empregando-se o ARIMA, foi constatado uma relação positiva entre o aumento da temperatura ambiental e as mortes por suicídio (TSAI; CHO, 2012). Utilizando abordagem metodológica semelhante, um estudo realizado no oriente (1976-1994) identificou correlação negativa significante entre o fluxo solar e os coeficientes de suicídio (YAMASAKI et al., 2017). Uma pesquisa que investigou a sazonalidade do suicídio segundo os dias da semana (1969-2010) observou maiores coeficientes nas segundas-feiras, seguido por um declínio sucessivo aos sábados e domingos (AJDACIC-GROSS et al., 2015).

Aplicando dados mensais (1983-2012), constatou-se tendência crescente de mortes por suicídio relacionada ao período de recessão econômica em um país da Europa (BRANAS et al., 2015). Estudo de série histórica compreendendo 30 países (1960-2012) notou o crescimento da mortalidade autoinfligida em períodos de maior taxa de desemprego, especialmente entre homens residentes em países da Europa Ocidental (NORSTRÖM; GRÖNQVIST, 2015). Outros fatores econômicos como elevadas taxas de inflação, também foram responsáveis pela tendência ascendente dos coeficientes do suicídio entre 1981 a 2011 (SUN; ZHANG, 2016).

Os modelos ARIMA são úteis para analisar séries temporais que buscam estabelecer relação entre o suicídio e questões sociais (BAKER; PHEDRAN, 2015; THIBODEAU, 2015). Entre 1980 e 2005, verificou-se associação significante no sexo feminino e masculino em relação as tendências do consumo de álcool e os coeficientes de suicídio (RAZVODOVSKY, 2012). Estudo semelhante realizado no Japão (1963-2007) também demonstrou correlação entre bebidas alcoólica e suicídios (NORSTRÖM; STICKLEY; SHIBUYA, 2011). Após implementação da política de combate a ingestão excessiva de bebidas alcoólicas na Rússia, percebeu-se entre 2000 a 2010, redução do suicídio nos homens (PRIDEMORE; CHAMLIN; ANDREEV, 2013).

Outras pesquisas sobre suicídio usando técnicas de modelagem ARIMA vem sendo realizadas pelo mundo, uma delas, investigou o comportamento temporal em jovens após adoção de políticas de restrição às armas de fogo (MCPHEDRAN; BEKER, 2012). Através 
desse modelo estatístico verificou-se tendência crescente da morte por suicídio relacionada a presença de doença infecciosa (RAZVODOVSKY, ZOTOV, 2017).

A análise de séries temporais no estudo do suicídio é relevante pois permite prever o risco futuro, verificar tendências e estabelecer possíveis associações, aspectos que podem ser oportunos para o planejamento de ações de prevenção (BERNAL; CUMMINS; GASPARRINI, 2017; KANGAVARI; SHOJAEI; NAZARI, 2017). O emprego do ARIMA tem sido útil, uma vez, que fornece dados com boa precisão (PRETI; LENTINI, 2016). 


\section{JUSTIFICATIVA}

O suicídio representa um problema mundial de saúde pública de elevada complexidade. Para possibilitar ações preventivas é primordial entender o comportamento temporal, assim como, identificar áreas onde as mortes autoprovocadas compartilham uma dinâmica de maior gravidade.

Embora existam diversos trabalhos internacionais que abordem os padrões espaciais do suicídio, no Brasil, a quantidade de estudos publicados ainda é limitada. A análise espacial é uma ferramenta valiosa nos estudos sobre violências e tem por objetivo identificar características espaciais por meio de mapas de risco. Essa técnica é capaz de apontar áreas prioritárias do problema estudado.

As análises de séries temporais são utilizados com frequência na epidemiologia e possuem o potencial de verificar tendências, sazonalidade e realizar previsões sobre o fenômeno de interesse. Em pesquisas sobre o suicídio, permite prever o risco futuro, além, de identificar a regularidade dos casos em períodos fixos de tempo, informações que podem ser utilizadas no aprimoramento de ações de vigilância à saúde.

Descrever a distribuição do suicídio no tempo e espaço contribuirá para melhores direcionamentos de intervenções em saúde, otimizando recursos e esforços, sobretudo na sua prevenção. A observação da evolução temporal e a identificação de áreas de risco para o suicídio no estado de Pernambuco, através da análise de séries temporais e técnicas de autocorrelação espacial, será um passo inicial que poderá gerar subsídios para a condução de estratégias que busquem reduzir essa violência. 


\section{OBJETIVOS}

\subsection{GERAL}

Descrever a ocorrência e a distribuição espaço-temporal da mortalidade por suicídio em residentes do estado de Pernambuco entre 1996 e 2015.

\subsection{ESPECÍFICOS}

1) Avaliar o grau de preenchimento dos registros dos óbitos por suicídio do SIM no estado de Pernambuco por decênios (1996-2005 e 2006-2015);

2) Identificar as características epidemiológicas da mortalidade por suicídio SIM no estado de Pernambuco por decênios (1996-2005 e 2006-2015);

3) Descrever o padrão espacial do suicídio no estado de Pernambuco segundo decênios (1996-2005 e 2006-2015);

4) Analisar a série temporal da mortalidade por suicídio no estado de Pernambuco entre 1996 e 2015. 


\section{PROCEDIMENTOS METODOLÓGICOS}

\section{1 ÁREA DE ESTUDO}

O estado de Pernambuco está situado na região Nordeste do Brasil e possui uma área territorial de $98.148,323 \mathrm{~km}^{2}$. Administrativamente é dividido em 184 municípios mais o Arquipélago de Fernando de Noronha. A população estimada para o ano de 2016 foi de 9.410.336 hab. e a densidade demográfica, em 2010, foi de 89,62 hab./km² (IBGE, 2016). O estado é composto por 12 Regionais de Saúde (RS) (ANEXO A), as quais constituem unidades político-administrativas da Secretaria Estadual de Saúde de Pernambuco (SES-PE)

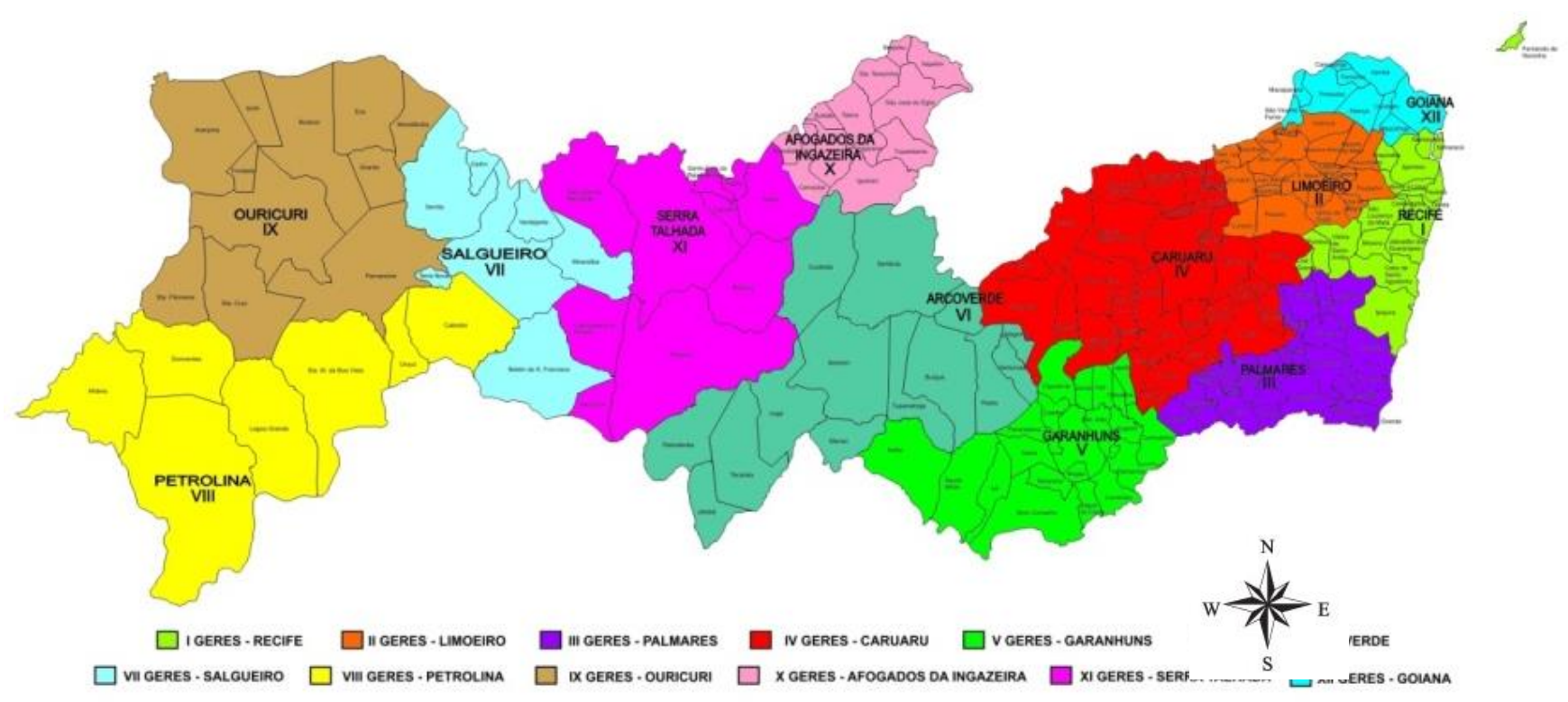

Figura 3- Distribuição das Regionais de Saúde em Pernambuco Fonte: SES/PE

\subsection{DESENHO DE ESTUDO}

Trata-se de um estudo ecológico. Tal estudo caracteriza-se por comparar dados de diferentes grupos populacionais (MORGENSTERN, 1995). Os dados ecológicos podem ser utilizados para mapear doenças, detectar aglomerados de risco e realizar correlações geográficas que investigam associações entre risco e exposição, além disso, frequentemente são obtidos com faciliadadee possuem simplicidade metodológica (WAKEFIELD, 2008).

As unidades de análise para identificação do padrão espacial foram constituídas pelos 184 municípios. Excluiu-se o Arquipélago Fernando de Noronha pela ausência de municípios 
vizinhos, pré-requisito necessário para aplicação das técnicas de análise espacial, assim como, os casos cujo informações sobre municípios de residência não constavam no Sistema de Informações sobre Mortalidade (SIM). Na análise da série temporal o uso dos meses como unidade de tempo justifica-se pela necessidade metodológica da criação de um modelo explicativo com um número elevado de observações.

\subsection{POPULAÇÃO DE ESTUDO E PERÍODO DE REFERÊNCIA}

Foram incluídos todos os óbitos de suicídio ocorridos em residentes do estado de Pernambuco com 10 anos ou mais, entre o período de 1996 a 2015. Por se tratar de um estudo que investigará a tendência temporal do suicídio optou-se trabalhar com um período 20 anos. O período de referência foi de 1 de janeiro de 1996 a 31 de dezembro de 2015.

\subsection{FONTE DE DADOS}

Os dados de mortalidade foram obtidos através do SIM, cujo instrumento de coleta é declaração de óbito (DO) (ANEXO B). Obedecendo a $10^{\circ}$ Classificação Internacional de Doenças (CID 10), o banco de dados foi composto pelas lesões autoprovocadas voluntariamente (X60-X84) (ANEXO C). Para a obtenção dos dados populacionais e bases cartográficas, utilizou-se como fonte de dados o Instituto Brasileiro de Geografia e Estatística (IBGE).

\subsection{DEFINIÇÃO DE INDICADORES E VARIÁVEIS}

Utilizou-se como indicador o coeficiente de mortalidade por suicídio, que expressa a relação entre a frequência absoluta de óbitos por suicídio e o número dos expostos ao risco de morrer ( $\mathrm{n}^{\mathrm{o}}$ de óbitos por suicídio residentes no estado de Pernambuco/população residente da área com dez anos ou mais ajustada para o meio do ano x 100.000 hab.). Para o coeficiente médio de mortalidade por decênios foram utilizadas as seguintes fórmulas: números de óbitos por suicídio (1996-2005) / população residente da área (1996-2005) com dez anos ou mais ajustada para o meio do ano x 100.000 hab.; e números de óbitos por suicídio (2006-2015) / população residente da área (2006-2015) com dez anos ou mais ajustada para o meio do ano x 100.000 hab. 
Quadro 1- Definição das variáveis selecionas

\begin{tabular}{|c|c|c|}
\hline VARIÁVEL & DEFINIÇÃO & CATEGORIZAÇÃO \\
\hline $\begin{array}{l}\text { Faixa etária em anos } \\
\text { completos }\end{array}$ & $\begin{array}{l}\text { Idade da vítima no momento do } \\
\text { óbito. }\end{array}$ & $\begin{array}{l}10 \text { a } 19 ; 20 \text { a } 39 ; 40 \text { a } 59 ; 60 \text { e } \\
\text { mais e ignorado. }\end{array}$ \\
\hline Sexo & Sexo biológico da vítima. & Masculino, feminino e ignorado. \\
\hline Raça/Cor & $\begin{array}{l}\text { Informadas por parentes ou pessoas } \\
\text { próximas da vítima. }\end{array}$ & $\begin{array}{l}\text { Branca, preta, amarela, parda, } \\
\text { indígena e ignorado. }\end{array}$ \\
\hline Situação conjugal & $\begin{array}{l}\text { Informado por parentes ou pessoas } \\
\text { próximas da vítima de acordo com o } \\
\text { registro oficial. }\end{array}$ & $\begin{array}{l}\text { Solteiro, casado, viúvo, } \\
\text { divorciado, união estável e } \\
\text { ignorado. }\end{array}$ \\
\hline $\begin{array}{l}\text { Escolaridade (última série } \\
\text { concluída) }\end{array}$ & $\begin{array}{l}\text { Anos de estudo da vítima até o } \\
\text { momento do óbito. }\end{array}$ & $\begin{array}{l}\text { Sem escolaridade, fundamental I } \\
\left(1^{\circ} \text { a } 4^{\circ} \text { série), fundamental II ( } 5^{\circ}\right. \\
\left.\text { a } 8^{\circ} \text { série }\right) \text { médio (antigo } 2^{\circ} \\
\text { grau), superior incompleto, } \\
\text { superior completo e ignorado. }\end{array}$ \\
\hline Município de residência & $\begin{array}{l}\text { Município o qual a vítima residia } \\
\text { habitualmente. }\end{array}$ & $\begin{array}{l}185 \text { municípios do estado de } \\
\text { Pernambuco. }\end{array}$ \\
\hline Ano de ocorrência & Ano em que ocorreu o óbito. & 1996 a 2015. \\
\hline $\begin{array}{l}\text { Regional de Saúde de } \\
\text { residência }\end{array}$ & $\begin{array}{l}\text { Unidades político-administrativas da } \\
\text { SES-PE a qual pertence o município } \\
\text { de residência da vítima. }\end{array}$ & $\begin{array}{l}\text { I, II, III, IV, V, VI, VII, VIII, } \\
\text { IX, X, XI, XII e ignorado. }\end{array}$ \\
\hline Local de ocorrência & Local de ocorrência do óbito. & $\begin{array}{l}\text { Hospital, outro estabelecimento } \\
\text { de saúde, domicílio, via pública, } \\
\text { outros e ignorado. }\end{array}$ \\
\hline Causa básica de morte & $\begin{array}{l}\text { Circunstância da violência que } \\
\text { produziu a lesão fatal. }\end{array}$ & CID 10:X60 a X84. \\
\hline Naturalidade & Município onde o falecido nasceu. & $\begin{array}{l}\text { UF do estado/código do } \\
\text { município. }\end{array}$ \\
\hline Ocupação & $\begin{array}{l}\text { Tipo de trabalho que o falecido } \\
\text { desenvolveu na maior parte da sua } \\
\text { vida. }\end{array}$ & $\begin{array}{l}\text { Classificação Brasileira de } \\
\text { Ocupações. }\end{array}$ \\
\hline Assistência médica & $\begin{array}{l}\text { Atendimento médico prestado } \\
\text { durante doença/agravo que } \\
\text { ocasionou a morte. }\end{array}$ & Sim, não e ignorado. \\
\hline Necropsia & Execução ou não de necropsia. & Sim, não e ignorado. \\
\hline $\begin{array}{l}\text { Circunstância do } \\
\text { óbito/tipo }\end{array}$ & \begin{tabular}{|l|} 
Tipo de morte violenta ou \\
circunstâncias em que se deu a \\
morte não natural.
\end{tabular} & $\begin{array}{l}\text { Acidente, suicídio, homicídio e } \\
\text { outros. }\end{array}$ \\
\hline Fonte de informação & $\begin{array}{l}\text { Fonte de informação utilizada para o } \\
\text { preenchimento dos campos da DO. }\end{array}$ & $\begin{array}{l}\text { Boletim de ocorrência, hospital, } \\
\text { família e outras. }\end{array}$ \\
\hline
\end{tabular}




\subsection{ANÁLISE DE DADOS}

\subsubsection{Análise da completude}

Por completude entende-se o grau de preenchimento do campo analisado, mensurado pela proporção de notificações com campo preenchido com categoria distinta daquelas indicadoras de ausência do dado (GLATT, 2005). Para cada variável estudada foi calculado o percentual de completude, analisado conforme adaptação dos escores propostos por Romero e Cunha (2006) (Quadro 2):

Quadro 2- Adaptação dos escores de completude propostos por Romero e Cunha

\begin{tabular}{|l|l|}
\hline \multicolumn{1}{|c|}{ CLASSIFICAÇÃO } & \multicolumn{1}{c|}{ COMPLETUDE (\%) } \\
\hline Excelente & $>95$ \\
\hline Bom & 90 até 95 \\
\hline Regular & $>80$ até 90 \\
\hline Ruim & $>50$ até 80 \\
\hline Muito ruim & $\leq 50$ \\
\hline
\end{tabular}

Para o estado e RS foram calculadas as proporções e a taxa de variação $(\Delta \%)$ da completude para os dois decênios:

$$
\Delta \%=((\text { ano } 2-\text { ano } 1) / \text { ano } 1) * 100 .
$$

\subsubsection{Análise estatística}

Na caracterização epidemiológica foram calculadas as proporções e a taxa de variação das variáveis selecionadas $(\Delta \%)$ para os dois decênios:

$$
\Delta \%=((\text { ano } 2-\text { ano } 1) / \text { ano } 1) * 100
$$

Com o objetivo de controlar o efeito de diferentes estruturas etárias e de sexo realizouse a padronização simultânea dos coeficientes de mortalidade brutos por suicídio por idade e sexo. Optou-se pelo método direto de padronização, adotando-se a população do estado de Pernambuco do censo 2010 do IBGE como a padrão. Considerou-se necessária a 
padronização para dispor de taxas de mortalidade que fossem comparáveis entre si e ao longo do período estudado. O programa $\mathrm{R}$ versão 3.4.1. foi empregado para as análises descritivas. Adotou-se o nível de significância de 5\%.

Para o cálculo de tendência da completude das variáveis foi empregado o modelo de regressão linear para as proporções de preenchimento das variáveis, por ano, para o estado de Pernambuco. No modelo Y (variável resposta) utilizou-se o grau de preenchimento das variáveis da DO por suicídio do SIM e X (variável explicativa), são os anos de ocorrência das mortes. Contudo, como Y é uma taxa sua distribuição de probabilidade e não gaussiana (um dos pressupostos para a aplicação do modelo de regressão linear), realizou-se a transformação em Y com o propósito de viabilizar o uso da técnica em questão:

$$
Y^{\prime}=\ln \left(\frac{1-Y}{Y}\right)
$$

Sendo assim, após a estimação, os modelos terão em geral a seguinte forma:

$$
Y=\frac{1}{e^{\beta_{0}+\beta_{1} X}+1}
$$

Onde $\beta_{0}$ e $\beta_{1}$ são os coeficientes estimados através da técnica de regressão linear. Todos os cálculos foram feitos utilizando o software R versão 3.4.1.

Os dados foram tabulados utilizando o programa TabWin versão 4.1.3 e dispostos por RS e analisados com auxílio do Statistical Package for the Social Sciences (SPSS) versão 15.0 .

\subsubsection{Análise espacial}

Inicialmente construiu-se o mapa temático dos coeficientes brutos da mortalidade por suicídio, em seguida, elaborou-se um mapa com coeficientes estimados através do método bayesiano empírico local.

Os métodos bayesianos empíricos ou inteiramente bayesianos propõem suavizar os coeficientes de pequenas áreas geográficas reduzindo as flutuações aleatórias, assim, é possível uma diferenciação mais precisa do que de fato é um risco elevado e o que seria um "falso" risco causado pelas flutuações aleatórias não associadas ao risco (ASSUNÇÃO et al., 1998). Ao estimar o risco de uma pequena área, o método bayesiano utiliza informações de 
outras áreas que compõe a região estudada, ou seja, leva em consideração a correlação espacial entre áreas vizinhas (QI et al., 2014). Quando utiliza a média de toda a população o método bayesiano empírico é considerado global, quando utiliza a média de eventos da vizinhança é considerado local (SILVA et al., 2014).

A abordagem bayesiana assume que os conhecimentos e as incertezas do real valor do risco de ocorrência de um evento de áreas inseridas em determinada região podem ser representados por uma distribuição de probabilidade (BECKER; NERO, 2012). Os estimadores bayesianos supõem que a taxa real é uma variável aleatória, onde possui uma média e uma variância conhecidas (BAYLE, 2001).

O estimador utilizado para o método bayesiano empírico se dá através da combinação linear entre a taxa observada em uma área $i$ e um valor médio $\mu_{i}$ ponderados por um fator $w_{i}$ (SOUZA et al., 2007):

$$
\theta i=w_{i} t_{i}+(1-w i) \mu_{i}
$$

Onde:

$\theta i$ - Taxa real do evento estudado; $i$ - Área; $W i$ - Fator de ponderação; T $i$ - Taxa de risco; $\mu_{\mathrm{i}}$ Média.

As médias serão estimadas da seguinte forma (SOUZA et al., 2007):

$$
\mu=\frac{\sum y_{i}}{\sum_{n_{i}}}
$$

Onde $y_{i}$ é a contagem de suicídios em cada área e $n_{i}$ a população da área. Para a suavização bayesiana empírica local será utilizada a taxa média do suicídio entre os vizinhos.

O fator de ponderação $w_{i}$ possui uma variação entre 0 e 1 que dependerá do tamanho da população na área $i$. Quanto menor a população de estudo da área $i$ menor será $w_{i}$. Sendo assim, regiões com populações pequenas terão uma correção maior em seus coeficientes, e regiões populosas terão pouca correção. $\mathrm{O}$ fator de ponderação $w_{i}$ será calculado dividindo-se a variância da taxa de suicídio entre os vizinhos pela soma desta variância com uma fração da média $\mu_{i} / n_{i}$ (SOUZA et al., 2007): 


$$
W_{i}=\frac{\theta_{\mathrm{i}}^{2}}{\frac{\theta_{\mathrm{i}}^{2}+\mu_{i}}{n_{i}}}
$$

Para estabelecer o padrão espacial dos óbitos por suicídio no estado de Pernambuco foram utilizados o Índice de Moran Global, o diagrama de espalhamento de Moran e o LISA.

De modo inicial aplicou-se o Índice de Moran Global para sintetizar a distribuição espacial dos casos de suicídio, observando a medida geral de associação espacial. Através deste índice é possível verificar se o suicídio ocorre de forma aleatória ou segue algum padrão de ocorrência no espaço.

O Índice de Moran Global é utilizado para sumarizar a distribuição espacial de dados (SILVA et al., 2011). Esse índice é um dos indicadores de autocorrelação espacial mais empregado, caracterizando-se por fornecer um único valor como medida geral da associação espacial existente no conjunto de dados (MARQUES et al., 2010). O Índice de Moran Global avalia a correlação espacial das variáveis de interesse para o estudo em diferentes áreas, ponderada pela proximidade geográfica medida pela matriz de vizinhança (MIRANDA et al., 2014).

Este índice avalia até que ponto o nível de uma variável para uma área é similar ou não às áreas vizinhas, ou seja, confere se valores medidos apresentam correlação espacial significativa (SANTOS; RAIA JÚNIOR, 2006). Como pressuposto, o teste de Moran não deve ser realizado em dados estacionários espacialmente. O termo estacionariedade espacial indica que a média da variável em estudo não é constante em todas as subáreas (BRAGA; MARQUES; BRAGA, 2015).

Os valores do Índice de Moran Global podem variar de -1 a 1 . Valores iguais a zero indicam ausência de autocorrelação espacial. Enquanto que valores próximos a zero indicam autocorrelação espacial não significativa (diferença entre vizinhos). Valores positivos implicam autocorrelação espacial positiva, ou seja, existência de similaridade entre municípios vizinhos; e valores negativos apresentam autocorrelação espacial negativa (SANTOS; RAIA JUNIOR, 2006).

Uma maneira adicional de visualizar a dependência espacial é através do diagrama de espalhamento de Moran (SANTOS; SILVA; PORTUGAL, 2015). Dividido em quatro quadrantes possui o objetivo de identificar áreas com associação espacial positiva ou negativa (ALMEIDA; GOMES; NASCIMENTO, 2014). Sua função é comparar os valores normalizados de cada área $\mathrm{Z}$ (sendo $Z$ o valor da área subtraída à média global) com a média 
dos valores normalizados de suas áreas vizinhas (WZ) (SOUZA et al., 2007). A visualização espacial do diagrama de espalhamento de Moran é realizada através mapa temático denominado Box Map, onde cada cor do mapa representa um quadrante do gráfico de espalhamento (BARROSO; FERREIRA NETO, 2016).

A partir do Índice de Moran Global é possível visualizar graficamente o grau de autocorrelação entre o suicídio e suas áreas vizinhas. A segunda etapa deu-se pela identificação dessas áreas através do diagrama de espalhamento de Moran, representado visualmente pelo Box Map, onde cada cor do mapa representa um quadrante do diagrama de espalhamento de Moran. Os quadrantes gerados pelo diagrama são interpretados da seguinte maneira:

- Q1: áreas com valores positivos e médias dos vizinhos positivas;

- Q2: áreas com valores negativos e médias dos vizinhos negativas;

- Q3: áreas com valores positivos e médias dos vizinhos negativas;

- Q4: áreas com valores negativos e médias dos vizinhos positivas.

Q1 e Q2 indicam pontos de associação espacial positiva, no sentido que uma localização possui vizinhos com valores semelhantes, Q3 e Q4 indicam pontos de associação espacial negativa, ou seja, uma localização possui vizinhos com valores diferentes. Nesta etapa considerou-se as regiões que possuem relação espacial positiva (Q1) (Figura 4).

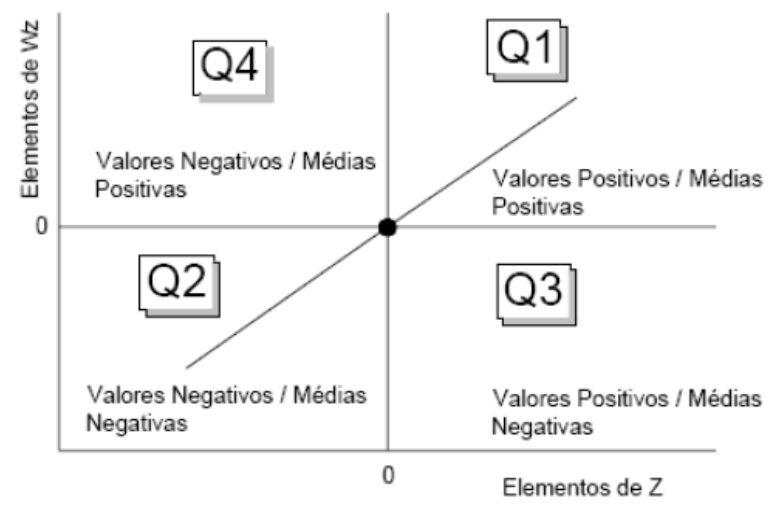

Figura 4- Diagrama de espalhamento de Moran Fonte: adaptado de Câmara et al. (2004).

Alguns casos requerem uma análise dos padrões espaciais mais detalhadas, diante disto, é indicada a utilização do LISA que evidencia locais onde a dependência espacial é ainda mais acentuada (MARQUES et al., 2010). O LISA produz um valor específico para cada região estudada, possibilitando a identificação de agrupamentos de áreas com valores de 
atributos semelhantes (clusters), assim como, áreas anômalas (outliers) e de mais de um regime espacial (SILVA et al., 2014).

Em situações onde é determinada a significância estatística do Índice Local de Moran, é válido gerar um mapa indicando as regiões que apresentam correlação local significativamente diferente do resto dos dados (CÂMARA et al., 2004). Tais regiões podem ser vistas como "bolsões" de homogeneidade, no caso, regiões de concentração de valores elevados dos atributos e regiões com valores reduzidos dos atributos, essas áreas possuem dinâmica espacial própria e merecem melhor detalhamento (SANTOS; RAIA JÚNIOR, 2006). No Lisa Map, os valores do índice local de Moran são classificados em três grupos: não significantes, com significância de 95\%, com significância de 99\% e com significância de 99,9\% (ANSELIN, 1995).

A existência de áreas críticas e aglomerados espaciais podem ser identificados através do Moran Map (GARCIA et al., 2016). Este mapa categoriza em quatro grupos os objetos para os quais os valores do índice de Moran ou LISA foram significantes, os demais objetos são classificados como "sem significância” (SOUZA; PINTO; SOUZA, 2014).

A terceira e última etapa foi composta pela construção do Moran Map. Este mapa considerou as áreas com relação espacial positiva apontadas no Box Map (Q1) com aquelas com significância espacial acima de 95\% identificadas no Lisa Map. Foram consideradas áreas críticas para o suicídio aquelas enquadradas na classe Q1 do Moran Map. O quadrante Q2 indicou áreas com baixo nível de suicídio e os quadrantes Q3 e Q4 foram considerados áreas de transição, uma vez, que podem indicar áreas com tendências de crescimento para o suicídio no estado de Pernambuco. Utilizou-se o programa TerraView 4.2.2 para a realização das análises espaciais.

\subsubsection{Análise da série temporal}

Série temporal (St) é um conjunto de dados dispostos no tempo. Sua análise consiste em desenvolver um modelo estatístico que explique o comportamento do evento ao longo do tempo. Nessa dissertação série temporal é o valor mensal da taxa de mortalidade por suicídio por 100.000 hab. (TMS) em Pernambuco, de janeiro de 2016 a dezembro de 2020.

De posse deste modelo, é possível, então, realizar previsões. O modelo aditivo representa bem o comportamento da série temporal, sendo constituído pela soma do seus componentes, a saber: tendência (T), sazonalidade (S) e erro aleatório (ui). 


$$
T M S t=T t+S t+u i
$$

A tendência revela o desempenho a longo prazo da série, ou seja, a sua trajetória média, considerando um largo período de tempo. A sazonalidade é a variação decorrente de momentos específicos. $\mathrm{O}$ erro aleatório insinua que há sempre uma variação que acontece de maneira casual, não podendo ser antecipada.

Uma análise de série temporal começa com a observação de seu gráfico. É através dessa observação que é possível identificar uma das características mais importantes da série para efeito de previsão: sua estacionariedade (GUJARATI, 2011). Uma série estacionária apresenta média e variância constantes, ou seja, não há tendência.

As análises de série temporal foram realizadas segundo abordagem ARIMA/ SARIMA. Essa técnica possui maior rigidez estatística e ampla flexibilidade no design da análise (AJDACIC-GROSS et al., 2015). O uso dos meses como unidade de tempo justificase pela necessidade metodológica da criação de um modelo explicativo com um número elevado de observações.

O ARIMA é representado por uma combinação do modelo auto regressivo (AR) com o de média móvel (MA) (LIN et al., 2015). Sua forma mais geral é o ARIMA (p, d, q), sendo AR: ( $p$ = grau da parte auto regressiva), ou seja, o valor mais recente da série é dado pela combinação linear de valores passados da série, mais um erro aleatório; $\mathrm{I}$ : $(\mathrm{d}$ = grau de diferenciação) e MA: (q = grau da parte de média móvel), onde o valor mais recente da série é dado pela combinação linear de erros aleatórios passados (SATO, 2013).

Três etapas foram utilizadas para a elaboração do modelo: identificação, estimativa e teste de parâmetro e aplicação. A primeira fase tem o propósito de avaliar a presença de estacionariedade e sazonalidade, assim como, determinar sua diferenciação e ordem. A estacionariedade ocorre quando suas observações dispõe-se aleatoriamente ao redor de uma média constante, ou seja, não há tendência (LATORRE; CARDOSO, 2001).

Para testar, a estacionariedade das séries utilizou-se a Função de Autocorrelação (FAC) e o teste Dickey-Fuller (ADF). A FAC, por meio do correlogramo, expressa a relação entre a covariância/variância da série temporal e as defasagens, logo, a série é classificada estacionária quando o correlogramo dispõe de flutuações suaves em torno de zero. O teste ADF investiga se a série é estacionária por meio da identificação de uma raiz unitária em seu processo gerador. Portanto, a hipótese nula $\left(\mathrm{H}_{0}\right)$ a ser considerada é que a série apresenta raiz unitária e, portanto, é não estacionária. 
Na segunda etapa determinou-se a estimação dos parâmetros AR e MA da tendência e parte sazonal, através do método da máxima verossimilhança. Os modelos ARIMA são baseados em um conjunto de suposições estatísticas. Duas das assunções mais importantes são: os resíduos (a diferença entre o valor efetivamente observado na série temporal e o valor previsto no modelo) são aleatórios e normalmente distribuídos (LEWIS, 2017). De posse do melhor ajuste, foram testados a aleatoriedade dos resíduos, por meio do teste Ljung-Box e FAC, assim como, sua normalidade. Por último, realizou-se a aplicação do modelo para a previsão do coeficiente de suicídio pelo SARIMA para o período de janeiro de 2016 até dezembro de 2020.

O programa R versão 3.4.1. foi utilizado para as análises. Empregou-se o pacote urca para a observação do ADF e o forecast para a obtenção do modelo final SARIMA, ambos disponíveis no $\mathrm{R}$. 


\section{CONSIDERAÇÕES ÉTICAS}

A pesquisa foi aprovada pelo Comitê de Ética em Pesquisa do Centro de Ciências de Saúde da Universidade Federal de Pernambuco (Parecer 2.045.304) (ANEXO D), mediante declaração de anuência fornecida pela SES-PE (ANEXO E). 


\section{RESULTADOS}

Essa seção será composta pela apresentação de cinco artigos, os quais correlacionamse aos objetivos específicos propostos nessa dissertação para descrever o comportamento espacial e temporal do suicídio no estado de Pernambuco.

1) Padrões espaço-temporal do suicídio: estudo ecológico;

2) Avaliação da completude das informações sobre suicídios, Pernambuco, Brasil, 1996 a 2015;

3) Mortalidade por suicídio no estado de Pernambuco, Brasil (1996 a 2015);

4) Mortalidade por suicídio em um estado do Nordeste brasileiro: uma análise dos padrões espaciais, 1996 a 2015;

5) Previsão do suicídio no estado de Pernambuco: análise com modelo de série temporal. 


\subsection{PADRÕES ESPAÇO-TEMPORAL DO SUICÍDIO: ESTUDO ECOLÓGICO}

\section{RESUMO}

Objetivo: analisar a distribuição espacial e temporal da mortalidade por suicídio em residentes do Estado de Pernambuco no período de 1996 a 2015, utilizando-se técnicas de análise espacial e estatísticas. Métodos: trata-se de um estudo ecológico que terá como unidade de análise os municípios. A fonte de dados será constituída pelos suicídios registrados no Sistema de Informações sobre Mortalidade, no período de 1996 a 2015. A tendência temporal será analisada pela técnica de regressão linear simples. A partir dos coeficientes brutos da mortalidade por suicídio será aplicado o método Bayesiano Empírico Local para correção de flutuações aleatórias do indicador. Os Índices de Moran Global e Local serão adotados para apontar a existência de correlação e aglomerados espaciais no território. Resultados Esperados: identificar mudanças temporais na mortalidade por suicídio no período estudado e localizar possíveis aglomerados espaciais que possam representar áreas prioritárias para o planejamento de intervenções e ações de saúde.

Descritores: Causas Externas; Mortalidade; Estatísticas Vitais; Suicídio; Análise Espacial; Tendências.

\section{INTRODUÇÃO}

O suicídio representa um importante problema de saúde pública, carregando consigo uma forte comoção social. Mundialmente, cerca de um milhão de pessoas cometem suicídio todos os anos ${ }^{(1)}$. Em 2015, o coeficiente de mortalidade de suicídio no mundo foi de 10,7 por 100.000 habitantes (hab.). No mesmo ano o Brasil registrou coeficiente de 6,3 por100.000 hab. ${ }^{(1)}$. Entretanto, as subnotificações, a ausência de dados em alguns países e a não regularidade nos envios dos registros sobre o suicídio à Organização Mundial de Saúde, limitam o conhecimento preciso desse evento(1).

Alguns fatores são fundamentais para compreensão do suicídio como a definição clara da distribuição geográfica, a identificação de subgrupos vulneráveis, assim como, o acompanhamento dos coeficientes de mortalidade ao longo do tempo ${ }^{(2)}$. Neste aspecto, o uso da análise espacial e a tendência temporal constituem ferramentas úteis em pesquisas referentes à morte autoprovocada.

Consideradas um conjunto de ferramentas que viabilizam a manipulação de dados contidos no espaço, as técnicas de análise espacial possuem papel relevante nas pesquisas epidemiológicas, possibilitando o mapeando de doenças e a identificação de 
grupos de risco(3). Quando aplicadas ao estudo do suicídio, essas técnicas proporcionam a visualização de diferentes padrões de mortes, além de identificar aglomerados espaciais de riscos e estabeler relações entre grupos suscetíveis e fatores sociodemográficos ${ }^{(2)}$.

No Brasil, a quantidade de estudos publicados utilizando técnicas de análise espacial e temporal aplicadas ao suicídio ainda é escassa. Descrever a distribuição do suicídio no tempo e espaço contribuirá para a identificação de áreas prioritárias, o que poderá auxiliar no direcionamento de intervenções em saúde, sobretudo, em ações de prevenção ao suicídio.

\section{QUESTÕES NORTEADORAS}

Qual a ocorrência e a distribuição espaço-temporal da mortalidade por suicídio em residentes do Estado de Pernambuco no período de 1996 a 2015?

\section{OBJETIVO}

Analisar a distribuição espacial e temporal da mortalidade por suicídio em residentes do Estado de Pernambuco no período de 1996 a 2015, utilizando-se técnicas de análise espacial e estatísticas.

\section{MÉTODO}

Trata-se de um estudo ecológico de análise temporal dos coeficientes de mortalidade por suicídio em residentes do Estado de Pernambuco, em maiores ou iguais de dez anos, ocorridos no período de 1996 a 2015. A unidade de análise será composta pelos 185 municípios que constituem o Estado. Os dados sobre os suicídios serão obtidos a partir do Sistema de Informações sobre Mortalidade, compostos pelas lesões autoprovocadas intencionalmente (X60-X84) descritas na $10^{\circ}$ Classificação Internacional de Doenças.

Para a análise da tendência temporal será empregada a técnica de regressão linear simples. Os coeficientes anuais de mortalidade por suicídio serão considerados a variável dependente e o ano do calendário a variável independente. As estimativas populacionais serão extraídas do Instituto Brasileiro de Geografia e Estatística. O programa R versão 
3.4.1 será utilizado para construir as tendências temporais e obter as estatísticas de ajuste dos modelos, para tal análise será adotada o nível de significância de $5 \%$.

$\mathrm{Na}$ análise espacial será construído o mapa temático dos coeficientes brutos da mortalidade. A correção da instabilidade estatística desses coeficientes será realizada através do método Bayesiano Empírico Local. O Índice de Moran Global será empregado para verificar a presença de autocorrelação espacial dos óbitos por suicídio. Ponderada pela proximidade geográfica medida pela matriz de vizinhança, este índice avalia até que ponto o nível de uma variável para uma área é similar ou não às áreas vizinhas. Seus valores variam de -1 a 1 . Valores positivos indicam autocorrelação espacial positiva e negativos, autocorrelação espacial negativa. Para a análise de um padrão mais detalhado será utilizado o Indicador Local de Associação Espacial, este indicador produz um valor específico para cada região estudada, possibilitando a identificação de agrupamentos de áreas com valores de atributos semelhantes ou áreas anômalas.

A pesquisa foi aprovada pelo Comitê de Ética em Pesquisa do Centro de Ciências de Saúde da Universidade Federal de Pernambuco no dia 04 de maio de 2017, sob parecer de número 2.045.304.

\section{RESULTADOS ESPERADOS}

Espera-se identificar possíveis alterações do perfil epidemiológico e na distribuição espacial do suicídio no decorrer de duas décadas. São resultados que poderão subsidiar a o planejamento de ações de intervenção do setor saúde e áreas afins, capazes de minimizar sua ocorrência.

\section{REFERÊNCIAS}

1. World Health Organization. (2017). Global Health Observatory (GHO) data. Available from:http://www.who.int/gho/mental_health/suicide_rates_crude/en/

2. Aktas, S. G; kantar Y. M. A Study of Suicide Mortality in Turkey (2002-2011). Journal of EU Research in Business [Internet]. 2017 Feb [cited 2017 jul 30]. Available from: http://ibimapublishing.com/articles/JEURB/2016/864344/

3. Bailey, T.C. Spatial statistical methods in health. Cad Saúde Pública [Internet]. 2001 Oct [cited 2017 ago 24]; 17(5): 1083-98. Available from: https://www.ncbi.nlm.nih.gov/pubmed/11679885 


\subsection{EVOLUÇÃO DA COMPLETUDE DAS INFORMAÇÕES SOBRE SUICÍDIOS NO} ESTADO DE PERNAMBUCO, BRASIL, 1996 A 2015

\section{RESUMO}

Objetivo: analisar a evolução da completude dos registros de suicídio do Sistema de Informação sobre Mortalidade no estado de Pernambuco, entre 1996 e 2015. Métodos: Calculou-se a proporção de completude das variáveis da Declaração de Óbito por Região de Saúde e a taxa de variação (\%) da completude entre os decênios. Para análise da tendência da completude empregou-se o modelo de regressão linear. Resultados: observou-se tendência crescente para a completude das variáveis: fonte de informação, raça/cor, estado civil, escolaridade, assistência médica e naturalidade. Sexo, idade e local de ocorrência mantiveram a completude excelente nos decênios. Os menores percentuais foram encontrados nas variáveis escolaridade $(44,0 \%)$, assistência médica $(47,1 \%)$ e fonte de informação $(58,9 \%)$. Conclusão: houve melhora na completude das variáveis analisadas, embora poucas tenham obtido classificação excelente. Foi observado um padrão irregular de completude para as Região de Saúde. A completude dos dados de suicídio é essencial para subsidiar ações preventivas.

Palavras-chave: Causas Externas. Suicídio. Sistemas de Informações. Estatísticas Vitais. Declaração de Óbito.

\section{ABSTRACT}

Objective: To analyze the evolution of the completeness of suicide records in the mortality information system of the state of Pernambuco, between 1996 and 2015. 
Methods: The degree of completeness of the variables in death certificates was calculated according to healthcare region, along with the rate of change $(\%)$ of completeness between 10-year periods. To analyze trends regarding completeness, a linear regression model was used. Results: An increasing tendency towards completeness was observed among these variables: source of information, race/color, marital status, schooling level, medical care and place of origin. Sex, age and place of occurrence continued to present excellent completeness over the 10year periods. The lowest percentages were found in relation to schooling $(44.0 \%)$, medical care $(47.1 \%)$ and source of information (58.9\%). Conclusion: The completeness of the variables analyzed showed improvement, but few of them reached excellence. An irregular pattern of completeness was observed among the healthcare regions. Completeness of suicide data is essential for providing the basis for preventive actions.

key words: External causes. Suicide. Information systems. Vital statistics. Death certificate.

\section{INTRODUÇÃO}

O suicídio é uma das principais causas de mortes não naturais no mundo. Estima-se que anualmente 800.000 pessoas morram por suicídio e, $75 \%$ ocorrem em países em desenvolvimento ou de baixa renda ${ }^{1}$. Considerando as tendências atuais, cerca de 1,53 milhões de pessoas irão cometer suicídio no ano 2020, sendo a sua tentativa 10 a 20 vezes mais frequente ${ }^{2}$. No Brasil, há uma tendência de aumento da mortalidade por suicídio, com importante diferenças regionais ${ }^{3}$. Entre 2000 e 2012, o coeficiente de suicídiodo país passou de 4,9 para 6,2 por 100.000 
hab., sendo a região Nordeste àquela que registrou o maior crescimento percentual (72,4\%), passando de 3,0 para 5,2 por 100.000 hab. ${ }^{4}$.

A prevenção do suicídio constitui um desafio para as políticas de saúde pública. O Plano de Ação da Organização Mundial da Saúde (OMS) estabelece o objetivo global para redução da mortalidade por suicídio em $10 \%$ até $2020^{5}$. Esta iniciativa e outros esforços para reduzir a mortalidade e a morbidade associadas ao comportamento suicida, requerem a disponibilidade de dados precisos e confiáveis que possam evidenciar a gravidade do problema, os principais grupos de risco envolvidos e o impacto dos esforços de prevenção ${ }^{2,6}$.

Informações precisas sobre os níveis e padrões de mortalidade são essenciais para o planejamento de iniciativas da saúde pública. O padrão-ouro para coleta de tais informações é o registro de mortalidade. Em países de alta renda, esse registro é $100 \%$ completo, diferente da situação em países em desenvolvimento ${ }^{7}$. Erros de notificação nas estatísticas vitais são descritos em muitos desses países, dentre as falhas mais comuns estão: a incompletude dos dados e o registro incorreto da causa básica de morte ${ }^{8}$.

No Brasil, o Sistema de Informações sobre Mortalidade (SIM) tem como instrumento de coleta de dados a Declaração de Óbito (DO), cujas variáveis possibilitam a construção de indicadores e a realização de análises epidemiológicas ${ }^{9}$. Todavia, problemas relacionados à qualidade dos dados registrados no SIM, como baixa cobertura, falhas na declaração da causa básica e baixa completude, são largamente discutidos na literatura ${ }^{9-11}$. Os dados registrados no SIM, apesar de possuírem extrema importância apresentam fragilidades, decorrentes principalmente do preenchimento inadequado do $\mathrm{DO}^{12}$. 
A agenda de ações estratégicas para a vigilância e a prevenção do suicídio do país, propõe como um dos seus eixos de atuação a qualificação da informação com o objetivo de fortalecer a vigilância de tentativas de suicídio e suicídios ${ }^{13}$. A implementação de estratégias para prevenção do suicídio é subsidiada pelas informações registradas no SIM e a completude dos dados é um critério essencial para a qualidade dessas informações. Esse estudo teve por objetivo analisar a evolução da completude dos registros de suicídio do Sistema de Informação sobre Mortalidade no estado de Pernambuco, entre 1996 e 2015.

\section{MÉTODOS}

O estado de Pernambuco está localizado na região Nordeste do Brasil, conta uma população estimada de 9.345 .603 hab. para o ano de 2015 e tem uma extensão territorial de $98.076,001 \mathrm{~km}^{2}$. Possui 184 municípios e o distrito de Fernando de Noronha, cinco mesorregiões (Metropolitana do Recife, Zona da Mata, Agreste, Vale do São Francisco e Sertão) e 12 Regiões de Saúde (RS) ${ }^{14}$.

Trata-se de um estudo sobre a completude das variáveis das DO por suicídios de residentes com idade igual ou maior de 10 anos, no estado de Pernambuco. Foram incluídos óbitos ocorridos nos decênios de 1996-2005 e 2006-2015, registrados no SIM, cuja causa básica compreendeu as categorias X60 a X84 da Décima Classificação Internacional de Doenças. Os dados foram analisados por decênios, com o propósito de obter maior estabilidade e possibilitar a comparação com o período mais recente.

Para o cálculo de tendência da completude das variáveis foi empregado o modelo de regressão linear para as proporções de preenchimento das variáveis, por 
ano, para o estado de Pernambuco. No modelo $Y$ (variável resposta) utilizou-se o grau de preenchimento das variáveis da DO por suicídio do SIM e X (variável explicativa), são os anos de ocorrência das mortes. Como $Y$ é uma taxa, a sua distribuição de probabilidade é não gaussiana (um dos pressupostos para a aplicação do modelo de regressão linear), portanto, realizou-se a transformação em Y, com o propósito de viabilizar o uso da técnica em questão:

$$
Y^{\prime}=\ln \left(\frac{1-Y}{Y}\right)
$$

Sendo assim, após a estimação os modelos terão, em geral a seguinte forma:

$$
Y=\frac{1}{e^{\beta_{0}+\beta_{1} X}+1}
$$

Onde $\beta_{0}$ e $\beta_{1}$ são os coeficientes estimados através da técnica de regressão linear. Todos os cálculos foram feitos utilizando o programa $R$ versão 3.4.1.

Foram analisadas as variáveis sociodemográficas (naturalidade, idade, sexo, raça/cor, estado civil, escolaridade e ocupação) e relacionadas com a ocorrência do óbito (local de ocorrência, assistência médica, necropsia, circunstância do óbito/tipo e fonte de informação). Os dados foram tabulados utilizando o programa TabWin verão 4.1.3 e dispostos por RS e analisados com auxílio do Statistical Package for the Social Sciences (SPSS) versão 15.0 .

Por completude entende-seo grau de preenchimento do campo analisado, mensurado pela proporção de notificações com campo preenchido com categoria 
distinta daquelas indicadoras de ausência do dado (ignorados e em branco) ${ }^{15}$. Para cada variável estudada foi calculado o percentual de completude, analisado conforme adaptação dos escores propostos por Romero e Cunha (2006) ${ }^{16}$, a saber: excelente quando a presença de informação era maior 95\%; bom quando a presença era maior que $90 \%$ até $95 \%$; regular quando era acima de $80 \%$ até $90 \%$; ruim com mais de $50 \%$ até $80 \%$ e muito ruim $\leq 50 \%$ de completude. Para o estado e RS foram calculadas as proporções e a taxa de variação $(\Delta \%)$ da completude para os dois decênios, usando a fórmula:

$$
\Delta \%=\left((2006 \text { a } 2015-1996 \text { a 2005)/1996 a 2005) })^{\star} 100\right.
$$

A pesquisa foi aprovada pelo Comitê de Ética em Pesquisa do Centro de Ciências de Saúde da Universidade Federal de Pernambuco (Parecer no 2.045.304).

\section{RESULTADOS}

No período analisado foram registrados no SIM 6.232 suicídios no estado de Pernambuco. O número de suicídios que passou de 2.841 (1996-2005) para 3.391 (2006-2015), variação de 16,2\%. A maior concentração de óbitos foi encontrada na I RS com $1.046(36,8 \%)$ na primeira década e $1.237(36,4 \%)$ na segunda.

A evolução da completude das variáveis para o estado de Pernambuco, de acordo com as equações dos modelos encontrados, mostrou tendência crescente para 6 variáveis: fonte de informação, raça/cor, estado civil, escolaridade, assistência médica e naturalidade. Apenas a variável ocupação apresentou tendência decrescente. As demais variáveis mostraram tendência constante (Tabela 1). 
A Tabela 2 apresenta o grau de preenchimento das variáveis por decênios. De 1996 a 2005 três variáveis (sexo, idade e local de ocorrência) tiveram completude excelente para todas as RS e Pernambuco. Nesse mesmo período, para o estado os menores percentuais de completude foram encontrados nas variáveis escolaridade $(44,0 \%)$, assistência médica $(47,1 \%)$ e fonte de informação $(58,9 \%)$. Ressalte-se que a variável assistência médica teve completude muito ruim, com menos de $50 \%$ de preenchimento em oito das 12 RS.

Para 2006 a 2015 sexo, idade e local de ocorrência mantiveram a completude excelente. Destaca-se a melhora no preenchimento da variável raça/cor que foi excelente na segunda década em nove RS e Pernambuco. Para Pernambuco a variável assistência médica teve preenchimento ruim $(57,7 \%)$. Comportamento semelhante foi verificado em oito RS e muito ruim em outras três. Houve melhora na completude da variável necropsia no estado, mas não foi excelente em nenhuma das RS e em duas (IX e X) obteve classificação muito ruim.

A comparação entre as duas décadas, mostrou que as variáveis escolaridade, fonte de informação e raça/cor tiveram os maiores aumentos no grau de preenchimento 66,4\%, 32,0\% e 30,5\%, respectivamente em Pernambuco (Tabela 3). Somente três variáveis tiveram redução na completude: ocupação $(-13,2 \%)$, circunstância do óbito/tipo (-6,4\%) e naturalidade (-5,3\%). Não houve redução na completude da variável ocupação em três RS (I, II e XII). Houve incremento de $363,9 \%$ na completude da variável escolaridade na I RS, enquanto na VI RS obtevese redução de $-15,4 \%$.

\section{DISCUSSÃO}


Observou-se entre as décadas estudas um aumento no número de suicídios $(16,2 \%)$ em Pernambuco, no mesmo período o Brasil teve crescimento de $33,2 \%^{17}$. O suicídio é um fenômeno complexo e multicausal, e possui entre seus determinantes fatores sociais, econômicos, culturais, biológicos e história de vida pessoa $^{3,18}$. A I RS concentrou a maior parte dos óbitos por suicídio em ambas as décadas. Isso provavelmente ocorre pelo fato desta região ser a mais populosa do estado, em 2015 compreendeu 44,4\% da população residente de Pernambuco ${ }^{19}$.

Os dados nacionais dos sistemas de informação podem ser usados para estudar as diferenças nas taxas entre os grupos (por exemplo, sexo, raça/etnia e grupos etários) e regiões geográficas, e são úteis na identificação de padrões no mecanismo de suicídio. Além de serem usados para chamar a atenção para a magnitude do problema e o estabelecimento de prioridades ${ }^{20}$. Esses dados são fundamentais para o desenvolvimento de um sistema de vigilância do suicídio de abrangência nacional.

A determinação da causa e do modo de morte é fundamental para fins legais e epidemiológicos ${ }^{21}$. Em todo o mundo, os sistemas de estatísticas vitais têm apresentado avanços no seu funcionamento ${ }^{22-24}$. Uma pesquisa com 148 países relatou melhores desempenhos desses sistemas em nações localizadas na Europa, Américas e Austrália ${ }^{25}$. No Brasil, o SIM é responsável pela captação de informações sobre óbitos ocorridos em todo o território nacional, e desde a sua implantação assinala evolução crescente em sua cobertura e na qualidade do registro das informações ${ }^{26}$.

Os resultados do estudo para os dois decênios demonstraram melhora na completude das variáveis analisadas, embora poucas tenham obtido classificação excelente. Apenas as variáveis sexo, idade e local de ocorrência permaneceram 
com classificação excelente em todas as RS durante os períodos. Acrescente-se que foi observado um padrão irregular de completude para as RS, com marcantes diferenças no preenchimento de algumas variáveis.

No que se refere à tendência do grau de preenchimento das variáveis encontrado no modelo de regressão linear, verificou-se inclinação crescente para fonte de informação, raça/cor, estado civil, escolaridade, assistência médica e naturalidade no estado de Pernambuco. Igualmente, o Brasil, entre 1980 e 2012, registrou tendência crescente da completude em relação aos dados de estatísticas vitais $^{25}$. Estudo que avaliou a incompletude dos dados do SIM (1996 a 2006) das mortes autoprovocadas no país verificou tendência declinante para as variáveis raça/cor e escolaridade, e ascendente para estado civil ${ }^{10}$. Parte dos avanços relacionados às melhorias da qualidade das informações geradas pelos sistemas de registro de morte deve-se aos investimentos financeiros e aprimoramento na funcionalidade desses sistemas ${ }^{27}$.

Ressalta-se que a única variável que apresentou tendência decrescente da completude foi ocupação. Entre os profissionais médicos, parece prevalecer a ideia de que existam variáveis mais ou menos importantes na $\mathrm{DO}^{11}$. Essa conduta pode ter surgido a partir da classificação estabelecida pelo Ministério da Saúde que agregavam as variáveis em indispensáveis, essenciais e secundárias ${ }^{28}$. Esse fato pode ter contribuído para uma equivocada sensação de que algumas variáveis requerem maior atenção em seu preenchimento que outras. Além disso, a fragilidade na qualidade do SIM decorrente da não digitação dos campos da DO podem contribuir para a incompletude das informações ${ }^{29}$.

Em relação à completude das variáveis analisadas, sexo, idade e local de ocorrência mantiveram a classificação excelente em ambos os períodos no estado e 
nas RS. Estudos internacionais também demonstram um alto nível de completude das variáveis sociodemográficas nos registros de óbito por suicídio ${ }^{30-32}$. Tal fato evidencia que os sistemas de estatísticas vitais são uma adequada fonte de informação para essas variáveis, porém, o mesmo não ocorre em relação às informações médicas e psicossociais ${ }^{30}$.

No cenário nacional, pesquisa realizada com dados de suicídio em idosos, entre 1996 a 2010, classificou o preenchimento do "sexo" e "local de ocorrência" como excelentes ( $>90 \%$ de completude) ${ }^{9}$. Da mesma forma, uma análise dos dados sobre suicídio por intoxicação exógena no SIM (2006-2008) mostrou-se excelente para a variável $\operatorname{sexo}^{33}$. A relativa simplicidade na obtenção da informação sobre o sexo, seja através de documento oficial ou caracterização biológica, pode contribuir para elevada completude dessa variável.

Para o estado de Pernambuco o presente estudo revelou os menores percentuais de completude na variável escolaridade. As estatísticas de mortalidade em um país Euroasiático em dois períodos distintos (2001-2008 e 2009-2013), constatou a incompletude de $44 \%$ das informações de escolaridade ${ }^{23}$. Análise relacionada à qualidade da informação dos óbitos por causas externas identificou a variável escolaridade com a menor proporção de preenchimento ${ }^{11}$.

A variável assistência médica obteve o segundo menor nível de completude com acentuada variação entre as RS. Estudo sobre a completude dos registros de suicídios no SIM em idosos, observou que as variáveis ligadas ao óbito (fonte de informação, assistência médica e realização de necropsia) tiveram as maiores incompletudes durante todo o período analisado 9 . Pesquisa sobre causas externas realizada no estado Pernambuco apontou a variável assistência médica como a de pior preenchimento ${ }^{34}$. Uma hipótese indica a pouca relevância dada pelos 
profissionais médicos com relação ao correto preenchimento da DO, ignorando-se, por vezes, o fato desse instrumento ser valoroso para a saúde pública e estudos epidemiológicos ${ }^{10}$.

A variável necropsia expressou melhora na completude no estado de Pernambuco quando se comparou as décadas. No entanto, na segunda década ainda se observou que oito RS tinham completude inferior a $80 \%$. Estabelecer a causa da morte é um requisito fundamental para as ações de prevenção. As mortes por suicídio constituem um desafio particular para os sistemas de estatísticas vitais. Deve ser evidente que a morte foi auto-infligida². Para determinação de um suicídio os médicos legistas necessitam de elevados padrões de evidências, com a incorporação de elementos que corroborem a intenção, tais como: depoimento de testemunhas confiáveis, história de tentativas de suicídio, registros psiquiátricos ou uma carta de suicídio ${ }^{35}$. Quando estas informações não estão disponíveis, a morte é classificada como acidental ou indeterminada ${ }^{36}$.

O Ministério da Saúde estabelece que para os óbitos decorrentes ou suspeitos de causa externa, o preenchimento da DO deve ser realizado por um perito ou médico legista do Instituto de Medicina Legal (IML) ou por um perito designado para localidades sem IML. Pernambuco conta com três IML localizados nos municípios de Petrolina, Caruaru e Recife, sedes das VIII, IV e I RS respectivamente, e mesmo nessas regiões não houve preenchimento completo dessa variável. Esse fato levanta dúvidas sobre a negligência no preenchimento da variável pelos profissionais do IML ou se parte dos óbitos por causas externas não foram encaminhados ao $\mathrm{IML}^{34}$.

Houve aumento na completude dos campos raça/cor e fonte de informação em todas as RS e no estado de Pernambuco. Em um estado norte americano (2003- 
2014), ao analisar a completude das informações no Sistema de Relatório de Mortes Violentas, constatou-se $93,4 \%$ dos dados "raça/cor" notificados ${ }^{31}$. No Brasil, a variável raça/cor foi inserida na DO em 1996. Registros nacionais do SIM revelam melhora gradativa da completude dessa variável, que passou de 43,2\% para 94,0\%, entre 1997 e 2011, respectivamente ${ }^{37}$. Nacionalmente, informações sobre mortalidade por suicídio vem demonstrando ampliação do preenchimento das variáveis raça/cor e fonte de informação ${ }^{9}$.

Naturalidade, ocupação e circunstância do óbito/tipo tiveram redução no preenchimento. $\mathrm{O}$ aumento da incompletude referente à naturalidade dos registros de óbitos por causas externas foi verificado em um estado do Nordeste brasileiro $(2000-2010)^{34}$. Pesquisas internacionais e nacionais apontam proporção elevada da ausência dos dados sobre ocupação nas estatísticas de mortalidade geral e suicídio ${ }^{23,38}$. Circunstância do óbito/tipo é subdivido na DO em acidente, suicídio, homicídio e outros, em 2010, constatou-se no SIM, 67,7\% de ausência de preenchimentos de dados por causas externas nesse campo ${ }^{11}$. O temor das implicações legais é um dos motivos mais justificados pelos médicos para a ausência do registro desta variável na DO, uma vez, que existe a possibilidade do uso de suas informações em processos judiciais ${ }^{11}$.

Entre os médicos aparenta figurar uma valorização diferenciada entre algumas variáveis em detrimento à outras, o que contribui para uma cultura de não preenchimento ou preenchimento inadequado daquelas consideradas menos relevantes ${ }^{39}$. Autores evidenciam a existência de falhas nos currículos das escolas médicas, que no processo de formação não valorizam a DO como instrumento de importância epidemiológica, e não preparam os profissionais para o seu adequado preenchimento $^{9,29,40}$. 
As ausências e erros das informações de óbitos ocorrem em vários países do mundo $25,41-42$. A falta do registro das variáveis dos óbitos pode influenciar, mascarar ou distorcer informações sobre mortalidade, dificultando o conhecimento da sua gravidade ${ }^{43}$. Estratégias de prevenção do suicídio podem ser dificultadas pela qualidade das informações dos sistemas de estatísticas vitais ${ }^{41}$. Medidas que visam a otimização dessas informações têm sido adotadas, como o adequado treinamento dos profissionais responsáveis pelo preenchimento dos dados e a realização de auditorias com o intuito de verificar a precisão e consistência dos dados ${ }^{32}$. A busca de informações em múltiplas fontes é aconselhável para a melhoria da qualidade das informações ${ }^{36}$.

Entre as limitações pertinentes ao estudo destaca-se a mudança da DO ocorrida no ano de 2011 a qual ocasionou modificações na estrutura de algumas variáveis. A utilização de dados secundários possui limitações inerentes, no entanto, o SIM representa uma fonte confiável de informações cuja qualidade tem melhorado de forma substancial nos últimos anos. Esse sistema é essencial para os estudos sobre suicídios e em especial para o planejamento das ações de prevenção. Portanto, pesquisas que avaliem a qualidade das informações são necessárias e contribuem para o continuo aprimoramento do sistema.

\section{CONCLUSÃO}

Houve um padrão irregular no comportamento da completude das variáveis entre as RS. Quanto a tendência de preenchimento dos dados, constatou-se, de modo geral, o crescimento em 6 campos (fonte de informação, raça/cor, estado civil, escolaridade, assistência médica e naturalidade). A boa completude dos dados de 
suicídio é essencial para o acompanhamento, definição de ações estratégicas e de prevenção. Destaca-se a relevância de adoção de medidas do setor público que busquem aumentar a completude dos dados na DO, como a realização de treinamentos direcionados aos profissionais médicos, que fortaleçam a prática do preenchimento adequado desse instrumento. 


\section{FIGURAS}

Tabela 1. Tendência da completude dos óbitos por suicídio em Pernambuco registrados no Sistema de Informações sobre Mortalidade, segundo variáveis sociodemográficas e de óbito 1996 a 2015

\begin{tabular}{llccc}
\hline \multicolumn{1}{c}{ Variável (Y) } & Modelo & R2 & p-valor & Tendência \\
\hline Sexo & - & - & Constante \\
Idade & $Y=\frac{1}{\mathrm{e}^{203.247308-0.101786 \mathrm{X}}+1}$ & 0,8867 & 0,000 & Constante \\
Fonte de informação & $Y=\frac{1}{\mathrm{e}^{383.07958-0.19231 \mathrm{X}}+1}$ & 0,7386 & 0,001 & Crescente \\
Raça/Cor & $Y=\frac{1}{\mathrm{e}^{92.49581-0.04704 \mathrm{X}}+1}$ & 0,3838 & 0,004 & Crescente \\
Estado civil & $Y=\frac{1}{\mathrm{e}^{233.55171-0.11666 \mathrm{X}}+1}$ & 0,7606 & 0,001 & Crescente \\
Escolaridade & $Y=\frac{1}{\mathrm{e}^{-122.92378+0.06067 \mathrm{X}}+1}$ & 0,42 & 0,002 & Descrente
\end{tabular}

Local de ocorrência

Constante

Assistência médica

$$
Y=\frac{1}{\mathrm{e}^{-55060+54.93 \mathrm{X}-0.0137 \mathrm{X}^{2}}+1}
$$

0,002

Crescente

Necropsia

Naturalidade

$$
Y=\frac{1}{e^{-3.967879+0.0487125 X-0.022076 X^{2}}+1}
$$

0,000

Crescente

Circunstâncias do óbito/tipo 
Tabela 2. Percentual da completude dos óbitos por suicídio nas Regiões de Saúde e estado de Pernambuco registrados no Sistema de Informações sobre Mortalidade, segundo variáveis sociodemográficas e de óbito, 1996-2005 e 2006-2015

\begin{tabular}{|c|c|c|c|c|c|c|c|c|c|c|c|c|c|c|}
\hline \multirow{3}{*}{ Variáveis } & \multirow{3}{*}{ Período } & \multicolumn{12}{|c|}{ Região de Saúde } & \multirow{3}{*}{$\begin{array}{c}\text { Pernambuco } \\
\% \\
\end{array}$} \\
\hline & & I & II & III & IV & V & VI & VII & VIII & IX & $\mathbf{x}$ & $\mathbf{X I}$ & XII & \\
\hline & & $\%$ & $\%$ & $\%$ & $\%$ & $\%$ & $\%$ & $\%$ & $\%$ & $\%$ & $\%$ & $\%$ & $\%$ & \\
\hline \multirow{2}{*}{ Naturalidade } & 1996-2005 & 85,8 & 92,8 & 94,5 & 91,2 & 86,9 & 81,2 & 88,9 & 95,4 & 91,0 & 65,6 & 95,7 & 96,0 & 88,5 \\
\hline & $2006-2015$ & 86,9 & 72,5 & 87,7 & 88,3 & 81,3 & 77,1 & 78,0 & 90,0 & 84,5 & 68,7 & 73,2 & 88,2 & 83,8 \\
\hline \multirow{2}{*}{ Idade } & $1996-2005$ & 100,0 & 100,0 & 100,0 & 99,8 & 100,0 & 100,0 & 100,0 & 100,0 & 100,0 & 100,0 & 100,0 & 100,0 & 99,9 \\
\hline & $2006-2015$ & 100,0 & 100,0 & 100,0 & 100 & 100,0 & 100,0 & 100,0 & 100,0 & 100,0 & 100,0 & 100,0 & 100,0 & 100,0 \\
\hline \multirow{2}{*}{ Sexo } & $1996-2005$ & 100,0 & 100,0 & 100,0 & 100 & 100,0 & 100,0 & 100,0 & 100,0 & 100,0 & 100,0 & 100,0 & 100,0 & 100,0 \\
\hline & 2006-2015 & 100,0 & 100,0 & 100,0 & 100 & 100,0 & 100,0 & 100,0 & 100,0 & 100,0 & 100,0 & 100,0 & 100,0 & 100,0 \\
\hline \multirow{2}{*}{ Raça/cor } & 1996-2005 & 67,4 & 78,8 & 73,2 & 77,8 & 63,8 & 85,5 & 83,3 & 76,5 & 86,5 & 85,9 & 80,3 & 78,8 & 74,0 \\
\hline & 2006-2015 & 96,0 & 94,7 & 93,5 & 97,7 & 95,9 & 99,3 & 94,9 & 98,4 & 96,1 & 98,8 & 97,4 & 99,2 & 96,6 \\
\hline \multirow{2}{*}{ Estado civil } & $1996-2005$ & 75,0 & 86,0 & 82,7 & 82,5 & 88,3 & 94,9 & 90,7 & 96,7 & 98,1 & 95,3 & 98,3 & 82,8 & 83,6 \\
\hline & 2006-2015 & 95,0 & 84,2 & 84,5 & 70,5 & 74,7 & 85,1 & 91,5 & 97,4 & 95,1 & 96,4 & 96,1 & 95,3 & 87,8 \\
\hline \multirow{2}{*}{ Escolaridade } & 1996-2005 & 18,0 & 51,8 & 55,1 & 46,8 & 43,7 & 85,5 & 70,4 & 64,1 & 81,9 & 79,7 & 82,1 & 55,6 & 44,0 \\
\hline & 2006-2015 & 83,5 & 72,1 & 65,2 & 40,7 & 46,9 & 72,3 & 93,2 & 91,1 & 90,3 & 88,0 & 89,5 & 85,8 & 73,2 \\
\hline \multirow{2}{*}{ Ocupação } & 1996-2005 & 80,5 & 69,8 & 74,8 & 81,8 & 84,5 & 76,1 & 83,3 & 95,4 & 95,5 & 89,1 & 88,0 & 78,8 & 81,7 \\
\hline & $2006-2015$ & 87,0 & 70,9 & 60,6 & 40,9 & 50,2 & 62,8 & 59,3 & 84,8 & 75,2 & 67,5 & 77,1 & 81,1 & 70,9 \\
\hline \multirow{2}{*}{ Local de ocorrência } & $1996-2005$ & 95,5 & 97,7 & 98,4 & 97,4 & 99,5 & 99,1 & 98,1 & 99,3 & 100,0 & 98,4 & 100,0 & 99,0 & 97,4 \\
\hline & $2006-2015$ & 98,6 & 95,1 & 98,7 & 97,3 & 97,5 & 96,6 & 100,0 & 99,5 & 100,0 & 100,0 & 98,7 & 98,4 & 98,2 \\
\hline \multirow{2}{*}{ Assistência médica } & 1996-2005 & 47,4 & 64,0 & 33,9 & 47,9 & 39,0 & 56,4 & 40,7 & 72,5 & 27,7 & 32,8 & 26,5 & 55,6 & 47,1 \\
\hline & 2006-2015 & 57,3 & 55,9 & 58,1 & 59,3 & 62,7 & 62,8 & 54,2 & 90,6 & 38,8 & 30,1 & 48,4 & 54,3 & 57,7 \\
\hline \multirow{2}{*}{ Necropsia } & $1996-2005$ & 88,2 & 91,9 & 53,5 & 70,7 & 48,8 & 72,6 & 53,7 & 73,9 & 40,0 & 35,9 & 34,2 & 83,8 & 72,9 \\
\hline & 2006-2015 & 79,9 & 74,9 & 83,9 & 88,1 & 79,3 & 75,7 & 61,0 & 92,7 & 42,2 & 48,2 & 54,2 & 81,1 & 76,9 \\
\hline \multirow{2}{*}{$\begin{array}{l}\text { Circunstância do } \\
\text { óbito/tipo }\end{array}$} & 1996-2005 & 100,0 & 100,0 & 100,0 & 100 & 100,0 & 99,1 & 100,0 & 99,3 & 100,0 & 100,0 & 100,0 & 100,0 & 99,9 \\
\hline & 2006-2015 & 96,6 & 90,3 & 90,3 & 86,6 & 93,8 & 88,5 & 98,3 & 97,9 & 97,6 & 91,6 & 92,8 & 93,7 & 93,5 \\
\hline \multirow{2}{*}{ Fonte de Informação } & 1996-2005 & 52,6 & 51,8 & 57,5 & 74,6 & 52,6 & 76,9 & 77,8 & 64,1 & 67,1 & 40,6 & 42,7 & 59,6 & 58,9 \\
\hline & 2006-2015 & 74,8 & 80,2 & 85,2 & 92 & 80,5 & 87,8 & 76,3 & 91,1 & 67,5 & 72,3 & 76,5 & 81,9 & 80,1 \\
\hline
\end{tabular}

Fonte: Sistema de Informação sobre Mortalidade. Secretaria Estadual de Saúde de Pernambuco, 2017. 
Tabela 3. Variação percentual da completude dos óbitos por suicídio nas Regiões de Saúde e estado de Pernambuco registrados no Sistema de Informações sobre Mortalidade, segundo variáveis sociodemográficas e de óbito, 1996-2005 e 2006-2015

\begin{tabular}{|c|c|c|c|c|c|c|c|c|c|c|c|c|c|}
\hline \multirow[t]{2}{*}{ Variáveis } & \multicolumn{13}{|c|}{ Região de Saúde } \\
\hline & I & II & III & IV & $\mathbf{V}$ & VI & VII & VIII & IX & $x$ & $\mathbf{X I}$ & XII & PE \\
\hline Naturalidade & 1,3 & $-0,2$ & $-7,2$ & $-3,2$ & $-6,4$ & -5 & $-12,3$ & $-5,7$ & $-7,1$ & 4,7 & $-23,5$ & $-8,1$ & $-5,3$ \\
\hline Idade & 0 & 0 & 0 & 0,2 & 0 & 0 & 0 & 0 & 0 & 0 & 0 & 0 & 0,1 \\
\hline Sexo & 0 & 0 & 0 & 0 & 0 & 0 & 0 & 0 & 0 & 0 & 0 & 0 & 0 \\
\hline Raça/cor & 42,4 & 20,2 & 27,7 & 25,6 & 50,3 & 16,1 & 13,9 & 28,6 & 11,1 & 15,0 & 21,3 & 25,9 & 30,5 \\
\hline Estado civil & 26,7 & $-2,1$ & 2,2 & $-14,5$ & $-15,4$ & $-10,3$ & 0,9 & 0,7 & $-3,1$ & 1,2 & $-2,2$ & 15,1 & 5,0 \\
\hline Escolaridade & 363,9 & 39,2 & 18,3 & $-13,2$ & 7,3 & $-15,4$ & 32,4 & 42,1 & 10,3 & 10,4 & 9 & 54,3 & 66,4 \\
\hline Ocupação & 8,1 & 1,6 & -19 & -50 & $-40,6$ & $-17,5$ & $-28,8$ & $-11,1$ & $-21,3$ & $-24,2$ & $-12,4$ & 3,8 & $-13,2$ \\
\hline Local de ocorrência & 3,2 & $-2,7$ & 0,3 & $-0,1$ & -2 & $-2,5$ & 1,9 & 0,2 & 0 & 1,6 & $-1,3$ & $-0,6$ & 0,8 \\
\hline Assistência médica & 20,9 & $-12,7$ & 71,4 & 23,8 & 60,8 & 11,3 & 33,2 & 25 & 40,1 & $-8,2$ & 82,6 & $-2,3$ & 22,5 \\
\hline Necropsia & $-9,4$ & $-18,5$ & 56,8 & 24,6 & 62,5 & 4,3 & 13,6 & 25,4 & 5,5 & 34,3 & 58,5 & $-3,2$ & 5,5 \\
\hline Circunstância do óbito/tipo & $-3,4$ & $-9,7$ & $-9,7$ & $-13,4$ & $-6,2$ & $-10,7$ & $-1,7$ & $-1,4$ & $-2,4$ & $-8,4$ & $-7,2$ & $-6,3$ & $-6,4$ \\
\hline Fonte de Informação & 42,2 & 54,8 & 48,2 & 23,3 & 53 & 14,2 & $-1,9$ & 42,1 & 0,6 & 78,1 & 79,2 & 37,4 & 32,0 \\
\hline
\end{tabular}




\section{REFERÊNCIAS}

1. World Health Organization. Preventing Suicide: A Global Imperative [Internet]. Geneva; 2014. [citado em 2017 dez 14]. Disponível em:

http://www.who.int/mental health/suicide-prevention/world report 2014/en/

2. Fond G, Llorca PM, Boucekine M, Zendjidjian X, Brunel L, Lancon C, et al.

Disparities in suicide mortality trends between United States of America and 25

European countries: retrospective analysis of WHO mortality database. Sci Rep. 2016;6:20256. https://www.nature.com/articles/srep20256

3. Botega NJ. Comportamento Suicida: epidemiologia. Psicol USP. 2014;25(3):231-

36. http://www.scielo.br/scielo.php?script=sci arttext\&pid=S0103$\underline{65642014000300231}$

4. Machado DB, Santos DN. Suicídio no Brasil, de 2000 a 2012. J bras psiquiat. 2015;64(1):45-54. http://www.scielo.br/scielo.php?script=sci arttext\&pid=S0047$\underline{20852015000100045}$

5. World Health Organization. Mental health action plan 2013-2020 [Internet]. Geneva: 2013. [citado em 2017 nov 25] Disponível em: http://apps.who.int/iris/bitstream/10665/89966/1/9789241506021 eng.pdf 6. Hagaman AK, Maharjan U, Kohrt BA. Suicide surveillance and health systems in Nepal: a qualitative and social network analysis. Int J Health Syst. 2016;10:46. https://www.ncbi.nlm.nih.gov/pmc/articles/PMC4895957/

7. Murray CJL, Rajaratnam JK, Marcus J, Laakso T, Lopez AD, et al. What Can We Conclude from Death Registration? Improved Methods for Evaluating Completeness. Plos Med. 2010;7(4):e1000262.

http://journals.plos.org/plosmedicine/article?id=10.1371/journal.pmed.1000262 
8. Qaddumi JAS, Nazzal Z, Yacoup AR, Mansour M, et al. Quality of death notification forms in North West Bank / Palestine: a descriptive estudy. BMC Res Notes. 2017;10(1):154.

https://bmcresnotes.biomedcentral.com/articles/10.1186/s13104-017-2469-0

9. Rios MA, Anjos KF, Meira SS, Nery AA, Casotti CA, et al. Completude do sistema de informação sobre mortalidade por suicídio em idosos no estado da Bahia. J Bras Psiquiatr. 2013;62(2):131-38

http://www.scielo.br/scielo.php?script=sci arttext\&pid=S0047-20852013000200006 10. Macente LB, Zandonade E. Avaliação da completude do Sistema de Informação sobre Mortalidade por suicídio na região Sudeste, Brasil, no período de 1996 a 2007. J Bras Psiquiatr. 2010;59(3):173-81.http://www.scielo.br/scielo.php?pid=S0047$\underline{20852010000300002 \& \text { script }=\text { sci } \text { abstract\&tlng=pt }}$

11. Messias KLM, Bispo Júnior JP, Pegado MFQ, Oliveira LC, Peixoto TG, Sales MAC, et al. Qualidade da informação dos óbitos por causas externas em Fortaleza, Ceará, Brasil. Ciênc Saúde Coletiva. 2016;21(4):1255-67.

http://www.scielo.br/scielo.php?pid=S1413-

$\underline{81232016000401255 \& \text { script }=\text { sci } \text { abstract\&tlng=pt }}$

12. Silva JAC, Yamaki VN, Oliveira JPS, Teixeira RKC, Santos FAF, Hosoume VSN. Declaração de óbito, compromisso no preenchimento: avaliação em Belém - Pará, em 2010. Rev Assoc Med Bras. 2013;59(4):335-340.

https://www.scienceopen.com/document?vid=83553f5b-ae79-431a-b759$\underline{\mathrm{e} 2 \mathrm{c} 96542 \mathrm{~d} 95 \mathrm{c}}$

13. Brasil. Ministério da Saúde. Agenda de Ações Estratégicas para a Vigilância e Prevenção do Suicídio e Promoção da Saúde no Brasil: 2017 a 2020 [Internet]. Brasília: Secretaria de Atenção à Saúde; 2017 [citado em 2018 set 11]. Disponível 
em: http://www.neca.org.br/wp-content/uploads/cartilha agenda-estrategicapublicada.pdf

14. Pernambuco. Secretaria Estadual de Saúde de Pernambuco. Portal da Saúde [Internet] 2018 [citado em 2018 set 11]. Disponível em:

http://portal.saude.pe.gov.br/secretaria-executiva-de-coordenacao-geral/gerenciasregionais-de-saude

15. Glatt R. Análise da qualidade da base de dados de aids do Sistema de Informação de Agravos de Notificação (SINAN). Dissertação (Mestrado profissional em vigilância em saúde). Escola nacional de saúde pública ENSP/Fiocruz. São Paulo, 2005.

16. Romero DE, Cunha AB. Avaliação da qualidade das variáveis sócio-econômicas e demográficas dos óbitos de crianças menores de um ano registrados no Sistema de Informação Sobre Mortalidade do Brasil (1996/2001). Cad Saúde Pública. 2016; 22(3):673-84. http://www.scielo.br/scielo.php?pid=S0102-

$\underline{311 \times 2006000300022 \& \text { script }=\text { sci arttext\&tIng=pt }}$

17. Brasil. Ministério da Saúde. Departamento de Informática do SUS. Informações de Saúde (TABNET) [Internet]. Brasília; 2018 [citado em 2017 nov 21]. Disponível em: http://tabnet.datasus.gov.br/cgi/deftohtm.exe?sim/cnv/ext10uf.def

18. Crump C, Sundquist K, Sundquist J, Winkleby MA. Sociodemographic, psychiatric and somatic risk factors for suicide: a Swedish national cohort study. Psychol Med. 2016;46(2):225-36.

https://www.cambridge.org/core/journals/psychological-medicine/article/divclasstitlesociodemographic-psychiatric-and-somatic-risk-factors-for-suicide-aswedish-national-cohort-studydiv/38C261DEB9A28F6D244169B517227414 
19. IBGE. Instituto Brasileiro de Geografia e Estatística [Internet]. 2018. [citado em 2017 nov 4]. Disponível em: https://www.ibge.gov.br/

20. Ikeda R, Hedegaard H, Bossarte R, Crosby AE, Hanzlick R, Roesler J, et al. Improving National Data Systems for Surveillance of Suicide-related Events. Am J Prev Med. 2014;47(3):122-29.

https://www.ncbi.nlm.nih.gov/pmc/articles/PMC4959537/

21. Di Vella, Compobasso CP. Death Investigation and Certification in Italy. Academic forensic pathology. 2015;5(3):454-61.

http://journals.sagepub.com/doi/abs/10.23907/2015.050

22. Fowler KA, Jack SP, Lyons BH, Betz CJ, Petrosky E. Surveillance for Violent Deaths - National Violent Death Reporting System, 18 States, 2014. MMWR. 2018;

67(2):1-36. https://www.cdc.gov/mmwr/volumes/67/ss/ss6702a1.htm

23. Özdemir R, Rao C, Öcek Z, Horasan D. Reliable mortality statistics for Turkey: Are we there yet? BMC Public Health. 2015;15:545.

https://bmcpublichealth.biomedcentral.com/articles/10.1186/s12889-015-1904-1

24. Joubert J, Rao C, Bradshaw D, Vos T, Lopez AD. Evaluating the Quality of National Mortality Statistics from Civil Registration in South Africa, 1997-2007. PLoS ONE. 2013;8(5):e64592.

http://journals.plos.org/plosone/article?id=10.1371/journal.pone.0064592

25. Mikkelsen L, PhillipsD, AbouZahr C, Setel P, Savigny D, Lozano R. A global assessment of civil registration and vital statistics systems: monitoring data quality and progress. The Lancet. 2015;386(10001):1395-1406.

http://www.thelancet.com/journals/lancet/article/PIIS0140-6736(15)60171-4/abstract 26. Frias PG, Szwarcwald CL, Morais Neto OL, Leal MC, Cortez-Escalante JJ, Souza Junior PRB. Utilização das informações vitais para a estimação de indicadores de 
mortalidade no Brasil: da busca ativa de eventos ao desenvolvimento de métodos. Cad Saúde Pública. 2017;33(3):e00206015.

http://www.scielo.br/scielo.php?pid=S0102-

$\underline{311 \times 2017000305014 \& \text { script }=\text { sci } \text { abstract\&tlng }=\text { pt }}$

27. AbouZahr C, Savigny D, MikkelsenL, Setel P, Lozano R, Nichols E. Civil registration and vital statistics: progress in the data revolution for counting and accountability. The Lancet. 2015;386(10001):1373-85.

http://www.thelancet.com/journals/lancet/article/PIIS0140-6736(15)60173-8/abstract

28. Brasil. Ministério da Saúde. Manual de Instrução para o preenchimento da declaração de óbito: 1997. Brasília: Fundação Nacional de Saúde; 1997.

29. Correia LOS, Padilha BM, Vasconcelos SMV. Métodos para avaliar a completitude dos dados dos sistemas de informação em saúde do Brasil: uma revisão sistemática. Cien Saude Colet. 2014;19(11):4467-78.

http://www.scielo.br/scielo.php?script=sci arttext\&pid=S1413-81232014001104467

30. Corcoran P, Arensman E. A study of the Irish system of recording suicide deaths. Crisis. 2010;31(4):174-82 https://econtent.hogrefe.com/doi/abs/10.1027/00275910/a000026?url ver=Z39.88-

2003\&rfr id=ori\%3Arid\%3Acrossref.org\&rfr dat=cr pub\%3Dpubmed

31. Smith ML, Akinyemi AA, Stanley JL, Mitchell CS. Violent Death Reporting in Maryland: Demographic Variability in Data Completeness. Am J Public Health. 2017; 107(10):1621-23

http://www.ajph.org/doi/abs/10.2105/AJPH.2017.303943?url ver=Z39.882003\&rfr id=ori:rid:crossref.org\&rfr dat=cr pub\%3dpubmed 
32. Phanawadee M, Jiraphongsa C. System, Report Sensitivity and Data Quality of the Injury Surveillance System, Ratchaburi Province, Thailand. OSIR. 2017;10(3):915 http://www.osirjournal.net/index.php/osir/article/view/105

33. Santos AS, Legay LF, Aguiar FP, Lovisi GM, Abelha L, Oliveira SP. Tentativas e suicídios por intoxicação exógena no Rio de Janeiro, Brasil: análise das informações através do linkage probabilístico. Cad Saúde Pública. 2014;30(5):1057-66.

http://www.scielo.br/scielo.php?script=sci abstract\&pid=S0102-

$\underline{311 \times 2014000501057 \& \operatorname{lng}=p t \& n r m=i s}$

34. Melo GBT, Valongueiro S. Incompletude dos registros de óbitos por causas externas no Sistema de Informações sobre Mortalidade em Pernambuco, Brasil, 2000-2002 e 2008-2010. Epidemiol Serv Saúde. 2015;24(4):651-60.

http://www.scielo.br/scielo.php?pid=S2237-

$\underline{96222015000400651 \& \text { script }=\text { sci } \text { abstract\&tIng }=\text { pt }}$

35. Rockett IRH, Kapusta ND, Coben JH. Beyond Suicide Action Needed to Improve Self-injury Mortality Accounting. JAMA Psychiatry. 2014;71(3):231-32.

https://www.ncbi.nlm.nih.gov/pmc/articles/PMC4370288/

36. Bakst SS, Braun T, Zucker I, Amitai Z, Shohat T. The accuracy of suicide statistics: are true suicide deaths misclassified? Soc Psychiatry Psychiatr Epidemiol. 2016;51(1):115-23. https://link.springer.com/article/10.1007\%2Fs00127-015-1119-x 37. Braz RM, Oliveira PT, Reis AT, MAchado NM et al. Avaliação da completude da variável raça/cor nos sistemas nacionais de informação em saúde para aferição da equidade étnico-racial em indicadores usados pelo Índice de Desempenho do Sistema Único de Saúde. Saúde debate. 2013;37(99):554-62.

http://www.scielo.br/scielo.php?script=sci arttext\&pid=S0103-11042013000400002 
38. Albuquerque PCC, Gurgel IG, Gurgel AM, Augusto LG, Siqueira MT. Sistemas de informação em saúde e as intoxicações por agrotóxicos em Pernambuco. Rev Bras Epidemiol. 2015;18(3):666-78. http://www.scielo.br/scielo.php?pid=S1415$\underline{790 \times 2015000300666 \& s c r i p t=s c i}$ abstract\&tlng=pt

39. Costa JMBS, Frias PG. Avaliação da completitude das variáveis da declaração de óbitos de menores de um ano residentes em Pernambuco, 1997-2005. Cien Saude Colet. 2011;16(Supl. 1):1267-74. http://www.scielo.br/scielo.php?pid=S1413$\underline{81232011000700059 \& \text { script }=\text { sci abstract\&tlng }=p t}$

40. Alazraqui M, Spinelli H, Zunino MG, Souza ER. Calidad de los sistemas de información de mortalidade por violências em Argentina y Brasil - 1990-2010. Cien Saude Colet. 2012;17(12):3279-88.

http://www.scielo.br/scielo.php?script=sci arttext\&pid=S1413-81232012001200013 41. Sutherland G, Milner A, Dwyer J, Bugeja L, Woodward A, Robinson J. Implementation and evaluation of the Victorian Suicide Register. Aust NZ J Public Health. 2017;42(3):296-302 https://onlinelibrary.wiley.com/doi/abs/10.1111/1753$\underline{6405.12725}$

42. Blair JM, Fowler KA, Jack SP, Crosby AE. The National Violent Death Reporting System: overview and future directions. Inj Prev. 2016;22(1):i6-i11.

http://injuryprevention.bmj.com/content/22/Suppl 1/i6.long

43. Morais RM, Costa AL. Uma avaliação do Sistema de Informações sobre Mortalidade. Saúde debate. 2017;41:101-17.

http://www.scielo.br/scielo.php?pid=S0103-11042017000500101\&script=sci arttext 
6.3 MORTALIDADE POR SUICÍDIO NO ESTADO DE PERNAMBUCO, BRASIL (1996$2015)^{3}$

\title{
RESUMO
}

Objetivo: Descrever as características epidemiológicas da mortalidade por suicídio no estado de Pernambuco, no período de 1996 a 2015. Método: Estudo com dados do Sistema de Informações sobre Mortalidade. Utilizou-se o modelo de regressão linear simples para verificar a tendência no período estudado. Resultados: Foram registrados 6.229 suicídios, dos quais $3.390(54,4 \%)$ aconteceram na segunda década de estudo. O coeficiente de mortalidade foi de 4,7 por 100.000 habitantes. A tendência temporal apresentou decréscimo de 23,5\% $(\mathrm{p}=0,031)$. No sexo masculino e faixa etária de 20 a 39 anos observou-se declínio na morte autoprovocada de $23,8 \%(p=0,018)$ e $26,1 \%(p=0,046)$, respectivamente. Conclusão: A análise temporal revelou redução dos coeficientes de mortalidade por suicídio. Essa observação poderá contribuir para melhores direcionamentos de intervenções em saúde, otimizando recursos e esforços, sobretudo na prevenção do suicídio.

Descritores: Suicídio; Causas Externas; Mortalidade; Estatísticas Vitais; Tendências.

\begin{abstract}
Objective: To describe the epidemiological characteristics of suicide mortality in the state of Pernambuco, from 1996 to 2015. Method: Study with data from the Sistema de Informações sobre Mortalidade. The simple linear regression model was used to verify the trend in the period analyzed. Results: There were 6,229 suicides, of which 3,390 (54.4\%) occurred in the second decade of study. The mortality rate was 4.7 per 100,000 inhabitants. The temporal trend presented a decrease of $23.5 \%(\mathrm{p}=0.031)$. For the male sex and the age range between 20 and 39 years, there was a decline in self-inflicted death of $23.8 \%(\mathrm{p}=0.018)$ and $26.1 \%$ ( $\mathrm{p}=0.046)$, respectively. Conclusion: The temporal analysis revealed a reduction in suicide mortality coefficients. This observation may contribute to better targeting of health interventions, optimizing resources and efforts, especially in suicide prevention.
\end{abstract}

${ }^{3}$ Manuscrito submetido e aceito pela Revista Brasileira de Enfermagem (ANEXO G), segundo formatação de submissão (ANEXO H). 
Keywords: Suicide; External Causes; Mortality; Vital Statistics; Trends.

\section{RESUMEN}

Objetivo: Describir las características epidemiológicas de la mortalidad por suicidio en el estado de Pernambuco, en el período de 1996 a 2015. Método: Estudio con los datos del Sistema de Informaciones sobre Mortalidad. Se utilizó el modelo de regresión lineal simple para verificar la tendencia en el período de estudio. Resultados: Se registraron 6.229 suicidios, de los cuales 3.390 (el 54,4\%) ocurrieron en la segunda década de estudio. El coeficiente de mortalidad fue de 4,7 por 100.000 habitantes. La tendencia temporal presentó una disminución del 23,5\% (p=0,031). En el sexo masculino y el grupo de edad de 20 a 39 años se observó un descenso en la muerte autoprovocada del $23,8 \%(\mathrm{p}=0,018)$ y el 26,1\% $(\mathrm{p}=0,046)$, respectivamente. Conclusión: El análisis temporal reveló una reducción de los coeficientes de mortalidad por suicidio. Esta observación puede contribuir a mejores formas de intervenciones en salud, optimizando los recursos y esfuerzos, sobre todo en la prevención del suicidio.

Palabras clave: Suicidio; Causas Externas; Mortalidad; Estadísticas Vitales; Tendencias.

\section{INTRODUÇÃO}

O comportamento suicida é apontado como um fenômeno complexo que se manifesta através de ideias e planejamentos que podem culminar em uma ação suicida, cujo desfecho pode ser fatal ou não ${ }^{(1)}$. Define-se suicídio como o ato humano intencional de cessar com a própria vida, sendo influenciado por aspectos demográficos, biológicos e sociais ${ }^{(2-3)}$.

Entre os fatores associados à morte autoprovocada estão tentativas prévias de suicídio, presença de doenças mentais, traços de personalidade agressiva e impulsiva, violência sofrida e isolamento social ${ }^{(4)}$. Alguns grupos populacionais, como os indígenas, apresentam risco mais elevado de cometerem suicídio ${ }^{(5)}$, o qual também é maior entre o sexo masculino e em indivíduos com 65 anos ou mais ${ }^{(6-7)}$.

A Organização Mundial de Saúde (OMS) estimou, para o ano de 2015, 788.000 mortes por suicídio, indicando coeficiente global de mortalidade de 10,7 por 100.000 habitantes (hab.) ${ }^{(8)}$. Entretanto, a ausência de dados em alguns países e a irregularidade nos 
envios dessas informações à OMS limitam o conhecimento preciso desse evento no mundo $^{(6,9)}$.

O Brasil se encontra entre os dez países que registram os maiores números absolutos de morte por suicídio ${ }^{(9)}$. No ano de 2015, ocorreram 11.736 casos, com coeficiente de mortalidade de 5,7 por 100.000 hab. $^{(10)}$ No estado de Pernambuco, entre 2011 e 2013, as mortes autoprovocadas representaram $4,2 \%$ do total das causas externas ${ }^{(11)}$.

A tendência da mortalidade por suicídio é influenciada por fatores como sexo, idade e meios empregados ${ }^{(12-14)}$. Identificar modificações temporais e no perfil epidemiológico do suicídio é relevante para subsidiar o planejamento de ações de intervenção do setor saúde e áreas afins capazes de minimizar sua ocorrência.

\section{OBJETIVO}

Analisar a tendência temporal e as características epidemiológicas da mortalidade por suicídio no estado de Pernambuco, no período de 1996 a 2015.

\section{MÉTODO}

\section{Aspectos éticos}

A pesquisa foi aprovada pelo Comitê de Ética em Pesquisa do Centro de Ciências de Saúde da Universidade Federal de Pernambuco. O estudo atendeu às diretrizes nacionais e internacionais para pesquisa envolvendo seres humanos.

\section{Desenho, local do estudo e período}

Trata-se de um estudo ecológico de tendência temporal. O estado de Pernambuco está situado na região Nordeste do Brasil e possui uma área territorial de $98.076,021 \mathrm{~km}^{2}$. Administrativamente, é dividido em 185 municípios distribuídos em 12 Regionais de Saúde. A população estimada para o ano de 2015 foi de 9.345 .173 hab. ${ }^{(15)}$

O estudo analisou os suicídios ocorridos entre 1996 e 2015 por residentes do estado de Pernambuco. Os dados são provenientes do Sistema de Informações sobre Mortalidade (SIM), correspondente ao grande grupo de causas de lesões autoprovocadas (X60-X84) da $10^{\mathrm{a}}$ 
revisão da classificação internacional de doenças (CID-10). As estimativas populacionais foram extraídas do Instituto Brasileiro de Geografia e Estatística (IBGE/2010). ${ }^{(15)}$

\section{População: critérios de inclusão e exclusão}

Foram incluídos todos os óbitos de suicídio ocorridos em residentes do estado de Pernambuco com 10 anos ou mais entre o período de 1996 a 2015. As variáveis escolaridade e ocupação não foram analisadas devido à elevada proporção de incompletudes $(39,4 \%$ e $25,6 \%$, respectivamente).

\section{Protocolo do estudo}

Os dados utilizados foram obtidos mediante declaração de anuência cedida pela Secretaria Estadual de Saúde de Pernambuco.

\section{Análise dos resultados e estatística}

A caracterização epidemiológica dos suicídios foi analisada segundo décadas (1996-2005 e 2006-2015). Observaram-se as seguintes variáveis: sexo, faixa etária, raça/cor, situação conjugal, local de ocorrência, Regional de Saúde e método utilizado para o óbito. Para cada variável, foram calculadas as proporções e taxas de variação $(\Delta \%)$ para os dois decênios, usando a fórmula: $\Delta \%=([$ Década 2 - Década 1]/ Década 1) $\times 100$.

Para a análise da tendência temporal utilizou-se a técnica de regressão linear simples. Os coeficientes de mortalidade por suicídio ([número de suicídio/população residente de Pernambuco com dez anos ou mais] $\times 100.000$ hab.) foram considerados a variável dependente e, o ano do calendário, a independente. O programa R versão 3.4.1. foi empregado para as análises descritivas e obtenção das equações das tendências lineares e estatísticas de ajuste dos modelos. Adotou-se o nível de significância de 5\%.

Com o objetivo de controlar o efeito de diferentes estruturas etárias e de sexo, realizou-se a padronização simultânea por idade e sexo dos coeficientes de mortalidade brutos por suicídio. Optou-se pelo método direto de padronização, adotando a população do estado de Pernambuco do censo 2010 do IBGE como a padrão. Considerou-se necessária a 
padronização para dispor de taxas de mortalidade que fossem comparáveis entre si e ao longo do período estudado.

\section{RESULTADOS}

No período estudado (1996-2015) foram registrados 6.229 suicídios pelo SIM, com coeficiente de mortalidade padronizado de 4,7 por 100.000 hab. Houve declínio no coeficiente de mortalidade total, que passou de 5,1 para 3,9 por 100.000 hab., com redução de 23,5\% ( $\mathrm{p}=0,031)$ (Figura 1). O coeficiente médio padronizado de mortalidade no sexo masculino foi de 7,4 por 100.000 hab., com redução de $-23,8$ (p=0,018) (Tabela 1). Entre as mulheres, esse coeficiente foi de 2,2 por 100.000 hab., com decréscimo de -22,2\%. A relação do coeficiente global médio entre homens e mulheres foi de 3:1. Quanto à faixa etária, verificou-se que apenas o grupo entre 20 e 39 anos exibiu uma tendência decrescente $\left(R^{2}=0,204 ; p=0,046\right)$ (Tabela 1).

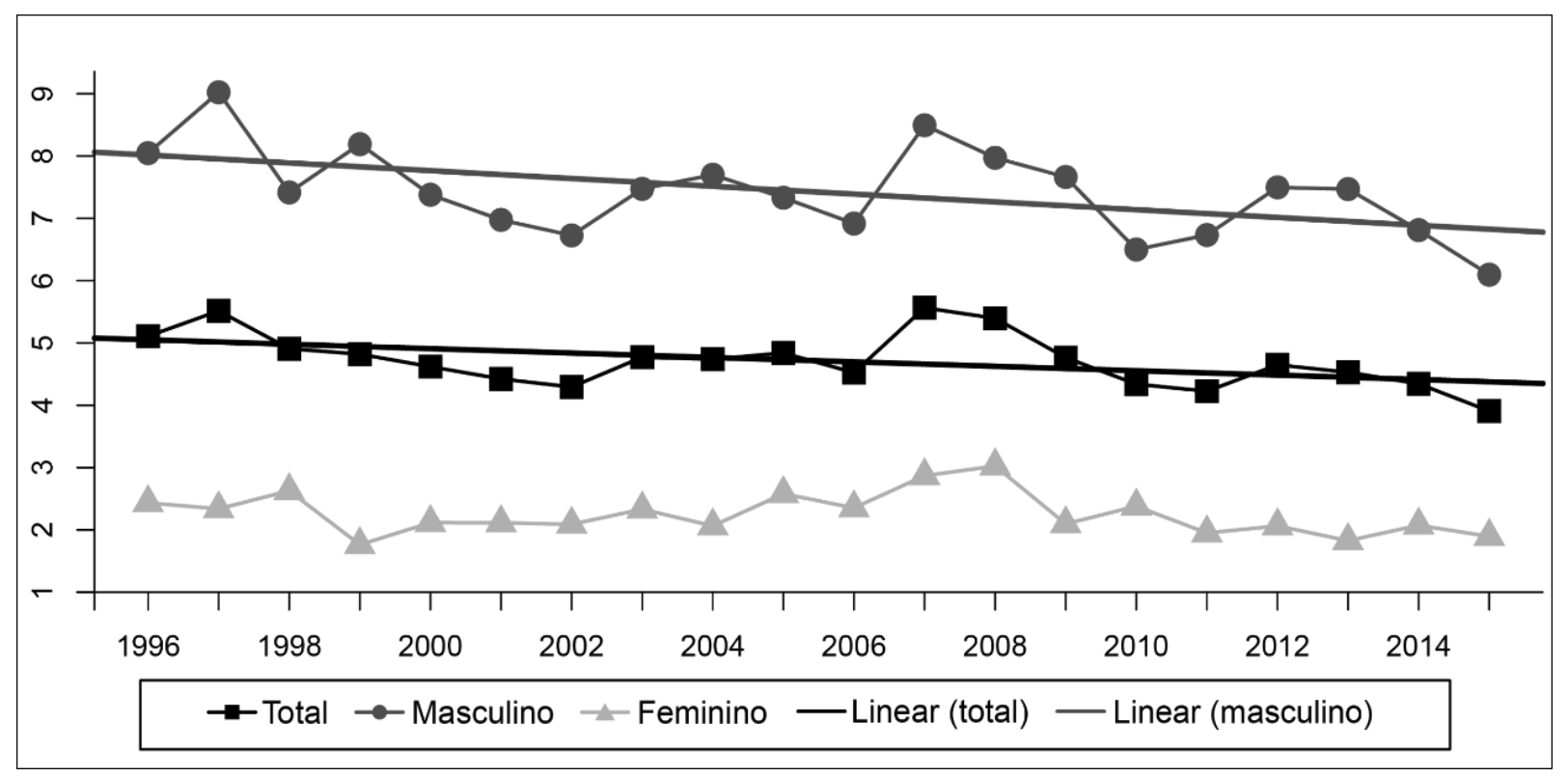

Figura 1- Coeficiente de mortalidade por suicídio da população total do estado de Pernambuco, Brasil, por sexo (1996-2015) 
Tabela 1- Análise de tendências e modelo ajustado do coeficiente padronizado de suicídio total, por sexo e faixa etária, da população residente do estado de Pernambuco, Brasil (1996-2015)

\begin{tabular}{cccccc}
\hline Variável & Categoria & Modelo & $\mathbf{R}^{2}$ & p-valor & $\Delta \%$ \\
\hline Total & PE & $\mathrm{y}=75.77-0.035 \mathrm{x}$ & 0,234 & 0,031 & $-23,5$ \\
Sexo & Masculino & $\mathrm{y}=132.929-0.063 \mathrm{x}$ & 0,273 & 0,018 & $-23,8$ \\
& Feminino & $\mathrm{y}=27.188-0.012 \mathrm{x}$ & 0,048 & 0,352 & - \\
\multirow{2}{*}{ Faixa etária } & 10 a 19 & $\mathrm{y}=-6.451+0.004 \mathrm{x}$ & 0,004 & 0,792 & - \\
& 20 a 39 & $\mathrm{y}=90.725-0.043 \mathrm{x}$ & 0,204 & 0,046 & $-26,1$ \\
& 40 a 59 & $\mathrm{y}=79.059-0.037 \mathrm{x}$ & 0,122 & 0,132 & - \\
& 60 e mais & $\mathrm{y}=198.089-0.095 \mathrm{x}$ & 0,167 & 0,074 & -
\end{tabular}

Fonte: Sistema de Informação sobre Mortalidade ${ }^{32}$

As análises das características epidemiológicas dos suicídios são apresentadas na Tabela 2. Constatou-se o predomínio do sexo masculino, com $2.127(74,9 \%)$ no primeiro decênio e $2.525(74,5 \%)$ no segundo; contudo, houve aumento de 1,6\% de mortes entre as mulheres. Quanto à faixa etária, a maior concentração (>40\%) está entre os adultos jovens (20 a 39 anos); entretanto, o agrupamento de 40 a 59 anos apresentou incremento de 11,3\%, com significância estatística $(\mathrm{p}=0,008)$. Os indivíduos pardos e solteiros foram os mais acometidos, registrando, respectivamente, acréscimo de 22,6\% ( $p<0,001)$ e 6,3\% ( $p=0,009)$. O local de ocorrência mais comum foi o domicílio, com 1.250 (45,2\%) óbitos na primeira década e 1.563 (47\%) na segunda. Em relação à Regional de Saúde, observou-se maior frequência na primeira, com 1.046 (36,9\%) entre 1996 e 2005 e $1.237(36,7 \%)$ entre 2006 e 2015. Embora sem significância, a IX Regional de Saúde apresentou a maior variação percentual das mortes por suicídio $(10,9 \%)$.

Tabela 2 - Caracterização epidemiológica dos óbitos por suicídio no estado de Pernambuco, Brasil, segundo décadas (1996-2005/2006-2015)

\begin{tabular}{|c|c|c|c|c|c|c|}
\hline \multirow{2}{*}{ Variáveis } & \multicolumn{2}{|c|}{ 1996-2005 } & \multicolumn{2}{|c|}{$2006-2015$} & \multirow{2}{*}{$\Delta \%$} & \multirow{2}{*}{ p-valor } \\
\hline & $\mathbf{n}$ & $\%$ & n & $\%$ & & \\
\hline Total de óbitos & 2.839 & 45,6 & 3.390 & 54,4 & 19,3 & - \\
\hline \multicolumn{7}{|l|}{ Sexo } \\
\hline Masculino & 2.127 & 74,9 & 2.525 & 74,5 & $-0,5$ & 0,714 \\
\hline Feminino & 712 & 25,1 & 865 & 25,5 & 1,6 & 0,714 \\
\hline \multicolumn{7}{|l|}{ Faixa etária } \\
\hline $10-19$ anos & 325 & 11,4 & 353 & 10,4 & $-8,8$ & 0,206 \\
\hline $20-39$ anos & 1.290 & 45,5 & 1.459 & 43 & $-5,5$ & 0,061 \\
\hline $40-59$ anos & 781 & 27,5 & 1.037 & 30,6 & 11,3 & 0,008 \\
\hline$\geq 60$ anos & 443 & 15,6 & 541 & 16 & 2,6 & 0,728 \\
\hline
\end{tabular}




\begin{tabular}{lcccccc} 
Raça/cor & & & & & & \\
Pardos & 1.367 & 65,1 & 2.613 & 79,8 & 22,6 & $<0,001$ \\
Brancos & 612 & 29,1 & 566 & 17,3 & $-40,5$ & $<0,001$ \\
Pretos & 104 & 5 & 80 & 2,4 & -52 & $<0,001$ \\
Amarelos & 11 & 0,5 & 2 & 0,1 & -80 & 0,002 \\
Indígenas & 7 & 0,3 & 13 & 0,4 & 33,3 & 0,884 \\
Situação conjugal & & & & & & \\
Solteiro & 1362 & 57,4 & 1815 & 61 & 6,3 & 0,009 \\
Casado & 872 & 36,7 & 884 & 29,7 & $-19,1$ & $<0,001$ \\
Viúvo & 86 & 3,6 & 133 & 4,5 & 25 & 0,139 \\
Separado judicialmente & 35 & 1,5 & 104 & 3,5 & 133,3 & $<0,001$ \\
União estável & 14 & 0,6 & 40 & 1,3 & 116,7 & 0,009 \\
Outros & 4 & 0,2 & 0 & 0 & -100 & - \\
Local de ocorrência do óbito & & & & & & \\
Domicílio & 1.250 & 45,2 & 1.563 & 47 & 4 & 0,932 \\
Hospital e outros & 938 & 33,9 & 988 & 29,7 & $-12,4$ & $<0,001$ \\
estabelecimentos de saúde & 287 & 10,4 & 393 & 11,8 & 13,5 & 0,242 \\
Via pública & 291 & 10,5 & 384 & 11,5 & 9,5 & 0,51 \\
Outros & & & & & & \\
Regional de Saúde & 1.046 & 36,9 & 1.237 & 36,7 & $-0,5$ & 0,855 \\
I & 222 & 7,8 & 247 & 7,3 & $-6,4$ & 0,474 \\
II & 127 & 4,5 & 155 & 4,6 & 2,2 & 0,881 \\
III & 467 & 16,5 & 528 & 15,6 & $-5,4$ & 0,391 \\
IV & 213 & 7,5 & 241 & 7,1 & $-5,3$ & 0,605 \\
V & 117 & 4,1 & 148 & 4,4 & 7,3 & 0,663 \\
VI & & & & & & \\
\hline Fonte: Sistema de Informação sobre & Mortalidade & & & &
\end{tabular}

Fonte: Sistema de Informação sobre Mortalidade

No sexo masculino, o enforcamento foi o método mais empregado na execução do suicídio, com elevação de 946 (44,5\%) para 1.450 (57,4\%), entre as décadas analisadas (aumento de 29,0\%) (Tabela 3). Houve mudança no padrão do método de morte utilizado pelo sexo feminino, no qual o enforcamento predominou no primeiro decênio, com 197 óbitos $(27,7 \%)$, e os pesticidas prevaleceram no segundo decênio, com 290 mortes (33,5\%), vide Tabela 3. O uso das armas de fogo destacou-se pela expressiva redução $(-58,6 \%)$ entre homens $(\mathrm{p}<0,001)$ e mulheres $(-63,2 \%)(\mathrm{p}<0,001)$, conforme constatado na mesma tabela. 
Tabela 3 - Caracterização por sexo do método de suicídio utilizado no estado de Pernambuco, Brasil, segundo décadas (1996-2005 e 2006-2015)

\begin{tabular}{|c|c|c|c|c|c|c|c|c|c|c|c|c|}
\hline \multirow{3}{*}{ Causa Básica (CID) } & \multicolumn{6}{|c|}{ Masculino } & \multicolumn{6}{|c|}{ Feminino } \\
\hline & \multicolumn{2}{|c|}{$1996-2005$} & \multicolumn{2}{|c|}{$2006-2015$} & \multirow[b]{2}{*}{$\Delta \%$} & \multirow[b]{2}{*}{ p-valor } & \multicolumn{2}{|c|}{ 1996-2005 } & \multicolumn{2}{|c|}{$2006-2015$} & \multirow[b]{2}{*}{$\Delta \%$} & \multirow[b]{2}{*}{ p-valor } \\
\hline & $\mathbf{N}$ & $\%$ & $\mathbf{n}$ & $\%$ & & & $\mathbf{N}$ & $\%$ & $\mathbf{N}$ & $\%$ & & \\
\hline Medicamentos X60 a 64 & 63 & 3,0 & 56 & 2,2 & $-26,7$ & 0,129 & 65 & 9,1 & 58 & 6,7 & $-26,4$ & 0,091 \\
\hline Pesticidas X68 & 259 & 12,2 & 386 & 15,3 & 25,4 & 0,004 & 141 & 19,8 & 290 & 33,5 & 69,2 & $<0,001$ \\
\hline $\begin{array}{l}\text { Produtos químicos e substâncias nocivas não } \\
\text { especificadas X69 }\end{array}$ & 106 & 5,0 & 81 & 3,2 & -36 & 0,003 & 54 & 7,6 & 52 & 6,0 & $-21,1$ & 0,254 \\
\hline $\begin{array}{l}\text { Enforcamento, estrangulamento e sufocação } \\
\text { X70 }\end{array}$ & 946 & 44,5 & 1.450 & 57,4 & 29 & $<0,001$ & 197 & 27,7 & 262 & 30,3 & 9,4 & 0,278 \\
\hline Afogamento e submersão X71 & 28 & 1,3 & 25 & 1,0 & $-23,1$ & 0,359 & 10 & 1,4 & 15 & 1,7 & 21,4 & 0,75 \\
\hline Armas de fogo X72 a X74 & 469 & 22,0 & 229 & 9,1 & $-58,6$ & $<0,001$ & 83 & 11,7 & 37 & 4,3 & $-63,2$ & $<0,001$ \\
\hline $\begin{array}{l}\text { Fumaça, fogo, chamas, vapor de água, gases ou } \\
\text { objetos quentes X76 e X77 }\end{array}$ & 54 & 2,5 & 36 & 1,4 & -44 & 0,008 & 80 & 11,2 & 44 & 5,1 & $-54,5$ & $<0,001$ \\
\hline $\begin{array}{l}\text { Objeto cortante, penetrante ou contundente } \\
\text { X78 e X79 }\end{array}$ & 82 & 3,9 & 116 & 4,6 & 17,9 & 0,254 & 35 & 4,9 & 39 & 4,5 & $-8,2$ & 0,794 \\
\hline Precipitação de um lugar elevado X80 & 40 & 1,9 & 51 & 2,0 & 5,3 & 0,827 & 24 & 3,4 & 26 & 3,0 & $-11,8$ & 0,789 \\
\hline $\begin{array}{l}\text { Outros meios especificados e não especificados } \\
\text { X83 e X84 }\end{array}$ & 56 & 2,6 & 67 & 2,7 & 3,8 & 1 & 15 & 2,1 & 32 & 3,7 & 76,2 & 0,089 \\
\hline *Demais X65, X66, X67, X75, X81, X82 & 24 & 1,1 & 28 & 1,1 & 0 & 1 & 8 & 1,1 & 10 & 1,2 & 9,1 & 1 \\
\hline Total & 2.127 & 100,0 & 2.525 & 100 & - & - & 712 & 100 & 865 & 100 & - & - \\
\hline
\end{tabular}

Fonte: Sistema de Informação sobre Mortalidade ${ }^{32}$

* X65 Álcool; X66 Autointoxicação intencional por solventes orgânicos, hidrocarbonetos halogenados e seus vapores; X67 Autointoxicação intencional por outros gases e vapores; X75 Dispositivos explosivos; X81 Precipitação ou permanência diante de um objeto em movimento; X82 Impacto de um veículo a motor. 


\section{DISCUSSÃO}

Os resultados demonstram redução do coeficiente de mortalidade por suicídio no período analisado. Tendência semelhante foi verificada nos coeficientes mundiais de suicídio, com redução de $26 \%$ entre 2000 e $2012^{(16)}$. Um estudo da tendência de mortalidade autoinfligida, realizado nos Estados Unidos e em 25 países da Europa (1990-2010), identificou uma queda de $20 \%$ nos coeficientes de mortalidade de 15 países europeus e 3,5\% nos Estados Unidos ${ }^{(17)}$. No Brasil, de 1990 a 2015, constatou-se diminuição nos coeficientes de mortalidade por suicídio de alguns estados, como Rio de Janeiro (58,8\%), Pernambuco $(27,2 \%)$, Paraná $(27,1 \%)$, Santa Catarina $(24,3 \%)$ e Rio Grande do Sul $(21,6 \%)^{(18)}$.

O coeficiente médio de mortalidade por suicídio verificado no estado de Pernambuco (4,7 por 100.000 hab.) foi inferior ao observado no Brasil entre 2000 e 2012 (5,7 por 100.000 hab. ${ }^{(19)}$. Tais coeficientes se distribuem de forma diferente entre as regiões do país, sendo influenciados por aspectos culturais e facilidade no acesso ao meio utilizado ${ }^{(5,10,19-20)}$. Em 2010, a Região Sul registrou coeficiente de 7,7 por 100.000 hab., enquanto a Região Nordeste teve índice de 4,6 suicídios por 100.000 hab., sugerindo que a morte autoprovocada é mais comum em regiões com maior qualidade de vida ${ }^{(21)}$. Tal relação, entretanto, não está totalmente esclarecida, uma vez que distintas pesquisas têm relacionado um maior risco de morte por suicídio a condições de desfavorecimento socioeconômico ${ }^{(22-25)}$.

Neste estudo, foi identificada uma redução significativa na tendência da morte autoprovocada entre o sexo masculino e pessoas com idade entre 20 e 39 anos. No Brasil, verificou-se aumento (2000-2012) nos coeficientes de suicídio em homens (24,6\%) desse grupo etário $(22,7 \%)^{(19)}$. Explicações como a expansão das oportunidades econômicas e educacionais e maior emancipação ideológica podem estar associadas à diminuição dos coeficientes de suicídio em adultos jovens ${ }^{(26)}$.

No Brasil, em 2006, foi instituída a portaria de Diretrizes Nacionais para Prevenção do Suicídio ${ }^{(27)}$. Nesse mesmo ano, o Ministério da Saúde lançou o Manual de Prevenção do Suicídio destinado às equipes de saúde mental, cujo objetivo era detectar precocemente condições associadas ao fenômeno suicida ${ }^{(28)}$. Tais iniciativas podem ter refletido na diminuição da mortalidade por suicídio em Pernambuco, uma vez que fomentam estratégias de prevenção, estimulam a educação permanente dos profissionais de saúde e sensibilizam a sociedade sobre esse problema de saúde pública. 
O modelo de atenção à saúde mental, implementado através da Rede de Atenção Psicossocial, proporcionou a ampliação dos serviços e o acesso ao tratamento de psicopatologias $^{(29)}$. De acordo com o Ministério da Saúde, a presença de Centros de Atenção Psicossocial (CAPS) nos municípios pode reduzir em $14 \%$ o risco de suicídio ${ }^{(30)}$. O número de implantação de CAPS tem crescido significativamente em todo o país ${ }^{(31)}$. Em Pernambuco, houve aumento do número de CAPS durante o período deste estudo, passando de 11 para 129 unidades $^{(32)}$.

Outros fatores estão relacionados com a redução da mortalidade daqueles que tentam o suicídio, como o suporte adequado e o tempo da assistência prestado entre a tentativa e a admissão hospitalar, além da disponibilidade de oferta do atendimento de urgência e emergência ${ }^{(33)}$. Entre os equipamentos existentes na rede de atenção em saúde mental para atendimento do comportamento suicida, encontram-se as emergências hospitalares e os recursos proporcionados pelo atendimento pré-hospitalar ${ }^{(34)}$. O estado de Pernambuco possui uma rede hospitalar robusta constituída por 27 serviços de urgência e emergência do Sistema Único de Saúde ${ }^{(35)}$. Também houve expansão na quantidade dos serviços pré-hospitalares. As unidades de pronto atendimento implementadas em 2010 atualmente totalizam 15 e a cobertura populacional do Serviço de Atendimento Móvel de Urgência (SAMU) passou de $20,8 \%$ para $61,8 \%$ entre 2004 e 2015 , respectivamente ${ }^{(35)}$.

Observou-se maior frequência de suicídio entre os homens. Este resultado apresenta-se consonante com a literatura nacional e internacional ${ }^{(6,9,17,19,36-38)}$. Entre as possíveis explicações está o uso de meios mais letais e a maior prevalência do consumo do álcool ${ }^{(39-41)}$.

O enforcamento foi o principal meio usado no suicídio entre os homens. Nas mulheres, houve mudança no perfil do método utilizado, sendo o enforcamento predominante na primeira década e os pesticidas, na segunda. Em todo o mundo, os métodos suicidas variam e dependem de fatores como disponibilidade ao acesso e aspectos culturais e sociodemográficos $^{(42)}$. De acordo com a OMS, a ingestão de pesticidas é o meio mais utilizado no mundo ${ }^{(43)}$. De modo geral, os homens utilizam métodos suicidas mais letais do que as mulheres ${ }^{(37-38)}$. A preferência destas por meios menos violentos pode estar atrelada ao menor nível de conhecimento e habilidades técnicas para manusear métodos mais brutais como armas de fogo e, além disso, existe a preocupação de que o corpo ou a face não sejam gravemente feridos ${ }^{(36-37)}$. A predileção do sexo masculino por métodos de alto risco pode estar relacionado ao desejo de não falhar, de modo a demonstrar sucesso, poder e emoções $\operatorname{restritas}^{(36)}$. 
No Brasil, o enforcamento é o meio comumente utilizado na morte autoinfligida $^{(10,19)}$. Um estudo internacional realizado em um país asiático observou resultados semelhantes ${ }^{(44)}$. Esse é um método cujo acesso é difícil de controlar, sendo crucial a identificação precoce do indivíduo em risco para a adoção de medidas que restrinjam seu uso ${ }^{(19)}$. Entre as possíveis causas do crescimento do uso de pesticidas, está a fragilidade do controle da produção e fiscalização dessas substâncias ${ }^{(19)}$.

Verificou-se redução significante no emprego das armas de fogo em ambos os sexos. Uma pesquisa realizada no Paraná (1996-2012) revelou declínio da mortalidade autoinfligida com armas de fogo entre mulheres $(-60,3 \%)$ e homens $(-48,5 \%)^{(45)}$. Uma hipótese pertinente diz respeito ao rigor quanto ao registro, posse e comercialização desse artefato.

Embora o suicídio seja um evento passível de prevenção, evitar a morte autoinfligida exige esforços de diversos setores públicos e da sociedade. Para reduzir o impacto dessas mortes é necessária a compreensão dos seus aspectos e identificação de subgrupos vulneráveis. Este estudo permitiu identificar o comportamento da mortalidade por suicídio, além de apontar as características epidemiológicas que podem contribuir para a formulação de estratégias de prevenção.

\section{Limitação do estudo}

A utilização de dados secundários representa uma limitação para o estudo, especialmente por apresentar falhas no preenchimento do instrumento de coleta (declaração de óbito). Entretanto, a qualidade desses dados tem melhorado de forma substancial nos últimos anos. Outra limitação são as subnotificações dos casos de suicídio ocasionadas, muitas vezes, pelo do forte estigma e falhas na determinação precisa da causa da morte.

\section{Contribuições para a área da saúde e política pública}

Verificou-se, por meio da caracterização epidemiológica, a presença de grupos específicos mais acometidos pelo suicídio. Esse fato revela que são oportunas as orientações de intervenções em saúde que buscam atingir essas populações. Espera-se que os resultados alcançados nesse artigo possam ser úteis para futuras estratégias de prevenção, controle e acompanhamento acerca do suicídio. 


\section{CONCLUSÃO}

A tendência temporal identificou o decréscimo do suicídio na população geral, nos homens e grupo etário entre 20 e 39 anos. Os indivíduos do sexo masculino, a faixa etária de 20 a 29 anos, os solteiros e pardos foram os mais acometidos. Mudanças dos meios suicidas revelada pelo sexo feminino apontam apara a adoção de medidas que controlem e fiscalizem de forma sistemática e eficiente a comercialização e utilização de pesticidas. Tais constatações poderão colaborar para melhores direcionamentos de intervenções em saúde, otimizando recursos e esforços, sobretudo, na prevenção do suicídio. 


\section{REFERÊNCIAS}

1. Turecki G, Brent DA. Suicide and suicidal behaviour. Lancet. 2016;387(10024):1227-39. DOI: 10.1016/S0140-6736(15)00234-2.

2. Klonsky ED, May AM, Saffer BY. Suicide, suicide attempts, and suicidal ideation. Annu Rev Clin Psychol. 2016;12:307-30. DOI: 10.1146/annurev-clinpsy-021815-093204.

3. Samaan Z, Bawor M, Dennis BB, El-Sheikh W, DeJesus J, Rangarajan S, et al. Exploring the determinants of suicidal behavior: conventional and emergent risk (DISCOVER): a feasibility study. Pilot Feasibility Stud. 2015;1(1):1-17. DOI: 10.1186/s40814-015-0012-4.

4. Arenas A, Gomez-Restrepo C, Rondon M. Suicidal Behaviour and Associated Factors in Colombia. Results from the 2015 National Mental Health Survey. Rev Colomb Psiquiatr. 2016;45:68-75. DOI: 10.1016/j.rcp.2016.03.006.

5. Orellana JD, Balieiro AA, Fonseca FR, Basta PC, Souza MLP. Spatial-temporal trends and risk of suicide in Central Brazil: an ecological study contrasting indigenous and non-indigenous populations. Rev Bras Psiquiat. 2016;38(3):222-30. DOI: 10.1590/1516-4446-2015-1720.

6. Khazaei S, Armanmehr V, Nematollahi S, Rezaeian S, Khazaei S. Suicide rate in relation to the Human Development Index and other health related factors: A global ecological study from 91 countries. J Epidemiol Glob Health. 2017;7(2):131-34. DOI: 10.1016/j.jegh.2016.12.002.

7. Skinner R, McFaull S, Rhodes AE, Bowes M, Rockett IRH. Suicide in Canada: is poisoning misclassification an issue? Can J Psychiatry. 2016;61(7):405-12. DOI: 10.1177/0706743716639918. 8. World Health Organization. Global health observatory data [Internet]. 2017 [cited 2018 Jan 8]. Available from: https://bit.ly/2ofaXAK

9. Värnik P. Suicide in the world. Int J of Environ Res and Public Health. 2012;9(3):760-71. DOI: 10.3390/ijerph9030760.

10. Brasil. Ministério da Saúde. Boletim Epidemiológico. Suicídio: saber, agir e prevenir [Internet]. 2017 [cited 2018 Jan 9]. Available from: https://bit.ly/2S8Fn8L Portuguese.

11. Melo GB, Alves SV, Lima ML. Mortality from external causes in Pernambuco, 2001-2003 and 2011-2013. Rev Bras Enferm. 2015;68(5):855-61. DOI: 10.1590/0034-7167.2015680513i.

12. Jukkala T, Stickley A, Mäkinen IH, Baburin A, Sparén P. Age, period and cohort effects on suicide mortality in Russia, 1956-2005. BMC Public Health. 2017;2017(17):235. DOI:

10.1186/s12889-017-4158-2.

13._Zhong BL, Chiu HF, Conwell Y. Elderly suicide trends in the context of transforming China, 1987-2014. Sci Rep. 2016;6:37724. DOI: 10.1038/srep37724.

14. Dogan N, Toprak D. Trends in suicide mortality rates for Turkey from 1987 to 2011: a joinpoint regression analysis. Arch Iran Med. 2015;18(6):355-61. DOI: 015186/AIM.006. 
15. Instituto Brasileiro de Geografia e Estatística. IBGE Estados [Internet]. 2016 [cited 2017 Oct 28] Available from: https://bit.ly/2WHL2RH Portuguese.

16. World Health Organization. Preventing suicide: a global imperative [Internet]. 2014 [cited 2017 Oct 16] Available from: https://bit.ly/2WGxp5p

17. Fond G, Llorca PM, Boucekine M, Zendjidjian. Disparities in suicide mortality trends between United States of America and 25 European countries: retrospective analysis of WHO mortality database. Sci Rep. 2016;6:2026. DOI: 10.1038/srep20256.

18. Malta DC, Minayo MC, Soares FA, Silva MM, Montenegro MM, Ladeira RM, et al. Mortality and years of life lost by interpersonal violence and self-harm: in Brazil and Brazilian states: analysis of the estimates of the Global Burden of Disease Study, 1990 and 2015. Rev Bras

Epidemiol. 2017;20(1):142-56. DOI: 10.1590/1980-5497201700050012.

19. Machado DB, Santos DN. Suicide in Brazil, from 2000 to 2012. J Bras Psiquiatr. 2015;64(1):45-

54. DOI: $10.1590 / 0047-2085000000056$.

20. Marín-León L, Oliveira HB, Botega NJ. Suicide in Brazil, 2004-2010: the importance of small counties. Rev Panam Salud Publica [Internet]. 2012 [cited 2017 Oct 9]; 32(5):351-59. Available from: https://bit.ly/2WFkOPM

21. Bando DH, Lester D. An ecological study on suicide and homicide in Brazil. Ciênc Saúde Coletiva. 2014;19(4):179-89. DOI: 10.1590/1413-81232014194.00472013.

22. Redmore J, Kipping R, Trickey A, May MT, Gunnell D. Analysis of trends in adolescent suicides and accidental deaths in England and Wales, 1972-2011. Br J Psychiatry. 2016;209(4):327-33. DOI: 10.1192/bjp.bp.114.162347.

23. Kiadaliri AA, Saadat S, Shahnavazi H, Haghparast-Bidgoli H. Overall, gender and social inequalities in suicide mortality in Iran, 2006-2010: a time trend province-level study. BMJ Open. 2014;4(8):1-8. DOI: 10.1136/bmjopen-2014-005227.

24. Santana P, Costa C, Cardoso G, Loureiro A, Ferrão J. Suicídio em Portugal: determinantes espaciais em um contexto de crise econômica. Health Place. 2015;35(2015):85-94. DOI: 10.1016/j.healthplace.2015.07.001.

25. Bantjes J, Iemmi V, Costa E, Channer K, Leone T, McDaid, et al. Poverty and suicide research in low- and middle-income countries: systematic mapping of literature published in English and a proposed research agenda. Glob Ment Health. 2016;3(2016):e32. DOI: 10.1017/gmh.2016.27. 26. Yin H, Xu L, Shao Y, Li L, Wan C. Relationship between suicide rate and economic growth and stock market in the People's Republic of China: 2004-2013. Neuropsychiatri Dis Treat. 2016;12:3119-28. DOI: 10.2147/NDT.S116148.

27. Brasil. Ministério da Saúde. Portaria no 1.876, de 14 de agosto de 2006. Institui Diretrizes Nacionais para Prevenção do Suicídio a serem implantadas em todas as unidades federadas, 
respeitadas as competências das três esferas de gestão. Diário Oficial da União [Internet]. 2006 Ago 15 [cited 2018 Set 20]. Available from: https://bit.ly/2HD1pYk Portuguese.

28. Brasil. Ministério da Saúde. Secretaria de Atenção à Saúde. Prevenção do suicídio: manual dirigido a profissionais das equipes de saúde mental [Internet]. 2006 [cited 2018 Set 22]. Available from: https://bit.ly/2O6efS3 Portuguese.

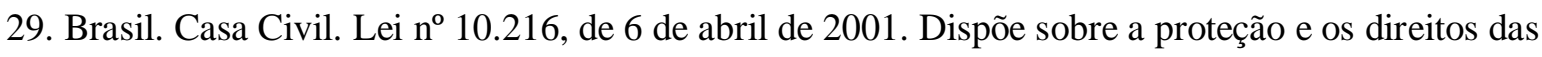
pessoas portadoras de transtornos mentais e redireciona o modelo assistencial em saúde mental. Diário Oficial da União [Internet]. 2001 Apr 9 [cited 2017 Aug 10]; Seção 1:2. Available from: https://bit.ly/1fkBJM1 Portuguese.

30. Brasil. Ministério da Saúde. Secretaria de Vigilância em Saúde. Suicídio: saber, agir e prevenir [Internet]. 2017 [cited 2018 Feb 16]; 48(30). Available from: https://bit.ly/2qDJ7PN Portuguese.

31. Macedo JP, Abreu MM, Fontenele MG, Dimenstein M. A regionalização da saúde mental e os novos desafios da Reforma Psiquiátrica brasileira. Saude soc. 2017;26(1):155-170. DOI:

10.1590/s0104-12902017165827.

32. Brasil. Ministério da Saúde. Secretaria Estadual de Saúde de Pernambuco. TabNet. Sistema de Informação sobre Mortalidade [Internet]. 2018 [cited 2018 Set 22]. Available from: https://bit.ly/2G8F07V Portuguese.

33. Magalhaes APN, Alves VM, Comassetto I, Lima PC, Mancussi e Faro AC, Nardi AE. Atendimento a tentativas de suicídio por serviço de atenção pré-hospitalar. J Bras Psiquiatr. 2014;63(1):16-22. DOI: 10.1590/0047-2085000000003.

34. Silva SL, Kohlrausch ER. Pre-hospital care to the individual with suicidal behavior: an integrative review. SMAD, Rev Eletrônica Saúde Mental Álcool Drog. 2016;12(2):108-115. DOI:

10.11606/issn.1806-6976.v12i2p108-115.

35. Pernambuco. Secretaria Estadual de Saúde. Plano estadual de saúde: 2016-2019 [Internet]. 2016 [cited 2018 Set 20]. Available from: https://bit.ly/2BfTL4A Portuguese.

36. Callanan V, Davis M. Gender differences in suicide methods. Soc Psychiatry Psychiatr Epidemiol. 2012; 47(6):857-869. DOI: 10.1007/s00127-011-0393-5.

37. Mergl R, Koburger N, Heinrichs K, Székely A, Tóth MD, Coyne J, et al. What are reasons for the large gender differences in the lethality of suicidal acts? An epidemiological analysis in four European countries. PLOS ONE. 2015;10(7):e0129062. DOI: 10.1371/journal.pone.0129062.

38. Veisania Y, Mohamadianb F, Delpishehc A, Khazaeid S. Socio-demographic factors associated with choosing violent methods of suicide, 2011-2016, Ilam province. Asian Journal of Psychiatry. 2018; 35(2018):72-75. DOI: 10.1016/j.ajp.2018.05.018.

39. Sena-Ferreira N, Pessoa VF, Boechat-Barros R, Figueiredo AE, Minayo MC. Fatores de risco relacionados com suicídios em Palmas (TO), Brasil, 2006-2009, investigados por meio de autópsia psicossocial. Ciênc Saúde Coletiva. 2014;19(1):115-26. DOI: 10.1590/1413-81232014191.2229. 
40. Braga LL, Dell'aglio DD. Suicide in adolescence: risk factors, depression and gender. Contextos Clínic. 2013;6(1):2-14. DOI: 10.4013/ctc.2013.61.01.

41. O'Neill S, Ennis E, Corry C, Bunting B. Factors associated with suicide in four age groups: a population based study. Arch Suicide Res. 2017;22(1):128-38. DOI:

10.1080/13811118.2017.1283265.

42. Fisher LB, Overholser JC, Dieter L. Methods of committing suicide among 2.347 people in Ohio. Death studies. 2015;39(1):39-43. DOI: 10.1080/07481187.2013.851130.

43. World Health Organization. Suicide fact sheet [Internet]. 2018 [cited 2018 Apr 2]. Available from: https://bit.ly/1pV1R8w.

44. Lim M, Lee SU, Park J-I. Difference in suicide methods used between suicide attempters and suicide completers. Int J Ment Health Syst. 2014;2014(8):54. DOI: 10.1186/1752-4458-8-54.

45. Rosa NM, Oliveira RR, Arruda GO, Mathias TA. Mortalidade por suicídio no Estado do Paraná segundo meios utilizados: uma análise epidemiológica. J Bras Psiquiatr. 2017;66(2):73-82. DOI: 10.1590/0047-2085000000153. 


\subsection{MORTALIDADE POR SUICÍDIO EM UM ESTADO DO NORDESTE BRASILEIRO:}

\section{UMA ANÁLISE DOS PADRÕES ESPACIAIS ${ }^{4}$}

\section{RESUMO}

O estudo descreve o padrão espacial do suicídio no estado de Pernambuco. Trata-se de estudo ecológico, com dados de óbitos por suicídio ocorridos entre 1996 e 2015, registrados no Sistema de Informações sobre Mortalidade. Para a investigação do padrão espacial foram construídos, segundo décadas, mapas temáticos dos coeficientes médios brutos e método bayesiano empírico local. A autocorrelação espacial, assim como, os conglomerados (clusters) críticos foram verificados pelo emprego do Índice de Moran Global e Indicador Local de Associação Espacial. No total, registraram-se 6.229 suicídios. O coeficiente médio de mortalidade foi de 4,5 e 4,6 por 100.000 habitantes na primeira década e segunda, respectivamente. Constatou-se forte autocorrelação espacial do suicídio, I = 0,6876 (19962005) e $I=0,68704$ (2006-2015). Três agrupamentos considerados críticos, foram identificados em cada período. Esses clusters somaram 25 municípios no primeiro decênio e 21 no segundo. As técnicas de análise espacial verificaram localidades de maior risco para o suicídio distribuídas em áreas afastadas da região metropolitana. Tal achado poderá auxiliar no direcionamento de intervenções em saúde, sobretudo, em ações de prevenção.

Palavras-chave: Causas externas; Suicídio; Mortalidade; Análise espacial; Conglomerados espaço-temporais

\footnotetext{
${ }^{4}$ Manuscrito submetido à revista Ciência e Saúde Coletiva (ANEXO I), segundo formatação de submissão (ANEXO J).
} 


\begin{abstract}
The study describes the spatial pattern of suicide in the state of Pernambuco. This is an ecological study, with data of deaths by suicide occurred between 1996 and 2015, registered in the Mortality Information System. For the investigation of the spatial pattern, thematic maps of the average gross coefficients and the local empirical Bayesian method were constructed for decades. The spatial autocorrelation, as well as the critical clusters were verified by the use of the Moran Global Index and Local Indicator of Spatial Association. In total, 6,229 suicides were registered. The average mortality rate was 4.5 and 4.6 per 100,000 inhabitants in the first and second decades, respectively. It was verified a strong spatial autocorrelation of suicide, $\mathrm{I}=0.6876$ (1996-2005) and $\mathrm{I}=0.68704$ (2006-2015).Three groups considered critical were identified in each study period. These clusters totaled 25 municipalities in the first decade and 21 in the second. The techniques of spatial analysis verified locations of higher risk for suicide distributed in remote areas from the metropolitan region. This finding may help in directing health interventions, especially in prevention actions.
\end{abstract}

Keywords: External causes; Suicide; Mortality; Spatial analysis; Space-time clusters

\title{
INTRODUÇÃO
}

O suicídio é um grave problema de saúde pública mundial ${ }^{1}$. Representou em 2015 a segunda causa de morte entre pessoas de 15 a 29 anos, com coeficiente global de mortalidade de 10,7 por 100.000 habitantes (hab.) $)^{2}$. Estimativas apontam que esse evento contribuirá com mais de $2 \%$ para a carga total de mortalidade até o ano $2020^{3}$.

No Brasil, o coeficiente de mortalidade por suicídio, em 2015, foi de 6,6 por 100.000 hab. ${ }^{4}$. Entretanto, esse indicador pode ocultar importantes variações regionais ${ }^{5}$ (BOTEGA, 2014). Entre 2000 e 2012, verificou-se maior coeficiente de suicídio na região Sul e menor na 
região Nordeste ${ }^{6}$. Houve crescimento de $15,9 \%$ do total de óbitos por suicídio ocorridos no Estado de Pernambuco entre dois triênios analisados (2001-2003 e 2011-2013) ${ }^{7}$.

Entre os fatores relacionados a morte autoprovocada, estão as psicopatologias, características de personalidade como impulsividade e agressividade, doenças crônicas, isolamento social, abuso de substâncias e mudanças socioeconômicas negativas ${ }^{8,9}$. Além dos fatores individuais, características do espaço geográfico como áreas pequenas e rurais podem influenciar a mortalidade por suicídio ${ }^{10,11}$.

Considerada um conjunto de técnicas que buscam descrever características existentes em dados espaciais, as ferramentas de análise espacial desempenham um papel relevante para epidemiologia ${ }^{12,13}$. Essas técnicas, são utilizadas para mapear doenças e agravos a saúde, medir associações socioeconômicas, ambientais ou demográficas e localizar agrupamentos de risco $^{14,15}$. Quando empregadas ao estudo do suicídio possibilitam a observação de diferentes modelos de distribuição espacial, assim como, a detecção de aglomerados espaciais de $\operatorname{risco}^{16,17}$.

Pesquisas nacionais utilizando técnicas de análise espacial aplicadas ao suicídio ainda são recentes. Nesse sentido, identificar a autocorrelação espacial da morte autoinfligida apontando áreas de maior gravidade poderá auxiliar no planejamento de intervenções de saúde capazes de reduzir sua ocorrência. Esse estudo teve como objetivo descrever o padrão espacial do suicídio no Estado de Pernambuco no período de 1996 a 2015.

\section{MÉTODOS}

O Estado de Pernambuco está situado na região Nordeste do Brasil, possui área territorial de $98.076,021 \mathrm{~km}^{2}$, população estimada para o ano de 2015 de 9.345 .173 hab., latitude $8^{\circ} 20^{\prime} 24^{\prime \prime}$ e longitude $37^{\circ} 48^{\prime} 36^{\prime \prime 18}$. Administrativamente, é dividido em 185 municípios distribuídos em 12 Regionais de Saúde (RS). 
Estudo ecológico, que analisou os suicídios em residentes do Estado Pernambuco, maiores de 10 anos, registrados entre 1996 e 2015. Os dados foram provenientes do SIM, correspondente ao grande grupo de causas de lesões autoprovocadas (X60-X84) da $10^{\mathrm{a}}$ Revisão da Classificação Internacional de Doenças (CID-10). As unidades de análise foram constituídas pelos 184 municípios. Excluiu-se o Arquipélago Fernando de Noronha (dois óbitos) pela ausência de municípios vizinhos, pré-requisito necessário para aplicação das técnicas de análise espacial. Da mesma forma, os casos cujo informações sobre municípios de residência não constavam no Sistema de Informações sobre Mortalidade (SIM) foram excluídos (20 óbitos).

As análises foram realizadas segundo décadas (1996-2005 e 2006-2015). Os coeficientes médios de mortalidade por suicídio dos decênios ((média de suicídio/média da população residente de Pernambuco maior que dez anos) x 100.000) foram utilizados como base para construção do mapa da distribuição espacial. As estimativas populacionais e base cartográfica foram obtidas do Instituto Brasileiro de Geografia e Estatística (IBGE).

Para a suavização dos coeficientes brutos de mortalidade foi usado o método estimador bayesiano empírico local. Este método, propõe corrigir a instabilidade estatística dos coeficientes, reduzindo as flutuações aleatórias, sobretudo, em pequenas áreas geográficas, refletindo de modo mais preciso o risco real ${ }^{19}$.

A presença de autocorrelação espacial global foi analisada através do Índice de Moran Global. Esse índice é utilizado para sumarizar a distribuição espacial dos dados, caracterizando-se por fornecer um valor único como medida geral da associação espacial ${ }^{20}$. Os resultados do Índice de Moran Global variam de -1 a 1, quanto mais próximo de um, mais forte é a autocorrelação espacial ${ }^{20}$. Valores iguais a zero indicam ausência de autocorrelação espacial; valores positivos implicam autocorrelação espacial positiva; e valores negativos apresentam autocorrelação espacial negativa ${ }^{20}$. 
Para verificar a autocorrelação espacial local utilizou-se o Índice de Moran Local. Essa estatística permite comparar o valor de cada município estudado com seus vizinhos, bem como, constatar regiões de aglomerados espaciais ${ }^{19}$. A identificação de áreas críticas ou de transição deu-se por meio do diagrama de espalhamento de Moran, representado visualmente pelo Box Map. Os quadrantes gerados a partir do diagrama possuem a seguinte interpretação: Q1 (áreas com valores positivos e médias dos vizinhos positivas); Q2 (áreas com valores negativos e médias dos vizinhos negativas); Q3 (áreas com valores positivos e médias dos vizinhos negativas); e Q4 (áreas com valores negativos e médias dos vizinhos positivas).

Os municípios com autocorreção espacial positiva com significância estatística foram verificados através da construção do Moran Map. Este, considera áreas com relação espacial positiva apontadas no Box Map (Q1) com aquelas com significância espacial acima de 95\%. Admitiu-se áreas críticas os municípios pertencentes a classe Q1 do Moran Map. O quadrante Q2 indica áreas com baixo nível de suicídio e os quadrantes Q3 e Q4 áreas de transição. As análises espaciais foram realizadas no software TerraView versão 4.2.2, com o auxílio de planilhas eletrônicas Excel@ $\odot$.

A pesquisa foi aprovada pelo Comitê de Ética em Pesquisa do Centro de Ciências de Saúde da Universidade Federal de Pernambuco (Parecer no 2.045.304).

\section{RESULTADOS}

Entre 1996 e 2015 foram registrados no SIM 6.229 suicídios no Estado de Pernambuco. Foram excluídos 22 casos, a população final de estudo totalizou 6.207 óbitos. O coeficiente médio da mortalidade por suicídio de 1996 a 2005 foi 4,5 por 100.000 hab., o município com maior coeficiente foi Orocó (18,8 por 100.000 hab.), pertencente à VIII RS. Entre 2006 e 2015 o coeficiente médio foi de 4,6 por 100.000 hab. Calumbi, XI RS, obteve o coeficiente mais elevado, (19,1 por 100.000 hab.). 
Em ambos períodos, a região leste (área litorânea e vizinhança) destacou-se por concentrar municípios com coeficientes mais baixos, os maiores valores foram localizados ao oeste, sudeste e área central de Pernambuco (Figura 1a e 1b).

O estimador bayesiano empírico local suavizou a distribuição dos coeficientes de mortalidade, que anteriormente poderiam estar elevadas pela flutuação aleatória dos coeficientes brutos. Esse fato ocasiona-se em municípios com pequena população, ou ainda, pela quantidade reduzida de óbitos, comum em áreas que sofrem com subnotificações. Deste modo, os maiores coeficientes foram identificados no município de Santa Filomena com 7,3 por 100.000 hab. (Figura 2a) e Santa Cruz da Baixa Verde, 7,7 por 100.000 hab. (Figura 2b), integrantes da IX e XI RS, respectivamente.

Os valores do Índice de Moran Global revelaram forte autocorrelação espacial, I = 0,6876 (1996-2005) e I =0,68704 (2006-2015) $(\mathrm{p}=0,001)$. As Figuras 3a e 3b, mostram a distribuição dos quadrantes gerados pelo diagrama de espalhamento de Moran da mortalidade por suicídio. De modo geral, nos dois intervalos de tempo, os municípios Q1 concentraram-se ao oeste e noroeste, nota-se ainda, um corredor de municípios estendendo-se do nordeste ao sudeste (Figuras 3a e 3b). Em relação as áreas de transição (Q3 e Q4) houve aumento no número de municípios entre os decênios, essas áreas distribuíram-se de forma dispersa principalmente ao leste, nordeste e sudeste (Figuras 3b).

O Moran Map foi utilizado para identificar aglomerados com significância estatística de 5\%. Três conglomerados (clusters) críticos (Q1) e de baixo nível de suicídio (Q2) foram localizados em ambas décadas. Os clusters Q1 totalizaram 25 municípios, treze posicionados ao oeste, formados predominantemente, pelas VIII e IX RS (Bodocó, Ipubi, Ouricuri, Parnamirim, Dormentes, Orocó, Santa Maria da Boa Vista, Araripina, Santa Cruz, Santa Filomena, Trindade, Petrolândia e Lagoa Grande); oito ao nordeste/sudeste, compostos por municípios das IV e V RS (Altinho, Cachoeirinha, Jurema, São Caetano, Lajedo, Caruaru, 
Ibirajuba e Canhotinho) e quatro ao nordeste, onde prevaleceram municípios da II RS (Bom Jardim, Machados, Orobó e São Vicente Ferrer) (Figura 4a).

No segundo decênio 21 municípios compuseram os clusters Q1 (Figura 4b). Onze localizados ao oeste, com constituição igual à observada no primeiro período (excetuando-se Orocó e Petrolândia); seis ao noroeste, essencialmente constituído pela XI RS (Calumbi, Santa Cruz da Baixa Verde, São José do Belmonte, Triunfo, Mirandiba e Serra Talhada) e quatro ao nordeste (Altinho, São Caetano, Caruaru e Bezerros) (Figura 4b).

\section{DISCUSSÃO}

Os municípios localizados nas regiões do interior do Estado destacaram-se por apresentar os maiores coeficientes de mortalidade e áreas críticas para a morte autoprovocada.

Nas décadas estudadas verificou-se um discreto aumento nos coeficientes médios de mortalidade por suicídio. No Brasil, entre 2000 e 2013, este coeficiente passou de 4,9 para 6,2 por 100.000 hab., sendo a região Nordeste aquela cujo crescimento foi mais expressivo $(72,4 \%)^{6}$. Entre os fatores que contribuem para tais variações estão aspectos socioculturais, econômicos e demográficos ${ }^{21,22,23}$. Alguns grupos específicos de risco para o suicídio têm sido apontados na literatura, é o caso dos indígenas, agricultores, solteiros, migrantes, católicos, assim como, aqueles com maior renda ${ }^{21,24,25}$.

A concentração de municípios críticos com significância estatística deu-se em regiões do interior do Estado. Ressalta-se que, 45,5\% desses possuem mais da metade da população residente em áreas rurais. Estudos utilizando técnicas de análise espacial têm demonstrado que a frequência do suicídio é mais elevada em áreas de campo, pequeno porte territorial e pouco habitadas ${ }^{11,26,27}$. Grupos de risco compostos especialmente por homens residentes em ambientes rurais, foram achados em pesquisas com mortes autoprovocadas por pesticidas e inalação de monóxido de carbono ${ }^{28,29}$. 
A privação econômica presente em áreas rurais pode ter impacto negativo sobre o suicídio $^{30}$. Deste modo, eventos adversos relacionados ao clima (redução da precipitação) e solo que impactam na produção agrícola, tem potencial de atingir o bem estar emocional, favorecendo eventos suicidas ${ }^{31}$. Questões como isolamento social, disponibilidade e acessibilidade limitadas aos serviços de saúde mental e pouca formação educacional propiciam altos coeficientes de suicídio em localidades afastadas dos grandes centros $\operatorname{urbanos}^{8,32}$.

Outros estudos, no entanto, vêm apontando o maior risco de morte por suicídio em regiões urbanas ${ }^{33,34}$. Clusters de áreas críticas para a morte autoprovocada em homens e mulheres foram encontrados próximos aos principais centros metropolitanos ${ }^{35}$. Agrupamentos de suicídio foram verificados em bairros localizados em áreas urbanas ${ }^{33}$.

Reduzido nível de profissionalização, baixa renda familiar, desemprego, fragmentação social com altas proporções de separações conjugais e viuvez podem falar a favor do suicídio em ambientes urbanos ${ }^{34}$. Outro fator que possui influência sobre o suicídio associado às regiões urbanas é a elevada frequência de migrantes ${ }^{24}$. Fatores estressantes relacionados às grandes cidades e elevada densidade populacional relacionam-se com surgimento de doenças mentais capaz a aumentar as chances de um evento suicida ${ }^{36}$.

De modo geral, as localidades críticas para o suicídio encontradas nesse estudo têm por base econômica a agropecuária, além de incluir a presença de um importante polo gesseiro. A atividade profissional pode estar influenciada na morte autoprovocada, uma vez que, possui a capacidade de facilitar o acesso ao meio suicida e condicionar eventos estressores cotidianos ${ }^{37}$. Pesquisa realizada no Espírito Santo, Brasil, estabeleceu correlação espacial entre o suicídio e municípios com economia baseada na agricultura e pecuária, aqui, os pesticidas destacaram-se por ocupar o segundo meio mais usado nas mortes autoinfligidas $^{25}$. Maiores coeficientes de suicídio foram verificados em uma região de 
mineração de carvão em Santa Catarina, com maior prevalência entre trabalhadores que desempenhavam tarefas duras; precárias condições de trabalho e instabilidade econômica poderiam explicar tal fato ${ }^{38}$.

Considerado um Estado de população pobre, Pernambuco possui renda média domiciliar per capita que varia da mais elevada na cidade do Recife ( $\mathrm{R} \$ 1.109,01)$ para a mais baixa em Manari $(\mathrm{R} \$ 154,19)^{39}$. Aspectos econômicas são frequentemente relacionadas ao evento suicida ${ }^{24,30}$. Uma análise da associação entre a mortalidade por suicídio e condições socioeconômicas, revelou a relação positiva entre tal violência e precárias condições sociais e econômicas $^{8}$. Foi encontrada autocorrelação espacial entre a morte autoprovocada e áreas economicamente desfavorecidas, em indivíduos do sexo masculino ${ }^{40}$. Entretanto, esta relação não está totalmente elucidada, uma vez, que pesquisas nacionais e internacionais têm apontado relação entre o suicídio e regiões mais ricas ${ }^{1,41}$.

Os dados secundários obtidos através do SIM apresentam algumas limitações como incompletudes e subnotificações, entretanto, percebe-se no Brasil uma crescente melhora nos registros e qualidade desses dados ${ }^{7,42}$. Embora se trate de uma difícil tarefa, sabe-se que grande parte dos suicídios são evitáveis, para isto, estratégias de cunho intersetorial são

necessárias $^{43}$. Este estudo proporcionou a localização de áreas críticas significantes para o suicídio, o que pode ser útil para conduzir ações preventivas, especialmente em áreas prioritárias do Estado de Pernambuco.

\section{CONCLUSÃO}

A existência de autocorrelação espacial da mortalidade por suicídio evidencia que este fenômeno não ocorre de forma aleatória no espaço. A região litorânea e sua vizinhança concentrou os menores coeficientes e o maior risco se manteve, na maior parte do período de estudo, nas regiões do interior do Estado. O estudo traz uma contribuição para a compreensão 
da distribuição espacial da mortalidade por suicídios em Pernambuco; Estado brasileiro que possui forte heterogeneidade socioeconômica, demográfica e cultural, questões que devem ser consideradas no planejamento das medidas de prevenção, sobretudo, nas áreas prioritárias identificadas. 


\section{FIGURAS}

Figura 1. Coeficiente médio de mortalidade por suicídio. Pernambuco, 1996 a 2015

A. 1996-2005

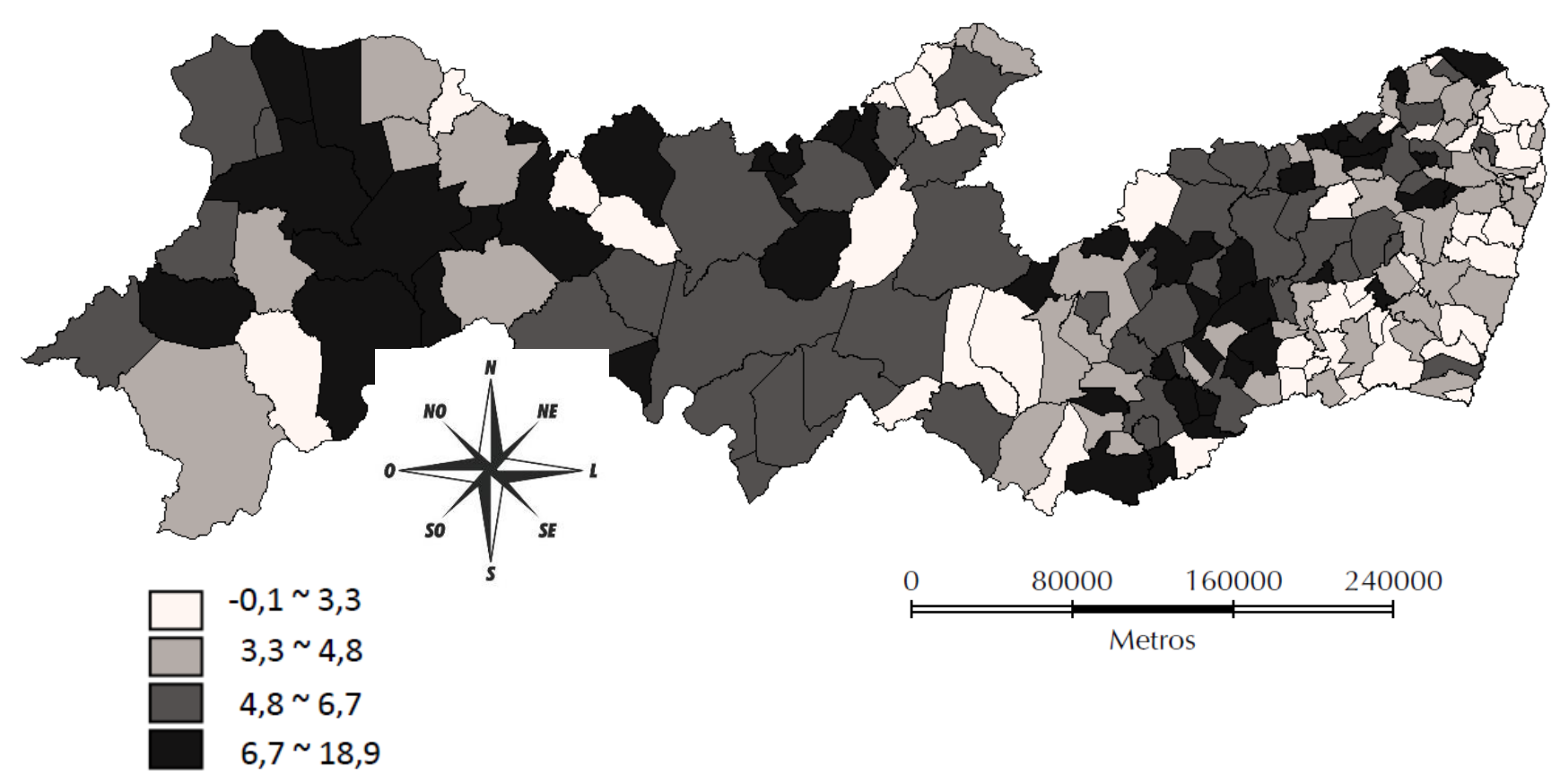

B. 2006-2015

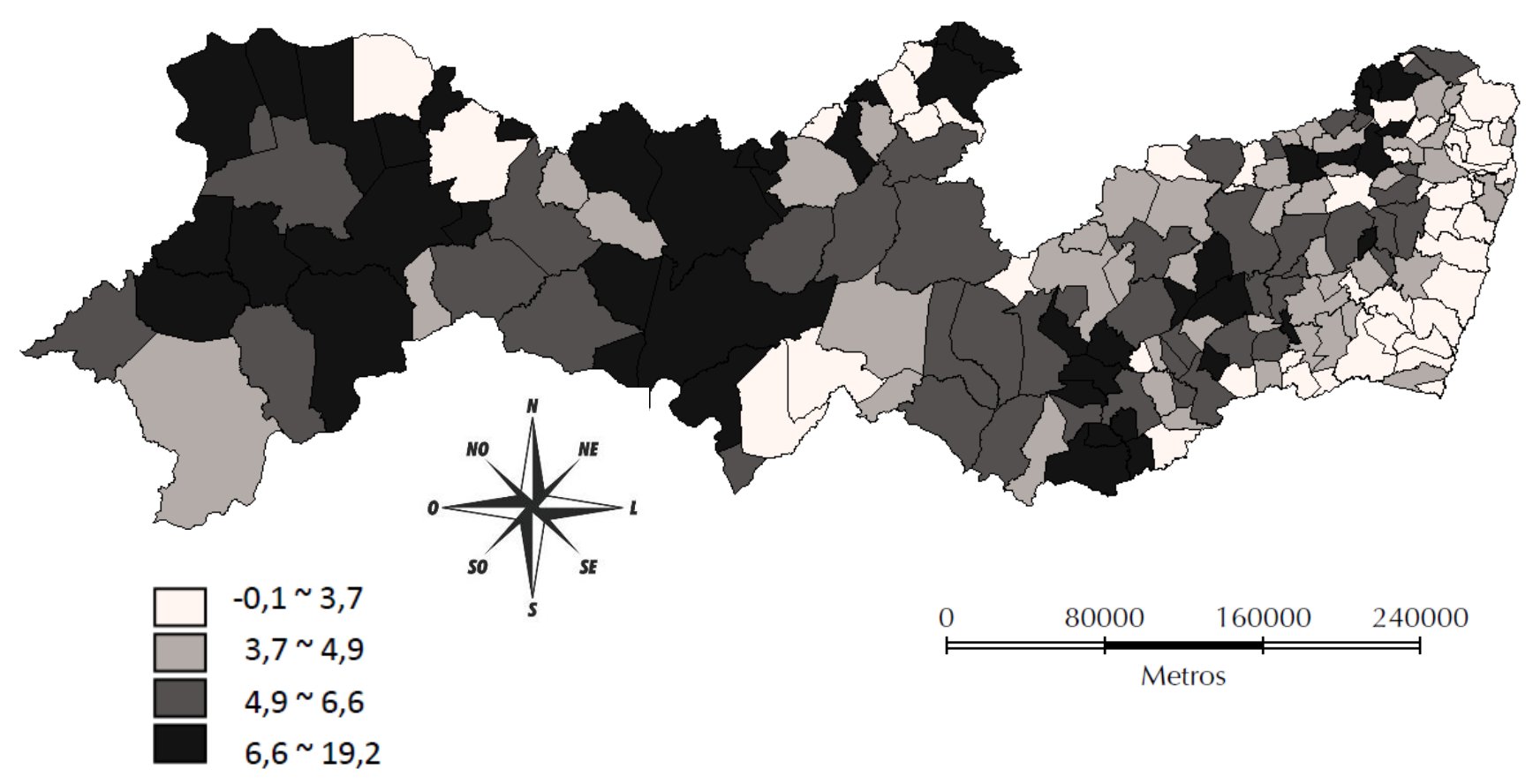


Figura 2. Coeficiente médio de mortalidade por suicídio estimado pelo método bayesiano empírico local. Pernambuco, 1996 a 2015

\section{A. 1996-2005}

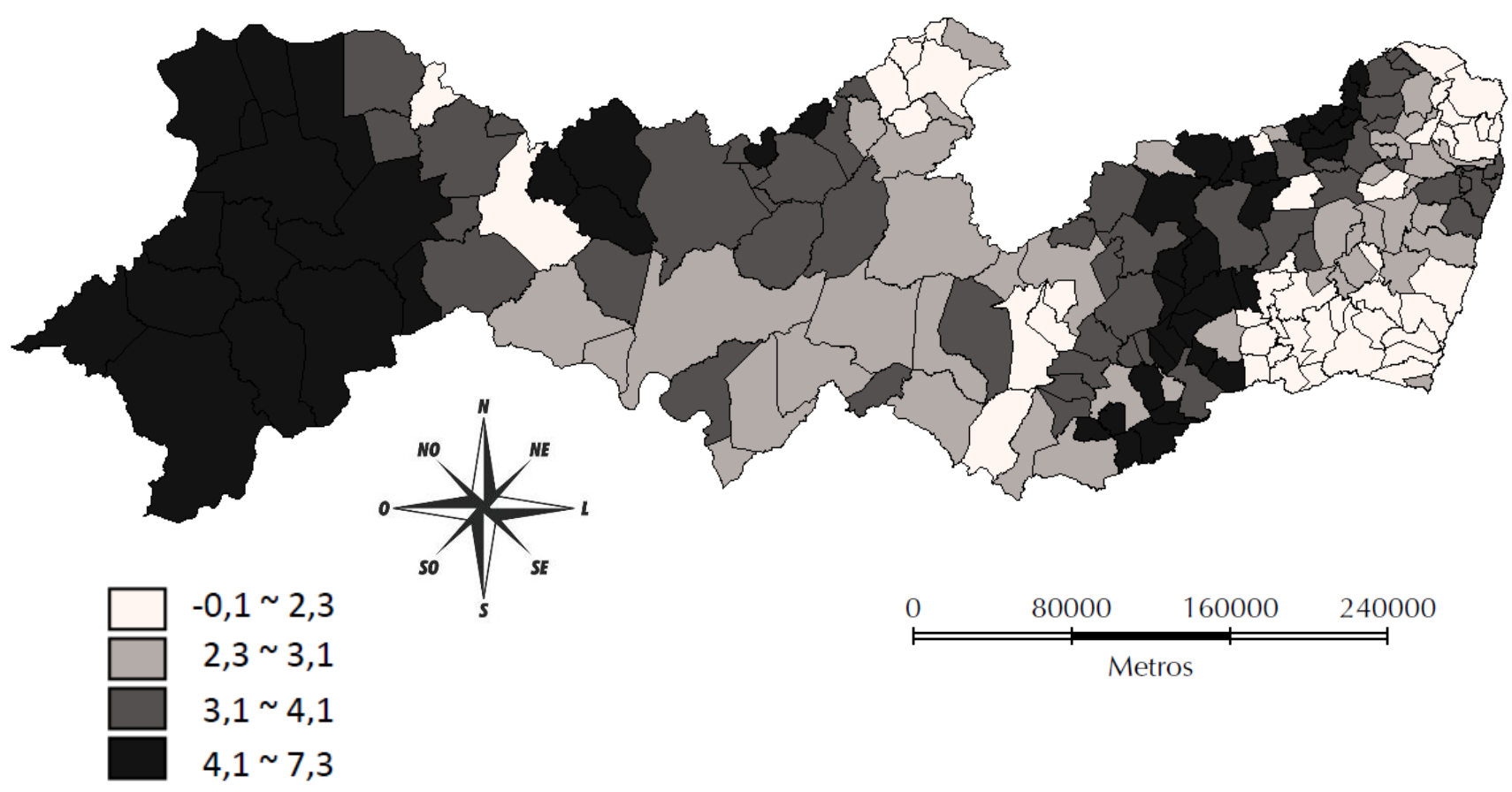

B. 2006-2015

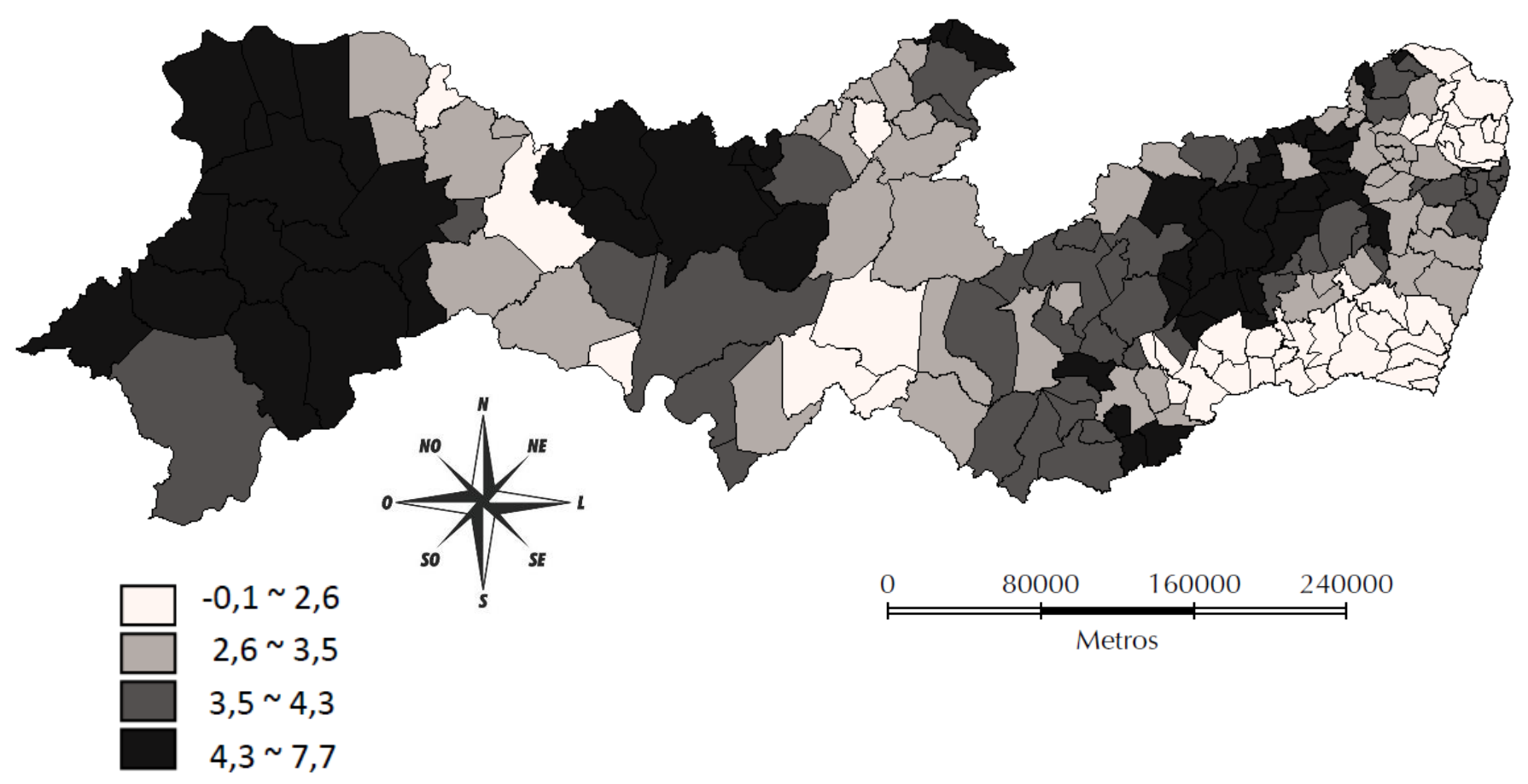


Figura 3. Distribuição espacial do diagrama de espalhamento de Moran do coeficiente médio de mortalidade por suicídio (Box Map). Pernambuco, 1996 a 2015

\section{A. 1996-2005}

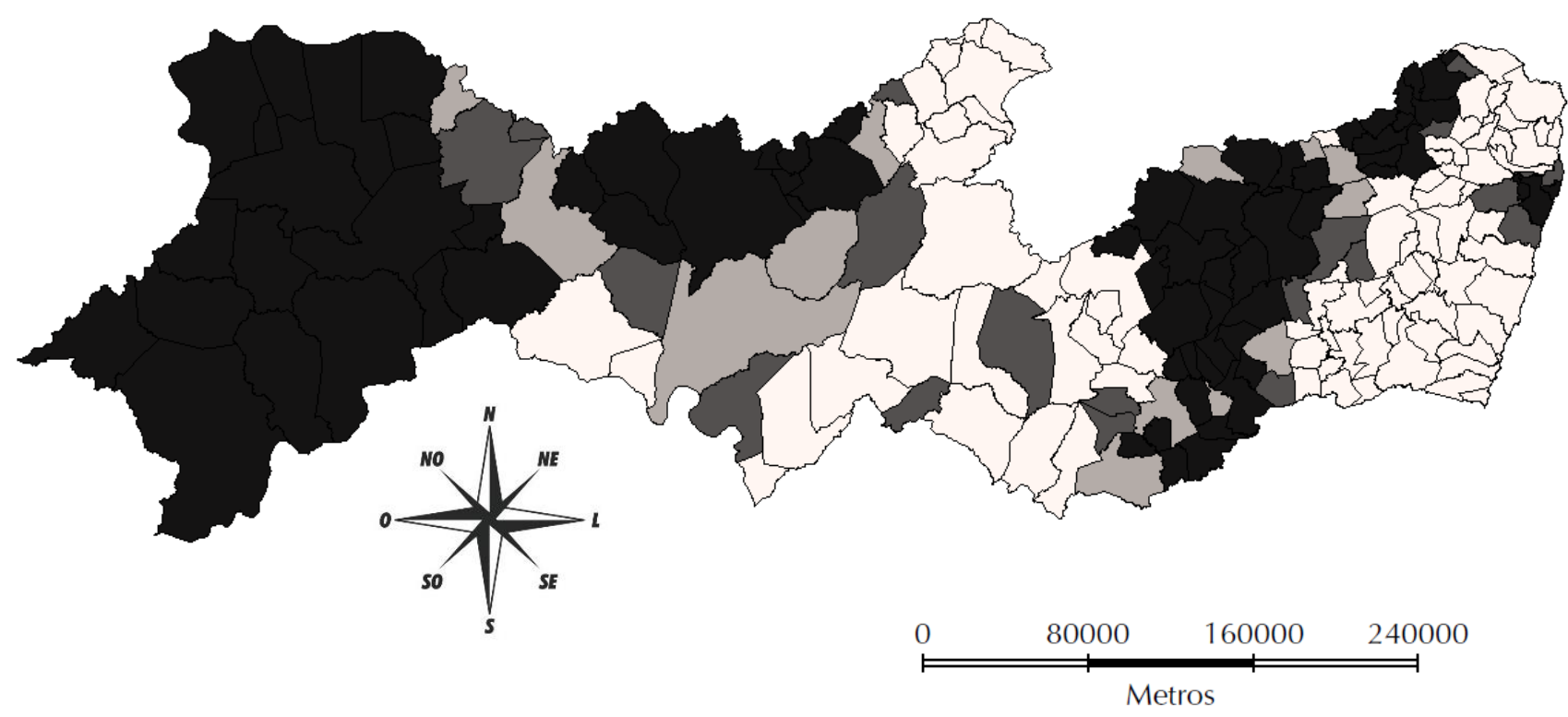

B. 2006-2015

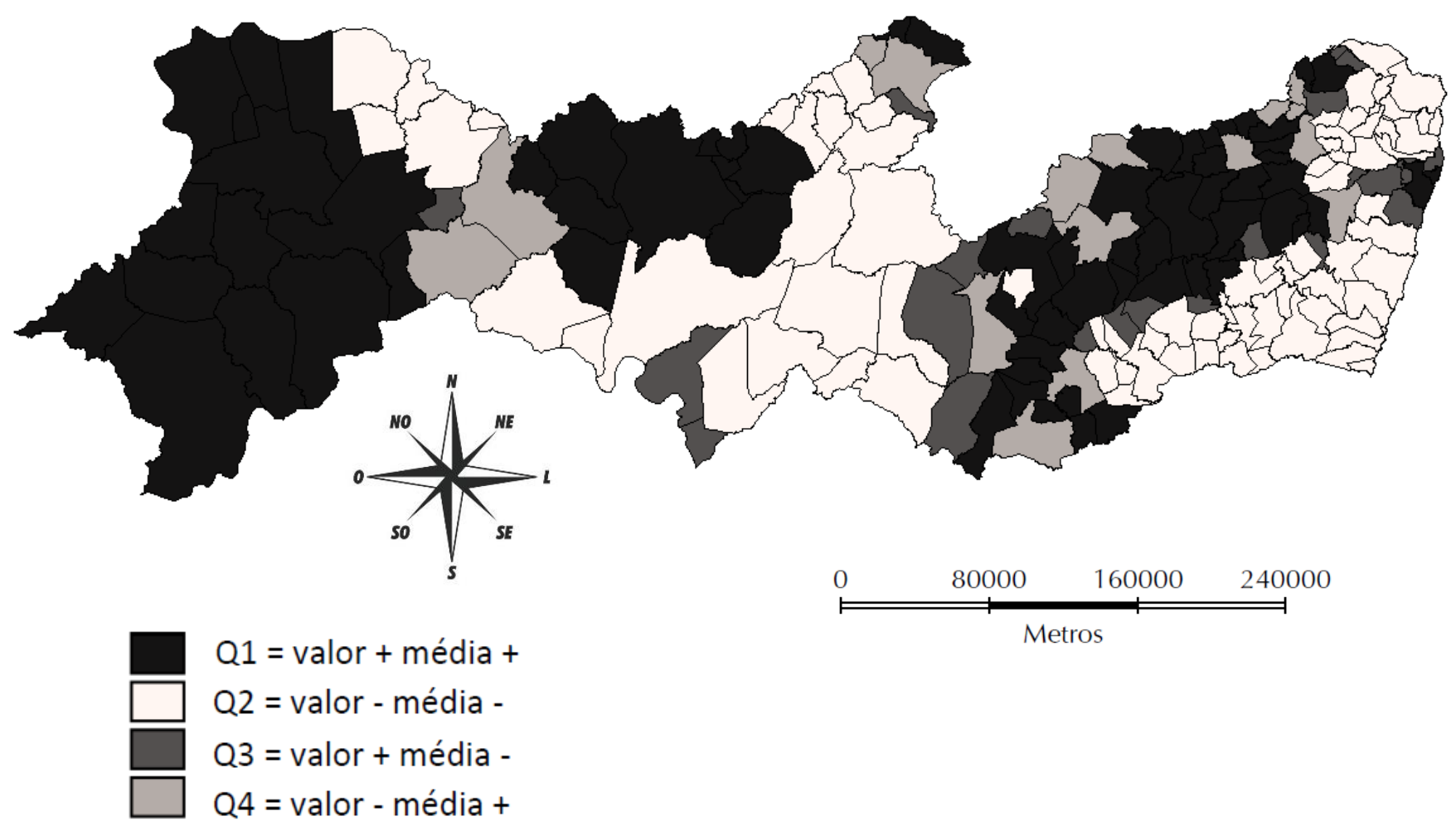


Figura 4. Identificação das áreas críticas para a mortalidade por suicídio, segundo o espalhamento de Moran com significância estatística de 5\% (Moran Map). Pernambuco, 19962015

\section{A. 1996-2005}

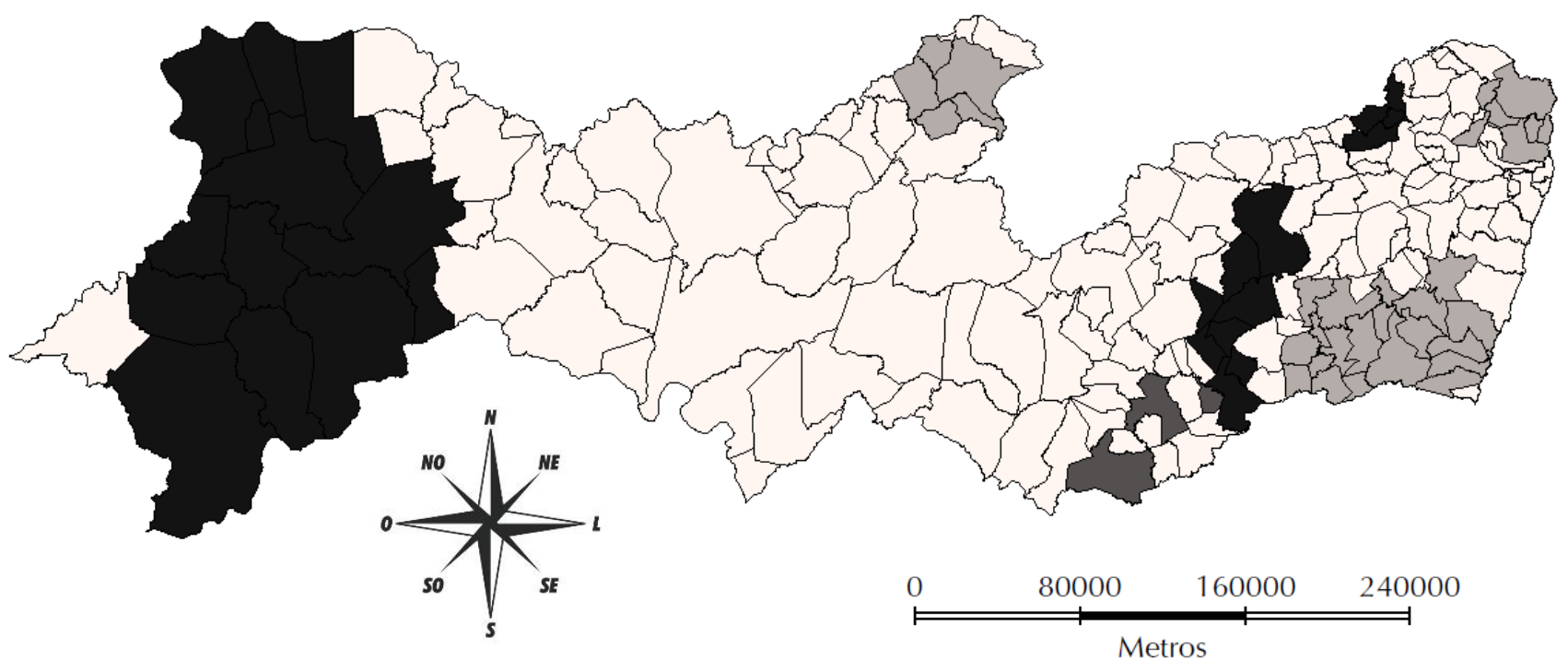

B. 2006-2015

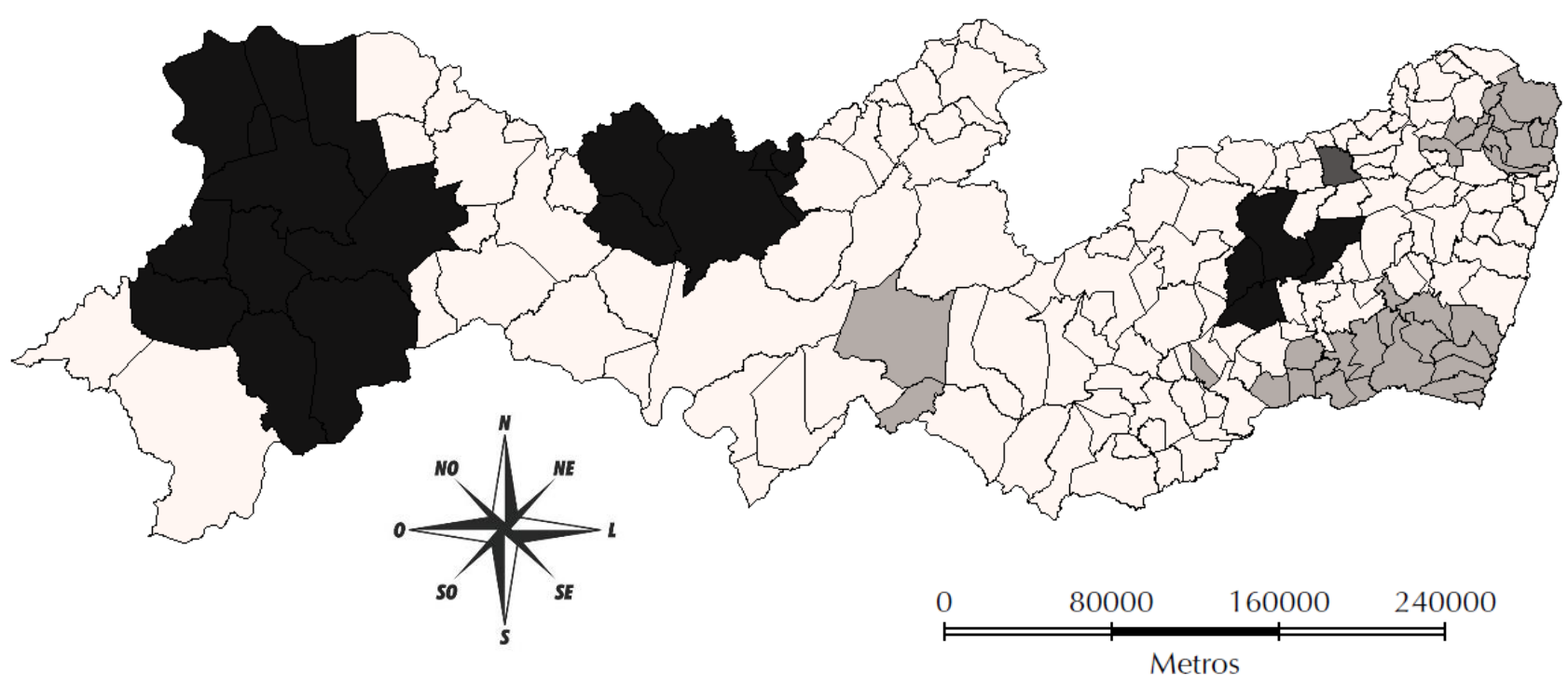

$\square$ Sem significância

Q1 = valor + média +

Q2 = valor - média -

Q4 = valor - média + 


\section{REFERÊNCIAS}

1. Khazaei S, Armanmehr V, Nematollahi S, Rezaeian S, Khazaei S. Suicide rate in relation to the human development index and other health related factors: A global ecological study from 91 countries. J Epidemiol Glob Health 2017; 7(2):131-134.

https://www.ncbi.nlm.nih.gov/pubmed/28188120

2. World Health Organization. Suicide Data.[acessado 2018 Fev 22]. Disponível em: http://www.who.int/mental_health/prevention/suicide/suicideprevent/en/

3. World Health Organization. Public health action for the prevention of suicide. Geneva: World Health Organization; 2012. [acessado 2018 Fev 22] Disponível em: http://www.who.int/mental_health/publications/prevention_suicide_2012/en/

4. Malta DC, Minayo MCS, Soares Filho AM, Silva MMA, Montenegro MMS, Ladeira RM, Morais Neto OL, Melo AP, Mooney M, Naghavi M. Mortalidade e anos de vida perdidos por violências interpessoais e autoprovocadas no Brasil e Estados: análise das estimativas do Estudo Carga Global de Doença, 1990 e 2015. Rev Bras Epidemiol 2017; 20 (Supl. 1):142156.http://www.scielo.br/scielo.php?pid=S1415790X2017000500142\&script=sci_abstract\&tl $\underline{\mathrm{ng}}=\mathrm{pt}$

5. Botega NJ. Comportamento suicida: epidemiologia. Psicol USP 2014; 25(3): 231-236. http://www.scielo.br/scielo.php?script=sci arttext\&pid=S0103-65642014000300231

6. Machado DB, Santos DN. Suicídio no Brasil, de 2000 a 2012. J Bras Psiquiatr 2015; 64(1):45-54. http://www.scielo.br/scielo.php?script=sci_arttext\&pid=S0047$\underline{20852015000100045}$

7. Melo GBT, Alves SV, Lima MLC. Mortalidade por causas externas em Pernambuco, 20012003 e 2011-2013. Rev Bras Enferm 2015; 68(5):855-861.

http://www.scielo.br/scielo.php?script=sci_arttext\&pid=S0034-71672015000500855 
8. Yoon TH, Noh M, Han J, Jung-Choi K, Khang YH. Deprivation and suicide mortality across 424 neighborhoods in Seoul, South Korea: a Bayesian spatial analysis. Int J Public Health 2015; 60(8):969-976. https://www.ncbi.nlm.nih.gov/pubmed/26022192

9. Arenas A, Gómez-Restrepo C, Rondón M. Suicidal Behaviour and associated factors in Colombia. Rev Colomb Psiquiatr 2016; 45(Supl. 1):68-75.

https://www.ncbi.nlm.nih.gov/pubmed/27993258

10. Samaan Z, Bawor M, Dennis BB, El-Sheikh W, DeJesus J, Rangarajan S, Vair J, Sholer

H, Hutchinson N, Iordan E, Mackie P, Islam S, Deghan M, Brasch J, Thabane L. Exploring the determinants of suicidal behavior: conventional and emergent risk (DISCOVER): a feasibility study. Pilot Feasibility Stud 2015; 1(1):1-17.

https://www.ncbi.nlm.nih.gov/pmc/articles/PMC5154080/

11. Marín-León L, Oliveira HB, Botega NJ. Suicide in Brazil, 2004-2010: the importance of small counties. Rev Panam Salud Public 2012; 32(5):351-359.

https://www.ncbi.nlm.nih.gov/pubmed/23338692

12. Becker JN,Nero MA. Avaliação da aplicação dos estimadores bayesianos empíricos na determinação das áreas de risco de transmissão da malária.Precedido doV Simpósio Brasileiro de Ciências Geodésicas e Tecnologias da Geoinformação; 2014 Nov 12-14; Recife, Brasil. Recife: UFPE; 2014.

https://www.ufpe.br/cgtg/SIMGEOIV/CD/artigos/SIG/118 5.pdf

13. Bailey TC. Spatial statistical methods in health. Cad Saude Publica 2001; 17(5):10831098. http://www.scielosp.org/scielo.php?pid=S0102311X2001000500011\&script=sci_arttext 14. Ngwa MC. Cholera in Cameroon, 2000-2012: spatial and temporal analysis at the operational (health district) and sub climate levels. PLoS Negl Trop Dis 2016; 10(11): e0005105 https://www.ncbi.nlm.nih.gov/pubmed/27855171 
15. Kirby RS, Delmelle E, Eberth JM. Advances in spatial epidemiology and geographic information systems. Ann Epidemiol2017;27(1):1-9.

http://www.annalsofepidemiology.org/article/S1047-2797(16)30495-1/abstract

16. JooY. Spatiotemporal study of elderly suicide in Korea by age cohort. Public Health 2017; 142(1):144-151. https://www.ncbi.nlm.nih.gov/pubmed/27613224

17. Knipe DW, Padmanathan P, Muthuwatta L, Metcalfe C, Gunnell D. Reginal. Variation in suicide rates in Sri Lanka between 1995 and 2011. A spatial and temporal analysis. BMC Public Health 2017; 17(1):193. https://www.ncbi.nlm.nih.gov/pmc/articles/PMC5310090/ 18. Instituto Brasileiro de Geografia e Estatística. IBGE Estados. [acessado 2017 Dec 15]. Disponível em: http://www.ibge.gov.br/estadosat/perfil.php?sigla=pe

19. Assunção RM, Barreto SM, Guerra HL, Sacuraí E. Mapas de taxas epidemiológicas: uma abordagem Bayesiana. Cad Saude Publica 1998; 14(4):713-723.

http://www.scielo.br/scielo.php?pid=S0102-

$\underline{311 X 1998000400013 \& \text { script }=\text { sci_abstract\&tlng=pt }}$

20. Anselin L. Local Indicators of Spatial Association - LISA. Geographic Analysis 1995; 27(1):93-115.

http://onlinelibrary.wiley.com/doi/10.1111/j.1538-4632.1995.tb00338.x/epdf

21. Orellana JD, Balieiro AA, Fonseca FR, Basta PC, Souza ML. Spatial-temporal trends and risk of suicide in Central Brazil: an ecological study contrasting indigenous and nonindigenous populations. Rev Bras Psiquiatr 2016; 38(3):222-230. http://www.scielo.br/scielo.php?script=sci_arttext\&pid=S1516-44462016000300222 22. Robinson WL, Case MH, Whipple CR, Gooden AS, Lopez-Tamayo R, Sharon F, Jason LA. Culturally grounded stress reduction and suicide prevention for African American adolescent. Pract Innov 2016; 1(2):117-128. https://www.ncbi.nlm.nih.gov/pmc/articles/PMC4978429/ 
23. Kiadaliri AA, Saadat S, Shahnavazi H, Haghparast-Bidgoli H. Overall, gender and social inequalities in suicide mortality in Iran, 2006-2010: a time trend province-level study. BMJ Open 2014; 4(8):e005227. http://bmjopen.bmj.com/content/4/8/e005227

24. Bando DH, Moreira RS, Pereira JC, Barrozo LV. Spatial clusters of suicide in the municipality of São Paulo 1996-2005: an ecological study. BMC Psychiatry 2012; 12(1):124. https://www.ncbi.nlm.nih.gov/pmc/articles/PMC3496688/

25. Macente LB, Zandonade E. Spatial distribution of suicide incidence rates in municipalities in the state of Espírito Santo (Brazil), 2003-2007: spatial analysis to identify risk areas. Rev Bras Psiquiatr 2012; 34(3):261-269.

http://www.scielo.br/scielo.php?script=sci_arttext\&pid=S1516-44462012000300005

26. Oka M, Kubota T, Tsubaki H, Yamauchi K. Analysis of the impact of geographical characteristics on the suicide rate and visualization of the result by GIS (Geographic Information System). Psychiatry Clin Neurosci 2015; 69(6):375-382.

https://www.ncbi.nlm.nih.gov/pubmed/25384900

27. Qi X, Hu W, Mengersen K, Tong S. Socio-environmental drivers and suicide in Australia: Bayesian spatial analysis. BMC Public Health 2014; 14(1):681.

https://bmcpublichealth.biomedcentral.com/articles/10.1186/1471-2458-14-681

28. Chang SS,Lu TH, Sterne JA, Eddleston M, Lin JJ, Gunnell D. The impact of pesticide suicide on the geographic distribution of suicide in Taiwan: a spatial analysis. BMC Public Health 2012; 12(1):260. https://bmcpublichealth.biomedcentral.com/articles/10.1186/1471$\underline{2458-12-260}$

29. Yoshioka E,SaijoY, Kawachi I. Spatial and temporal evolution of the epidemic of charcoal-burning suicide in Japan. Soc Psychiatry Psychiatr Epidemiol 2016; 51(6):857-868. https://www.ncbi.nlm.nih.gov/pubmed/26814811 
30. Cheung YT, Spittal MJ, Williamson MK, Tung SJ, Pirkis J. Application of scan statistics to detect suicide clusters in Australia. PLoS ONE 2013; 8(1): e54168.

http://journals.plos.org/plosone/article?id=10.1371/journal.pone.0054168

31. Alston M. Rural male suicide in Australia. Soc Sci Med 2012; 74(4): 515-522.

https://www.ncbi.nlm.nih.gov/pubmed/20541304

32. Fontanella CA, Hiance-Steelesmith DL, Phillips GS, Bridge JA, Lester N, Sweeney HA. Widening rural-urban disparities in youth suicides, United States, 1996-2010. JAMA Pediatr 2015; 169(5):466-473. https://www.ncbi.nlm.nih.gov/pmc/articles/PMC4551430/

33. Ngui AN, Apparicio P, Moltchanova E, Vasiliadis HM. Spatial analysis of suicide mortality in Québec: spatial clustering and area factor correlates. Psychiatry Res 2014; 220(12):20-30. http://www.psy-journal.com/article/S0165-1781(14)00612-X/abstract

34. Hsu CY. Geography of suicide in Hong Kong: spatial patterning, and socioeconomic correlates and inequalities. Soc SciMed 2015; 130(1):190-203.

http://www.sciencedirect.com/science/article/pii/S0277953615001021

35. Tomita M, Kubota T, Ishioka F. Spatial clustering properties in the temporal variation of suicide rates/numbers among Japanese citizens: a comprehensive comparison and discussion. PLoS One 2015; 10(7):e0127358. https://www.ncbi.nlm.nih.gov/pmc/articles/PMC4498741/ 36. Miles R, Coutts C, Mohamadi A. Neighborhood urban form, social environment, and depression. J Urban Health 2012;89(1):1-18.

https://www.ncbi.nlm.nih.gov/pubmed/22038283

37. Yamauchi T, Sasaki T, Yoshikawa T, Matsumoto S, Takahashi M, Suka M. Differences in work-related adverse events by sex and industry in cases involving compensation for mental disorders and suicide in Japan from 2010 to 2014. J Occup Environ Med. No prelo2018. https://www.ncbi.nlm.nih.gov/pubmed/29370013 
38. Portella CH, Moretti GP, Panatto AP, Rosa MI, Quevedo J, Simões PW. Epidemiological profile of suicide in the Santa Catarina coal mining region from 1980 to 2007. Trends Psychiatry Psychother 2013; 35(2):128-133.

https://www.ncbi.nlm.nih.gov/pubmed/25923303

39. Instituto Brasileiro de Geografia e Estatística. Censo Demográfico 2010. [acessado 2018 Jan 28]. Disponível em:

https://ww2.ibge.gov.br/home/estatistica/populacao/censo2010/default.shtm

40. Hong J, Knapp M. Geographical inequalities in suicide rates and area deprivation in South Korea. J Ment Health Policy Econ 2013; 16(3):109-119.

https://www.ncbi.nlm.nih.gov/pubmed/24327481

41. Bando DH, Lester, H. An ecological study on suicide and homicide in Brazil. Cien Saude Colet 2014;19(4): 1179-1189. https://www.ncbi.nlm.nih.gov/pubmed/24820601

42. Messias KLM, Bispo Júnior JP, Pegado MF, Oliveira LC, Peixoto TG, Sales MA.

Qualidade da informação dos óbitos por causas externas em Fortaleza, Ceará, Brasil. Cien Saude Colet 2016; 21(4):1255-1266. http://www.scielo.br/scielo.php?pid=S1413$\underline{81232016000401255 \& \text { script }=\text { sci_abstract } \& \text { tlng }=p t}$

43. Aktas SG, Kantar YM. A study of suicide mortality in Turkey (2002-2011). Journal of EU Research in Business 2016; 2016(2016):1-17.

http://ibimapublishing.com/articles/JEURB/2016/864344/864344.pdf 


\subsection{PREVISÃO DO SUICÍDIO NO ESTADO DE PERNAMBUCO: ANÁLISE COM MODELO DE SÉRIE TEMPORAL}

\section{RESUMO}

Objetivo: analisar os padrões temporais da mortalidade por suicídio. Métodos: estudo ecológico com dados do Sistema de Informações sobre Mortalidade, dos óbitos por suicídio ocorridos no estado de Pernambuco, entre 1996 e 2015. Foi utilizado o Modelo Auto Regressivo Integrado de Médias Móveis (ARIMA) com componente sazonal (p,d,q). O modelo preditivo foi desenvolvido para prever as taxas de suicídio entre janeiro de $2016 \mathrm{e}$ dezembro de 2020. Resultados: no período analisado foram registrados 6.229 suicídios com taxa de mortalidade de 4,7 por 100.000 habitantes (hab.). A decomposição da série temporal detectou certa sazonalidade. Foi observada menor taxa em junho de $2002(0,161$ por 100.000 hab.) e maior em agosto de 2007 (0,541 por 100.000 hab.). O modelo SARIMA com maior ajuste foi $(1,2,1)$ e $(1,1,1)$, para tendência e sazonalidade, respectivamente. A taxa de mortalidade por suicídio prevista em dezembro de 2020 foi de 0,3842 por 100.000 hab. Conclusão: a aplicação do SARIMA mostrou-se adequada para a análise do comportamento temporal do suicídio e sua previsão. Considerando que poucos trabalhos nacionais realizaram análises preditivas da morte autoprovocada, os achados desse estudo podem colaborar para a condução de estratégias que busquem a redução do suicídio.

Descritores: Suicídio; Estudos de séries temporais; Previsão; Tendências; Sazonalidade. 


\section{INTRODUÇÃO}

O suicídio é definido como o ato humano intencional de cessar com a própria vida ${ }^{1}$. É considerado um fenômeno complexo, influenciado por aspectos demográficos, biológicos e sociais $^{2}$. Esta violência representa um importante problema de saúde pública no mundo. ${ }^{3} \mathrm{~A}$ Organização Mundial de Saúde (OMS) estimou para o ano de 2015, 788.000 mortes por suicídios com taxa global de mortalidade de 10,7 por 100.000 habitantes (hab.). ${ }^{4}$ Entretanto, a ausência de dados sobre o suicídio em alguns países, assim como, a irregularidade nos envios dessas informações à OMS, limita o conhecimento preciso desse evento no mundo. ${ }^{3-5}$

O Brasil encontra-se entre os dez países que registram os maiores números absolutos de morte por suicídio. ${ }^{5}$ No período de 2011 a 2015, foram registrados 55.649 óbitos por suicídio no Brasil, com um taxa geral de 5,5 por 100.000 hab., variando de 5,3 em 2011 a 5,7 em 2015 . Na região Nordeste, entre 2000 e 2014, verificou-se no estado do Piauí a maior média da taxa de suicídio, 7,7 por 100.000 hab. $^{7}$

Reduzir as mortes por suicídio tornou-se prioridade para as políticas públicas de saúde $^{8}$. Métodos estatísticos, como as séries temporais são usados para descrever padrões futuros da morte autoprovocada, o que pode ser útil na sua prevenção ${ }^{9}$. As séries temporais buscam descrever o comportamento de eventos, por meio dos seus componentes (tendência, sazonalidade e variação aleatória), avaliar os possíveis fatores envolvidos e realizar estimativas de previsão ${ }^{10}$. No âmbito da epidemiologia, é útil para planejar ações de saúde e avaliar sua eficácia ${ }^{11}$.

Existe uma elevada quantidade de procedimentos estatísticos utilizados para observar o comportamento de uma série temporal, entre elas, está o Modelo Auto Regressivo Integrado de Médias Móveis (ARIMA) e o ARIMA com componente sazonal (SARIMA) ${ }^{12}$. O ARIMA foi está entre os métodos mais clássicos da análise de séries temporais ${ }^{9}$. Esse modelo vêm sendo empregado nos estudos internacionais da série temporal de mortalidade por suicídio ${ }^{12-}$ $13-14-15$.

Identificar o comportamento temporal do suicídio, é relevante para subsidiar o planejamento de ações de intervenção do setor saúde e áreas afins, capazes de minimizar a ocorrência da morte autoprovocada. Este estudo teve como objetivo analisar a série temporal da mortalidade por suicídio no estado de Pernambuco, entre 1996 e 2015. 


\section{MÉTODOS}

O estado de Pernambuco está situado na região Nordeste do Brasil e possui uma área territorial de 98.076,021 km². Administrativamente é dividido em 185 municípios distribuídos em 12 Regionais de Saúde. A população estimada para o ano de 2015 foi de 9.345 .173 hab. ${ }^{16}$.

Estudo ecológico de série temporal que analisou os suicídios em residentes do estado Pernambuco, maiores ou iguais de 10 anos de idade, ocorridos entre janeiro de 1996 e dezembro de 2015. Os dados foram provenientes do Sistema de Informações sobre Mortalidade (SIM), correspondente ao grande grupo de causas de lesões autoprovocadas (X60-X84) da 10 Revisão da Classificação Internacional de Doenças (CID-10). As estimativas populacionais foram extraídas do Instituto Brasileiro de Geografia e Estatística (IBGE).

Série temporal (St) é um conjunto de dados dispostos no tempo. Sua análise consiste em desenvolver um modelo estatístico que explique o comportamento do evento ao longo do tempo. Neste artigo a série temporal é o valor mensal da taxa de mortalidade por suicídio por 100.000 hab. (TMS) em Pernambuco, de janeiro de 2016 a dezembro de 2020. De posse do modelo estatístico, é possível, então, realizar previsões. O modelo aditivo representa bem o comportamento da série temporal, sendo constituído pela soma do seus componentes, a saber: tendência $(\mathrm{T})$, sazonalidade $(\mathrm{S})$ e erro aleatório (ui).

$$
T M S t=T t+S t+u i
$$

A tendência revela o desempenho a longo prazo da série, ou seja, a sua trajetória média, considerando um largo período de tempo. A sazonalidade é a variação decorrente de momentos específicos. $\mathrm{O}$ erro aleatório insinua que há sempre uma variação que acontece de maneira casual, não podendo ser antecipada.

Uma análise de série temporal começa com a observação de seu gráfico. É através dessa observação que é possível identificar uma das características mais importantes da série para efeito de previsão: sua estacionariedade ${ }^{17}$. Uma série estacionária apresenta média e variância constantes. As análises de séries temporais foram realizadas segundo abordagem ARIMA/SARIMA. Essa técnica possui maior rigidez estatística e ampla flexibilidade no design da análise ${ }^{18}$.

O modelo ARIMA/SARIMA é construído pelos argumentos do Item autoregressivo (AR), Integração (I) e média móvel (MA). Numa série temporal, o principal dado empregado 
na modelagem é o valor da variável em períodos passados. O valor do AR especifica a defasagem de tempo considerada na geração do modelo. Em relação ao item I, quando se diferencia uma série temporal em um período, subtrai-se o valor de uma data pelo seu valor em uma data imediatamente anterior. Caso essa operação já alcance a estacionariedade, diz-se que a série temporal é integrada de primeira ordem. Calcular a MA é obter médias para subperíodos da série temporal. Esse procedimento corrige as variações decorrentes do componente de erro da série.

Três etapas foram utilizadas para a elaboração do modelo: identificação, estimativa e teste de parâmetro e aplicação. A primeira fase tem o propósito de avaliar a presença de estacionariedade e sazonalidade, assim como, determinar sua diferenciação e ordem. A estacionariedade ocorre quando suas observações dispõe-se aleatoriamente ao redor de uma média constante, ou seja, não há tendência ${ }^{19}$.

Para testar, a estacionariedade das séries utilizou-se a Função de Autocorrelação (FAC) e o teste Dickey-Fuller (ADF). A FAC, por meio do correlogramo, expressa a relação entre a covariância/variância da série temporal e as defasagens, logo, a série é classificada estacionária quando o correlogramo dispõe de flutuações suaves em torno de zero. O teste ADF investiga se a série é estacionária por meio da identificação de uma raiz unitária em seu processo gerador. Portanto, a hipótese nula $\left(\mathrm{H}_{0}\right)$ a ser considerada é que a série apresenta raiz unitária e, portanto, é não estacionária.

Na segunda etapa determinou-se a estimação dos parâmetros AR e MA da tendência e parte sazonal, através do método da máxima verossimilhança. Os modelos ARIMA são baseados em um conjunto de suposições estatísticas. Duas das assunções mais importantes são: os resíduos (a diferença entre o valor efetivamente observado na série temporal e o valor previsto no modelo) são aleatórios e normalmente distribuídos ${ }^{20}$. De posse do melhor ajuste, foram testados a aleatoriedade dos resíduos, por meio do teste Ljung-Box e FAC, assim como, sua normalidade. Por último, realizou-se a aplicação do modelo para a previsão da taxa de suicídio pelo SARIMA para o período de janeiro de 2016 até dezembro de 2020.

O programa R versão 3.4.1.foi utilizado para as análises. Empregou-se o pacote urca para a observação do ADF e o forecast para a obtenção do modelo final SARIMA, ambos disponíveis no R.A pesquisa foi aprovada pelo Comitê de Ética em Pesquisa do Centro de Ciências de Saúde da Universidade Federal de Pernambuco (Parecer 2.045.304). 


\section{RESULTADOS}

No período analisado foram registrados pelo SIM 6.229 suicídios no estado de Pernambuco, com taxa de mortalidade médio de 4,7 por 100.000 hab. Observou-se menor taxa em junho de 2002 (0,161 por 100.000 hab.) e maior em agosto de 2007 (0,541 por 100.000 hab.) (Figura 1a). A decomposição da série temporal é exibida na Figura 1b, onde pressupõe-se, por meio da tendência a não estacionariedade. Percebe-se certa sazonalidade na série, embora não muito acentuada (Figura 1c). Na Figura 1c, a sazonalidade é vista em maior detalhe.

Figura 1- Taxa de mortalidade (A), decomposição da série histórica (B) e sazonalidade (C), das taxas mensais de mortalidade por suicídio no estado de Pernambuco de janeiro de 1996 até dezembro de 2015

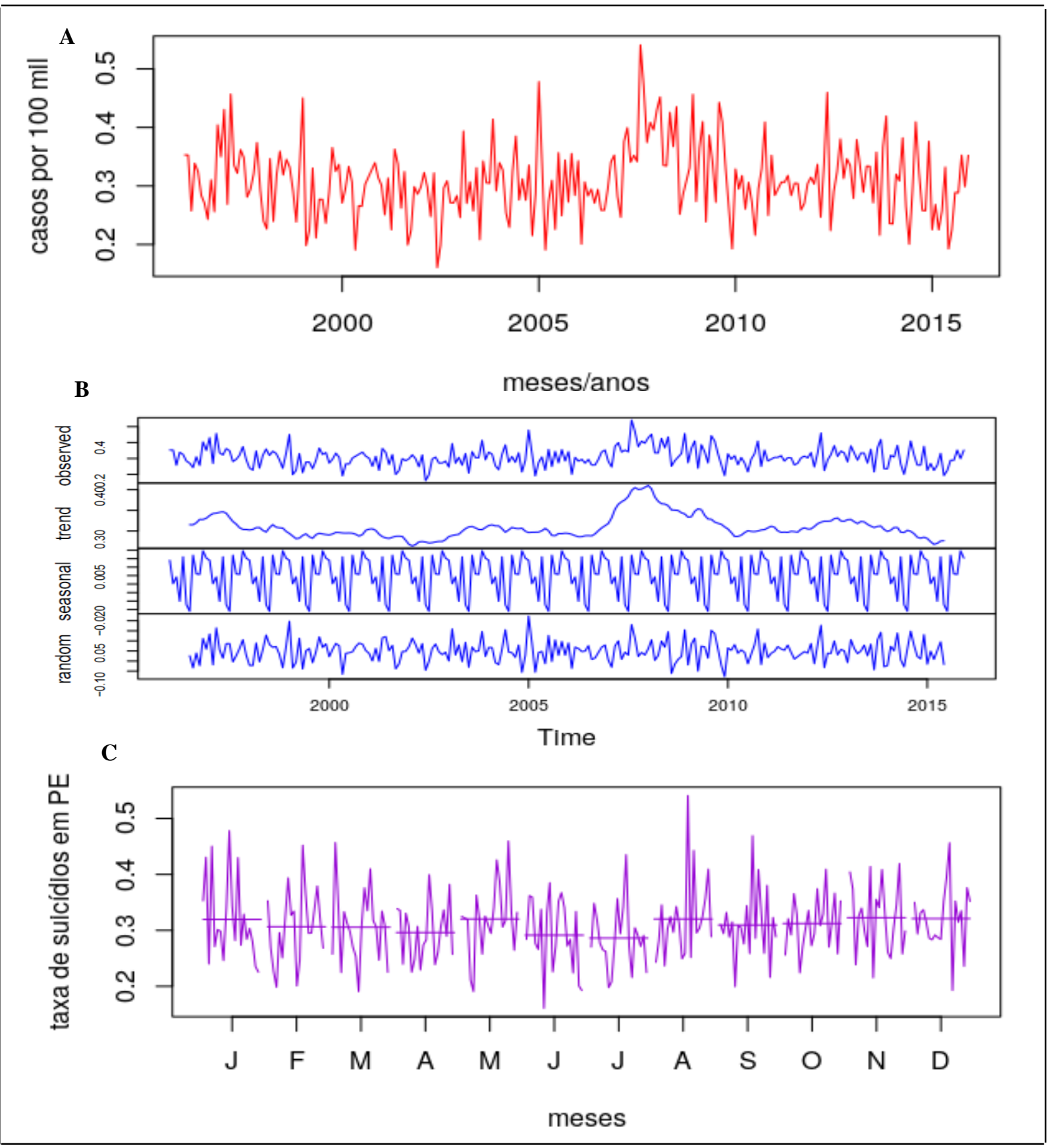


Para testar a estacionariedade da série temporal foram feitos dois testes: 1. Função da autocorrelação e seu correlogramo; 2. Teste de Dickey-Fuller. O correlogramo da FAC (Figura 2a) indica a não estacionariedade, uma vez que seus valores não apresentam-se dispersos em torno de zero. Essa informação é confirmada pelo valor do ADF (estatística t = -1.2337) portanto, aceita-se $\mathrm{H}_{0}$, ou seja, a série é não-estacionária no modelo escolhido. Verifica-se na Figura $2 \mathrm{~b}$ que a série alcança a estacionariedade após a primeira diferenciação $(\mathrm{d}=1)$, indicando que a tendência foi removida. O teste ADF corrobora com este resultado (estatística t = -19.813). Agora, o valor da estatística calculada é, em módulo, bem superior ao valores críticos apresentados para 1,5 e $10 \%$. Logo, rejeita-se a $\mathrm{H}_{0}$ e considera-se a série temporal estacionária de primeira ordem.

Para realizar previsões, aplicou-se a taxa de mortalidade de suicídio um modelo ARIMA com componente sazonal, ou seja, um modelo SARIMA. O modelo SARIMA final que produziu o maior ajuste teve os argumentos $(1,2,1)$ e $(1,1,1)$, para as partes de tendência e sazonal, respectivamente. É possível perceber que os valores dos dados originais (linha vermelha) e os dados reproduzidos segundo modelo SARIMA ajustado (linha azul) são aproximados (Figura 2c). 
Figura 2- Função de Autocorrelação (A), primeira diferenciação da série temporal (B) e série temporal bruta observada e modelo SARIMA ajustado (C) das taxas de mortalidade por suicídio no estado de Pernambuco (1996-2015)

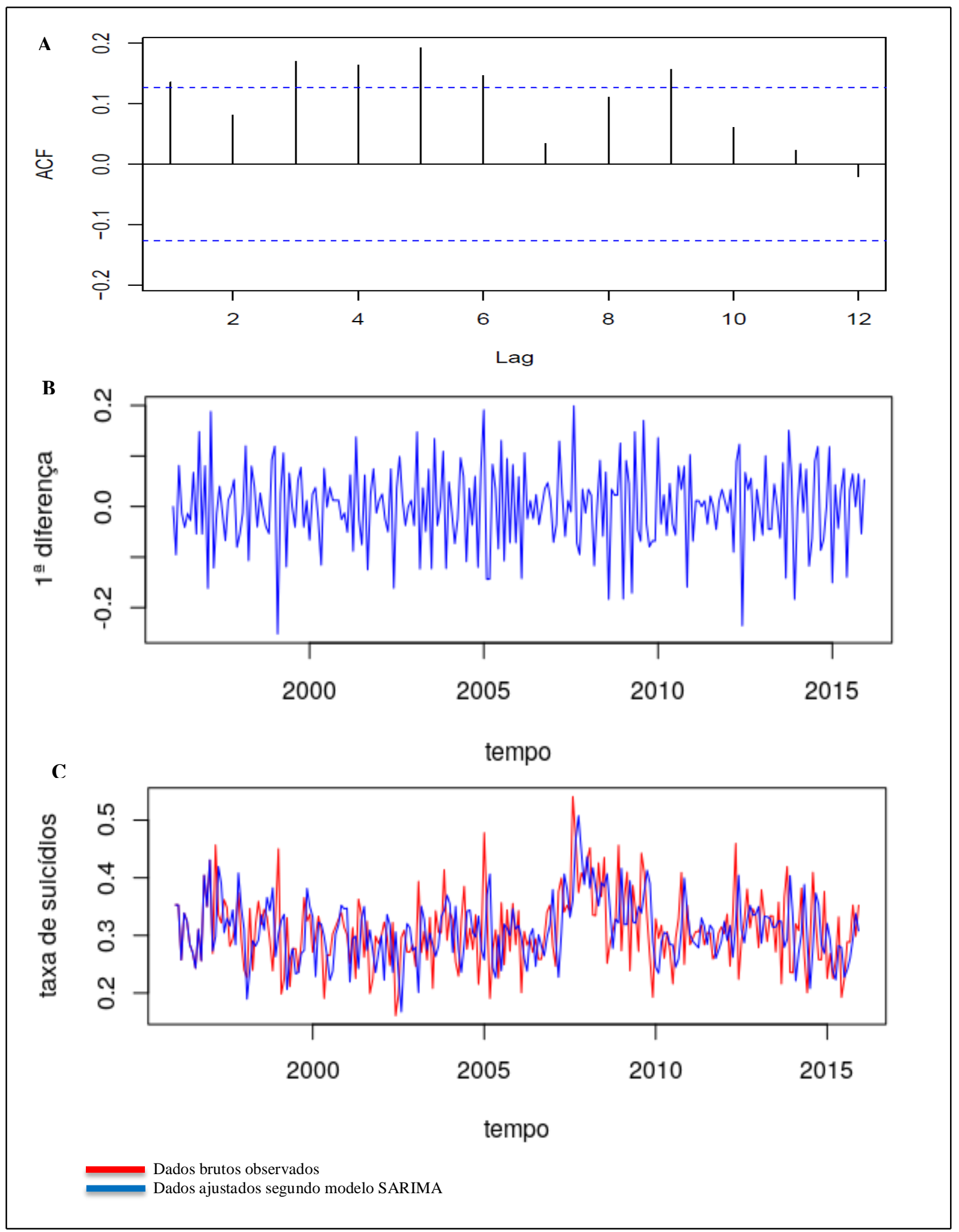


A Figura 3a, resultante do teste Ljung-Box, indica o comportamento dos resíduos do modelo testado $(1,2,1)(1,1,1)$, e aponta para a aleatoriedade, que oscila em torno do zero. Através do FAC quase não se nota a presença da autocorrelação dos dados, exceto, pela observação do Lag 2 (Figura 3b). Os resíduos foram considerados normalmente distribuídos (Figura 3c). Na Figura 4, o nível de significância considerado na previsão das taxas de suicídio é representado pelo trecho destacado, a linha azul representa a previsão dessas taxas. Observa-se a para dezembro de 2020 uma previsão da taxa de suicídio de 0,3842 por 100.000 hab. (Tabela 1).

Figura 3- Análise dos resíduos do modelo SARIMA segundo teste Ljung-Box (A), Função de Autocorrelação (B) e teste de normalidade (C)

A Residuals from $\operatorname{ARIMA}(1,2,1)(1,1,1)[12]$

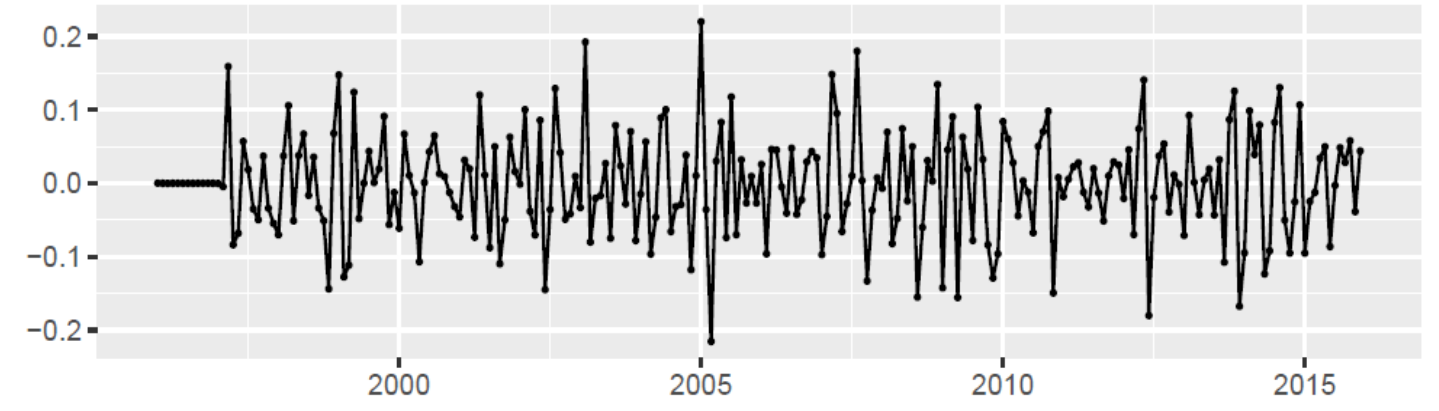

B
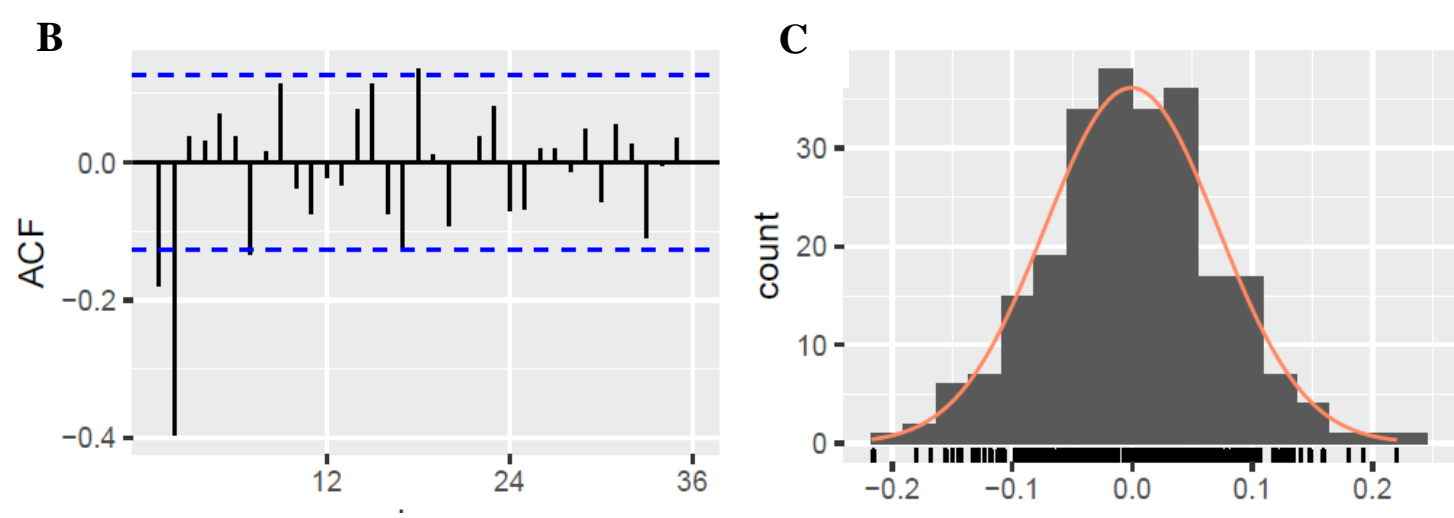
Figura 4- Previsão das taxas de mortalidade por suicídio no estado de Pernambuco para o período de janeiro de 2016 a dezembro de 2020

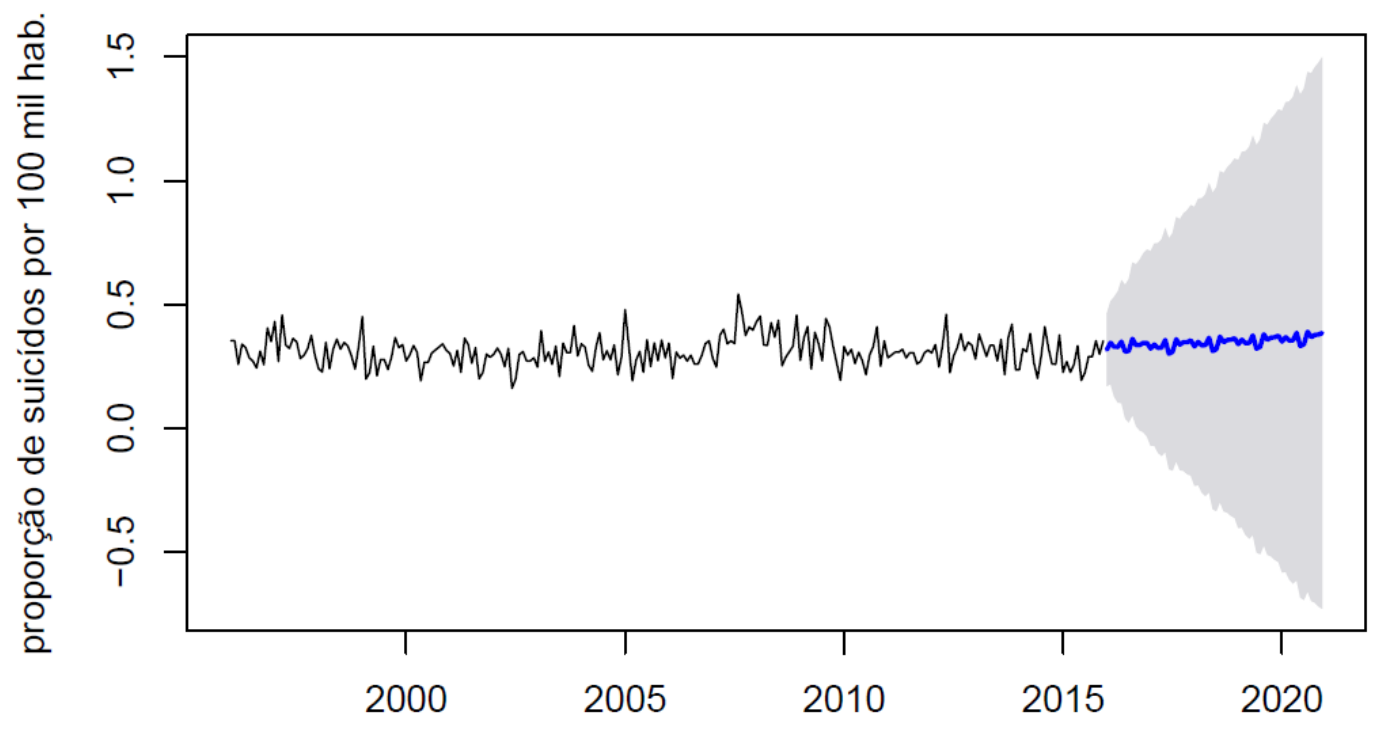

Tabela 1- Previsão das taxas de mortalidade por suicídio mensais (Intervalo de confiança - IC de 95\%) para o estado de Pernambuco entre janeiro de 1996 e dezembro de 2020

\begin{tabular}{cccc}
\hline Mês/Ano & TMS esperada & Inferior 95\% IC & Superior 95\% IC \\
\hline Jan 2016 & 0.3167 & 0.1693 & 0.4641 \\
Fev 2016 & 0.3447 & 0.1773 & 0.5122 \\
Mar 2016 & 0.3283 & 0.1264 & 0.5302 \\
Abr 2016 & 0.3276 & 0.1029 & 0.5522 \\
Mai 2016 & 0.3492 & 0.1006 & 0.5979 \\
Jun 2016 & 0.3087 & 0.0392 & 0.5782 \\
Jul 2016 & 0.3121 & 0.0223 & 0.6019 \\
Ago 2016 & 0.3606 & 0.0518 & 0.6694 \\
Set 2016 & 0.3347 & 0.0075 & 0.6618 \\
Out 2016 & 0.3353 & -0.0093 & 0.6801 \\
Nov 2016 & 0.3445 & -0.0171 & 0.7062 \\
Dez 2016 & 0.3436 & -0.0345 & 0.7218 \\
Jan 2017 & 0.3211 & -0.0722 & 0.7144 \\
Fev 2017 & 0.3373 & -0.0712 & 0.7460 \\
Mar 2017 & 0.3236 & -0.0996 & 0.7470 \\
Abr 2017 & 0.3248 & -0.1130 & 0.7627 \\
Mai 2017 & 0.3559 & -0.0961 & 0.8081 \\
Jun 2017 & 0.3000 & -0.1661 & 0.7662 \\
Jul 2017 & 0.3081 & -0.1718 & 0.7881 \\
Ago 2017 & 0.3589 & -0.1347 & 0.8525 \\
Set 2017 & 0.3369 & -0.1700 & 0.8440 \\
Out 2017 & 0.3471 & -0.1731 & 0.8675 \\
Nov 2017 & 0.3470 & -0.1864 & 0.8804 \\
Dez 2017 & 0.3543 & -0.1921 & 0.9007 \\
Jan 2018 & 0.3299 & -0.2337 & 0.8937 \\
Fev 2018 & 0.3480 & -0.2306 & 0.9267 \\
Mar 2018 & 0.3340 & -0.2604 & 0.9285 \\
& & &
\end{tabular}


Continuação

\begin{tabular}{cccc}
\hline Mês/Ano & TMS esperada & Inferior 95\% IC & Superior 95\% IC \\
\hline Abr 2018 & 0.3350 & -0.2745 & 0.9445 \\
Mai 2018 & 0.3648 & -0.2598 & 0.9895 \\
Jun 2018 & 0.3112 & -0.3283 & 0.9508 \\
Jul 2018 & 0.3187 & -0.3356 & 0.9731 \\
Ago 2018 & 0.3692 & -0.2997 & 1.0382 \\
Set 2018 & 0.3468 & -0.3366 & 1.0303 \\
Out 2018 & 0.3556 & -0.3421 & 1.0535 \\
Nov 2018 & 0.3570 & -0.3550 & 1.0690 \\
Dez 2018 & 0.3631 & -0.3630 & 1.0893 \\
Jan 2019 & 0.3391 & -0.4044 & 1.0827 \\
Fev 2019 & 0.3570 & -0.4021 & 1.1163 \\
Mar 2019 & 0.3431 & -0.4323 & 1.1187 \\
Abr 2019 & 0.3442 & -0.4470 & 1.1355 \\
Mai 2019 & 0.3743 & -0.4327 & 1.1815 \\
Jun 2019 & 0.3205 & -0.5022 & 1.1433 \\
Jul 2019 & 0.3282 & -0.5101 & 1.1665 \\
Ago 2019 & 0.3788 & -0.4749 & 1.2326 \\
Set 2019 & 0.3565 & -0.5125 & 1.2256 \\
Out 2019 & 0.3657 & -0.5186 & 1.2500 \\
Nov 2019 & 0.3668 & -0.5325 & 1.2663 \\
Dez 2019 & 0.3732 & -0.5412 & 1.2878 \\
Jan 2020 & 0.3493 & -0.5833 & 1.2820 \\
Fev 2020 & 0.3673 & -0.5819 & 1.3166 \\
Mar 2020 & 0.3673 & -0.6129 & 1.3200 \\
Abr 2020 & 0.3546 & -0.6285 & 1.3379 \\
Mai 2020 & 0.3848 & -0.6152 & 1.3848 \\
Jun 2020 & 0.3311 & -0.6855 & 1.3478 \\
Jul 2020 & 0.3388 & -0.6944 & 1.3721 \\
Ago 2020 & 0.3895 & -0.6601 & 1.4392 \\
Set 2020 & 0.3673 & -0.6987 & 1.4334 \\
Out 2020 & 0.3765 & -0.7059 & 1.4589 \\
Nov 2020 & 0.3778 & -0.7208 & 1.4765 \\
Dez 2020 & 0.3842 & -0.7306 & 1.4991 \\
\hline & & & \\
\hline
\end{tabular}




\section{DISCUSSÃO}

A série temporal representada pelas taxas de mortalidade por suicídio alcançou estacionariedade após a primeira diferenciação. Na decomposição da série foi identificado o componente sazonal, porém, pouco acentuado.

Observou-se no período analisado taxa de mortalidade média por suicídio menor $(4,7$ por 100.000 hab.) do que o verificado no Brasil entre 2000 a 2012 (5,7 por 100.000 hab. $)^{21}$. Sendo influenciado por aspectos sociais e culturais essa taxa apresenta-se distinta entre as unidades federadas do país ${ }^{22-23}$. No ano de 2015, os estados da região Sul obtiveram maiores taxas, o Rio Grande do Sul registrou o mais elevado (10,5 por 100.000 hab. $)^{24}$. Nessa região as mortes autoprovocadas estão associadas às áreas rurais e campestres, caracterizadas pela presença de imigrantes, população rural e economia baseada na agricultura e pecuária ${ }^{25}$.

A distribuição da série temporal mostrou-se não estacionária, obtendo-se tal característica após a primeira diferenciação. A suposição mais importante em uma estrutura de série temporal para a aplicação do ARIMA é a estacionariedade, que ocorre quando as observações dispõe-se aleatoriamente ao redor de uma média constante ${ }^{19-26}$. De forma geral, os estudos que utilizam o ARIMA/SARIMA obtém esse pressuposto mediante uma ou duas diferenciações ${ }^{13-27}$.

Os resultados da decomposição da série temporal demonstraram certa sazonalidade. Pesquisa realizada na cidade de São Paulo, Brasil (1996-2010), encontrou um padrão sazonal de suicídio, com taxa de mortalidade superior em novembro e inferior entre maio e junho ${ }^{28}$. Fatores climáticos tem sido associados à sazonalidade do suicídio ${ }^{29}$. Entretanto, essa relação não encontra-se totalmente esclarecida, uma vez, que outras pesquisas relatam correlação negativa ${ }^{30-31}$.

Outras questões como a temperatura ambiental e incidência solar também são relacionados ao aspecto sazonal da morte autoprovocada ${ }^{32}$. Uma explicação biológica é pautada nos receptores cerebrais da serotonina, que podem ter rápido aumento em sua concentração diante o aumento da temperatura do ambiente, fato que pode influenciar o humor e desencadear comportamentos impulsivos e/ou agressivos ${ }^{33}$.

Percebeu-se valores aproximados entre os dados originais e aqueles reproduzidos pelo SARIMA ajustado. O modelo ARIMA/SARIMA, tem sido utilizado em estudos de séries temporais da mortalidade por suicídio, sobretudo, naqueles relacionados às questões climáticas, sazonais, sociodemográficas e econômicas ${ }^{12-13-14-15}$. Estudos utilizando o modelo ARIMA têm percebido associações entre o suicídio e o divórcio, taxa de inflação elevada e 
desemprego ${ }^{13-34}$. Mudanças negativas de status social ou econômico são fatores de risco para o suicídio bem estabelecidos na literatura, e estão relacionadas ao desenvolvimento de psicopatologias envolvidas no fenômeno suicida ${ }^{22}$.

No modelo ARIMA/SARIMA duas das questões mais relevantes são aleatoriedade e normalidade dos resíduos, ambas, comprovadas nesse estudo. A condição de independência das observações em uma série histórica é frequentemente quebrada em estudos epidemiológicos, isto é explicado, especialmente, pela presença de algumas variáveis, principalmente a sazonalidade ${ }^{11}$. Para detectar a autocorrelação residual utiliza-se o gráfico de resíduos juntamente com o FAC, uma vez controlada, esta não representará um obstáculo para o uso de métodos como o ARIMA ${ }^{35}$.

De acordo com o modelo SARIMA ajustado a taxa de mortalidade por suicídio esperada para Pernambuco em dezembro é de 2020 é de 0,3842 por 100.000 hab. Nos estudos sobre suicídio os modelos ARIMA tem demonstrado boa precisão na sua previsão ${ }^{12}$. Na China (2002-2013), um estudo que empregou modelo ARIMA apontou, para o ano de 2014, redução dos casos de morte por lesões incluindo aquelas decorrentes do suicídio ${ }^{9}$. Baseados em dados passados, previsões realizadas por esse modelo ajudam a estabelecer medidas de cuidado e prevenção ${ }^{36}$. O Alerta precoce baseado em dados de mortalidade é primordial para o desenvolvimento de estratégias de vigilância em saúde que busquem a redução da morte auto provocada $^{37}$. Nessa perspectiva, o uso de séries temporais e técnicas estatísticas como o ARIMA são úteis para o auxiliar ações de saúde para o enfrentamento dessa violência. 


\section{CONCLUSÃO}

A série temporal apresentou sazonalidade pouco acentuada. O modelo SARIMA de melhor ajuste produziu os argumentos $(1,2,1)$ e $(1,1,1)$. Esse modelo mostrou-se adequado para prever a tendência do suicídio para os próximos cinco anos (2016-2020), e apontou valores com poucas variações. Antever o risco da morte autoinfligida é particularmente importante para ajustar e adotar intervenções específicas de prevenção que busquem a redução dessa violência, nesse sentido, o ARIMA representa um método relevante para obtenção de resultados confiáveis de previsão. 


\section{REFERÊNCIAS}

1. Turecki G, Brent DA. Suicide and suicidal behaviour. Lancet [Internet]. 2016; 387(10024):1227-1239.

http://www.thelancet.com/journals/lancet/article/piiS0140-6736(15)00234-2/fulltext

2. Crump C, Sundquist K, Sundquist J, Winkleby MA. Sociodemographic, psychiatric and somatic risk factors for suicide: a Swedish national cohort study. Psychol Med [Internet]. 2014; 44(2):279-289.

https://www.cambridge.org/core/journals/psychological-medicine/article/divclasstitlesociodemographic-psychiatric-and-somatic-risk-factors-for-suicide-a-swedishnational-cohort-studydiv/38C261DEB9A28F6D244169B517227414

3. Khazaei S, Armanmehr V, Nematollahi S, Rezaeian S, Khazaei S. Suicide rate in relation to the Human Development Index and other health related factors: A global ecological study from 91 countries. J Epidemiol Glob Health. 2017; 7:131-34.

https://www.sciencedirect.com/science/article/pii/S2210600616300430

4. WORLD HEALTH ORGANIZATION (WHO). Global Health Observatory. 2015.

Disponível em: http://www.who.int/gho/mental_health/suicide_rates/en/_Accessed Abr 2018.

5. Värnik P. Suicide in the World. Int J of Environ Res and Public Health [Internet]. 2012; 9(3):760-771. https://www.ncbi.nlm.nih.gov/pmc/articles/PMC3367275/

6. Brasil. Ministério da Saúde. Secretaria de Vigilância em Saúde. Suicídio: Saber, agir e prevenir. Brasília, DF. v. 48, n 30. 2017.

<http://portalarquivos2.saude.gov.br/images/pdf/2017/setembro/21/2017-025-Perfilepidemiologico-das-tentativas-e-obitos-por-suicidio-no-Brasil-e-a-rede-de-atencao-asaude.pdf>

7. Santos EGO, Barbosa IR. Conglomerados espaciais da mortalidade por suicídio no nordeste do Brasil e sua relação com indicadores socioeconômicos. Cad saúde colet [Internet]. 2017; 25(3):371-379, 2017.

http://www.scielo.br/scielo.php?pid=S1414-

$\underline{462 X 2017000300371 \& \text { script }=\text { sci_abstract \&tlng }=\mathrm{pt}}$

8. Zalsman G et al. Suicide prevention strategies revisited: 10-year systematic review. Lancet [Internet]. 2016; 3(7):646 659. http://www.thelancet.com/journals/lanpsy/article/PIIS22150366(16)30030-X/abstract?utm_medium=referral\&utm_source=r360

9. Lin Y, Chen M, Chen G, Wu X, Lin T. Application of an auto regressive integrated moving average model for predicting injury mortality in Xiamen, China. BMJ Open [Internet]. 2015; 5(12):e008491. http://bmjopen.bmj.com/content/5/12/e008491 
10. Zhang X, Zhang T, Young AA, Li X. Applications and comparisons of four time series models in epidemiological surveillance data. PLoS One [Internet]. 2014; 9(2):e88075. http://journals.plos.org/plosone/article?id=10.1371/journal.pone.0088075

11. Bernal JL, Cummins S, Gasparrini A. Interrupted time series regression for the evaluation of public health interventions: a tutorial. Int J Epidemiol [Intenet]. 2017; 46(1):348-

355.http://researchonline.lshtm.ac.uk/2550793/

12. Preti A, Lentini G. Forecast models for suicide: Time-series analysis with data from Italy. Chrono biol Int [Internet]. 2016; 33(9):1235-1246.

https://www.tandfonline.com/doi/abs/10.1080/07420528.2016.1211669?journalCode=icbi20

13. Norström T, Grönqvist $\mathrm{H}$. The Great Recession, un employment and suicide. J Epidemiol Community Health [Internet]. 2014; 0:1-7.

http://jech.bmj.com/content/early/2014/10/21/jech-2014-204602

14. Shelygin KV. The suicide mortality and alcoholism in the Murmansk oblast.

Probl Sotsialnoi Gig Zdravookhranenniiai Istor Med [Internet]. 2013; (6):19-

21.https://www.ncbi.nlm.nih.gov/pubmed/24649607

15. Tsai JF, Cho WC. Temperature change dominates the suicidal seasonality in Taiwan: A time-series analysis. J Affect Disord [Internet]. 2012; 136(3):412-418.

https://www.sciencedirect.com/science/article/pii/S0165032711007233

16. Instituto Brasileiro de Geografia e Estatística. IBGE Estados 2016.

http://www.ibge.gov.br/estadosat/perfil.php?sigla=pe. Accessed Jan 2018.

17. Gujarati DN, Porter DC. Ecometria Básica. 5 ed. Porto Alegre: AMGH Editora, 2011.

18. Ajdacic-Gross $\mathrm{V}$ et al. Understanding weekly cycles in suicide: an analysis of Austrian and Swiss data over 40 years. Epidemiol Psychiatr Sci [Internet]. 2015; 24(4):315-321. https://www.cambridge.org/core/journals/epidemiology-and-psychiatricsciences/article/understanding-weekly-cycles-in-suicide-an-analysis-of-austrian-and-swissdata-over-40-years/F079286A89342A79E23A74EB89FE3112

19. Latorre MRDO, Cardoso MRA. Análise de séries temporais em epidemiologia: uma introdução sobre os aspectos metodológicos. Rev. Bras. Epidemi [Internet]. 2001; 4(3):145152. http://www.scielo.br/scielo.php?pid=S1415-

$\underline{790 \times 2001000300002 \& \text { script }=\text { sci abstract\&tlng }=\mathrm{pt}}$

21. Machado DB, Santos DN. Suicídio no Brasil, de 2000 a 2012. J bras psiquiat [Internet]. 2015; 64(1):45-54.

http://www.scielo.br/scielo.php?script=sci_arttext\&pid=S0047-20852015000100045

22. Botega NJ. Comportamento Suicida: epidemiologia. Psicol USP [Internet]. 2014; 25(3):231-236.

http://www.scielo.br/scielo.php?script=sci_arttext\&pid=S0103-65642014000300231 
23. Orellana JD, Balieiro AA, Fonseca FR, Basta PC, Souza ML. Spatial-temporal trends and risk of suicide in Central Brazil: an ecological study contrasting indigenous and nonindigenous populations. Rev Bras Psiquiatr [Internet] 2016; 38(3):222-230. http://www.scielo.br/scielo.php?script=sci_arttext\&pid=S1516-44462016000300222

24. Malta DC, Minayo MC, Soares FA, Silva MM, Montenegro MM, Ladeira RM, et al. Mortality and years of life lost by interpersonal violence and self-harm: in Braziland Brazilian states: analysis of the estimates of the Global Burden of Disease Study, 1990 and 2015. Rev Bras Epidemiol [internet]. 2017; 20(1):142-56. http://www.scielo.br/scielo.php?script=sci_arttext\&pid=S1415-790X2017000500142

25. Macente LB, Zandonade E. Spatial distribution of suicide incidence rates in municipalities in the state of Espírito Santo (Brazil), 2003-2007: spatial analysis to identify risk areas. Rev bras psiquiat [Internet]. 2012; 34(3): 261-269. Disponível em: http://www.scielo.br/scielo.php?script=sci_arttext\&pid=S1516-44462012000300005

26. Appiah ST, Otoo, H, Nabubie IB. Times Series Analysis Of Malaria Cases In Ejisu Juaben Municipality. International Journal of Scientific\& Technology Research [Internet]. 2015; 4(6):220-226. http://www.ijstr.org/final-print/june2015/Times-Series-Analysis-Of-Malaria-Cases-In-Ejisujuaben-Municipality.pdf

27. Sato RC. Gerenciamento de doenças utilizando séries temporais com o modelo ARIMA. Einstein (São Paulo) [Online]. 2013; 11(1):128-131. http://www.scielo.br/scielo.php?script=sci_arttext\&pid=S1679-45082013000100024

28. Bando DH, Volpe FM. Seasonal variation of suicide in the city of São Paulo, Brazil, 1996-2010.Crisis [Internet]. 2014; 35(1):5-9. https://econtent.hogrefe.com/doi/abs/10.1027/0227-5910/a000222?url_ver=Z39.882003\&rfr_id=ori\%3Arid\%3Acrossref.org\&rfr_dat=cr_pub\%3Dpubmed

29. Williams MN, Hill SR, Spicer J. Will climate change increase or decrease suicide rates? The differing effects of geographical, seasonal, and irregular variation in temperature on suicide. Climatic Change [Internet]. 2015; 130(4):519-528. https://link.springer.com/article/10.1007/s10584-015-1371-9

30. Folly WSD. Suicide seasonality: Evidence of 11-year cyclic oscillations in Brazilian suicide rates. Cad. saúde colet [online]. 2013; 21(1):96-102. http://www.scielo.br/scielo.php?script=sci_arttext\&pid=S1414-462X2013000100015

31. Yamasaki A et al. Solar Flux Exhibits a Negative Correlation with Suicide Rate. Remedy Publications [Internet]. 2017; 2:1059

http://remedyoa.com/pdfs_folder/roa-v2-id1059.pdf

32. Qi X; Hu W; Page A; Tong S. Associations between climate variability, unemployment and suicide in Australia: a multicity study. BMC Psychiatry [Internet] 2015; 15:114. https://bmcpsychiatry.biomedcentral.com/articles/10.1186/s12888-015-0496-8 
33. Zhang G, Tao R. Enhanced responsivity of 5-HT2A receptors at warm ambient temperatures is responsible for the augmentation of the 1-(2,5-dimethoxy-4-iodophenyl)-2aminopropane (DOI)-induced hyperthermia. Neurosci Lett [Internet]. 2011; 490(1): 68-71. https://www.ncbi.nlm.nih.gov/pmc/articles/pmid/21172407/

34. Sun BQ, Zhang J. Economic and Sociological Correlates of Suicides: Multilevel Analysis of the Time Series Data in the United Kingdom. J Forensic Sci [Internet]. 2016; 61(2):345351. https://onlinelibrary.wiley.com/doi/abs/10.1111/1556-4029.13033

35. Bhaskaran K, Gasparrini A, Hajat S, Smeeth L, Armstrong B. Time series regression studies in environmental epidemiology. Int J Epidemiol [Internet]. 2013; 42(4):1187-1195. https://www.ncbi.nlm.nih.gov/pmc/articles/PMC3780998/

36. Cortes $\mathrm{F}$ et al. Time series analysis of dengue surveillance data in two Brazilian cities. Acta Trop [Internet]. 2018; 182:190-197 https://www.sciencedirect.com/science/article/pii/S0001706X17311312?via\%3Dihub

37. Zhang $\mathrm{X}$ et al. Temporal and long-term trend analysis of class $\mathrm{C}$ notifiable diseases in China from 2009 to 2014. BMJ Open [Internet]. 2016; 6(10):e011038.

http://bmjopen.bmj.com/content/6/10/e011038 


\section{CONCLUSÃO}

a) Embora a análise da completude dos registros de óbitos por suicídio do SIM tenha demonstrado melhora, algumas variáveis como ocupação e circunstância do óbito apresentaram redução no preenchimento. A ausência do registro das variáveis dos óbitos podem mascarar ou distorcer informações, dificultando o conhecimento da gravidade. A boa completude dos dados de suicídio é essencial ao conhecimento das características sociodemográficas e dos óbitos, informações primordiais para o estabelecer ações estratégicas e de prevenção.

b) Verificou-se por meio da caracterização epidemiológica a presença de grupos específicos mais acometidos pelo suicídio. Esse fato revela que são oportunas orientações de intervenções em saúde que busquem atingir essas populações. A mudança dos meios suicidas revelada pelo sexo feminino, aponta apara a adoção de medidas que controlem e fiscalizem de forma sistemática e eficiente a comercialização e utilização de pesticidas.

c) A adoção de técnicas de análise espacial revelou a autocorreção espacial do suicídio em Pernambuco. Áreas prioritárias com significância estatística foram localizadas, sobretudo, fora do eixo da Região Metropolitana do Recife. Questões como a elevada heterogeneidade socioeconômica, demográfica e cultural de Pernambuco, além, da identificação de clusters que por vezes extrapolam os limites administrativos das Regiões de Saúde devem ser consideradas no planejamento das medidas de prevenção.

d) O emprego do modelo ARIMA/SARIMA mostrou-se adequado para prever a tendência do suicídio para os próximos cinco anos (2016-2010), além de identificar certa sazonalidade, embora não muito acentuada. Antever o risco da morte autoinfligida é particularmente importante para ajustar e adotar intervenções específicas de prevenção que busquem a redução dessa violência, nesse sentido, o ARIMA representa uma ferramenta relevante para obtenção de resultados confiáveis de previsão. 


\section{REFERÊNCIAS}

ABREU, K. P. et al. Comportamento suicida: fatores de risco e intervenções preventivas. Revista Eletrônica de Enfermarem [online], Goiânia, v. 12, n. 1, p. 195-200, 2010. Disponível em: <https://www.fen.ufg.br/fen_revista/v12/n1/pdf/v12n1a24.pdf> Acesso em: 31 dez. 2016.

AJDACIC-GROSS, V. et al. Understanding weekly cycles in suicide: an analysis of Austrian and Swiss data over 40 years. Epidemiology and Psychiatric Sciences [online], Cambridge, v. 24, n. 4, 315-321, 2015. Disponível em:

<https://www.cambridge.org/core/journals/epidemiology-and-psychiatricsciences/article/understanding-weekly-cycles-in-suicide-an-analysis-of-austrian-and-swissdata-over-40-years/F079286A89342A79E23A74EB89FE3112\#> Acesso em: 29 mar. 2018.

AKTAS, S. G.; KANTAR Y. M. A Study of Suicide Mortality in Turkey (2002-2011).

Journal of EU Research in Business [online], v. 2016, 2016. Disponível em:

<http://ibimapublishing.com/articles/JEURB/2016/864344/864344.pdf> Acesso em: 26 fev. 2017.

ALAMEDA-PALACIOS, J.; MIGUEL RUIZ-RAMOS, M.; GARCÍA-ROBREDO, B. Suicidio, prescripción de antidepresivos y desempleo em Andalucía. GacetaSanitaria [online], Barcelona, v. 28, n. 4, p. 309-312, 2014. Disponível em:

<http://www.gacetasanitaria.org/es/suicidio-prescripcion-antidepresivos-desempleoandalucia/articulo/S0213911113002318/> Acesso em: 16 jan. 2018.

ALEMU, Z. A et al. Non random distribution of child undernutrition in Ethiopia: spatial analysis from the 2011 Ethiopia demographic and health survey. International Journal for Equity Health [online],London, v. 15, n. 1, 2016. Disponível em:

<https://www.ncbi.nlm.nih.gov/pubmed/27912766> Acesso em: 24 fev. 2017.

ALMEIDA, M. C. S.; GOMES, C. M. S.; NASCIMENTO, L. F. C. Análise espacial da mortalidade neonatal no estado de São Paulo, 2006-2010. Revista Paulista de Pediatria [online], São Paulo, v. 32, n. 4, p. 374-380, 2014. Disponível em:

<http://www.scielo.br/scielo.php?pid=S010305822014000400374\&script=sci_arttext\&tlng=pt> Acesso em: 18 fev. 2017.

ALMEIDA, L.; QUINTÃO, S. Depressão e Ideação Suicida em Idosos Institucionalizados e Não Institucionalizados em Portugal. Acta Médica Portuguesa [online], Lisboa, v. 25, n. 6, p. 350-358, 2012. Disponível em:

<http://actamedicaportuguesa.com/revista/index.php/amp/article/viewFile/1351/944> Acesso em: 12 fev. 2017. 
ÁLVARO-MECA, A. et al. Epidemiology of suicide in Spain, 1981e 2008: a spatiotemporal analysis. Public Health[online], Weinheim, v. 127, n. 4, p. 380-385. 2013. Disponível em: <https://www.ncbi.nlm.nih.gov/pubmed/23375621> Acesso em: 25 fev. 2017.

ANSELIN, L. Local Indicators of Spatial Association - LISA. Geographic Analysis. v. 27, n. 91, p. 114, 1995. Disponível em:

$<$ http://isites.harvard.edu/fs/docs/icb.topic868440.files/Anselin1995\%20LISA.pdf> Acesso em: 14 fev. 2017.

ANTUNES, J. L.; CARDOSO, M. R. Uso da análise de séries temporais em estudos epidemiológicos. Epidemiologia e Serviço de Saúde, Brasília, v. 24, n. 3, p. 565-576, 2015. Disponível em: <http://www.scielo.br/scielo.php?pid=S2237-

96222015000300565\&script=sci_abstract $>$ Acesso em: 29 mar. 2018.

ARENAS, A.; GÓMEZ-RESTREPO, C.; RONDÓN, M. Suicidal Behaviour and Associated Factors in Colombia. Revista Colombiana de Psiquiatria [online], Bogotá, v. 45, p. 68-75, 2016. Disponível em:<https://www.ncbi.nlm.nih.gov/pubmed/27993258> Acesso em: 14 jan. 2017.

ASSUNÇÃO, R. M et al. Mapas de taxas epidemiológicas: uma abordagem Bayesiana. Cadernos de Saúde Pública [online], Rio de Janeiro, v. 14, n. 4, p. 713-723, 1998.

Disponível

em: $<$ http://www.dpi.inpe.br/cursos/ser301/referencias/Renato_et_al_TxEpiAbordagemBayesi ana CSP 1998.pdf> Acesso em: 25 dez. 2016.

AYUSO-MATEOS, J. L. et al. Recomendaciones preventivas y manejo del comportamento suicida em España. Revista de Psiquiatría y Salud Mental [online], Santiago, v. 5, n. 1, p. 08-23, 2012. Disponível em: <http://www.elsevier.es/es-revista-revista-psiquiatria-saludmental-286-articulo-recomendaciones-preventivas-manejo-del-comportamiento-

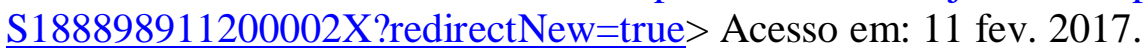

AZAM, M. N et al. Modeling Occurrence of Dengue Cases in Malaysia. Iranian Journal of Public Health [online], Tihrān, v. 45, n. 11, p. 1511-1512, 2016. Disponível em: <https://www.ncbi.nlm.nih.gov/pmc/articles/PMC5182261/> Acesso em: 29 mar. 2018.

BABALOLA, O.; RAZZAQUE A.; BISHAI, D. Temperature extremes and infant mortality in Bangladesh: Hotter months, lower mortality. PLoS ONE [online], San Francisco, v. 13, n. 1, 2018. Disponível em: <http://journals.plos.org/plosone/article?id=10.1371/journal.pone.0189252 > Acesso em: 29 mar. 2018. 
BAILEY, T. C. Spatial statistical methods in health. Cadernos de Saúde Pública [online], Rio de Janeiro, v. 17, n. 5, p.1083-1098. 2001. Disponível em: $<$ http://www.scielosp.org/scielo.php?pid=S0102311X2001000500011\&script=sci_arttext $>$ Acesso em: 15 fev. 2017.

BAKER, J.; MCPHEDRAN, S. Australian Firearm Related Deaths: New Findings and Implications for Crime Prevention and Health Policies following revisions to Official Death Count Data. International Journal of Criminal Justice Sciences [Online], v. 10, n. 1, p. 1-9. Disponível em: 〈http://www.sascv.org/ijcjs/pdfs/bakersamaraijcjs2015vol10issue1.pdf> Acesso em: 16 jan. 2018.

BAKHIYI, C. L. J. Positive and negative life events and reasons for living modulate suicidal ideation in a sample of patients with history of suicide attempts. Psychiatry Research [online], Amsterdam, v. 1, n, 88, p. 64-71, 2017. Disponível em:

<http://www.journalofpsychiatricresearch.com/article/S0022-3956(16)308718/abstract> Acesso em: 14 fev. 2017.

BANDO, D. H. et al. Spatial clusters of suicide in the municipality of São Paulo 1996-2005: an ecological study. BMC Psychiatry [online], London, v. 12, n. 124, p. 01-08, 2012. Disponível em: <https://www.ncbi.nlm.nih.gov/pmc/articles/PMC3496688/> Acesso em: 12 dez. 2016

BANDO, D. H.; LESTER, D. An ecological study on suicide and homicide in Brazil. Ciência \& Saúde Coletiva [online], Rio de Janeiro, v. 19, n. 4, p. 1179-1189. 2014. Disponível em: <https://www.ncbi.nlm.nih.gov/pubmed/24820601> Acesso em: 31 dez. de 2016.

BARBOZA, G. E. The geography of child maltreatment: a spatiotemporal analysis usingbayesian hierarchical analysis with integrated nested laplace approximation. Journal of Interpersonal Violence [online], Barcelona, 2016. Disponível em: $<$ https://www.ncbi.nlm.nih.gov/pubmed/?term=The+Geography+of+Child+Maltreatment $\% 3 \mathrm{~A}+\mathrm{A}+$ Spatiotemporal+Analysis+Using+Bayesian+Hierarchical+Analysis+With+Integrate d+Nested+Laplace+Approximation> Acesso em: 28 fev. 2017.

BARROSO, C. M. R.; FERREIRA NETO, J. V. Identificação e hierarquização de áreas que concentram População jovem vulnerável à violência letal no estado de Alagoas, Brasil 2004/2012. In. XVI Safety, Health and Environment World Congress. Jul. 2016. Anais... Salvador, Brasil. Disponível em: 〈http://copec.eu/congresses/shewc2016/proc/works/4.pdf〉. Acesso em: 18 fev. 2017.

BEAUTRAIS, A. et al. Effective strategies for suicide prevention in New Zealand: a review of the evidence. New Zealand Medical Journal [online], v. 23, n. 1251, p. 01-13, 2007. Disponível 
em: $<$ http://citeseerx.ist.psu.edu/viewdoc/download?doi=10.1.1.564.6382\&rep=rep1\&type=pd f> Acesso em: 10 fev. 2017.

BECKER, J. N.; NERO, M. A. Avaliação da aplicação dos estimadores bayesianos Empíricos na determinação das áreas de risco de Transmissão da malária. In. V Simpósio Brasileiro de Ciências Geodésicas e Tecnologias da Geoinformação, 6., 2012, Recife. Anais... Recife: UFPE, 2014. p. 002-0010. Disponível em: <https://www.ufpe.br/cgtg/SIMGEOIV/CD/artigos/SIG/118 5.pdf> Acesso em: 14 fev. 2017.

BERNAL, J. L.; CUMMINS, S.; GASPARRINI, A. Interrupted time series regression for the evaluation of public health interventions: a tutorial. International Journal of Epidemiology [online], London, v. 46, n. 1, p. 348-355, 2017. Disponível em: <https://www.ncbi.nlm.nih.gov/pmc/articles/PMC5407170/> Acesso em: 29 mar. 2018.

BERTOLOTE, J. M. O suicídio e sua prevenção. 1 ed. São Paulo: Unesp, 2012, 15 p.

BERTOLOTE, J. M; MELLO-SANTOS, C.; BOTEGA, N. J. Detecção do risco de suicídio nos serviços de emergência psiquiátrica. Revista Brasileira de Psiquiatria [online], São Paulo, v. 32, n. 2, p. 87-95, 2010. Disponível em: <http://www.scielo.br/scielo.php?script=sci_arttext\&pid=S1516-44462010000600005> Acesso em: 31 dez. 2016.

BEZERRA FILHO, J. G.et al. Estudo ecológico sobre os possíveis determinantes socioeconômicos, demográficos e fisiográficos do suicídio no estado do Rio de Janeiro, Brasil, 1998-2002. Cadernos de Saúde Pública [online], Rio de Janeiro, v. 28, n. 5, p. 833844, 2012. Disponível em: <http://www.scielo.br/scielo.php?script=sci_arttext\&pid=S0102311X2012000500003> Acesso em: 31 dez. 2016.

BOTEGA, N. J. Comportamento Suicida: epidemiologia. Psicologia USP, São Paulo, v. 25, n. 3, p. 231-236, 2014. Disponível em:

<http://www.scielo.br/scielo.php?script=sci_arttext\&pid=S0103-65642014000300231> Acesso em: 28 dez. 2016.

BOTEGA, N. J. Crise Suicida: avaliação e manejo. 1 ed. Porto Alegre: Ed. Artmed, 2015, 12 p.

BOX, G. E. P.; JENKINS, G. M. Time-series analysis: forecasting and control. San Francisco: Holden-Day, 1976. 
BRAGA, G. B.; MARQUES, M. A.; BRAGA, B. B. Análise da distribuição espacial das estruturas voltadas à atenção primária à saúde do sudeste brasileiro. Revista Espaço para a Saúde [online], Londrina, v. 16, n. 3, p. 14-26, 2015. Disponível em:

<http://www.uel.br/revistas/uel/index.php/espacoparasaude/article/view/20728/17267> Acesso em: 10 fev. 2017.

BRAGA, L.; DELL'AGLI D, D. Suicídio na adolescência: fatores de risco, depressão e gênero. Contextos Clínicos [Online], São Leopoldo, v. 6, n. 1, p. 02-14, 2013. Disponível em: 〈http://revistas.unisinos.br/index.php/contextosclinicos/article/view/ctc.2013.61.01〉 Acesso em: 13 fev. 2017.

BRANAS, B. B et al. The impact of economic austerity and prosperity events on suicide in Greece: a 30-year interrupted time-series analysis. BMJ Open [online], London, v. 1, n. 1, 2015. Disponível em: 〈http://bmjopen.bmj.com/content/5/1/e005619> Acesso em: 29 mar. 2018.

BRASIL. Ministério da Saúde. Secretaria de Atenção à Saúde. Departamento de Ações Programáticas Estratégicas. Agenda de Ações Estratégicas para a Vigilância e Prevenção do Suicídio e Promoção da Saúde no Brasil: 2017 a 2020. Brasília, DF. 1 ed. 2017a. Disponível em: <http://www.neca.org.br/wp-content/uploads/cartilha agenda-estrategicapublicada.pdf> Acesso em: 29 mar. 2018

BRASIL. Ministério da Saúde. Secretaria de Vigilância em Saúde. Suicídio: Saber, agir e prevenir. Brasília, DF. v. 48, n 30. 2017b. Disponível em: $<$ http://portalarquivos2.saude.gov.br/images/pdf/2017/setembro/21/2017-025-Perfilepidemiologico-das-tentativas-e-obitos-por-suicidio-no-Brasil-e-a-rede-de-atencao-asaude.pdf> Acesso em: 29 mar. 2018

BRASIL. Ministério da Saúde. Secretaria de Vigilância em Saúde. Departamento de Vigilância de Doenças e Agravos Não Transmissíveis e Promoção da Saúde. Saúde Brasil 2014: uma análise da situação de saúde e das causas externas. Brasília, DF. 1 ed. 2015a.

BRASIL. Departamento de Informática do SUS. TABNET. Estatísticas vitais. 2015b. Disponível em: <http://www2.datasus.gov.br/DATASUS/index.php?area=0205> Acesso em: 11 jan. 2018

BRASIL. Portaria. 1.876, de 14 de agosto de 2006. Institui Diretrizes Nacionais para Prevenção do Suicídio, a ser implantadas em todas as unidades federadas, respeitadas as competências das três esferas de gestão. Diário [Oficial] da República Federativa do Brasil, Brasília, DF, 15 de agosto. Disponível em: <http://bvsms.saude.gov.br/bvs/saudelegis/gm/2006/prt1876_14_08_2006.html $>$ Acesso em: 12 dez. 2016. 
BRAZ, R. M. et al. Spatial dependence of malaria epidemics in municipalities of the Brazilian Amazon. Revista Brasileira de Epidemiologia [online], v. 17, n. 3, p. 615-628, 2014. Disponível em: <http://www.scielosp.org/scielo.php?script=sci_arttext\&pid=S1415790X2014000400615> Acesso em: 16 fev. 2017.

BRAZINOVA, A.et al. Suicide rate trends in the Slovak Republic in 1993-2015. International Journal of Social Psychiatry [online], v. 63, n. 2, p. 161-168, 2017.Disponível em: $<$ https://www.ncbi.nlm.nih.gov/pubmed/?term=Suicide+rate+trends+in+the+Slovak+Rep ublic+in+1993-2015> Acessoem: 17 mar. 2017.

BRZOZOWSKI, F. S. et al. Suicide time trends in Brazil from 1980 to 2005. Cadernos de Saúde Pública [online], Rio de Janeiro, v. 26, n. 7, p. 1293-1302, 2010. Disponível em: <http://www.scielo.br/scielo.php?script=sci arttext\&pid=S0102-311X2010000700008> Acesso em: 10 jan. 2016.

BUUS, N. et al. Experiences of parents whose sons or daughters have (had) attempted suicide. Journal of Advanced Nursing [online], v. 70, n. 4, p. 823-832, 2014. Disponível em: <https://www.ncbi.nlm.nih.gov/pubmed/24020792 > Acessoem: 10 jan. 2018.

CÂMARA, G. et al. Análise espacial e geoprocessamento. In: DRUCK, S. et al. Análise espacial de dados geográficos. Brasília, DF: Embrapa, 2004. Disponível em <http://www.dpi.inpe.br/gilberto/livro/analise/> Acessoem: 18 fev. 2017.

CAMUS, A. O mito de Sísifo. 1 ed. França: Gallimard, 1941, 6 p.

CARROLL, R.; METCALFE, C.; GUNNELL, D. Hospital presenting self-harm and risk of fatal and non-fatal repetition: systematic review and meta-analysis. PLoS One [online], San Francisco, v. 9, n. 2, 2014, Disponível em:

<https://www.ncbi.nlm.nih.gov/pmc/articles/PMC3938547/>Acesso em: 31 dez. 2016.

CAVALCANTE, F.; MINAYO, M. C. S. Estudo qualitativo sobre tentativas e ideações suicidas com 60 pessoas idosas brasileiras. Ciência \& Saúde Coletiva [online], Rio de Janeiro, v. 20, n. 6, p. 1655-1666, 2015. Disponível em:

$<$ http://www.scielo.br/scielo.php?pid=S1413-

81232015000601655\&script=sci_abstract\&tlng=pt $>$ Acesso em: 15 fev. 2017.

CAVICCHIOLI NETO, V. et al. Desenvolvimento e Integração de Mapas Dinâmicos Georreferenciados para o Gerenciamento e Vigilância em Saúde. Journal of Health Informatics [online], São Paulo, v. 6, n. 1, p. 3-9, 2014. Disponível em: <http://www.jhi-sbis.saude.ws/ojs-jhi/index.php/jhi-sbis/article/view/284>Acesso em: 15 fev. 2017. 
CECCON, R. F. et al. Suicídio e trabalho em metrópoles brasileiras: um estudo ecológico.

Ciência \& Saúde Coletiva [online], Rio de Janeiro, v. 19, n. 7, p. 2225-2234, 2014.

Disponível em: <http://www.scielo.br/scielo.php?script=sci_arttext\&pid=S1413-

81232014000702225> Acesso em: 30 dez. 2016.

CHAN, C. H.et al. Changes in South Korean urbanicity and suicide rates, 1992 to 2012. BMJ Open [online], London, v. 5, n. 12, 2015. Disponível em:

<http://bmjopen.bmj.com/content/5/12/e00945> Acesso em: 16 jan. 2018.

CHANG, S. S. et al. Regional Changes in Charcoal-Burning Suicide Rates in East/Southeast Asia from 1995 to 2011: A Time Trend Analysis. PLoS Medicine [online], San Francisco, v. 11, n. 4, 2014. Disponível em:

<http://journals.plos.org/plosmedicine/article?id=10.1371/journal.pmed.1001622> Acesso em: 16 jan. 2018.

CHANG, S, S. et al. The impact of pesticide suicide on the geographic distribution of suicide in Taiwan: a spatial analysis. BMC Public Health[online], London, v. 12, n. 260, 2012.

Disponível em: <https://bmcpublichealth.biomedcentral.com/articles/10.1186/1471-2458-12260> Acesso em: 10 jan. 2017.

CHEN, Y. Y. et al. Spatial analysis of schistosomiasis in hubei province, China: a GIS based analysis of schistosomiasis from 2009 to 2013. PLoS ONE [online], San Francisco, v. 10, n. 4, 2015. Disponível em:

<http://journals.plos.org/plosone/article?id=10.1371/journal.pone.0118362 >Acesso em: 28 fev. 2017.

CHEUNG, Y. T. D. et al. Application of scan statistics to detect suicide clusters in Australia. PLoS ONE [online], San Francisco, v. 8, n. 1, 2013. Disponível em:

$<$ http://journals.plos.org/plosone/article? $\mathrm{id}=10.1371 /$ journal.pone.0054168 > Acesso em: 25 fev. 2017.

CHEUNG, Y. T.; SPITTAL, M. J.;YIP, P. S. Spatial analysis of suicide mortality in Australia: investigation of metropolitan-rural-remote differentials of suicide risk across states/territories. Social Science \& Medicine, New York, n. 75, v. 8, p. 1460-1468, 2012. Disponível em: 〈https://www.ncbi.nlm.nih.gov/pubmed/22771036> Acesso em: 11 jan. 2017.

CONTE, M. et al. Programa de Prevenção ao Suicídio: estudo de caso em um município do sul do Brasil. Ciência \& Saúde Coletiva [online], Rio de Janeiro, v. 17, n. 8, p. 2017-2026, 2012. Disponível em:

<http://www.scielo.br/scielo.php?script=sci_arttext\&pid=S141381232012000800013>Acesso em: 1 mar. 2017. 
CORTÉS-ALFARO, A. Conducta suicida adolescencia y riesgo. Revista Cubana de

Medicina General Integral [online], Ciudad de La Habana, v. 30, n. 1, p. 132-139, 2014.

Disponível em: <http://scielo.sld.cu/scielo.php?script=sci_arttext\&pid=S0864-

21252014000100013> Acesso em: 16 jan. 2018.

COSTA, J. 2013. Representações do Suicídio no Alentejo. Dissertação (Mestrado em psicologia clínica e da saúde). Escola de ciências Sociais. Universidade de Évora. Évora, 2013.

CRIGHTON, E. J. et al. A spatial analysis of COPD prevalence, incidence, mortality and health service use in Ontario. Public Health Report [online], Washington, v. 26, n. 3, p. 1018, 2015. Disponível em: <https://www.ncbi.nlm.nih.gov/pubmed/25785665> Acesso em: 28 fev. 2017.

CUNHA E SILVA, D. et al. Análise da relação entre a distribuição espacial das morbidades por obesidade e hipertensão arterial para o estado de São Paulo, Brasil, de 2000 a 2010. Ciência \& Saúde Coletiva [online], Rio de Janeiro, 2014, v.19, n. 6, p.1709-1719. Disponível em: <http://www.scielo.br/scielo.php?pid=S141381232014000601709\&script=sci_abstract\&tlng=en> Acesso em: 16 jan. 2018.

CURTIN, S.C.; WARNER, M.; EDEGAARD, H. Increase in Suicide in the United States, 1999-2014. National Center for Health Statistics data brief [Online], Hyattsville, n. 241, p. 1-8, 2016. Disponível em: <https://www.cdc.gov/nchs/data/databriefs/db241.pdf> Acesso em: 27 mar. 2018.

DE, P et al. Post Millennium Development Goals Prospect on Child Mortality in India: An Analysis Using Autoregressive Integrated Moving Averages (ARIMA) Model. Scientific Research Publishing [online], v. 8, p. 1845-1872, 2016. Disponível em: <http://www.scirp.org/journal/PaperInformation.aspx?paperID=73140> Acesso em: 29 mar. 2018.

DIAZ-FRUTOS, D. et al. Suicide ideation among oncologic patients in a Spanish ward. Psychology, Health \& Medicine [online], v. 12, n. 3, p. 261-221, 2015. Disponível em: <https://www.ncbi.nlm.nih.gov/pubmed/26109239> Acesso em: 12 fev. 2017.

DOGRU, A. O. et al. GIS based spatial pattern analysis: Children with Hepatitis A in Turkey. Environmental Research [online], New York, v. 156, p. 349-357, 2017. Disponível em: $<$ https://www.sciencedirect.com/science/article/pii/S0013935117306114> Acesso em: 16 jan. 2018.

DURKHEIM, É. O Suicídio: estudo de sociologia. 1 ed. São Paulo: Edipro, ([1897] 2014), 124-130p. 
ERLANGSEN A.; STENAGER E.; CONWELL Y. Physical diseases as predictors of suicide in older adults: a nationwide, register-based cohort study. Social Psychiatry and Psychiatric Epidemiology [online], Berlin, v. 50, n. 9, p. 1427-1439, 2015. Disponível em: <https://www.ncbi.nlm.nih.gov/pubmed/25835959> Acesso em: 16 jan. 2018.

FERGUSON, W. J.; KEMP, K.; KOST, G.Using a geographic information system to enhance patient access to point-of-care diagnostics in a limited-resource setting. International Journal of Health Geographics [online], London, v. 15, n. 10, 2016. Disponível em: <https://www.ncbi.nlm.nih.gov/pmc/articles/PMC4774034/> Acesso em: 25 fev. 2017.

FERREIRA, V. L. P. O suicídio e a eutanásia. Lusíada. Direito (Porto), Lisboa, n. 4, p. 257 266, 2015. Disponível em: 〈http://revistas.lis.ulusiada.pt/index.php/ldp/article/view/2062> Acesso em: 02 de jan. 2017.

FINDLAY, L. Depression and suicidal ideation among Canadians aged 15 to 24. Public Health Report [online], Washington, v. 28, n. 1, p. 03-11, 2017. Disponível em: <https://www.ncbi.nlm.nih.gov/pubmed/28098916> Acesso em: 24 jan. 2017.

FOND, G. et al. Disparities in suicide mortality trends between United States of America and 25 European countries: retrospective analysis of WHO mortality database. Scientific Reports [online], London, v. 6. n. 20256, 2016. Disponível em: <https://www.ncbi.nlm.nih.gov/pmc/articles/PMC4756707/> Acessoem: 24 jan. 2018.

FONTANELLA C.A. et al. Widening Rural-Urban Disparities in Youth Suicides, United States, 1996-2010. JAMA Pediatrics [online], Chicago, v. 169, n. 169, p. 466-473,2015. Disponível em: <https://www.ncbi.nlm.nih.gov/pmc/articles/PMC4551430/> Acesso em: 24 jan. 2018.

FOWLER, K. A et al. Surveillance for Violent Deaths - National Violent Death Reporting System, 18 States, 2014. MMWR Surveill Summ [online], Atlanta, v. 2, n. 67, p. 1-36, 2018. Disponível em:<https://www.ncbi.nlm.nih.gov/pubmed/29389917> Acesso em: 24 jan. 2018.

GARCIA, M. C. C. et al. Hospitalizations and re-Hospitalizations Due to Tuberculosis: Economic Costs and Spatial Distribution Analysis in an Endemic Northeastern City, Brazil. International Archives of Medicine [online], London, v. 9, n. 333, 2016. Disponível em: <http://imed.pub/ojs/index.php/iam/article/view/2009> Acesso em: 14 fev. 2017.

GLATT, R. Análise da qualidade da base de dados de aids do Sistema de Informação de Agravos de Notificação (SINAN). Dissertação (Mestrado profissional em vigilância em saúde). Escola nacional de saúde pública ENSP/Fiocruz. São Paulo, 2005. 
GONÇALVES, L. R. C.; GONÇALVES, E; OLIVEIRA JUNIOR, L. B. Determinantes espaciais e socioeconômicos do suicídio no Brasil: uma abordagem regional. Nova economia [online], Belo Horizonte, v. 21, n. 2, p. 281-316, 2011. Disponível em: <http://www.scielo.br/scielo.php?script=sci_arttext\&pid=S0103-63512011000200005> Acesso em: 31 dez. 2016.

GUIMARÃES, R. B. Geografia e saúde coletiva no Brasil. Saúde e Sociedade [online], São Paulo, v. 25, n. 4, p. 869-879, 2016. Disponível em:

$<$ http://www.scielo.br/scielo.php?pid=S0104-

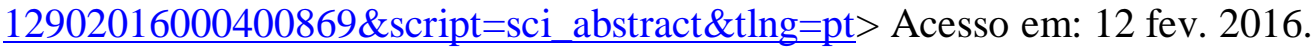

GUJARATI, D. N.; PORTER, D. C. Ecometria Básica. 5 ed. Porto Alegre: AMGH Editora, 2011.

HAGAMAN, A. K; MAHARJAN, U; KOHRT, B. A. Suicide surveillance and health systems in Nepal: a qualitative and social network analysis. International Journal of Mental Health Systems [online], London, v. 10, n. 46, 2016. Disponível em:

<https://ijmhs.biomedcentral.com/articles/10.1186/s13033-016-0073-7> Acesso em: 25 fev. 2018.

HERNÁNDEZ-ÁVILA, J. E. et al. Nation-Wide, Web-Based, Geographic Information System for the Integrated Surveillance and Control of Dengue Fever in Mexico. PLoS ONE [online], San Francisco, v. 9, n. 1, 2013. Disponível em:

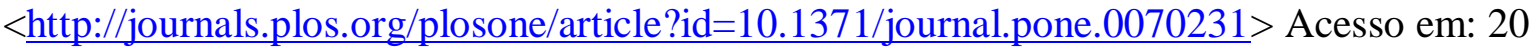
fev. 2017.

HONG J.; KNAPP M. Geographical inequalities in suicide rates and area deprivation in South Korea. The Journal of Mental Health Policy and Economics [online], Milano, v. 16, n. 3, 109-119, 2013. Disponível em: 〈https://www.ncbi.nlm.nih.gov/pubmed/24327481> Acesso em: 16 jan. 2018.

HSU, C. Y. Geography of suicide in Hong Kong: spatial patterning, and socioeconomic correlates and inequalities. Social Science \& Medicine [online], New York, v. 130, p. 190203, 2015. Disponível em: <http://www.sciencedirect.com/science/article/pii/S0277953615001021> Acesso em: 24 fev. 2017.

IBGE. Instituto Brasileiro de Geografia e Estatística. IBGE Estados 2016. Disponível em: <http://www.ibge.gov.br/estadosat/perfil.php?sigla=pe>

Acesso em: 10 jan. 2017. 
JOHNSON, A. M. Spatial Patterns and Neighborhood Characteristics of Overall Suicide Clusters in Florida From 2001 to 2010. American Journal Preventive Medicine [online], New York, v. 52, n. 1, p. 01-07, 2017. Disponível em:

<https://www.ncbi.nlm.nih.gov/labs/articles/27692756/> Acesso em: 25 fev. 2017.

JONES, P. et al. Identifying probable suicide clusters in wales using national mortality data. PLoS One [online], San Francisco, v. 8, n. 8, 2013. Disponível em:

<https://www.ncbi.nlm.nih.gov/pubmed/24015189> Acesso em: 15 fev. 2017.

JOO, Y. Spatiotemporal study of elderly suicide in Korea by age cohort. Public Health [online], Weinheim, v. 142, p. 144-151, 2017. Disponível em:<https://www.ncbi.nlm.nih.gov/pubmed/27613224> Acessado em: 28 fev. 2017.

JOUBERT, J. et al. Evaluating the Quality of National Mortality Statistics from Civil Registration in South Africa, 1997-2007. T, PLo SONE [online], San Francisco, v. 8, n. 5, 2013. Disponível em:

<https://www.ncbi.nlm.nih.gov/pmc/articles/PMC3664567/> Acesso em: 30 jan. 2018.

KANE, M. J. et al. Comparison of ARIMA and Random Forest time series models for prediction of avian influenza H5N1 outbreaks. BMC Bioinformatics [online], London, v. 15, p. 276, 2014. Disponível em:

$<$ https://bmcbioinformatics.biomedcentral.com/articles/10.1186/1471-2105-15-276 >Acesso em: 29 mar. 2018.

KANGAVARI, H. N.; SHOJAEI, A; NAZARI, S. S. Suicide Mortality Trends in Four Provinces of Iran with the Highest Mortality, from 2006-2016. Journal of research in health sciences [online], Hamadãn, v. 17, n. 2, p. 1-9, 2017. Disponível em:

<http://jrhs.umsha.ac.ir/index.php/JRHS/article/view/3149/pdf > Acesso em: 29 mar. 2018.

KAWAGUCHI, H.; KOIKE, S. Association between the Density of Physicians and Suicide Rates in Japan: Nationwide Ecological Study Using a Spatial Bayesian Model. PLoS One [online], San Francisco, v.11, n. 2, 2016. Disponível em:

<https://www.ncbi.nlm.nih.gov/pmc/articles/PMC4740411/> Acesso em: 28 fev.2017.

KEGLER, S. R.; STONE, D. M.; HOLLAND, K. M. Trends in Suicide by Level of Urbanization - United States, 1999-2015. Morbidity and Mortality Weekly Report [online], Atlanta, v. 66, n. 10, p. 270-273, 2017. Disponível em: <https://www.cdc.gov/mmwr/volumes/66/wr/mm6610a2.htm> Acesso em: 16 jan. 2018. 
KHAZAEI, S. et al. Suicide rate in relation to the Human Development Index and other health related factors: A global ecological study from 91 countries. Journal of Epidemioly and Global Health [online], Amsterdam, v. 16, n. 7, p. 131-134, 2017. Disponível em: <https://www.ncbi.nlm.nih.gov/pubmed/28188120> Acesso em: 13 fev. 2017.

KIADALIRI, A. A. et al. Overall, gender and social inequalities in suicide mortality in Iran, 2006-2010: a time trend province-level study. BMJ Open [online], London, v. 4, n. 8, 2014. Disponível em: 〈http://bmjopen.bmj.com/content/4/8/e005227> Acesso em: 16 jan. 2018.

KIM, S. Y. K.; VRIES, R. G.; PETEET, J. R. P. Euthanasia and assisted suicide of patients with psychiatric disorders in the nether lands 2011 to 2014. JAMA Psychiatry [online], Chicago, v. 73, n. 3, p. 362-368, 2016. Disponível em: <https://jamanetwork.com/journals/jamapsychiatry/fullarticle/2491354> Acesso em: 16 jan. 2018 .

KIRBY, R. S.; DELMELLE, E.; EBERTH, J. M. Advances in spatial epidemiology and geographic information systems. Annals Epidemioly [online], New York, v. 27, n. 1, p. 1-9, 2017. Disponível em: <http://www.annalsofepidemiology.org/article/S1047-2797(16)304951/abstract> Acesso em: 24 fev. 2017.

KLONSKY, E. D.; MAY, A. M. Differentiating Suicide Attempters from Suicide Ideators: A Critical Frontier for Suicidology Research. Suicide and Life-Threatening Behavior [online], New York, v. 44, n. 1, 2014. Disponível em: <https://www.ncbi.nlm.nih.gov/pubmed/24313594> Acesso em: 12 fev. 2017.

KNIPE, D. W. et al. Reginal variation in suicide rates in Sri Lanka between 1995 and 2011. a spatial and temporal analysis. BMC Public Health [online], London, v. 17, n. 1, 2017. Disponível em: <https://www.ncbi.nlm.nih.gov/pmc/articles/PMC5310090/> Acesso em: 17 jan. 2018.

KNIPE, D. W. et al. Suicide in Sri Lanka 1975-2012: age, period and cohort analysis of police and hospital data. BMC Public Health [online], London, v. 14, 2014. Disponível em: <https://www.ncbi.nlm.nih.gov/pmc/articles/PMC4148962/> Acessoem: 16 jan. 2018.

KOLIFARHOOD, G. et al. Spatial and non-spatial determinants of successful tuberculosis treatment outcomes: An implication of Geographical Information Systems in health policymaking in a developing country. Journal of Epidemioly Global Health [online], Amsterdam, v. 5, n. 3, p. 221-230, 2015. Disponível em: <https://www.ncbi.nlm.nih.gov/pubmed/26231398> Acesso em: 24 fev. 2017. 
LAIDO, Z. et al. Epidemiology of suicide among children and adolescents in Austria, 20012014. Wien Klin Wochenschr [online], v. 129, n. 3, p. 121-128, 2017. Disponível em: <https://www.ncbi.nlm.nih.gov/pubmed/27743176> Acesso em: 17 mar. 2017.

LASLETT, A. M.; JIANG, H.; CHIKRITZHS, T. Child injury deaths linked with adult alcohol consumption: A time series analysis. Drug and Alcohol Dependence [Online], Lausana, v. 185, p. 360-366, 2018. Disponível em: <https://www.sciencedirect.com/science/article/pii/S0376871618300152> Acesso em: 16 mar. 2018.

LATORRE, M. R.; CARDOSO, M. R. Análise de séries temporais em epidemiologia: uma introdução sobre os aspectos metodológicos. Revista Brasileira de Epidemiologia [online], São Paulo, v. 4, n. 3, p. 145-152, 2001. Disponível em:

$<$ http://www.scielo.br/scielo.php?pid=S1415-

790X2001000300002\&script=sci_abstract\&tlng=pt > Acesso em: 29 mar. 2018.

LIMA, R. C.; MOREIRA, E. B.; NÓBREGA, R. S. A influência climática sobre a epidemia dengue na cidade do Recife por Sistema de Informações Geográficas. Revista Brasileira de Geografia Física [online], Recife, v. 9, n. 2, p. 384-398, 2016. Disponível em: <http://www.revista.ufpe.br/rbgfe/index.php/revista/article/view/1398/930> Acesso em: 24 fev. 2017.

LIN, Y. et al. Application of an autoregressive integrated moving average model for predicting injury mortality in Xiamen, China. BMJ Open [online], London, v. 5, n. 12, 2015. Disponível em: <http://bmjopen.bmj.com/content/5/12/e008491> Acesso em: 29 mar. 2018.

LIU, B. P.; WANG, X. T.; JIA, C. X Suicide attempters with high and low suicide intent: Different populations in rural China. Psychiatry Research [online], Amsterdam, v. 8, n. 251, p. 176-181, 2017. Disponível em: 〈https://www.ncbi.nlm.nih.gov/pubmed/28213187> Acesso em: 28 fev. 2017.

LIU, Q. et al. Forecasting incidence of hemorrhagic fever with renal syndrome in China using ARIMA model. BMC Infectious Diseases [online], London, v. 11, n. 218, 2011. Disponível em: <https://bmcinfectdis.biomedcentral.com/articles/10.1186/1471-2334-11-218 >Acesso em: 29 mar. 2018.

MACENTE, L. B; ZANDONADE, E. Spatial distribution of suicide incidence rates in municipalities in the state of Espírito Santo (Brazil), 2003-2007: spatial analysis to identify risk areas. Revista Brasileira de Psiquiatria, São Paulo [online], v. 34, v. 3, p. 261-269, 2012. Disponível em: <http://www.scielo.br/scielo.php?script=sci_arttext\&pid=S151644462012000300005> Acesso em: 16 jan. 2018. 
MACHADO, D. B.; SANTOS, D. N. Suicídio no Brasil, de 2000 a 2012.Jornal Brasileiro de Psiquiatria [online], Rio de Janeiro, v. 64, n. 1, p. 45-54, 2015. Disponível em: <http://www.scielo.br/scielo.php?script=sci_arttext\&pid=S0047-20852015000100045> Acesso em: 30 dez. 2016.

MARÍN-LEÓN, L.; OLIVEIRA, H. B.; BOTEGA, N. J. Suicide in Brazil, 2004-2010: the importance of small counties. Revista Panamericana de Salud Pública [online], Washington, v. 32, n. 5, p. 351-359, 2012. Disponível em: <https://www.ncbi.nlm.nih.gov/pubmed/23338692> Acesso em: 30 dez. 2016.

MARQUES, A. P. S. et al. Análise exploratória de dados de área para índices de furto na mesorregião de Presidente Prudente-SP. In: III Simpósio Brasileiro de Ciências Geodésicas e Tecnologias da Geoinformação. 2010, Recife. Anais... Recife: SBCGTG, 2010. Disponível em:

<https://www.ufpe.br/cgtg/SIMGEOIII/IIISIMGEO_CD/artigos/CartografiaeSIG/SIG/A_223. pdf> Acesso em: 10 fev. 2017.

MARTINS-JUNIOR, D. F. et al. Suicide attempts in Brazil, 1998-2014: an ecological study. BMC Public Health [online], London, v. 16, n. 990, 2016. Disponível em:

<https://www.ncbi.nlm.nih.gov/pmc/articles/PMC5025588/> Acesso em: 10 jan. 2017.

MATTHAY, E. C.; GALIN, J.; AHERN, J. Changing Patterns in Rates and Means of Suicide in California, 2005 to 2013. American Journal Public Health [online], New York, v. 107, n. 3, p 427-429, 2017. Disponível em:

<https://www.ncbi.nlm.nih.gov/pubmed/28177819> Acesso em: 16 jan. 2018.

MCLOUGHLIN, A. B.; GOULD, M. S.; MALONE, K. M. Global trends in teenage suicide: 2003-2014. The Quarterly Journal of Medicine [online], Oxford, v. 108, n. 10, p. 765-780, 2015. Disponível em:

<https://www.ncbi.nlm.nih.gov/pubmed/?term=Global+trends+in+teenage+suicide $\% 3 \mathrm{~A}+200$ 3\%E2\%80\%932014> Acesso em: 17 mar. 2017.

MCPHEDRAN, S.; BAKER, J. Suicide Prevention and Method Restriction: Evaluating the Impact of Limiting Access to Lethal Means Among Young Australians. Archives of suicide research [online], London, v. 16, n. 2, p. 135-146, 2012. Disponível em:

<https://www.ncbi.nlm.nih.gov/pubmed/22551044> Acesso em: 29 mar. 2018.

MELEIRO, A. M. A. S. Atendimento de pacientes com comportamento suicida na prática médica. Revista Brasileira de Medicina [online], Rio de Janeiro, v. 70, n. 4, p. 22-27, 2013. Disponível em: <http://www.moreirajr.com.br/revistas.asp?fase $=$ r003\&id_materia=5659> Acesso em: 24 fev. 2017. 
MELO, G. B. T.; ALVES, S. V.; LIMA, M. L. C. Mortalidade por causas externas em Pernambuco, 2001-2003 e 2011-2013. Revista Brasileira de Enfermagem [online], Brasília, v. 68 , n. 5, p. 855-861. Out. 2015 set. Disponível em:

<http://www.scielo.br/scielo.php?script=sci_arttext\&pid=S0034-71672015000500855>

Acesso em: 24 fev. 2017.

MENDONÇA, F.; ARAÚJO, W. M.; FORGAÇA, T. K. A geografia da saúde no Brasil: Estado da arte e alguns desafios. Investigaciones Geográficas [online], Santiago, v. 48, p. 41-52, 2014. Disponível em:

$<$ http://www.investigacionesgeograficas.uchile.cl/index.php/IG/article/viewFile/36675/38269

$>$ Acesso em: 14 fev. 2017.

MINAYO, M.C.S. et al. Tendência da mortalidade por suicídio na população brasileira e idosa, 1980-2006. Revista de Saúde Pública [online], São Paulo, v. 46, n. 2, p. 300-309, 2012. Disponível em: <http://pesquisa.bvsalud.org/portal/resource/pt/lil-618478> Acesso em: 30 dez. 2016.

MIRANDA, M. J.et al. Associação espacial entre variáveis socioeconômicas e risco relativo de nascimentos pré-termo na Região Metropolitana de São Paulo (RMSP) e na Área Metropolitana de Lisboa (AML). Saúde e Sociedade [online], São Paulo, v.23, n.4, p.11421153, 2014. Disponível em: 〈http://www.revistas.usp.br/sausoc/article/view/104283/102924> Acesso em: 15 fev. 2017.

MORGENSTERN, H. Ecologic Studies in Epidemiology: Concepts, Principles, and Methods. Annual Review of Public Health [online], Palo Alto, v. 16. P. 61-81, 1995. Disponível em: $<$ https://www.ncbi.nlm.nih.gov/pubmed/?term=Ecologic+Studies+in+Epidemiology\%3A+Co ncepts\%2C+Principles\%2C+and+Methods > Acesso em: 28 fev. 2017.

MÜLLER, S. A.; PEREIRA, G.; ZANON, R. B. Prevention and postvention strategies of the suicide: Study with professionals of a Center of Psychosocial Attention. Revista de Psicologia da IMED [online], Passo Fundo, v. 9, n. 2, p. 6-23, 2017. Disponível em: <https://seer.imed.edu.br/index.php/revistapsico/article/viewFile/1686/1500> Acesso em: 14 mar. 2018.

MURAD, A. A. Using geographical information systems for defining the accessibility to health care facilities in Jeddah City, Saudi Arabia. Geospatial Health [online], v. 1, n. 3, p. 661-669, 2014. Disponível em: 〈https://www.ncbi.nlm.nih.gov/pubmed/25599637> Acesso em: 25 fev. 2017.

NARDI, S.M. T. et al. Geoprocessamento em Saúde Pública: fundamentos e aplicações.

Revista do Instituto Adolfo Lutz [online], São Paulo, v. 72, n. 3, p. 185-91, 2013. Disponível em: <http://189.126.110.61/rialutz/article/view/22284> Acesso em: 13 fev. 2017. 
NGUI, A. N. et al. Spatial analysis of suicide mortality in Québec: spatial clustering and area factor correlates. Psychiatry Research [online], Amsterdam, v. 220, n. 1-2, p. 20-30, 2014. Disponível em: 〈http://www.psy-journal.com/article/S0165-1781(14)00612-X/abstract> Acesso em: 10 jan. 2017.

NGWA, M. C. Cholera in Cameroon, 2000-2012: Spatial and Temporal Analysis at the Operational (Health District) and Sub Climate Levels. PLOS Neglected Tropical Diseases [online], San Francisco, v. 10, n. 11, 2016. Disponível em: <https://www.ncbi.nlm.nih.gov/pubmed/27855171> Acesso em: 24 fev. 2017.

NOCK, M. K. et al. Prevalence, correlates, and treatment of lifetime suicidal behavior among adolescents: results from the National Comorbidity Survey Replication Adolescent Supplement. JAMA Psychiatry [online], Chicago, v. 70, n. 3, p. 300-310, 2013. Disponível em: 〈https://www.ncbi.nlm.nih.gov/pubmed/23303463> Acesso em: 10 jan. 2017.

NORSTRÖM, T.; GRÖNQVIST, H. The Great recession, unemployment and suicide. Journal of Epidemiology and Community Health [online], London, 2015. Disponível em: <http://jech.bmj.com/content/early/2014/10/21/jech-2014-204602> Acesso em: 29 mar. 2018.

NORSTRÖM, T.; STICKLEY, A.; SHIBUYA, K. The importance of alcoholic beverage type for suicide in Japan: A time-series analysis, 1963-2007. Drug and Alcohol Review [online], v. 23, p. 251-256, 2012. Disponível em:

<https://onlinelibrary.wiley.com/doi/abs/10.1111/j.1465-3362.2011.00300.x > Acesso em: 29 mar. 2018.

O’CARROL, P. W. et al. Public Health Informatics and Information Systems. 2003. 21: 432-463.

OKA, M. et al. Analysis of the impact of geographical characteristics on the suicide rate and visualization of the result by GIS (Geographic Information System). Psychiatry and Clinical Neurosciences, [online], Berlin, v. 69, n. 6, p. 375-382, 2015. Disponível em: <https://www.ncbi.nlm.nih.gov/pubmed/25384900> Acesso em: 15 fev. 2017.

O'NEILL, S. et al. Factors Associated with Suicide in Four Age Groups: A Population Based Study. Archives of Suicide Research [online], London, 2017. Disponível em:<https://www.ncbi.nlm.nih.gov/pubmed/28166461> Acesso em: 28 fev. 2017.

ORELLANA, J. D. et al. Spatial-temporal trends and risk of suicide in Central Brazil: an ecological study contrasting indigenous and non-indigenous populations. Revista Brasileira de Psiquiatria [online], São Paulo, n. 38, v. 3, p. 222-230, 2016. Disponível em: $\langle$ http://www.scielo.br/scielo.php?script=sci arttext\&pid=S1516-44462016000300222 $>$ Acesso em: 26 fev. 2017. 
ORES, L. C. et al. Risco de suicídio e comportamentos de risco à saúde em jovens de 18 a 24 anos: um estudo descritivo. Cadernos de Saúde Pública [online], Rio de Janeiro, v. 28, n. 2, p. 305-312, 2012. Disponível em:

<http://www.scielo.br/scielo.php?script=sci_arttext\&pid=S0102311X2012000200009>

Acesso em: 31 dez. 2016.

ÖZDEMIR, R et al. Reliable mortality statistics for Turkey: Are we there yet? BMC Public Health [online], London, v. 15, n. 545, 2015. Disponível em:

<https://www.ncbi.nlm.nih.gov/pubmed/26058703> Acesso em: 12 jan. 2018.

\section{PAN AMERICAN HEALTH ORGANIZATION. Suicide Mortality in the Americas:}

Regional Report. 2014. Disponível em:

$<$ http://www.paho.org/hq/index.php?option=com_content\&view=article\&id=10114\%3A2014 -new-paho-report-more-than-7-suicides-per-hour-in-the-americas\&Itemid=1926\&lang=en> Acesso em: 17 mar. 2017.

PELTZER, K.; PENGPID, S. Early Substance Use Initiation and Suicide Ideation and Attempts among School-Aged Adolescents in Four Pacific Island Countries in Oceania.

International Journal of Environmental Research and Public Health [online], Basileia, v. 12, n. 10, p. 12291-12303, 2015. Disponível em:

<https://www.ncbi.nlm.nih.gov/pubmed/26437423> Acesso em: 26 de fev. 2017.

PEREIRA, R. A.; ALVES-SOUZA, R. A.; VALE, T. S. O processo de transição epidemiológica no Brasil: uma revisão de literatura. Revista Científica FAEMA [online], Ariquemes, v. 6, n. 1, p. 99-108, 2015. Disponível em:

$<$ http://www.faema.edu.br/revistas/index.php/Revista-FAEMA/article/view/322> Acesso em: 15 fev. 2017.

PÉREZ-COSTILLAS, L.et al. Clusters de casos de suicídio espacio-temporal em lacomunidad de Antequera (España). Revista de Psiquiatría y Salud Mental[online], Santiago, v. 8, n. 26, p. 26-34, 2015. Disponível em: <http://www.elsevier.es/es-revistarevista-psiquiatria-salud-mental-286-articulo-clusters-casos-suicidio-espacio-temporalcomunidad-S1888989114000421>. Acesso em: 14 fev. 2017.

PHILLIPS, J. A. Factors associated with temporal and spatial patterns in suicide rates across U.S. states, 1976-2000. Demography [online], Washington, v. 50, n. 2, p. 591-614, 2013. Disponível em: <https://www.ncbi.nlm.nih.gov/pubmed/23196429> Acesso em: 28 fev. 2017.

PINEL, P. Traitémédico-philosophique sur l'aliénationmentale, ou La manie. Paris: Richard, Cailleet Ravier, 1801. Disponível em: <https://books.google.com.br/books?id=OT1FAAAAcAAJ\&printsec=frontcover\&hl=pt-

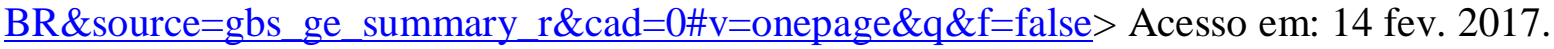


PINTO, L. W. et al. Fatores associados com a mortalidade por suicídio de idosos nos municípios brasileiros no período de 2005-2007. Ciência \& Saúde Coletiva [online], Rio de Janeiro, v. 17, n. 8, p. 2003-2009, 2012. Disponível em:

<http://www.scielo.br/scielo.php?script=sci_arttext\&pid=S1413-81232012000800011 >

Acesso em: 31 dez. 2016.

PIUVEZAM, G. et al. Mortalidade em Idosos por Doenças Cardiovasculares: Análise Comparativa de Dois Quinquênios. Arquivos Brasileiros de Cardiologia[online], São Paulo, n. 105, v. 4, p. 371-380, 2015. Disponível em: $<$ http://www.scielo.br/pdf/abc/2015nahead/pt_0066-782X-abc-20150096.pdf $>$ Acesso em: 21 fev. 2016.

PORTA, M. A dictionary of epidemiology. 6th ed. New York: Oxford University Press; 2014.

PRETI A.; LENTINI G. Forecast models for suicide: Time-series analysis with data from Italy. Chronobiology international [online], London, v. 33, n. 9, p. 1235-1246, 2016. Disponível em:

<https://www.ncbi.nlm.nih.gov/pubmed/27484712> Acesso em: 29 mar. 2018.

PRIDEMORE, W. A.; CHAMLIN M. B.; ANDREEV, E. Reduction in Male Suicide Mortality Following the 2006 Russian Alcohol Policy: An Interrupted Time Series Analysis. American Journal of Public Health [online], Washington, v. 103, n. 11, p 2021-2026, 2013. Disponível em:<https://www.ncbi.nlm.nih.gov/pubmed/24028249> Acesso em: 29 mar. 2018.

QADDUMI, J. A et al. Quality of death notification forms in North West Bank/Palestine: a descriptive study. BMC Research Notes [online], London, v. 10, n. 1, p. 154, 2017.

Disponível em: <https://www.ncbi.nlm.nih.gov/pmc/articles/PMC5387246/> Acesso em: 12 jan. 2018.

QI, X. et al. Socio-environmental drivers and suicide in Australia: Bayesian spatial analysis. BMC Public Health [online] London, v. 14, n. 681, 2014. Disponível em:

<https://bmcpublichealth.biomedcentral.com/articles/10.1186/1471-2458-14-681 >Acessoem: 16 jan. 2018.

QI X. et al. Spatial clusters of suicide in Australia. BMC Psychiatry [online], London, v. 12, n. 86, 2012. Disponível em:

<https://bmcpsychiatry.biomedcentral.com/articles/10.1186/1471-244X-12-86 > Acesso em: 16 jan. 2018.

QU, H. M. et al. Effect of combination model on fitting cancer mortality and prediction.

Europe PMC [online], v. 38, n. 1, p. 117-120, 2017. Disponível em:

<http://europepmc.org/abstract/med/28100389> Acesso em: 29 mar. 2018. 
RAZVODOVSKY, Y. Alcohol consumption and suicide rates in Russia. Suicidology Online [online], Vienna, v. 2, p. 67-74, 2011. Disponível em:

$<$ https://pdfs.semanticscholar.org/09ab/434ed383d304872add6db96f5fc5c3ab5218.pdf > Acess o em: 29 mar. 2018.

RAZVODOVSKY, Y.; ZOTOV, P. B. Suicide and Tuberculosis Mortality: A Comparative Analysis of Time Series. Russian Medical Biological Herald, v. 25, n. 4, p. 606-611, 2017. Disponível em: <https://journals.eco-vector.com/pavlovj/article/view/7735> Acesso em: 29 mar. 2018.

REDMORE, J. et al. Analysis of trends in adolescent suicides and accidental deaths in England and Wales, 1972-2011.The British Journal of Psychiatry [online], London, v. 209, n. 4, 2016, p 327-333. Disponível em: <http://bjp.rcpsych.org/content/209/4/327> Acesso em: 16 jan. 2018.

RESHADAT, S. et al. Spatial accessibility of the population to urban health centres in Kermanshah, Islamic Republic of Iran: a geographic information systems analysis. Eastern Mediterranean Health Journal [online], Alexandria, v. 21, n. 6, p. 389-395, 2015. Disponível em: <https://www.ncbi.nlm.nih.gov/pubmed/26369997> Acesso em: 26 fev. 2017.

ROMERO, D. E.; CUNHA, A. B. Avaliação da qualidade das variáveis sócio-econômicas e demográficas dos óbitos de crianças menores de um ano registrados no Sistema de Informação Sobre Mortalidade do Brasil (1996/2001). Cadernos de Saúde Pública [online], Rio de Janeiro, v. 22, n. 3, p.673-684, 2006. Disponível em:

$<$ http://www.scielo.br/scielo.php?pid=S0102-

311X2006000300022\&script=sci_arttext\&tlng=pt> Acesso em: 26 fev. 2018.

SAMAAN, Z. et al. Exploring the Determinants of Suicidal Behavior: Conventional and Emergent Risk (DISCOVER): a feasibility study. Pilot and Feasibility Studies [online], London, v. 1, n. 17, 2015. Disponível em:

<https://www.ncbi.nlm.nih.gov/pmc/articles/PMC5154080/>Acessoem: 10 jan. 2017.

SAMAN, D. M. et al. Does place of residence affect risk of suicide? a spatial epidemiologic investigation in Kentucky from 1999 to 2008. BMC Public Health [online], London, v. 12, n. 108, 2012. Disponível em: <http://bmcpublichealth.biomedcentral.com/articles/10.1186/14712458-12-108> Acesso em: 25 fev. 2017.

SÁNCHEZ-CERVANTES, F. S.; SERRANO-GONZÁLEZ, R.; MÁRQUEZ-CARAVEO, M. Suicidios en menores de 20 años. México 1998-2011. Salud Mental, Ciudad de México, v. 38, n. 5, p. 379-389, 2015. Disponível em: <http://www.scielo.org.mx/scielo.php?script=sci_arttext\&pid=S0185-33252015000500379> Acesso em: 16 jan. 2018. 
SANTANA, P.; FREITAS, A. A Geografia da Saúde da População: evolução dos últimos 20 anos em Portugual. CEGOT, Universidade de Coimbra, 2015. Disponível em: <http://www.uc.pt/fluc/gigs/GeoHealthS/Geografia-saude-populacao-20anos-Portugal.pdf> Acesso em: 26 fev. 2017.

SANTOS, M. Por uma nova Geografia. São Paulo: HUCITEC, 2004. SANTOS, M. O Território e o Saber Local: Algumas Categorias de Análise. Cadernos IPPUR, Rio de Janeiro, 1999.

SANTOS, E. G. O.; BARBOSA, I. R. Conglomerados espaciais da mortalidade por suicídio no nordeste do Brasil e sua relação com indicadores socioeconômicos. Cadernos Saúde Coletiva [online], Rio de Janeiro, v. 25, n. 3, p. 371-379, 2017. Disponível em: $<$ http://www.scielo.br/scielo.php?pid=S1414-

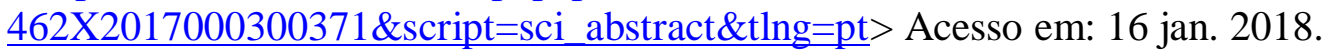

SANTOS, L.; RAIA JUNIOR, A. A. Análise espacial de dados geográficos: a utilização da Exploratory Spatial Data Analysis - ESDA para identificação de áreas críticas de acidentes de trânsito no município de São Carlos (SP). Society \& Natural Resources [online], v. 18, n. 35, p. 97-107, 2006. Disponível em: <http://www.seer.ufu.br/index.php/sociedadenatureza/article/view/9251> Acesso em: 10 jan. 2017.

SANTOS, H, G; SILVA, J. A. M; PORTUGAL, J. L. Análise espacial do índice de desenvolvimento humano municipal na região semiárida brasileira. Revista Brasileira de Geomática [online], Curitiba, v.3, n. 2, p.70-76, 2015. Disponível em: <https://periodicos.utfpr.edu.br/rbgeo/index > Acesso em: 01 mar. 2017.

SATO, R. C. Gerenciamento de doenças utilizando séries temporais com o modelo ARIMA. Einstein (São Paulo), São Paulo, v. 11, n. 1, p. 128-131, 2013. Disponível em: $<$ http://www.scielo.br/scielo.php?script=sci arttext\&pid=S1679-45082013000100024> Acesso em: 29 mar. 2018.

SCOCCO, P. et al. Stigma and psychological distress in suicide survivors. Journal of Psychosomatic Research [online], London, v. 94, p. 36-46, 2017. Disponível em: <https://www.ncbi.nlm.nih.gov/pubmed/28183401> Acesso em: 01 mar. 2017.

SKINNER, R. et al. Suicide and self-inflicted injury hospitalizations in Canada (1979 to 2014/15). Health promotion and chronic disease prevention in Canada [Online], v. 36, n. 11, p. 243-251. Disponível em: 〈https://www.ncbi.nlm.nih.gov/pmc/articles/PMC5432047/> Acesso em: 14 mar. 2018. 
SENA-FERREIRA, N. et al. Fatores de risco relacionados com suicídios em Palmas (TO), Brasil, 2006-2009, investigados por meio de autópsia psicossocial. Ciência \& Saúde

Coletiva [online], Rio de Janeiro, v. 19, n. 1, p. 115-126, 2014. Disponível em: $<$ http://www.scielo.br/scielo.php?pid=S141381232014000100115\&script=sci_abstract\&tl ng=pt $>$ Acesso em: 03 jan. 2017.

SERRANO, M. B. Substance use or abuse, internet use, psychopathology and suicidal ideation in adolescents? Adicciones [online], Palma de Mallorca, v. 20, n. 10, 2017. Disponível em: 〈https://www.ncbi.nlm.nih.gov/pubmed/28170053〉 Acesso em: 24 fev. 2017.

SHAO Y. et al. Epidemiology and temporal trend of suicide mortality in the elderly in Jiading, Shanghai, 2003-2013: a descriptive, observational study. BMJ Open [online], London, v. 6, n. 8, 2016. Disponível em: 〈http://bmjopen.bmj.com/content/6/8/e012227> Acesso em: 16 jan. 2018.

SHELYGIN, K. Suicides and Alcohol Consumption in Russia, 1959-2013. Med Crav [online], Edmond, v. 5, n. 5, 2017. Disponível em:

$<$ https://www.researchgate.net/publication/321151005 Suicides and Alcohol Consumption in_Russia_1959-2013> Acesso em: 29 mar. 2018.

SHNEIDMAN, E. Suicide as psychache: A clinical approach to self-destructive behavior. New Jersey, NJ: Jason Aronson, 1993.

SILVA, D. C. et al. Análise da relação entre a distribuição espacial das morbidades por obesidade e hipertensão arterial para o estado de São Paulo, Brasil, de 2000 a 2010. Ciência \& Saúde Coletiva [online], Rio de Janeiro, v. 19, n. 6, p. 1709-1719, 2014. Disponível em: $\langle$ http://www.scielosp.org/scielo.php?pid=S141381232014000601709\&script=sci_abstract $>$ Acesso em: 18 fev. 2017.

SILVA, P. H. N. V. et al. Estudo espacial da mortalidade por acidentes de motocicleta em Pernambuco. Revista de Saúde Pública [online], São Paulo, v. 45, n. 2, p. 409-415, 2011. Disponível em: <http://www.scielo.br/scielo.php?script=sci_arttext\&pid=S003489102011000200020> Acesso em: 10 jan. 2016.

SILVA, T. P. S. S.; SOUGEY, E. B.; SILVA, J. Estigma social no comportamento suicida: reflexões bioéticas. Revista Bioética [online], Brasília, v. 23, n. 2, p. 419-426, 2015. Disponível em: <http://www.scielo.br/scielo.php?script=sci_arttext\&pid=S198380422015000200419> Acesso em: 10 jan. 2017.

SINYOR, M.; TSE R.; PIRKIS, J. Global trends in suicide epidemiology. Current Opinion in Psychiatry [online], Philadelphia, v. 30, n. 1, p. 1-6, 2017. Disponível em: <https://www.ncbi.nlm.nih.gov/pubmed/27845946> Acesso em: 10 jan. 2016. 
SOUSA, A. S. B.; SILVA, S. C.; CAVALCANTE, M. F. A. Mortalidade por causas externas em adultos jovens em Teresina-PI no período de 2001-2011. Revista Internacional

Interdisciplinar[online], Florianópolis, v. 9, n. 1, p. 57-65, 2016. Disponível em:

$<$ http://revistainterdisciplinar.uninovafapi.edu.br/index.php/revinter/article/view/594/pdf_285

$>$ Acesso em: 15 fev. 2017.

SOUZA, M. L. P.; ORELLANA, J. D. Y. Desigualdades na mortalidade por suicídio entre indígenas e não indígenas no estado do Amazonas, Brasil. Jornal Brasileiro de Psiquiatria [online], Rio de Janeiro, v. 62, n. 4, p. 245-252, 2013. Disponível em:

<http://www.scielo.br/scielo.php?script=sci_arttext\&pid=S0047-20852013000400001 >

Acesso em: 26 fev. 2017.

SOUZA, T. O.; PINTO, L. W.; SOUZA, E.R. Spatial study of homicide rates in the state of Bahia, Brazil, 1996-2010. Revista de Saúde Pública [online]. São Paulo, v. 48, n. 3, p 468477, 2014. Disponível em: <https://www.ncbi.nlm.nih.gov/pubmed/25119942> Acesso em: 21 fev. 2016.

SOUZA, W. V. Análise espacial de dados de áreas. In: SANTOS, S. M.; SOUZA, W.V. (Org.). Introdução à estatística espacial para a saúde pública. Brasília, DF: Ed. Ministério da Saúde, 2007.

SULliVAN, E. M. et al. Suicide Trends Among Persons Aged 10-24 Years - United States, 1994-2012.Morbidity and Mortality Weekly Report[online], Atlanta, v. 64, n. 8, p. 201-205, 2015. Disponível em:

<https://www.ncbi.nlm.nih.gov/pubmed/?term=Suicide+Trends+Among+Persons+Aged+10 \%E2\%80\%9324+Years+\%E2\%80\%94+United+States\%2C+1994\%E2\%80\%932012.>

Acesso em: 17 mar. 2017.

SUN, B. Q.; ZHANG, J. Economic and Sociological Correlates of Suicides: Multilevel Analysis of the Time Series Data in the United Kingdom. The Australian journal of forensic sciences [online], Sydney, v. 61, n. 2, p. 345-351, 2016. Disponível em: <https://www.ncbi.nlm.nih.gov/pubmed/27404607> Acesso em: 29 mar. 2018.

SUTHERLAND, G. et al. Implementation and evaluation of the Victorian Suicide Register. Australian and New Zealand Journal of Public Health [online], Canberra, 2017. Disponível em: <https://www.ncbi.nlm.nih.gov/pubmed/29044826> Acesso em: 30 jan. 2018.

THIBODEAU, L. Mortalité par suicide au Canada depuis le début du XX e siècle: perspectives sociodémographiques et macroéconomiques. Tese (Departamento de demografia). Universidade de Montreal. Montreal, 2015. 
TOMITA, M.; KUBOTA, T.; ISHIOKA, F. Spatial Clustering Properties in the Temporal Variation of Suicide Rates/Numbers among Japanese Citizens: A Comprehensive Comparison and Discussion. PLoS One [online], San Francisco, v. 10, n. 7, 2015. Disponível em: <https://www.ncbi.nlm.nih.gov/pmc/articles/PMC4498741/> Acesso em: 10 jan. 2017.

TSAI, J. F.; CHO, W. Re-examination of the seasonality of suicide in Taiwan during 19912008: A population-based study. Psychiatry Research [online], Amsterdam, v. 186, n. 1, p. 147-149, 2011. Disponível em: <http://www.psy-journal.com/article/S0165-1781(10)004750/fulltext> Acesso em: 29 mar. 2018.

TSAI, P. J. Application of Moran's test with an empirical Bayesian rate to leading health care problems in Taiwan in a 7-year period (2002-2008). Global Journal of Health Science [online], Toronto, v. 4, n. 5, p. 63-77, 2012. Disponível em:

<https://www.ncbi.nlm.nih.gov/pmc/articles/PMC4776905/>Acesso em: 26 fev. 2017.

VÄRNIK, P. Suicide in the World. International Journal of Environmental Research and Public Health[online], Basileia, v. 9, n. 3, p. 760-771, 2012. Disponível em:

<https://www.ncbi.nlm.nih.gov/pmc/articles/PMC3367275/> Acesso em: 30 dez. 2016.

VENÂNCIO, T. S.; TUAN, T. S.; NASCIMENTO, L. F. C. Incidência de tuberculose em crianças no estado de São Paulo, Brasil, sob enfoque espacial. Ciência \& Saúde Coletiva [online], Rio de Janeiro, v. 20, n. 5, p. 1541-1547, 2015. Disponível em:

$<$ http://www.scielo.br/scielo.php?pid=S141381232015000501541\&script=sci_arttext\&tlng=p t> Acesso em: 21 fev. 2016.

VENCO, S.; BARRETO, M. O sentido social do suicídio no trabalho. Revista do Tribunal Superior do Trabalho, Brasília[online], v. 80, n. 1, 2014. Disponível em:

$<$ https://juslaboris.tst.jus.br/bitstream/handle/1939/61186/021_venco.pdf?sequence=1\&isAllo $\underline{\text { wed }=y}>$ Acesso em: 15 fev. 2017.

VIDAL, C. E. L.; GONTIJO, E.C. D M.; LIMA, L. A. Tentativas de suicídio: fatores prognósticos e estimativa do excesso de mortalidade. Cadernos de Saúde Pública [online], Rio de Janeiro, v. 29, n. 1, p. 175-187, 2013. Disponível em: $<$ http://www.scielo.br/scielo.php?pid=S0102311X2013000100020\&script=sci abstract\&tlng $=\mathrm{pt}>$ Acesso em: 10 jan. 2016.

VIJAYAKUMAR, L. Suicide Prevention: Beyond Mental Disorder. Indian Journal of Psychological Medicine [online], v. 38, n. 6, p. 514-516, 2016. Disponível em: <https://www.ncbi.nlm.nih.gov/pmc/articles/PMC5178033/> Acesso em: 10 jan. 2016. 
WAKEFIELD, J. Ecologic studies revisited. Annual Review of Public Health [online], Palo Alto, v. 29, p. 75-90, 2008. Disponível em:

<http://faculty.washington.edu/jonno/papers/annrev08.pdf> Acesso em: 24 fev. 2017.

WALKER, S. C. Evidence-Based Program Service Deserts: A Geographic Information Systems (GIS) Approach to Identifying Service Gaps for State-Level Implementation Planning. Administration and Policy in Mental Health and Mental Health Services Research [online], New York, v. 43, n. 6, p. 850-860, 2016. Disponível em: <https://www.ncbi.nlm.nih.gov/pubmed/27260345> Acesso em: 25 fev. 2017.

WANG, Z. et al. 2016. Age-period-cohort analysis of suicide mortality by gender among white and black Americans, 1983-2012. International journal for equity in health [Online], London, v. 15, p. 107, 2016. Disponível em: <https://www.ncbi.nlm.nih.gov/pmc/articles/PMC4944259/pdf/12939 2016 Article 400.pdf $>$ Acesso em: 5 mar. 2018.

WANG, C. W.; CHAN, C. L.; YIP, P. S. Suicide rates in China from 2002 to 2011: an update. Social Psychiatry and Psychiatric Epidemiology [online], Berlin, v. 49. n. 6, p. 929-941, 2014. Disponível em:

$<$ https://www.ncbi.nlm.nih.gov/pubmed/?term=Suicide+rates+in+China+from+2002+to+201 1\%3A+an+update> Acesso em: 17 mar. 2017

WORLD HEALTH ORGANIZATION. Suicide Data. 2015. Disponível em: <http://www.who.int/mental health/prevention/suicide/suicideprevent/en/> Acesso em: 28 fev. 2017.

WORLD HEALTH ORGANIZATION. Preventing Suicide: A Global Imperative. Geneva: World Health Organization. 2014. Disponível em:

$<$ http://www.who.int/mental_health/suicide-prevention/world_report_2014/en/>Acesso em: 16 jan. 2017.

WORLD HEALTH ORGANIZATION. Mental health action plan 2013-2020. Geneva: World Health Organization. 2013. Disponível em: <http://apps.who.int/iris/bitstream/10665/89966/1/9789241506021 eng.pdf > Acesso em: 24 jan. 2017.

WORLD HEALTH ORGANIZATION. Public health action for the prevention of suicide. Geneva: World Health Organization. 2012. Disponível em: Acesso em: 16 jan. 2018. Disponível em: <http://www.who.int/mental_health/publications/prevention_suicide_2012/en/> Acesso em: 28 fev. 2017. 
WRUBLACK, S. C. et al. As ferramentas de geoprocessamentos como recurso didático e suas possíveis contribuições para a educação ambiental. Revista Eletrônica do Mestrado em Educação Ambiental [online], Rio Grande, 2014. Disponível em: <https://www.seer.furg.br/remea/article/view/4446/2797> Acesso em: 12 fev. 2016.

XIN, Q.; SHILU, T.; WENBIAO, H. Spatial distribution of suicide in Queensland, Australia. BMC Psychiatry [online], London, v.10, n. 106, 2012. Disponível $\mathrm{em}:<$ http://bmcpsychiatry.biomedcentral.com/articles/10.1186/1471-244X-10-106 $>$ Acesso em: 12 fev. 2016.

YAMASAKI, A. et al. Solar Flux Exhibits a Negative Correlation with Suicide Rate. Remedy Open Access [online], California, v. 2, n. 1059, 2017. Disponível em: $<$ http://remedyoa.com/pdfs_folder/roa-v2-id1059.pdf> Acesso em: 29 mar. 2018.

YEH, S. T.; NG, Y. Y.; WU, S. C. Risk of suicide according to the level of psychiatric contact in the older people: Analysis of national health insurance databases in Taiwan.

Comprehensive Psychiatry [online], New York, v. 1, n. 74, p. 189-195, 2017. Disponível em: <https://www.ncbi.nlm.nih.gov/pubmed/28213305> Acesso em: 28 fev. 2017.

YIN, H. et al. Relationship between suicide rate and economic growth and stock market in the People's Republic of China: 2004-2013. Neuropsychiatric disease and treatment [Online], Albany, v. 12, p. 3119-3128, 2016. Disponível em:

<https://www.ncbi.nlm.nih.gov/pmc/articles/PMC5153284/pdf/ndt-12-3119.pdf> Acesso em: 11 mar. 2018.

YOON, T. H. et al. Deprivation and suicide mortality across 424 neighborhoods in Seoul, South Korea: a Bayesian spatial analysis. International Journal of Public Health [online], Basileia, v. 60, n. 8, p. 969-976, 2015. Disponível em: <https://www.ncbi.nlm.nih.gov/pubmed/26022192> Acesso em: 16 jan. 2018.

YOSHIOKA, E.; SAIJO, Y.; KAWACHI, I. Spatial and temporal evolution of the epidemic of charcoal-burning suicide in Japan. Social Psychiatry and Psychiatric Epidemiology [online], Berlin, v. 51, n. 6, p. 857-868, 2016. Disponível em: <https://www.ncbi.nlm.nih.gov/pubmed/26814811> Acesso em: 25 fev. 2017.

ZALSMAN, G. Suicide prevention strategies revisited: 10-year systematic review. The Lancet Psychiatry [online], Kidlington, v. 3, n. 7, p. 646-659, 2016. Disponível em: <https://www.ncbi.nlm.nih.gov/pubmed/27289303> Acesso em: 24 fev. 2017.

ZANNIN, A. Suicídio em idosos no Brasil de 2005 a 2010. 2013. Especialização em Saúde Pública - Universidade do Rio Grande do Sul, Porto Alegre, 2013. Disponível em: 
$<$ https://www.lume.ufrgs.br/bitstream/handle/10183/78449/000899681.pdf?sequence=1 >Aces so em: 16 jan. 2018.

ZHONG, B. L. et al. Suicidal ideation among Chinese cancer inpatients of general hospitals: Prevalence and correlates. Oncotarget [online], Albany, v. 8, n. 15, p. 25141-25150, 2017. Disponível em: 〈https://www.ncbi.nlm.nih.gov/pubmed/28212579> Acesso em: 12 fev. 2017. 


\section{ANEXo A- DISTRIBUIÇÃO DOS MUNICÍPIOS DE PERNAMBUCO SEGUNDO REGIONAIS DE SAÚDE}

\begin{tabular}{|c|c|}
\hline $\begin{array}{l}\text { REGIONAL } \\
\text { DE SAÚDE }\end{array}$ & MUNICÍPIOS \\
\hline$-1-1-2$ & $\begin{array}{l}\text { Abreu e Lima, Araçoiaba, Cabo de Santo Agostinho, Camaragibe, Chã } \\
\text { Grande, Chã de Alegria, Glória de Goitá, Fernando de Noronha, Igarassu, } \\
\text { Ipojuca, Itamaracá, Itapissuma, Jaboatão dos Guararapes, Moreno, Olinda, } \\
\text { Paulista, Pombos, Recife, São Lourenço da Mata e Vitória de Santo Antão. }\end{array}$ \\
\hline II & $\begin{array}{l}\text { Bom Jardim, Buenos Aires, Carpina, Casinhas, Cumaru, Feira Nova, João } \\
\text { Alfredo, Lagoa de Itaenga, Lagoa do Carro, Limoeiro, Machados, Nazaré } \\
\text { da Mata, Orobó, Passira, Paudalho, Salgadinho, Surubim, Tracunhaém, } \\
\text { Vertente do Lério e Vicência. }\end{array}$ \\
\hline III & $\begin{array}{l}\text { Água Preta, Amaraji, Barreiros, Belém de Maria, Catende, Cortês, Escada, } \\
\text { Gameleira, Jaqueira, Joaquim Nabuco, Lagoa dos Gatos, Maraial, } \\
\text { Palmares, Primavera, Quipapá, Ribeirão, Rio Formoso, São Benedito do } \\
\text { Sul, São José da Coroa Grande, Sirinhaém, Tamandaré e Xexéu. }\end{array}$ \\
\hline IV & $\begin{array}{l}\text { Agrestina, Alagoinha, Altinho, Barra de Guabiraba, Belo Jardim, Bezerros, } \\
\text { Bonito, Brejo da Madre de Deus, Cachoeirinha, Camocim de São Felix, } \\
\text { Caruaru, Cupira, Frei Miguelinho, Gravatá, Ibirajuba, Jataúba, Jurema, } \\
\text { Panelas, Pesqueira, Poção, Riacho das Almas, Sairé, Sanharó, Santa Cruz } \\
\text { do Capibaribe, Santa Cruz do Cambucá, São Bento do Uma, São Caetano, } \\
\text { São Joaquim do Monte, Tacaimbó, Taquaritinga do Norte, Toritama e } \\
\text { Vertentes. }\end{array}$ \\
\hline $\mathbf{V}$ & $\begin{array}{l}\text { Águas Belas, Angelim, Bom Conselho, Brejão, Caetés, Calçados, } \\
\text { Canhotinho, Capoeiras, Correntes, Garanhus, Iati, Itaíba, Jucati, Jupi, } \\
\text { Lagoa do Ouro, Lajedo, Palmerina, Paranatama, Saloá, São João e } \\
\text { Terezinha. }\end{array}$ \\
\hline VI & $\begin{array}{l}\text { Arcoverde, Buíque, Custódia, Ibimirim, Inajá, Jatobá, Manarí, Pedra, } \\
\text { Petrolândia, Sertânia, Tacaratu, Tupanatinga e Venturosa. }\end{array}$ \\
\hline VII & $\begin{array}{l}\text { Belém do São Francisco, Cedro, Mirandiba, Salgueiro, Serrita, Terra Nova, } \\
\text { Verdejante. }\end{array}$ \\
\hline VIII & $\begin{array}{l}\text { Afrânio, Cabrobó, Dormentes, Lagoa Grande, Orocó, Petrolina e Santa } \\
\text { Maria da Boa Vista. }\end{array}$ \\
\hline IX & $\begin{array}{l}\text { Araripina, Bodocó, Exu, Granito, Ipubi, Moreilândia, Ouricuri, } \\
\text { Parnamirim, Santa Cruz, Santa Filomena e Trindade. }\end{array}$ \\
\hline $\mathbf{X}$ & $\begin{array}{l}\text { Afogados da Ingazeira, Brejinho, Carnaíba, Iguaraci, Ingazeira, Itapetim, } \\
\text { Quixaba, Santa Terezinha, São José do Egito, Solidão, Tabira e } \\
\text { Tuparetama. }\end{array}$ \\
\hline XI & $\begin{array}{l}\text { Betânia, Calumbi, Carnaubeira da Penha, Flores, Floresta, Itacuruba, Santa } \\
\text { Cruz da Baixa Verde, São José do Belmonte, Serra Talhada e Triunfo. }\end{array}$ \\
\hline XII & $\begin{array}{l}\text { Goiana, Aliança, Camutanga, Condado, Ferreiros, Itambé, Itaquitinga, } \\
\text { Macaparana, São Vicente Ferrer e Timbaúba. }\end{array}$ \\
\hline
\end{tabular}




\section{ANEXO B - MODELO DA DECLARAÇÃO DE ÓBITO}

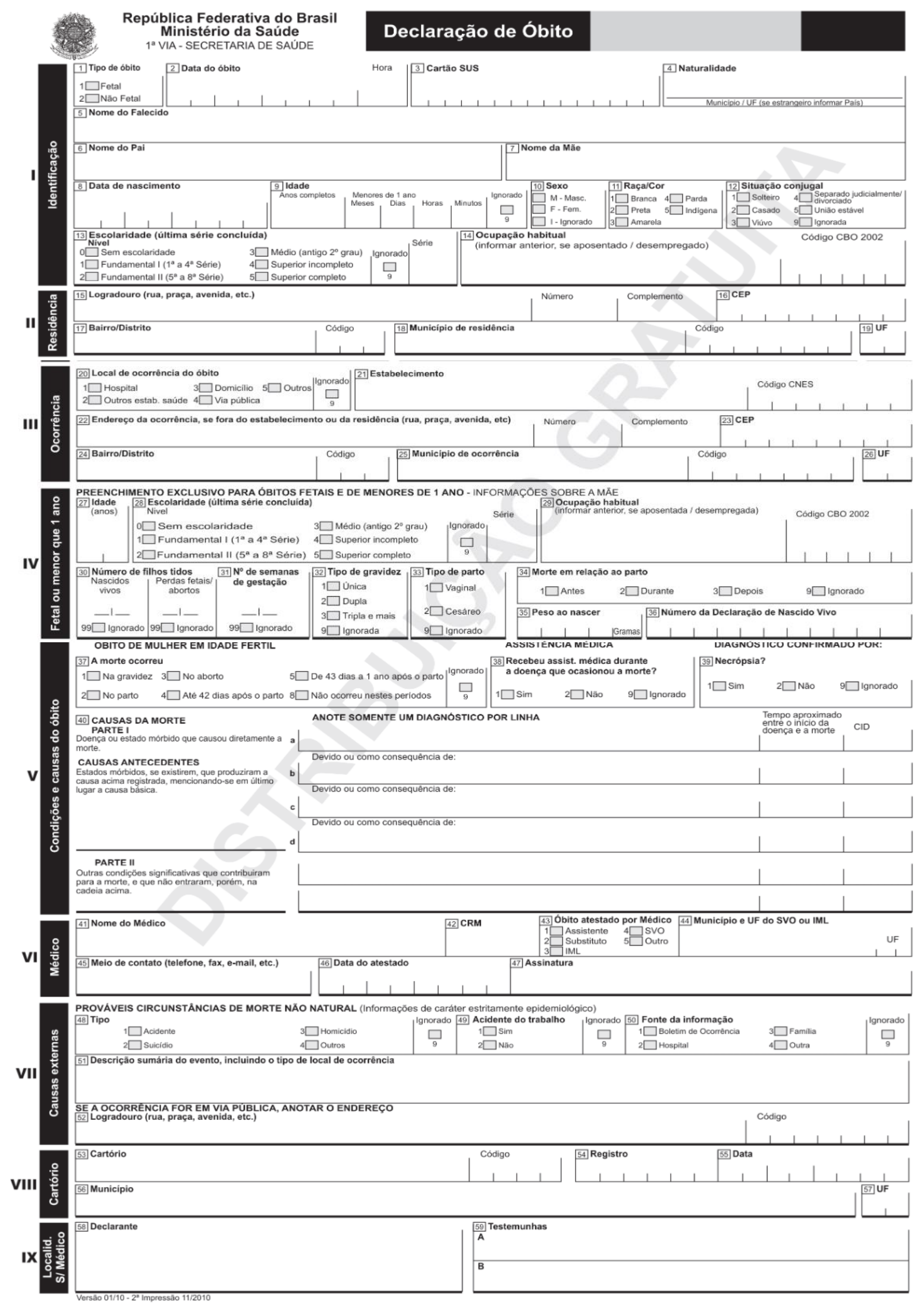




\section{ANEXO C - CID 10: X60-X84. LESÕES AUTOPROVOCADAS VOLUNTARIAMENTE, SEGUNDO CATEGORIAS}

X60

X61

X62

X63

X64

X65

X66

X67

X68

X69

$\mathrm{X} 70$

X71 Lesão autoprovocada intencionalmente por afogamento e submersão.

X72 Lesão autoprovocada intencionalmente por disparo de arma de fogo de mão.

$\mathrm{X} 73$

X74

$\mathrm{X} 75$

$\mathrm{X} 76$

Autointoxicação por exposição, intencional, a analgésicos, antipiréticos e antirreumáticos, não opiáceos.

Autointoxicação por exposição, intencional, a drogas anticonvulsivantes (antiepilépticos) sedativos, hipnóticos, antiparkinsonianos e psicotrópicos não classificados em outra parte.

Autointoxicação por exposição, intencional, a narcóticos e psicodislépticos (alucinógenos) não classificados em outra parte.

Autointoxicação por exposição, intencional, a outras substâncias farmacológicas de ação sobre o sistema nervoso autônomo.

Autointoxicação por exposição, intencional, a outras drogas, medicamentos e substâncias biológicas e às não especificadas.

Autointoxicação voluntária por álcool.

Autointoxicação intencional por solventes orgânicos, hidrocarbonetos halogenados e seus vapores.

Autointoxicação intencional por outros gases e vapores.

Autointoxicação por e exposição, intencional, a pesticidas.

Autointoxicação por exposição, intencional, a outros produtos químicos e substâncias nocivas não especificadas.

Lesão autoprovocada intencionalmente por enforcamento, estrangulamento e sufocação.

Lesão autoprovocada intencionalmente por disparo de espingarda, carabina, ou arma de fogo de maior calibre.

Lesão autoprovocada intencionalmente por disparo de outra arma de fogo e de arma de fogo não especificada

Lesão autoprovocada intencionalmente por dispositivos explosivos. 
X77 Lesão autoprovocada intencionalmente por vapor de água, gases ou objetos quentes.

X78 Lesão autoprovocada intencionalmente por objeto cortante ou penetrante.

X79 Lesão autoprovocada intencionalmente por objeto contundente.

X80 Lesão autoprovocada intencionalmente por precipitação de um lugar elevado.

X81 Lesão autoprovocada intencionalmente por precipitação ou permanência diante de um objeto em movimento.

X82 Lesão autoprovocada intencionalmente por impacto de um veículo a motor.

X83 Lesão autoprovocada intencionalmente por outros meios especificados.

X84 Lesão autoprovocada intencionalmente por meios não especificados. 


\section{ANEXO D - PARECER CONSUBSTANCIADO DO COMITÊ DE ÉTICA EM PESQUISA}

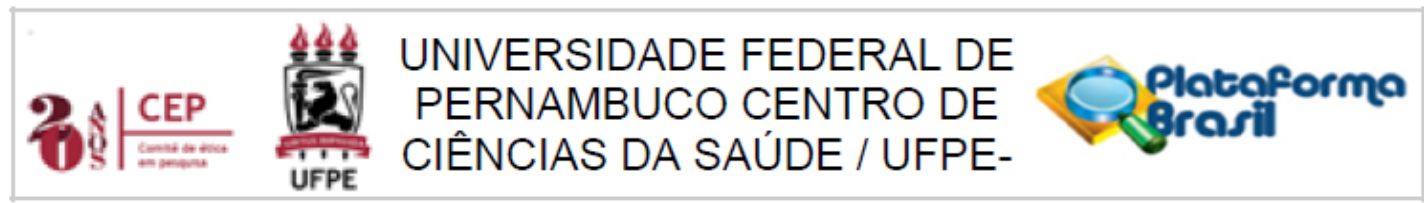

\section{PARECER CONSUBSTANCIADO DO CEP}

\section{DADOS DO PROJETO DE PESQUISA}

Título da Pesquisa: PADRÕES ESPAÇO-TEMPORAL DO SUICÍDIO NO ESTADO DE PERNAMBUCO, BRASIL

Pesquisador: Bárbara Marcela Beringuel

Área Temática:

Versão: 1

CAAE: 66557317.0 .0000 .5208

Instituição Proponente: CENTRO DE CIÊNCIAS DA SAÚDE

Patrocinador Principal: Financiamento Próprio

DADOS DO PARECER

Número do Parecer: 2.045 .304

\section{Apresentaçäo do Projeto:}

Trata-se do projeto de dissertação da pesquisadora Bárbara Marcela Beringuel, discente do curso de mestrado do Programa de Pós-graduação em Saúde Coletiva da UFPE, sob a orientação da Profa. Cristine Vieira do Bonfim e co-orientação da Profa. Amanda Priscila de Santana Cabral intitulado "Padrões espaçotemporal do suicídio no estado de Pernambuco, Brasil. A proposta pretende descrever a ocorrência e a distribuição espaço-temporal da mortalidade por suicídio em residentes do estado de Pernambuco entre 1996 e 2015. A fonte de dados será constituída pelos casos registrados de suicídio no Sistema de Informação de Mortalidade (SIM), disponíveis na Secretaria de Saúde do Estado de Pernambuco - Serviço Executiva de Vigilância em Saúde. A estimativa amostral é de 6.060, correspondente ao número de suicídios no estado no período de 1996 a 2015. A tendência

temporal será realizada através da técnica de regressão linear simples. Para a análise espacial dos dados será empregada a abordagem Bayesiana

empírica local com a finalidade de suavizar os coeficientes de mortalidade por suicídio. Para a identificação da correlação e possíveis aglomerados

espaciais de suicídio serão utilizados o Índice de Moran Global e o Indicador Local de Associação Espacial. Os critérios de inclusão definidos foram: Todos os óbitos de suicídio em residentes do

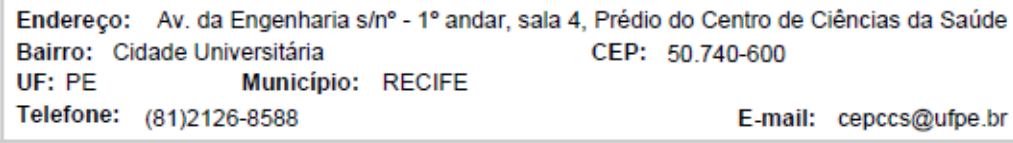




\section{a

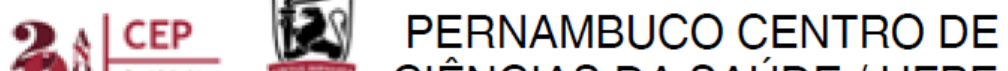 Wô $=\underset{\text { UFPE }}{-}$ CIÊNCIAS DA SAÚDE / UFPE-

Continuaçāo do Parecer: 2.045.304

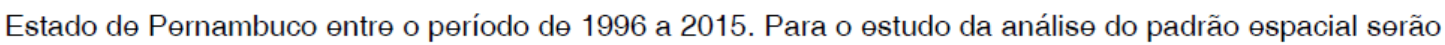
excluídos os óbitos por suicídio, no período өstudado, cujo município de residência não esteja identificado.

Objetivo da Pesquisa:

Geral: Descrever a ocorrência $\theta$ a distribuição $\ominus$ spaço-temporal da mortalidade por suicídio $\Theta m$ residentes do estado de Pernambuco entre 1996 ө 2015.

Específicos

1)Caracterizar os óbitos por suicídio, segundo variáveis sociodemográficas, em residentes do Estado de Pernambuco por decênios (1996-2005/2006-2015);

2)Descrever a tendência temporal do suicídio em residentes do Estado de Pernambuco no período total de estudo (1996-2015);

3)Mapөar a distribuição өspacial do suicídio por municípios $\theta$ Regionais de Saúde (RS), por decênios (19962005/2006-2015).

\section{Avaliaçāo dos Riscos e Benefícios:}

Embora se trate de um $\theta$ studo com dados secundários, alguns riscos como a privacidade $\Theta$ o consentimento individual podem estar presentes entre os dilemas éticos. Tais riscos serão amenizados, uma vez que a identificação pessoal dos indivíduos não será exposta, os resultados obtidos serão apresentados de forma agregada, não permitindo a identificação individual dos participantes. Outro risco apresentado trata-se da

possibilidade de perdas ou $\theta x t r a v i o s ~ d e$ alguns dados do banco. Para minimizar tal aspecto o pesquisador principal se responsabiliza em manter tais dados em local seguro $\theta$ privado.

O presente projeto possui o benefício de explorar os padrõ $\theta$ s $ө$ spaciais $\theta$ temporais do suicídio, aspectos estes pouco conhecidos $\theta$ investigados no

cenário nacional, sobretudo, no Estado de Pernambuco. Deste modo, os resultados gerados por esta pesquisa poderá contribuir na condução de melhores ações de intervenções em saúde.

O presente projeto possui o ben€fício de explorar os padrões өspaciais $\Theta$ temporais do suicídio, aspectos estes, pouco conhecidos $\Theta$ investigados no cenário nacional, sobretudo, no Estado de Pernambuco. Deste modo, os resultados gerados por esta pesquisa poderá contribuir na condução

Endereço: Av. da Engenharia s/nำ 1ำ andar, sala 4, Prédio do Centro de Ciências da Saúde

Bairro: Cidade Universitária CEP: $50.740-600$

UF: PE Município: RECIFE

Telefone: (81)2126-8588

E-mail: cepccs@ufpe.br 


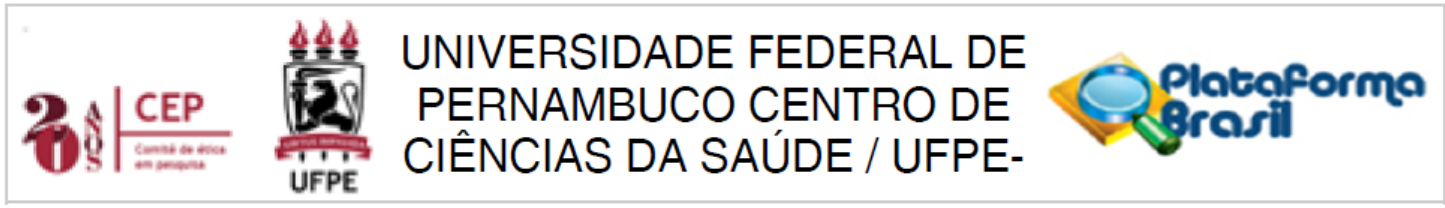

Continuaçāo do Parecer: 2.045.304

de melhores ações de intervenções em saúde.

Em face do exposto, considero os riscos $\theta$ benefícios apropriados para a proposta de pesquisa.

\section{Comentários e Consideraçōes sobre a Pesquisa:}

A proposta é relevante, principalmente, para a área de saúde mental coletiva. Possui embasamento teórico com referências atualizadas. Há contextualização do problema em termos nacionais $\theta$ regionais. O projeto está bem escrito $\theta$ apresenta de forma clara os objetivos $\theta$ o método para alcance dos mesmos. A pesquisadora solicita dispensa de TCLE. Considero pertinente a solicitação, haja vista que o projeto terá como fonte de dados (secundários) informações disponíveis no SIM, disponibilizadas pela Secretaria Estadual de Saúde de Pernambuco. O cronograma está condizendo com as өtapas propostas. O orçamento está adequado. Os resultados serão relevantes para a criação $\theta$ implementação de $\theta$ stratégias de prevenção do suicídio no estado de Pernambuco.

\section{Consideraçōes sobre os Termos de apresentação obrigatória:}

Em termos de projeto, foram apresentados todos os өlementos obrigatórios: introdução, justificativa, pergunta condutora, hipótese, objetivos, métodos, cronograma, orçamento $\theta$ anexos.

No que se refere aos documentos solicitados pelo CEP/CCS/UFPE, foram apresentados: folha de rosto, carta de anuência, Currículo lattes de todos os pesquisadores, projeto de pesquisa, termo de confidencialidade, declaração de vínculo, declaração de autorização de uso de dados $\theta$ solicitação de dispensa de TCLE.

\section{Recomendaçōes:}

Sem recomendações.

\section{Conclusōes ou Pendências e Lista de Inadequaçōes:}

Diante do exposto, sugiro a aprovação do projeto.

\section{Consideraçōes Finais a critério do CEP:}

O Protocolo foi avaliado na reunião do CEP $\theta$ está APROVADO para iniciar a coleta de dados. Informamos que a APROVAÇÃO DEFINITIVA do projeto só será dada após o өnvio da Notificação com o Relatório Final da pөsquisa. O pesquisador deverá fazer o download do modelo de Rөlatório Final para өnviá-lo via "Notificação", pela Plataforma Brasil. Siga as instruções do link "Para enviar Relatório Final", disponível no site do CEP/UFPE. Após apreciação desse relatório, o CEP өmitirá novo Parecer Consubstanciado definitivo pelo sistema Plataforma Brasil.

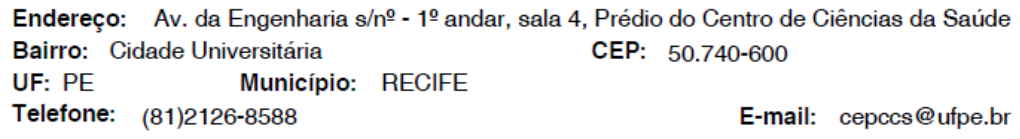




\section{3. UNIVERSIDADE FEDERAL DE
PERNAMBUCO CENTRO DE Platoformo
Parasil
UFPE CIÊNCIAS DA SAÚDE / UFPE-}

Continuaçāo do Parecer: 2.045.304

Informamos, ainda, que o (a) pesquisador (a) deve desenvolver a pesquisa conforme delineada neste

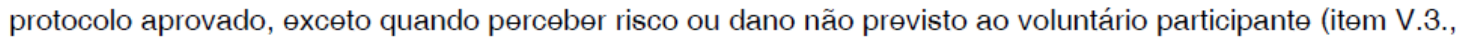
da Resolução CNS/MS № 466/12).

Eventuais modificações nөsta pөsquisa dөvem ser solicitadas através de EMENDA ao projeto, identificando a parte do protocolo a ser modificada $\Theta$ suas justificativas.

Para projetos com mais de um ano de exөcução, é obrigatório que o pesquisador responsável pelo Protocolo de Pesquisa apresente a este Comitê de Ética, relatórios parciais das atividades desenvolvidas no período de 12 meses a contar da data de sua aprovação (item X.1.3.b., da Resolução CNS/MS № 466/12).

O CEP/UFPE deve ser informado de todos os efeitos adversos ou fatos relevantes que alterem o curso normal do estudo (item V.5., da Rөsolução CNS/MS № 466/12). É papel do/a pөsquisador/a assegurar todas as medidas imediatas $\theta$ adequadas frente a $\theta$ vento adverso grave ocorrido (mesmo que tenha sido em outro centro) $\theta$ ainda, өnviar notificação à ANVISA - Agência Nacional de Vigilância Sanitária, junto com seu posicionamento.

Este parecer foi elaborado baseado nos documentos abaixo relacionados:

\begin{tabular}{|c|c|c|c|c|}
\hline Tipo Documento & Arquivo & Postagem & Autor & Situação \\
\hline $\begin{array}{l}\text { Informações Básicas } \\
\text { do Projeto }\end{array}$ & $\begin{array}{l}\text { PB_INFORMAÇÕES_BÁSICAS_DO_P } \\
\text { ROJETO 888935.pdf }\end{array}$ & $\begin{array}{c}03 / 04 / 2017 \\
09: 00: 42\end{array}$ & & Aceito \\
\hline $\begin{array}{l}\text { Projeto Detalhado / } \\
\text { Brochura } \\
\text { Investigador }\end{array}$ & PROJETODETALHADO1.docx & $\begin{array}{c}\text { 03/04/2017 } \\
09: 00: 17\end{array}$ & $\begin{array}{l}\text { Bárbara Marcela } \\
\text { Beringuel }\end{array}$ & Aceito \\
\hline Outros & Declaracaodematricula.pdf & $\begin{array}{c}31 / 03 / 2017 \\
14: 45: 36\end{array}$ & $\begin{array}{l}\text { Bárbara Marcela } \\
\text { Beringuel }\end{array}$ & Aceito \\
\hline Outros & \begin{tabular}{|l|} 
Declaracaodeautorizacaodeusodedados. \\
pdf
\end{tabular} & $\begin{array}{c}31 / 03 / 2017 \\
14: 44: 52 \\
\end{array}$ & $\begin{array}{l}\text { Bárbara Marcela } \\
\text { Beringuel }\end{array}$ & Aceito \\
\hline Outros & DөclaracaodeAnuөncia.pdf & $\begin{array}{c}31 / 03 / 2017 \\
14: 43: 30\end{array}$ & $\begin{array}{l}\text { Bárbara Marcela } \\
\text { Beringuel }\end{array}$ & Aceito \\
\hline Outros & $\begin{array}{l}\text { TermodeCompromisso } \theta \text { Confidencialidad } \\
\text { ө.pdf }\end{array}$ & $\begin{array}{l}31 / 03 / 2017 \\
14: 41: 05\end{array}$ & $\begin{array}{l}\text { Bárbara Marcela } \\
\text { Beringuel }\end{array}$ & Aceito \\
\hline Outros & CurriculoAmandadeSantanaCabral.docx & $\begin{array}{c}31 / 03 / 2017 \\
14: 39: 53 \\
\end{array}$ & $\begin{array}{l}\text { Bárbara Marcela } \\
\text { Beringuel }\end{array}$ & Aceito \\
\hline Outros & CurriculoCristineVieiradoBonfim.docx & $\begin{array}{c}31 / 03 / 2017 \\
14: 37: 36 \\
\end{array}$ & $\begin{array}{l}\text { Bárbara Marcela } \\
\text { Beringuel }\end{array}$ & Aceito \\
\hline Outros & CurriculoBarbaraMarcela.docx & $\begin{array}{c}31 / 03 / 2017 \\
14: 36: 31 \\
\end{array}$ & $\begin{array}{l}\text { Bárbara Marcela } \\
\text { Beringuel }\end{array}$ & Aceito \\
\hline TCLE / Tөrmos de & JUSTIFICATIVADEAUSENCIATCLE.do & $31 / 03 / 2017$ & Bárbara Marcela & Aceito \\
\hline
\end{tabular}

Endereço: Av. da Engenharia s/nำ - 1ํandar, sala 4, Prédio do Centro de Ciências da Saúde

Bairro: Cidade Universitária CEP: $50.740-600$

UF: PE Município: RECIFE

Telefone: (81)2126-8588

E-mail: cepccs@ufpe.br 


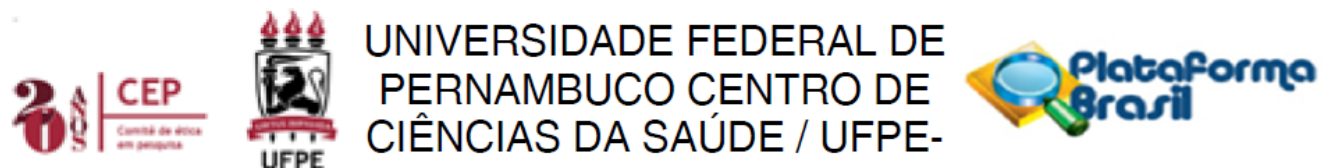

Continuaçāo do Parecer: 2.045.304

\begin{tabular}{|l|l|c|l|c|}
\hline $\begin{array}{l}\text { Assentimento / } \\
\text { Justificativa d } \\
\text { Ausência }\end{array}$ & $\begin{array}{l}\text { JUSTIFICATIVADEAUSENCIATCLE.do } \\
\text { cx }\end{array}$ & $14: 34: 40$ & Beringuel & Aceito \\
\hline Folha de Rosto & Folhaderosto.pdf & $\begin{array}{c}31 / 03 / 2017 \\
14: 12: 46\end{array}$ & $\begin{array}{l}\text { Bárbara Marcela } \\
\text { Beringuel }\end{array}$ & Aceito \\
\hline
\end{tabular}

Situação do Parecer:

Aprovado

Necessita Apreciaçāo da CONEP:

Não

RECIFE, 04 de Maio de 2017

Assinado por:

LUCIANO TAVARES MONTENEGRO

(Coordenador) 


\title{
ANEXO E - DECLARAÇÃO DE ANUÊNCIA DA SECRETARIA ESTADUAL DE SAÚDE DE PERNAMBUCO
}

\author{
SECRETARIA DE SAÚDE DO ESTADO DE PERNAMBUCO \\ SECRETARIA EXECUTIVA DE GESTÃO DO TRABALHO E EDUCAÇÃO NA SAÚDE \\ DIRETORIA GERAL DE EDUCAÇĀO NA SAÚDE \\ GERÊNCIA DE DESENVOLVIMENTO PROFISSIONAL
}

Recife, 30 de março de 2017

\section{DECLARAÇÃo DE ANUÊNCIA}

Declaro estar ciente da realização da pesquisa: PADRÕES ESPAÇOTEMPORAL DO SUICÍDIO NO ESTADO DE PERNAMBUCO, BRASIL, da pesquisadora: Bárbara Marcela Beringuel, aluna do Programa de PósGraduação em Saúde Coletiva (Mestrado) do Centro de Ciências da Saúde da Universidade Federal de Pernambuco, sob a orientação da Professora Dra Cristine Vieira do Bonfim e Co-orientadora $\mathrm{Dr}^{\mathrm{a}}$ Amanda Priscila de Santana Cabral, nas dependências da Secretaria Executiva de Vigilância em Saúde, da Secretaria Estadual de Saúde/PE, e afirmo que esta instituição tem condições para o desenvolvimento deste projeto, condicionada à aprovação do Projeto pelo Comitê de Ética em Pesquisa.

Sendo assim autorizo sua execução, desde que a mesma cumpra com os requisitos da Res. CNS 466/12 e suas complementares, comprometendo-se a utilizar os materiais e dados coletados exclusivamente para os fins de pesquisa.

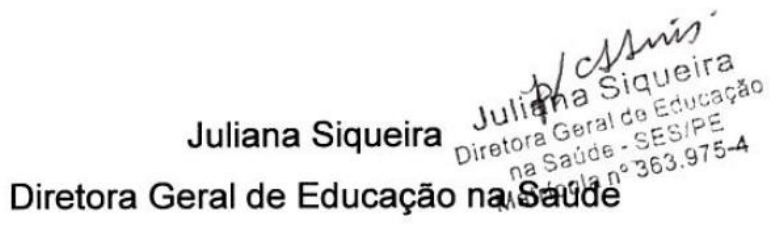

Rua Dona Maria Augusta Nogueira, 519 - Bongí - Recife - PE CEP: 50.751-530 - Fone: 3184-0031/ 3184-0032/ 3184-0033 


\section{ANEXO F - COMPROVANTE DE SUBMISSÃO DO ARTIGO 1 A ONLINE BRAZILIAN JOURNAL OF NURSING}

nursing; health; care; patients; wellness; disease; evidenced based practice

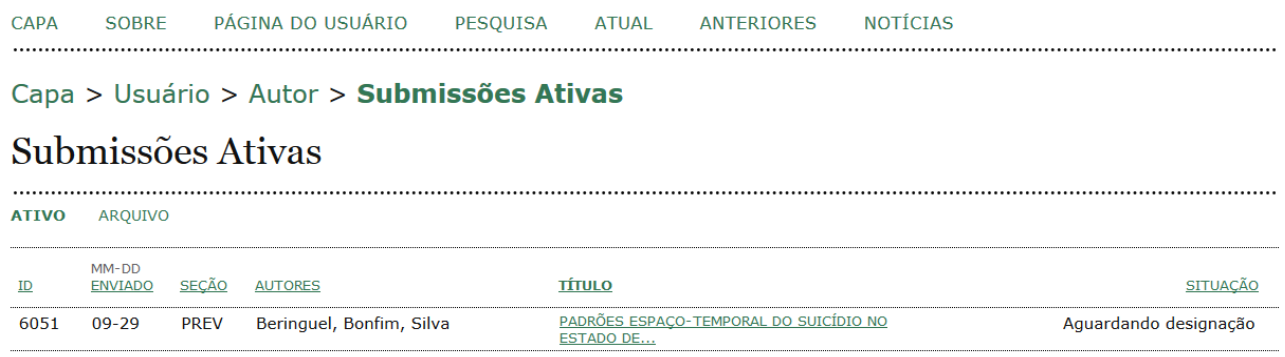

Iniciar nova submissão

CLIQUE AQUI para iniciar os cinco passos do processo de submissão.

OBJN old issues (2002 until 4(2), 2005)

\section{IDIOMA}

Selecione o idioma

Português (Brasil) -

Submeter

TAMANHO DE FONTE

(Ai] $A$ iA

USUÁRIO

Logado como:

bmberingue

- Perfil

- Sair do sistema

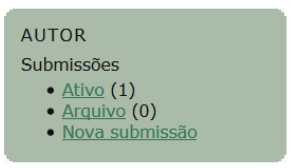

INFORMAÇÕES

- Para leitores

- Para Butores

CONTEÚDO DA REVISTA

Pesquisa

Escopo da Busca 
ANEXO G - COMPROVANTE DE SUBMISSÃo dO ARTIGO 3 A REVISTA BRASILEIRA DE ENFERMAGEM

ScíEĹO Revista Brasileira de Enfermagem

* Home Author

Author Dashboard / Submission Confirmation

Submission Confirmation

BPrint

Thank you for your submission

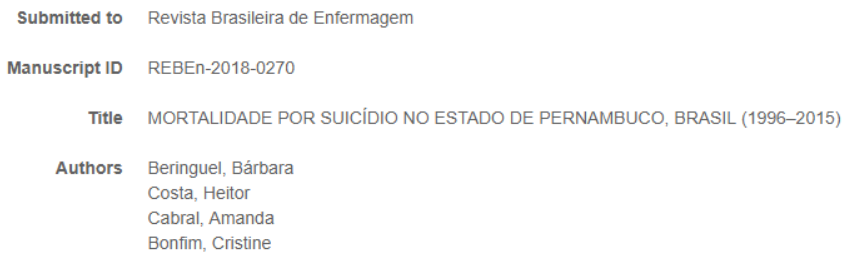




\title{
ANEXO H - INSTRUÇÕES DE FORMATAÇÃO AOS AUTORES SEGUNDO AS NORMAS DA REVISTA BRASILEIRA DE ENFERMAGEM
}

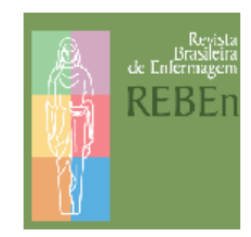

ISSN 0034-7167 versão impressa ISSN 1984-0446 versão online

\section{INSTRUÇÕES AOS AUTORES}

- Política Editorial

- Processo de Avaliação do Manuscrito

- Categorias de Manuscritos

- Preparo dos Manuscritos

- Processo de Submissão e Avaliação de Manuscritos

- Revisão técnica de língua portuguesa e tradução dos manuscritos

- Taxas de Submissão e de Editoração

Política Editorial

\begin{abstract}
A REBEn é atualmente na versão eletrônica. Tem, como público alvo, profissionais e estudantes de Enfermagem e da Saúde. Recebe a submissão de manuscritos nos idiomas português, inglês e espanhol.
\end{abstract}

Para manuscritos aceitos para publicação redigidos em português, será solicitada a tradução da versão final para o inglês, para publicação na versão eletrônica.

Além dos fascículos regulares, podem ser publicados, números temáticos, de acordo com avaliação da pertinência pela Comissão de Publicação ou Conselho Editorial da REBEn.

Os manuscritos devem destinar-se exclusivamente à REBEn, não sendo permitida sua submissão simultânea a outro(s) periódico(s). Quando publicados, passam a ser propriedade da revista.

\section{- Declaração sobre Ética e Integridade em Pesquisa}

Para a publicação, a REBEn considera condição sine qua non que os manuscritos a ela submetidos tenham cumprido as diretrizes ético-legais que envolvem a elaboração de trabalhos acadêmicos e / ou técnico-científicos e a pesquisa com seres humanos ou com animais.

tm se tratando de pesquisa envolvendo seres humanos, e atendendo o disposto na Resoluçao civs nu 460/2012

(http://aplicacao.saude.gov.br/plataformabrasil/login.jsf), o(s) autor(es) deve(m) mencionar no manuscrito, a aprovação do projeto por Comitê de Ética reconhecido pela Comissão Nacional de Ética em Pesquisa, do Conselho Nacional de Saúde (CONEPCNS), ou por órgão equivalente, quando tiver sido executada em outro país. Do mesmo modo, deve(m) mencionar no manuscrito os procedimentos adotados para obtenção da assinatura do Termo de Consentimento Livre e Esclarecido pelos participantes da pesquisa.

A REBEn adota a exigência da Organização Mundial da Saúde e do Comitê Internacional de Editores de Revistas Médicas de registro prévio dos ensaios clínicos (estudos experimentais randomizados) em plataforma que atenda os critérios elaborados por estas duas organizações. O número do registro do ensaio clínico deverá constar em nota de rodapé, na Página de Identificação do manuscrito, aspecto a que se condiciona a publicação.

Nos trabalhos de pesquisa experimental envolvendo animais, deve ser respeitada a Lei no 11.794 , de 8 de outubro de 2008 , que regulamenta o inciso VII do $\S 1^{\circ}$ do Art. 225 da Constituição Federal, estabelecendo procedimentos para o uso científico de animais; e as normas estabelecidas no Guide for the Care and Use of Laboratory Animals (Institute of Laboratory Animal Resources, National Academy of Sciences, Washington, D.C., Estados Unidos), de 1996, e nos Princípios Éticos na Experimentação Animal (Colégio Brasileiro de Experimentação Animal - COBEA, disponível em: <www.cobea.org.br>), de 1991.

A REBEn apoia as Recomendações para a Condução, Relatório, Edição e Publicação de Trabalhos Acadêmicos em Revistas Médicas (Recommendations for the Conduct, Reporting, Editing, and Publication of Scholarly Work in Medical Journals), do Comitê Internacional de Editores de Revistas Médicas (International Committee of Medical Journal Editors). Essas recomendações, relativas à integridade e padrões éticos na condução e no relatório de pesquisas, estão disponíveis na URL $<$ http://www.icmje.org/urm main.html >.

Do mesmo modo, apoia os padrões internacionais para publicação de pesquisa responsável, desenvolvidos pelo COPE (Committee on Publication Ethics) e destinados a editores e autores (disponíveis em: < http://publicationethics.org/internationalstandards-editors-and-authors $>$ ).

Conceitos, ideias ou opiniões emitidos nos manuscritos, bem como a procedência e exatidão das citações neles contidas, são de inteira responsabilidade do(s) autor(es).

A Revista Brasileira de Enfermagem adota o sistema Ithenticate para identificação de plagiarismo.

\section{Processo de Avaliação do Manuscrito}

Inicialmente, o escritório editorial avalia o atendimento às normas; a inclusão dos documentos, o atendimento ao estilo Vancouver; o resumo estruturado; a inclusão dos descritores escolhidos entre os DeCS (Descritores em Ciências da Saúde) e MeSH (Medical Subject Headings).

Quando algum destes aspectos não for atendido, o manuscrito é devolvido para adequação as normas. Atendidas as normas, o manuscrito é encaminhado pelos editores Chefes aos editores associados para análise por pares (peer review), adotando-se a avaliação duplo-cega (double blind review), com que se busca garantir o anonimato dos autores e dos avaliadores. Os pareceres emitidos pelos avaliadores podem considerar o manuscrito aceito, rejeitado ou, ainda, que requer revisões, seja de forma ou de conteúdo. Os pareceres emitidos pelos avaliadores são apreciados pelas Editoras-Chefes, e um parecer final sustentado pelas revisões é enviado para os autores. 
Categorias de Manuscritos

Editorial - Texto sobre assunto de interesse para o momento histórico ou a produção do conhecimento veiculada a um determinado fascículo, com possível repercussão Enfermagem e Saúde. Pode conter até duas (2) páginas, incluindo até duas referências, quando houver.

Pesquisa - Estudo original e inédito, que contribui para agregar informação nova ou para corroborar o conhecimento disponível sobre objeto de investigação relacionado ao escopo da Enfermagem e Saúde. Estão incluídos nesta categoria os ensaios clínicos randomizados. Deve conter um máximo de quinze (15) páginas, incluindo resumos e no máximo 50 referências.

Revisão - Estudo que reúne, de forma ordenada, resultados de pesquisas a respeito de um tema específico, auxiliando na explicação e compreensão de diferenças encontradas entre estudos primários que investigam a mesma questão, e aprofundando o conhecimento sobre o objeto da investigação. Utiliza métodos sistemáticos e critérios explícitos para identificar, selecionar e avaliar criticamente pesquisas relevantes, e para coletar e analisar dados dos estudos incluídos na revisão. Deve conter um máximo de vinte (20) páginas, incluindo resumos e no máximo 50 referências.

Reflexão - Formulação discursiva aprofundada, focalizando conceito ou constructo teórico da Enfermagem ou de área afim; ou discussão sobre um tema específico, estabelecendo analogias, apresentando e analisando diferentes pontos de vista, teóricos e/ou práticos. Deve conter um máximo de dez (10) páginas, incluindo resumos e no máximo 10 referências

Relato de Experiência - Estudo em que se descreve uma situação da prática (ensino, assistência, pesquisa ou gestão/gerenciamento), as estratégias de intervenção e a avaliação de sua eficácia, de interesse para a atuação profissional. Deve conter um máximo de dez (10) páginas, incluindo resumos e no máximo 10 referências.

páginas, incluindo 2 referências, se houver;

Carta ao Editor - máximo 1 página.

Resposta do autor - máximo 250 palavras.

Preparo dos Manuscritos

\section{Aspectos gerais}

Recomendamos a utilização dos guidelines disponíveis no http://www.equator-network.org/ para consolidação do manuscrito.

A REBEn adota o estilo Vancouver, disponíveil na URL < http://www.icmje.org/urm main.html>.

Os manuscritos de todas as categorias aceitos para submissão à REBEn deverão ser preparados da seguinte forma:

Arquivo do Microsoft\&\#174; Office Word, com configuração obrigatória das páginas em papel A4 (210x297mm) e margens de 2 $\mathrm{cm}$ em todos os lados, fonte Times New Roman tamanho 12, espaçamento de 1,5 pt entre linhas, parágrafos com recuo de 1,25 $\mathrm{cm}$.

- O uso de negrito deve se restringir ao título e subtítulos do manuscrito.

- O itálico será aplicado somente para destacar termos ou expressões relevantes para o objeto do estudo.

- Nas citações de autores, ipsis litteris:

- Com até três linhas, usar aspas e inseri-las na sequência normal do texto;

- Naquelas com mais de três linhas, destacá-las em novo parágrafo, sem aspas, fonte Times New Roman tamanho 11, espaçamento simples entre linhas e recuo de $3 \mathrm{~cm}$ da margem esquerda.

- No caso de fala de depoentes ou sujeitos de pesquisa, destacá-las em novo parágrafo, sem aspas, fonte Times New Roman tamanho 11, espaçamento simples entre linhas e recuo de $3 \mathrm{~cm}$ da margem esquerda.

- As citações de autores no texto devem ser numeradas de forma consecutiva, na ordem em que forem mencionadas pela primeira vez no texto;

- As citações de autores no texto devem ser numeradas de forma consecutiva, na ordem em que forem mencionadas pela primeira vez no texto;

- Devem ser utilizados números arábicos, entre parênteses e sobrescritos, sem espaço entre o número da citação e a palavra anterior, e antecedendo a pontuação da frase ou parágrafo [Exemplo: cuidado(5), ].

- Quando se tratar de citações sequenciais, os números serão separados por um traço [Exemplo: cuidado(1-5);]; quando intercaladas, separados por vírgula [Exemplo: cuidado(1,3,5).].

Não devem ser usadas abreviaturas no título e subtítulos do manuscrito, no resumo, tabelas e figuras.

No texto, usar somente abreviações padronizadas. Na primeira citação, a abreviatura é apresentada entre parênteses, e os termos a que corresponde devem precedê-la.

As notas de rodapé deverão ser restritas ao mínimo indispensável.

Apêndices e anexos serão desconsiderados. 


\section{Estrutura do texto}

Artigos de Pesquisa e de Revisão devem seguir a estrutura convencional: Introdução, Método, Resultados, Discussão e Conclusões (pesquisas de abordagem quantitativa) ou Considerações Finais (pesquisas de abordagem qualitativa) e Referências. Os manuscritos de outras categorias podem seguir estrutura diferente.

\section{Documento principal}

O documento principal, sem identificação dos autores, deve conter:

1) Título do artigo: no máximo de 12 palavras no idioma do manuscrito;

2) Resumo e os descritores: resumo limitado a 150 palavras no mesmo idioma do manuscrito. O resumo deverá estar estruturado em Objetivo, Método, Resultados e Conclusão (ou Considerações Finais).

Logo abaixo do resumo incluir cinco descritores no idioma do manuscrito:

- Português ou espanhol extraídos do DeCS: http://decs.bvs.br; - Inglês cinco extraídos do MeSH: http://www.ncbi.nlm.nih.gov/mesh

3) Corpo do texto: Consiste no corpo do manuscrito, propriamente dito;

A estrutura do manuscrito nas categorias pesquisa e revisão é: introdução, objetivo, método, resultados, discussão e conclusão (para pesquisa quantitativa) ou considerações finais (pesquisa qualitativa); Todos os subtítulos devem ser destacados em negrito no texto.

\section{As figuras, tabelas e quadros devem ser apresentadas no corpo do manuscrito.}

Ilustrações (tabelas, quadros e figuras, como fotografias, desenhos, gráficos, etc.) serão numeradas, consecutivamente, com algarismos arábicos, na ordem em que forem inseridas no texto, não podendo ultrapassar o número de cinco.

Qualquer que seja o tipo de ilustração, sua identi?cação aparece na parte superior, precedida da palavra designativa (tabela, figura, quadro) seguida do número de ordem de sua ocorrência no texto, em algarismos arábicos, travessão e do respectivo título (Ex.: Tabela 1 - título). Após a ilustração, na parte inferior, inserir a legenda, notas e outras informações necessárias à sua compreensão, se houver (ver: ABNT NBR 14724 / 2011 - Informação e documentação - Trabalhos acadêmicos - Apresentação). A fonte consultada deverá ser incluída abaixo das imagens somente se for de dados secundários.

As tabelas devem ser padronizadas conforme recomendações do Instituto Brasileiro de Geogra?a e Estatística - IBGE. Normas de apresentação tabular. 3.ed. Rio de Janeiro, 1993, disponíveis em http://biblioteca.ibge.gov.br/visualizacao/livros /liv23907.pdf

Os subtítulos do método e discussão deverão ser destacados em negrito conforme recomendação do_check list.

As ilustrações devem estar em boa qualidade de leitura em alta resolução. Tabelas, gráficos e quadros devem ser apresentados de forma editável no corpo no manuscrito.

4) Fomento: antes da lista de referências, é obrigatório citar fonte de fomento à pesquisa (se houver).

5) Agradecimentos: Podem ser destinados às pessoas que contribuíram para a realização do estudo, mas não se constituem autores e devem ser apresentados na página de título até que a avaliação seja concluída por questões de conflito de interesse.

6) Referências: o número de referências é limitado conforme a categoria do manuscrito. As referências, apresentadas no final do trabalho, devem ser numeradas, consecutivamente, de acordo com a ordem em que foram incluídas no texto; e elaboradas de acordo com o estilo Vancouver. Exemplos de referências nesse estilo, elaborados e atualizados pela Biblioteca Nacional de Medicina dos Estados Unidos (U.S. National Library of Medicine - NLM), podem ser obtidos na URL <http://www.nlm.nih.gov /bsd/uniform requirements.html>.

No mínimo, 50\% das referências devem ser preferencialmente produções publicadas nos últimos 5 anos e destas, $20 \%$ nos últimos 2 anos.

Recomenda-se evitar citações de teses, dissertações, livros e capítulos, exceto quando se tratar de referencial teórico (Ex: Handbook Cochrane). Da mesma forma deve-se evitar citações de artigos de jornais ou revistas não científicas (Magazines).

Para os artigos disponibilizados em português e inglês, deve ser citada a versão em inglês, com a paginação correspondente. Sempre que disponível, indicar a versão eletrônica dos artigos citados, facilitando a sua localização. Dar preferência para o endereço do artigo em formato pdf.

Exemplos mais comuns de referências:

1 Freire P. Pedagogia da Autonomia: saberes necessários à prática educativa. 43a ed. São Paulo: Paz e Terra; 2011.

2 Heidemann IBS, Boehs AE, Wosny AMi, Stulp KP. [Theoretical, conceptual and methodological incorporation of the educator Paulo Freire in research]. Rev Bras Enferm [Internet]. 2010[cited 2014 Mar 10];63(3):416-20. Available from: http://www.scielo.br/pdf/reben/v63n3/a11v63n3.pdf Portuguese.

3 Lenardt MH, Sousa JAV, Grden CRB, Betiolli SE, Carneiro NHK, Ribeiro DKMN. Gait speed and cognitive score in elderly users of the primary care service. Rev Bras Enferm [Internet]. 2015 [ cited $2017 \mathrm{Apr} 17$ ];68(6):851-6. Available from: http://www.scielo.br/pdf/reben/v68n6/en_0034-7167-reben-68-06-1163.pdf 


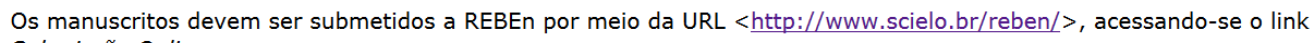
Submissão Online.

Antes de submeter o manuscrito os autores devem verificar as normas da REBEn, seguir rigorosamente o check list e ter todos os documentos necessários para submissão. É obrigatório, o preenchimento completo dos metadados no formulário de submissão.

Cada documento deve ser anexado, separadamente, no campo indicado pelo sistema.

Para iniciar o processo, o responsável pela submissão deverá cadastrar-se previamente no sistema como autor criando/associando o cadastro do ORCID (Open Researcher and Contributor ID). O sistema é autoexplicativo e, ao concluir o processo, será gerada uma ID para o manuscrito, com código numérico (Exemplo: REBEn 2017-0001). O responsável pela submissão receberá uma mensagem informando a URL do manuscrito e um login, para que possa acompanhar, na interface de administração do sistema, o progresso do documento nas etapas do processo editorial.

No passo 4 da submissão, os autores devem indicar quatro possíveis pareceristas para avaliação do manuscrito. Estes indicados deverão ser obrigatoriamente doutores e não podem ter nenhum conflito de interesse. Os pareceristas podem ser acatados ou não pelos editores associados. Os revisores podem ser localizados na plataforma lattes de acordo com a temática do manuscrito.

Lembramos que o não atendimento a todas essas instruções resultará na devolução dos documentos para adequação, causando maior atraso na apreciação pelos editores.

\section{Processo de revisão por pares}

Inicialmente, os editores avaliam o atendimento às normas para preparação de manuscritos; a inclusão do número do registro do ensaio clínico, quando for o caso, o atendimento ao estilo Vancouver na elaboração da lista de referências; a clareza e objetividade do resumo; a inclusão dos descritores escolhidos entre os DeCS (Descritores em Ciências da Saúde) e MeSH (Medical Subject Headings); e o potencial do manuscrito para publicação e possível interesse dos leitores.

Quando algum destes aspectos não for considerado satisfatório, o manuscrito é rejeitado, sendo automaticamente arquivado no sistema. Quando avaliado positivamente, o manuscrito é encaminhado para análise por pares (peer review), adotando-se a avaliação duplo-cega (double blind review), com que se busca garantir o anonimato dos autores e dos avaliadores. Os pareceres emitidos pelos avaliadores podem considerar o manuscrito aceito, rejeitado ou, ainda, que requer revisões, seja de forma ou de conteúdo. Os pareceres emitidos pelos avaliadores são apreciados pelas Editores Chefes, e um parecer final é enviado para os autores.

O autor responsável pela submissão deve ter à mão toda a documentação necessária: página de título; documento principal, Declaração de ciência dos autores sobre as instruções de publicação da REBEn (Modelo de Declaração de Ciência de Instruções); carta ao editor; comprovante de aprovação do projeto de pesquisa pelo Comitê de Ética; comprovante de pagamento de taxa de submissão e Declaração de responsabilidade pela autoria, exclusividade de envio do manuscrito à REBEn, transferência de Direitos Autorais e ausência de conflito de interesses (Modelo de Declaração de Autoria).

Um check list para auxiliar os autores está disponível.

Para iniciar o processo, o responsável pela submissão deverá cadastrar-se previamente no sistema como autor. O sistema é

criando/associando o cadastro do ORCID (Open Researcher and Contributor ID). O sistema é autoexplicativo e, ao concluir o processo, será gerada uma ID para o manuscrito, com código numérico (Exemplo: REBEn 2017-0001). O responsável pela submissão receberá uma mensagem informando a URL do manuscrito e um login, para que possa acompanhar, na interface de administração do sistema, o progresso do documento nas etapas do processo editorial.

No passo 4 da submissão, os autores devem indicar quatro possíveis pareceristas para avaliação do manuscrito. Estes indicados deverão ser obrigatoriamente doutores e não podem ter nenhum conflito de interesse. Os pareceristas podem ser acatados ou não pelos editores associados. Os revisores podem ser localizados na plataforma lattes de acordo com a temática do manuscrito.

Lembramos que o não atendimento a todas essas instruções resultará na devolução dos documentos para adequação, causando maior atraso na apreciação pelos editores. 
Para iniciar o processo, o responsável pela submissão deverá cadastrar-se previamente no sistema como autor criando/associando o cadastro do ORCID (Open Researcher and Contributor ID). O sistema é autoexplicativo e, ao concluir o processo, será gerada uma ID para o manuscrito, com código numérico (Exemplo: REBEn 2017-0001). O responsável pela submissão receberá uma mensagem informando a URL do manuscrito e um login, para que possa acompanhar, na interface de administração do sistema, o progresso do documento nas etapas do processo editorial.

No passo 4 da submissão, os autores devem indicar quatro possíveis pareceristas para avaliação do manuscrito. Estes indicados deverão ser obrigatoriamente doutores e não podem ter nenhum conflito de interesse. Os pareceristas podem ser acatados ou não pelos editores associados. Os revisores podem ser localizados na plataforma lattes de acordo com a temática do manuscrito.

Lembramos que o não atendimento a todas essas instruções resultará na devolução dos documentos para adequação, causando maior atraso na apreciação pelos editores.

\section{Processo de revisão por pares}

Inicialmente, os editores avaliam o atendimento às normas para preparação de manuscritos; a inclusão do número do registro do ensaio clínico, quando for o caso, o atendimento ao estilo Vancouver na elaboração da lista de referências; a clareza e objetividade do resumo; a inclusão dos descritores escolhidos entre os DeCS (Descritores em Ciências da Saúde) e MeSH (Medical Subject Headings); e o potencial do manuscrito para publicação e possível interesse dos leitores.

Quando algum destes aspectos não for considerado satisfatório, o manuscrito é rejeitado, sendo automaticamente arquivado no sistema. Quando avaliado positivamente, o manuscrito é encaminhado para análise por pares (peer review), adotando-se a avaliação duplo-cega (double blind review), com que se busca garantir o anonimato dos autores e dos avaliadores. Os pareceres emitidos pelos avaliadores podem considerar o manuscrito aceito, rejeitado ou, ainda, que requer revisões, seja de forma ou de conteúdo. Os pareceres emitidos pelos avaliadores são apreciados pelas Editores Chefes, e um parecer final é enviado para os autores.

O autor responsável pela submissão deve ter à mão toda a documentação necessária: página de título; documento principal, Declaração de ciência dos autores sobre as instruções de publicação da REBEn (Modelo de Declaração de Ciência de Instruções); carta ao editor; comprovante de aprovação do projeto de pesquisa pelo Comitê de Ética; comprovante de pagamento de taxa de submissão e Declaração de responsabilidade pela autoria, exclusividade de envio do manuscrito à REBEn, transferência de Direitos Autorais e ausência de conflito de interesses (Modelo de Declaração de Autoria).

Um check list para auxiliar os autores está disponível.

Para iniciar o processo, o responsável pela submissão deverá cadastrar-se previamente no sistema como autor. O sistema é autoexplicativo e, ao concluir o processo, será gerada uma ID para o manuscrito, com código numérico (Exemplo: 000001). 0 responsável pela submissão receberá uma meñsagem informando a URL do manuscrito e úm login, para que possa acompánhar, na interface de administração do sistema, o progresso do documento nas etapas do processo editorial.

Inicialmente, os editores avaliam o atendimento às normas para preparação de manuscritos; a inclusão do número do registro do ensaio clínico, quando for o caso, em nota de rodapé; o atendimento ao estilo Vancouver na elaboração da lista de referências; a clareza e objetividade do resumo; a inclusão dos descritores escolhidos entre os DeCS (Descritores em Ciências da Saúde) e MeSH (Medical Subject Headings); e o potencial do manuscrito para publicação e possível interesse dos leitores.

Quando algum destes aspectos não for considerado satisfatório, o manuscrito é rejeitado, sendo automaticamente arquivado no sistema. Quando avaliado positivamente, o manuscrito é encaminhado para análise por pares (peer review), adotando-se a avaliação duplo-cega (double blind review), com que se busca garantir o anonimato dos autores e dos avaliadores. Os pareceres emitidos pelos avaliadores podem considerar o manuscrito aceito, rejeitado ou, ainda, que requer revisões, seja de forma ou de conteúdo. Os pareceres emitidos pelos avaliadores são apreciados pelas Editoras-Chefes, e um parecer final é enviado para os autores.

Revisão técnica de língua portuguesa e tradução dos manuscritos

A revisão técnica de linguagem, tradução do resumo para a versão em espanhol e inglês e a tradução dos manuscritos para a versão em inglês deverá ser providenciada pelos autores, conforme orientação da Secretaria da REBEn. O não cumprimento dessa exigência ocasionará o arquivamento do manuscrito.

Taxas de Submissão e de Editoração

Ao submeter um manuscrito para publicação na REBEn, é necessário realizar o pagamento de TAXA DE SUBMISSÃO, no valor de $R \$ 220,00$ (duzentos e vinte reais).

Em caso de o artigo ser aceito, é obrigatório o pagamento da TAXA DE EDITORAÇÃo, no valor de R\$1.100,00 (um mil e cem reais).

Essas taxas deverão ser pagas por meio de depósito bancário, em nome da Associação Brasileira de Enfermagem, CNPJ 33.989.468-0001-00, no Banco do Brasil, Agência: 0452-9, Conta Corrente: 220.482-7.

Para depósito internacional, o usuário deverá usa o código SWIFT - BRASBRRJBSA e IBAN (International Bank Account Number) - BR4800000000034750002204827C1 - Banco do Brasil - em nome da Associação Brasileira de Enfermagem.

O comprovante de pagamento da TAXA DE SUBMISSÃO deve ser inserido no sistema, no momento da submissão do manuscrito, como Documento Suplementar. No processo inicial de checagem inicial da documentação submetida, serão arquivados automaticamente manuscritos que não estiverem acompanhados da comprovação do pagamento da TAXA DE SUBMISSÃO. Ao ser efetivada a submissão e verificada a conformidade do manuscrito às normas de publicação, prossegue-se o processo de editoração. Finalizado o processo de avaliação, não se devolve a taxa de submissão caso o manuscrito não seja aceito para publicação.

O comprovante de pagamento da TAXA DE EDITORAçÃo deverá ser encaminhado ao e-mail escritorio.reben@abennacional.org.br, no prazo máximo de sete dias após o recebimento da confirmação de que o artigo foi aceito para publicação. $O$ não cumprimento dessa condição sujeita o artigo ao arquivamento em definitivo. 
ANEXO I - COMPROVANTE DE SUBMISSÃO DO ARTIGO 4 A REVISTA CIÊNCIA E SAÚDE COLETIVA
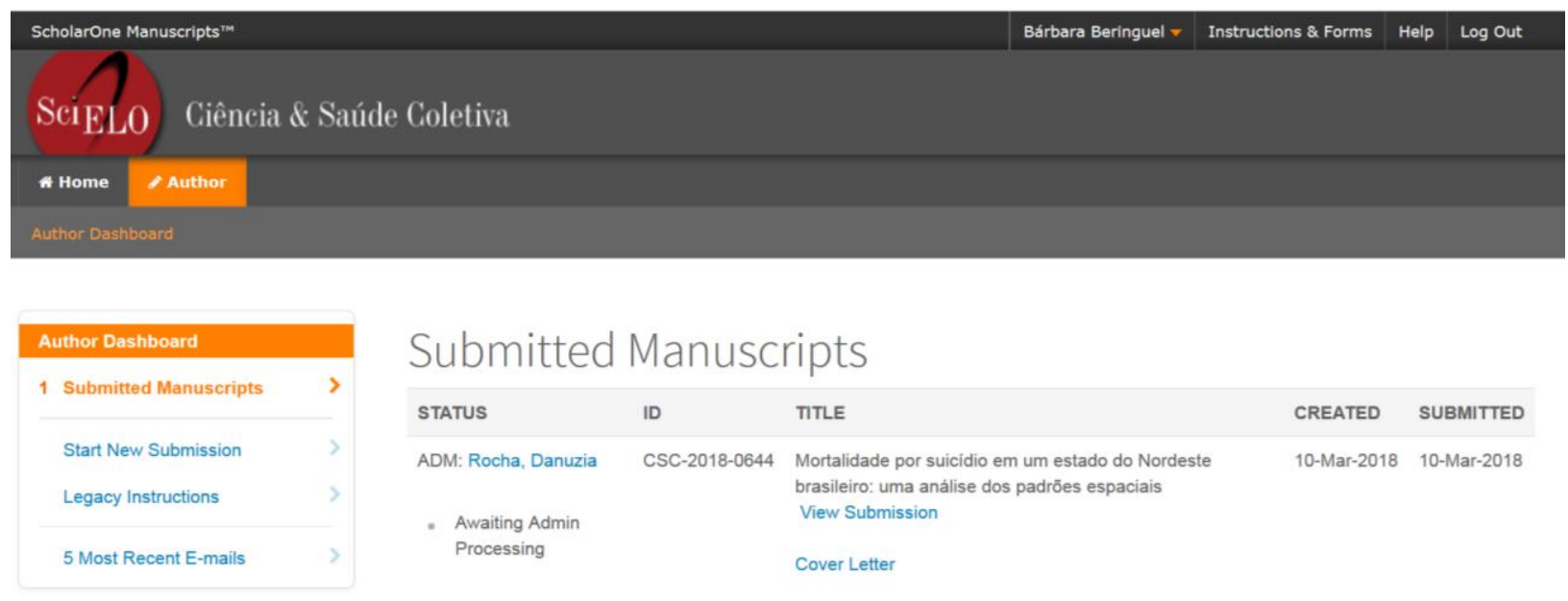

Submitted Manuscripts

\begin{tabular}{lllll}
\hline STATUS & ID & TITLE & CREATED & SUBMITTED \\
\hline ADM: Rocha, Danuzia & CSC-2018-0644 & $\begin{array}{l}\text { Mortalidade por suicídio em um estado do Nordeste } \\
\text { brasileiro: uma análise dos padrōes espaciais } \\
\text { View Submission }\end{array}$ & 10-Mar-2018 & 10-Mar-2018 \\
$\begin{array}{l}\text { - Awaiting Admin } \\
\text { Processing }\end{array}$ & Cover Letter & & \\
& & &
\end{tabular}




\section{ANEXO J - INSTRUÇÕES DE FORMATAÇÃO AOS AUTORES SEGUNDO AS NORMAS DA REVISTA CIÊNCIA E SAÚDE COLETIVA}

Ciência \& Saúde Coletiva

ISSN 1413-8123 versão impressa

ISSN 1678-4561 versão online

\section{INSTRUÇÕES AOS AUTORES}

- Instruções para colaboradores

- Orientações para organização de números temáticoso

- Recomendações para a submissão de artigos

- Apresentação de manuscritos

Instruções para colaboradores

Ciência \& Saúde Coletiva publica debates, análises e resultados de investigações sobre um tema específico considerado relevante para a saúde coletiva; e artigos de discussão e análise do estado da arte da área e das subáreas, mesmo que não versem sobre o assunto do tema central. A revista, de periodicidade mensal, tem como propósitos enfrentar os desafios, buscar a consolidação e promover uma permanente atualização das tendências de pensamento e das práticas na saúde coletiva, em diálogo com a agenda contemporânea da Ciência \& Tecnologia

\section{Orientações para organização de números temáticoso}

A marca da Revista Ciência \& Saúde Coletiva dentro da diversidade de Periódicos da área é o seu foco temático, segundo o propósito da ABRASCO de promover, aprofundar e socializar discussões acadêmicas e debates interpares sobre assuntos considerados importantes e relevantes, acompanhando o desenvolvimento histórico da saúde pública do país.

Os números temáticos entram na pauta em quatro modalidades de demanda:

- Por Termo de Referência enviado por professores/pesquisadores da área de saúde coletiva (espontaneamente ou sugerido pelos editores-chefes) quando consideram relevante o aprofundamento de determinado assunto.

para serem julgados em seu mérito por pareceristas.

- Por Organização Interna dos próprios Editores-chefes, reunindo sob um título pertinente, artigos de livre demanda, dentro dos critérios já descritos.

O Termo de Referência deve conter: (1) título (ainda que provisório) da proposta do número temático; (2) nome (ou os nomes) do Editor Convidado; (3) justificativa resumida em um ou dois parágrafos sobre a proposta do ponto de vista dos objetivos, contexto, significado e relevância para a Saúde Coletiva; (4) listagem dos dez artigos propostos já com nomes dos autores convidados; (5) proposta de texto de opinião ou de entrevista com alguém que tenha relevância na discussão do assunto; (6) proposta de uma ou duas resenhas de livros que tratem do tema.

Por decisão editorial o máximo de artigos assinados por um mesmo autor num número temático não deve ultrapassar três, seja como primeiro autor ou não.

Sugere-se enfaticamente aos organizadores que apresentem contribuições de autores de variadas instituições nacionais e de colaboradores estrangeiros. Como para qualquer outra modalidade de apresentação, nesses números se aceita colaboração em espanhol, inglês e francês.

Recomenda-se que os artigos submetidos não tratem apenas de questões de interesse local, ou se situe apenas no plano descritivo. As discussões devem apresentar uma análise ampliada que situe a especificidade dos achados de pesquisa ou revisão no cenário da literatura nacional e internacional acerca do assunto, deixando claro o caráter inédito da contribuição que o artigo traz.

A revista C\&SC adota as "Normas para apresentação de artigos propostos para publicação em revistas médicas", da Comissão Internacional de Editores de Revistas Médicas, cuja versão para o português encontra-se publicada na Rev Port Clin Geral 1997; 14:159-174. O documento está disponível em vários sítios na World Wide Web, como por exemplo, www.icmje.org ou

www.apmcg.pt/document/71479/450062.pdf. Recomenda-se aos autores a sua leitura atenta.

\section{Seções da publicação}

Editorial: de responsabilidade dos editores chefes ou dos editores convidados, deve ter no máximo 4.000 caracteres com espaço.

Artigos Temáticos: devem trazer resultados de pesquisas de natureza empírica, experimental, conceitual e de revisões sobre o assunto em pauta. Os textos de pesquisa não deverão ultrapassar os 40.000 caracteres. 
Artigos de Temas Livres: devem ser de interesse para a saúde coletiva por livre apresentação dos autores através da página da revista. Devem ter as mesmas características dos artigos temáticos: máximo de 40.000 caracteres com espaço, resultarem de pesquisa e apresentarem análises e avaliações de tendências teóricometodológicas e conceituais da área.

Artigos de Revisão: Devem ser textos baseados exclusivamente em fontes secundárias, submetidas a métodos de análises já teoricamente consagrados, temáticos ou de livre demanda, podendo alcançar até o máximo de 45.000 caracteres com espaço.

Opinião: texto que expresse posição qualificada de um ou vários autores ou entrevistas realizadas com especialistas no assunto em debate na revista; deve ter, no máximo, 20.000 caracteres com espaço.

Resenhas: análise crítica de livros relacionados ao campo temático da saúde coletiva, publicados nos últimos dois anos, cujo texto não deve ultrapassar 10.000 caracteres com espaço. Os autores da resenha devem incluir no início do texto a referência completa do livro. As referências citadas ao longo do texto devem seguir as mesmas regras dos artigos. No momento da submissão da resenha os autores devem inserir em anexo no sistema uma reprodução, em alta definição da capa do livro em formato jpeg.

Cartas: com apreciações e sugestões a respeito do que é publicado em números anteriores da revista (máximo de 4.000 caracteres com espaço).

Observação: O limite máximo de caracteres leva em conta os espaços e inclui texto e bibliografia. 0 resumo/abstract e as ilustrações (figuras e quadros) são considerados à parte.

\section{Apresentação de manuscritos}

1. Os originais podem ser escritos em português, espanhol, francês e inglês. Os textos em português e espanhol devem ter título, resumo e palavras-chave na língua original e em inglês. Os textos em francês e inglês devem ter título, resumo e palavras-chave na língua original e em português. Não serão aceitas notas de vé-de-báaina ou no final dos artiaos.

2. Os textos têm de ser digitados em espaço duplo, na fonte Times New Roman, no corpo 12, margens de $2,5 \mathrm{~cm}$, formato Word e encaminhados apenas pelo endereço eletrônico

(http://mc04.manuscriptcentral.com/csc-scielo) segundo as orientações do site.

3. Os artigos publicados serão de propriedade da revista C\&SC, ficando proibida a reprodução total ou parcial em qualquer meio de divulgação, impressa ou eletrônica, sem a prévia autorização dos editores-chefes da Revista. A publicação secundária deve indicar a fonte da publicação original.

4. Os artigos submetidos à C\&SC não podem ser propostos simultaneamente para outros periódicos.

5. As questões éticas referentes às publicações de pesquisa com seres humanos são de inteira responsabilidade dos autores e devem estar em conformidade com os princípios contidos na Declaração de Helsinque da Associação Médica Mundial (1964, reformulada em 1975,1983, 1989, 1989, 1996 e 2000).

6. Os artigos devem ser encaminhados com as autorizações para reproduzir material publicado anteriormente, para usar ilustrações que possam identificar pessoas e para transferir direitos de autor e outros documentos.

7. Os conceitos e opiniões expressos nos artigos, bem como a exatidão e a procedência das citações são de exclusiva responsabilidade dos autores.

8. Os textos são em geral (mas não necessariamente) divididos em seções com os títulos Introdução, Métodos, Resultados e Discussão, às vezes, sendo necessária a inclusão de subtítulos em algumas seções. Os títulos e subtítulos das seções não devem estar organizados com numeração progressiva, mas com recursos gráficos (caixa alta, recuo na margem etc.).

9. O título deve ter 120 caracteres com espaço e o resumo/abstract, com no máximo 1.400 caracteres com espaço (incluindo palavras-chave/key words), deve explicitar o objeto, os objetivos, a metodologia, a abordagem teórica e os resultados do estudo ou investigação. Logo abaixo do resumo os autores devem indicar até no máximo, cinco (5) palavras-chave. palavras-chave/key words. Chamamos a atenção para a importância da clareza e objetividade na redação do resumo, que certamente contribuirá no interesse do leitor pelo artigo, e das palavras-chave, que auxiliarão a indexação múltipla do artigo. As palavras-chaves na língua original e em inglês devem constar no DeCS/MeSH

\section{Autoria}

1. As pessoas designadas como autores devem ter participado na elaboração dos artigos de modo que possam assumir publicamente a responsabilidade pelo seu conteúdo. A qualificação como autor deve pressupor: a) a concepção e o delineamento ou a análise e interpretação dos dados, b) redação do artigo ou a sua revisão crítica, e c) aprovação da versão a ser publicada. As contribuições individuais de cada autor devem ser indicadas no final do texto, apenas pelas iniciais (ex. LMF trabalhou na concepção e na redação final e CMG, na pesquisa e na metodologia).

2. O limite de autores no início do artigo deve ser no máximo de oito. Os demais autores serão incluídos no final do artigo. 


\section{Nomenclaturas}

1. Devem ser observadas rigidamente as regras de nomenclatura de saúde pública/saúde coletiva, assim como abreviaturas e convenções adotadas em disciplinas especializadas. Devem ser evitadas abreviaturas no título e no resumo.

2. A designação completa à qual se refere uma abreviatura deve preceder a primeira ocorrência desta no texto, a menos que se trate de uma unidade de medida padrão.

\section{Ilustrações}

1. O material ilustrativo da revista C\&SC compreende tabela (elementos demonstrativos como números, medidas, percentagens, etc.), quadro (elementos demonstrativos com informações textuais), gráficos (demonstração esquemática de um fato e suas variações), figura (demonstração esquemática de informaç̃es por meio de mapas, diagramas, fluxogramas, como também por meio de desenhos ou fotografias). Vale lembrar que a revista é impressa em apenas uma cor, o preto, e caso o material ilustrativo seja colorido, será convertido para tons de cinza.

2. O número de material ilustrativo deve ser de, no máximo, cinco por artigo, salvo exceções referentes a artigos de sistematização de áreas específicas do campo temático. Nesse caso os autores devem negociar com os editores-chefes.

3. Todo o material ilustrativo deve ser numerado consecutivamente em algarismos arábicos, com suas respectivas legendas e fontes, e a cada um deve ser atribuído um breve título. Todas as ilustrações devem ser citadas no texto.

4. As tabelas e os quadros devem ser confeccionados no mesmo programa utilizado na confecção do artigo (Word).

5. Os gráficos devem estar no programa Excel, e os dados numéricos devem ser enviados, em separado no programa Word ou em outra planilha como texto, para facilitar o recurso de copiar e colar.

Os gráficos gerados em programa de imagem (Corel Draw ou Photoshop) devem ser enviados em arquivo aberto com uma cópia em pdf.

6. Os arquivos das figuras (mapa, por ex.) devem ser salvos no (ou exportados para o) formato Ilustrator ou Corel Draw com uma cópia em pdf. Estes formatos conservam a informação vetorial, ou seja, conservam as linhas de desenho dos mapas. Se for impossível salvar nesses formatos; os arquivos podem ser enviados nos formatos TIFF ou BMP, que são formatos de imagem e não conservam sua informação vetorial, o que prejudica a qualidade do resultado. Se usar o formato TIFF ou BMP, salvar na maior resolução (300 ou mais DPI) e maior tamanho (lado maior $=18 \mathrm{~cm}$ ). O mesmo se aplica para o material que estiver em fotografia. Caso não seja possível enviar as ilustrações no meio digital, o material original deve ser mandado em boas condições para reprodução.

\section{Agradecimentos}

1. Quando existirem, devem ser colocados antes das referências bibliográficas.

2. Os autores são responsáveis pela obtenção de autorização escrita das pessoas nomeadas nos agradecimentos, dado que os leitores podem inferir que tais pessoas subscrevem os dados e as conclusões.

3. O agradecimento ao apoio técnico deve estar em parágrafo diferente dos outros tipos de contribuição.

\section{Referências}

1. As referências devem ser numeradas de forma consecutiva de acordo com a ordem em que forem sendo citadas no texto. No caso de as referências serem de mais de dois autores, no corpo do texto deve ser citado apenas o nome do primeiro autor seguido da expressão et al.

2. Devem ser identificadas por números arábicos sobrescritos, conforme exemplos abaixo:

ex. 1: "Outro indicador analisado foi o de maturidade do PSF" $11 \ldots$

ex. 2: "Como alerta Maria Adélia de Souza 4, a cidade..."

As referências citadas somente nos quadros e figuras devem ser numeradas a partir do número da última referência citada no texto.

3. As referências citadas devem ser listadas ao final do artigo, em ordem numérica, seguindo as normas gerais dos Requisitos uniformes para manuscritos apresentados a periódicos biomédicos(http://www.nlm.nih.gov/bsd/uniform_requirements.html).

4. Os nomes das revistas devem ser abreviados de acordo com o estilo usado no Index Medicus (http://www.nlm.nih.gov/).

5. O nome de pessoa, cidades e países devem ser citados na língua original da publicação.

Exemplos de como citar referências

\section{Artigos em periódicos}

1. Artigo padrão (incluir todos os autores)

Pelegrini MLM, Castro JD, Drachler ML. Eqüidade na alocação de recursos para a saúde: a experiência no Rio Grande do Sul, Brasil. Cien Saude Colet 2005; 10(2):275-286. 
Maximiano AA, Fernandes RO, Nunes FP, Assis MP, Matos RV, Barbosa CGS, Oliveira-Filho EC. Utilização de drogas veterinárias, agrotóxicos e afins em ambientes hídricos: demandas, regulamentação e considerações sobre riscos à saúde humana e ambiental. Cien Saude Colet 2005; 10(2):483-491.

2. Instituição como autor

The Cardiac Society of Australia and New Zealand. Clinical exercise stress testing. Safety and performance guidelines. Med J Aust 1996; 164(5):282-284

3. Sem indicação de autoria

Cancer in South Africa [editorial]. S Afr Med J 1994; 84:15.

4. Número com suplemento

Duarte MFS. Maturação física: uma revisão de literatura, com especial atenção à criança brasileira. Cad Saude Publica 1993; 9(Supl. 1):71-84.

5. Indicação do tipo de texto, se necessário

Enzensberger W, Fischer PA. Metronome in Parkinson's disease [carta]. Lancet 1996; 347:1337.

\section{Livros e outras monografias}

6. Indivíduo como autor

Cecchetto FR. Violência, cultura e poder. Rio de Janeiro: FGV; 2004.

Minayo MCS. O desafio do conhecimento: pesquisa qualitativa em saúde. $8^{a}$ Edição. São Paulo, Rio de Janeiro: Hucitec, Abrasco; 2004.

7. Organizador ou compilador como autor

Bosi MLM, Mercado FJ, organizadores. Pesquisa qualitativa de serviços de saúde. Petrópolis: Vozes; 2004.

8. Instituição como autor

Instituto Brasileiro do Meio Ambiente e dos Recursos Naturais Renováveis (IBAMA). Controle de plantas anuáticas nor meio de anrotóxicos e afins. Brasília: DII IO/IBAMA: 2001.

9. Capítulo de livro

Sarcinelli PN. A exposição de crianças e adolescentes a agrotóxicos. In: Peres F, Moreira JC, organizadores. É veneno ou é remédio. Agrotóxicos, saúde e ambiente. Rio de Janeiro: Fiocruz; 2003. p. 43-58.

10. Resumo em Anais de congressos

Kimura J, Shibasaki $\mathrm{H}$, organizadores. Recent advances in clinical neurophysiology. Proceedings of the 10th International Congress of EMG and Clinical Neurophysiology; 1995 Oct 15-19; Kyoto, Japan. Amsterdam: Elsevier; 1996.

11. Trabalhos completos publicados em eventos científicos

Coates V, Correa MM. Características de 462 adolescentes grávidas em São Paulo. In: Anais do V Congresso Brasileiro de adolescência; 1993; Belo Horizonte. p. 581-582.

12. Dissertação e tese

Carvalho GCM. O financiamento público federal do Sistema Único de Saúde 1988-2001 [tese]. São Paulo: Faculdade de Saúde Pública; 2002.

Gomes WA. Adolescência, desenvolvimento puberal e sexualidade: nível de informação de adolescentes e professores das escolas municipais de Feira de Santana - BA [dissertação]. Feira de Santana (BA): Universidade Estadual de Feira de Santana; 2001.

\section{Outros trabalhos publicados}

13. Artigo de jornal

Novas técnicas de reprodução assistida possibilitam a maternidade após os 40 anos. Jornal do Brasil; 2004 Jan $31 ;$ p. 12

\section{Material no prelo ou não publicado}

Leshner AI. Molecular mechanisms of cocaine addiction. N Engl J Med. In press 1996.

Cronemberg S, Santos DVV, Ramos LFF, Oliveira ACM, Maestrini HA, Calixto N. Trabeculectomia com mitomicina C em pacientes com glaucoma congênito refratário. Arq Bras Oftalmol. No prelo 2004.

\section{Material eletrônico}

16. Artigo em formato eletrônico

Morse SS. Factors in the emergence of infectious diseases. Emerg Infect Dis [serial on the Internet] 1995 Jan-Mar [cited 1996 Jun 5];1(1):[about 24 p.]. Available from: http://www.cdc.gov/ncidod/EID/eid.htm

Lucena AR, Velasco e Cruz AA, Cavalcante R. Estudo epidemiológico do tracoma em comunidade da Chapada do Araripe - PE - Brasil. Arq Bras Oftalmol [periódico na Internet]. 2004 Mar-Abr [acessado 2004 Jul 12];67(2): [cerca de 4 p.]. Disponível em: http://www.abonet.com.br/abo/672/197-200.pdf

17. Monografia em formato eletrônico

CDI, clinical dermatology illustrated [CD-ROM]. Reeves JRT, Maibach H. CMEA Multimedia Group, producers. $2^{\mathrm{a}}$ ed. Version 2.0. San Diego: CMEA; 1995.

18. Programa de computador

Hemodynamics III: the ups and downs of hemodynamics [computer program]. Version 2.2. Orlando (FL): Computerized Educational Systems; 1993.

Os artigos serão avaliados através da Revisão de pares por no mínimo três consultores da área de conhecimento da pesquisa, de instituições de ensino e/ou pesquisa nacionais e estrangeiras, de comprovada produção científica. Após as devidas correções e possíveis sugestões, o artigo será aceito se tiver dois pareceres favoráveis e rejeitado quando dois pareceres forem desfavoráveis. 